\title{
Principles for independent fiscal institutions and case studies
}

\author{
by
}

Lisa von Trapp, Ian Lienert and Joachim Wehner*

\begin{abstract}
Independent fiscal institutions serve to promote sound fiscal policy and sustainable public finances. Today IFIs are considered among the most important innovations in the emerging architecture of public financial management. Within the OECD area, their number has more than tripled and is expected to continue to rise. This publication provides a unique set of in depth case studies of IFIs in 18 OECD member countries in light of many of the good practices for effective IFIs identified in the OECD Recommendation on Principles for Independent Fiscal Institutions.

JEL classification: H11, H50, H83

Keywords: Parliamentary Budget Office(s), financial management, fiscal councils, fiscal policy, independent fiscal institutions, public finances, transparency, legislature
\end{abstract}

* This publication was authored by Lisa von Trapp (lead) in the Budgeting and Public Expenditures Division of the Public Governance and Territorial Development Directorate, OECD, and Ian Lienert and Joachim Wehner, independent consultants. Jason Jacques, Director of Fiscal Analysis, Office of the Parliamentary Budget Officer, Canada drafted a first note on Italy and contributed to the notes on Canada and France. A first draft of the annex on the Austrian Parliamentary Budget Office was prepared by Helmut Berger, Head, Parliamentary Budget Office. A first note on Finland was drafted by Heidi Silvennoinen, Executive Director for Fiscal Policy Evaluation, National Audit Office of Finland. A first note on France was drafted by Boris Melmoux-Eude, Deputy Rapporteur General, High Council for Public Finances, France. A first note on Spain was drafted by Ignacio Fernández-Huertas, María Fernández, and Daniel Santabárbara, staff in the Independent Authority for Fiscal Responsibility, Spain, with the approval of Ana Buisán, Chief of Staff. The authors are grateful for the extensive comments provided throughout the drafting of all of the country case studies by PBO Network members representing both parliaments and independent fiscal institutions. We are also grateful for comments provided by members of the OECD Budgeting and Public Expenditures team, Jón Blöndal, Ronnie Downes, and Scherie Nicol. 


\section{Introduction}

This paper provides in depth case studies of independent fiscal institutions (IFIs) in 18 OECD member countries. It is the most comprehensive study of its kind to date and will be updated on a rolling basis to include new institutions. The case studies were developed under the auspices of the OECD Network of Parliamentary Budget Officials and Independent Fiscal Institutions (PBO Network) ${ }^{1}$ and, in their first iteration, ${ }^{2}$ served to inform the OECD Council Recommendation on Principles for Independent Fiscal Institutions (2014). ${ }^{3}$ The paper is structured as follows. The introduction presents a brief overview of IFIs today using comparative data drawn from the case studies and discussions with PBO Network members, and in light of the Principles. ${ }^{4}$ The second section re-introduces the principles. The third section contains case studies for Australia, Austria, Belgium, Canada, Denmark, Finland, France, Ireland, Italy, Korea, Mexico, Netherlands, Portugal, Slovak Republic, Spain, Sweden, United Kingdom, and United States.

The 22 principles in the OECD Council Recommendation on Principles for Independent Fiscal Institutions are geared towards member and non-member countries that have established or are considering establishing an IFI. The principles codify lessons learned and good practices and aim to assist countries to design an enabling environment conducive to the good governance and performance of an IFI and to ensuring its long-term viability. The principles seek to reinforce the core values that IFIs both promote and operate under - independence, non-partisanship, transparency and accountability - while demonstrating technical competence and producing relevant work of the highest quality that stands up to public scrutiny and informs the public debate. They cover: local ownership; independence and non-partisanship (including ways to enhance independence and non-partisanship through the appointment process for leadership and staff); mandate; resources; relationship with the legislature; access to information; transparency; communications; and external evaluation. The country case studies are designed around the following 11 sections which are linked to the principles: ${ }^{5}$

1. context in which the IFI was created, covering both the economic and political context and including aspects such as whether there was broad political support for the project and whether the IFI was part of a broader reform process;

2. relationship of the IFI with the executive and the legislature, highlighting both formal and informal links between the IFI, the government and the parliament, as well as other institutions which might provide similar or complementary analysis;

3. legal basis for establishment, in particular the level of legislation;

4. mandate, including how clearly it is defined, whether it is broad or narrow, specific functions and reporting requirements covered, and institutional coverage;

5. functions, expanding on the section on the mandate to describe more fully the outputs of the IFI and how these may have evolved over time; 
6. work programme, covering how it is decided, how it is linked to the budget timetable and how work is prioritised;

7. budget, including how it is set, whether it is commensurate with the scope of the mandate, specific protections and whether the budget has ever come under threat;

8. staffing, covering both the leadership and the secretariat staff, the appointment process and the process for removal, qualifications and restrictions, term lengths, remuneration and whether the leadership has full freedom over the hiring process for secretariat staff;

9. access to information, including whether access is provided for in legislation or other mechanisms, any restrictions and whether information is provided in practice in a timely manner;

10. transparency, including if and how the IFI makes its work publicly available, the relationship with the media and, where possible, evidence that the IFI has gained credibility with the media, financial markets and the public; and

11. governance, advisory support, monitoring and evaluation, including whether the IFI has an oversight board or other advisory panels, whether work is subjected to peer review and whether the institution or its work is subject to any evaluation process.

\section{IFIs today}

Independent fiscal institutions (commonly referred to as independent parliamentary budget offices or fiscal councils) are independent public institutions with a mandate to critically assess, and in some cases provide non-partisan advice on, fiscal policy and performance. While fiscal decision-making is ultimately the responsibility of democratically elected officials, IFIs serve - often in combination with credible fiscal rules to promote sound fiscal policy and sustainable public finances. Core IFI functions, such as assessing or preparing macroeconomic and fiscal forecasts and monitoring and evaluating fiscal plans and outcomes, can help to address biases towards spending and deficits. And by making their analysis public, IFIs foster greater transparency and accountability and enrich the public debate. As such, IFIs raise reputational and electoral costs for governments that choose to pursue imprudent fiscal policies or break key commitments.

Although still relatively few and novel worldwide, diverse examples of IFIs have existed for decades in countries such as Belgium (1936), the Netherlands (1945), Denmark (1962), Austria (1970) and the United States (1974). Based in part on the experience of these older institutions in the mid-1990s a number of economists and academics floated the idea that countries could adapt some of the good experiences of independent central banking to the fiscal sphere. But it was the surge of government deficits and debts during the 2008-09 crisis that gave real impetus to this project. With commitments to sustainable public finances under close scrutiny, policymakers were searching for new ways to safeguard fiscal discipline and rebuild public trust in their capacity to manage public budgets prudently and transparently. Today IFIs are considered among the most important innovations in the emerging architecture of public financial management.

Since 2008, the number of IFIs within the OECD has more than tripled and is expected to continue to rise within the $\mathrm{OECD}^{6}$ and globally. The largest growth in new institutions can be seen in the European Union (EU) following reforms to the fiscal framework. According to the Treaty on Stability, Coordination and Governance, euro area member states must have an independent body monitor compliance with national fiscal rules and produce or endorse 
macroeconomic projections. ${ }^{7}$ Most recently, the Five Presidents' Report (June 2015) recommended the creation of an advisory European Fiscal Board to co-ordinate and complement the national fiscal councils and to provide a public and independent assessment, at European level, of how budgets - and their execution - perform against the economic objectives and recommendations set out in the EU fiscal governance framework. ${ }^{8}$

Outside of the EU, new IFIs - for example, Canada (2008) and Australia (2011) - have been established to increase fiscal transparency and enhance the role of the legislature in the budget process. ${ }^{9}$ In addition to the EU, international organisations such as the IMF, World Bank and the OECD have encouraged the establishment of IFIs.

Figure 1. The growth of IFIs in the OECD

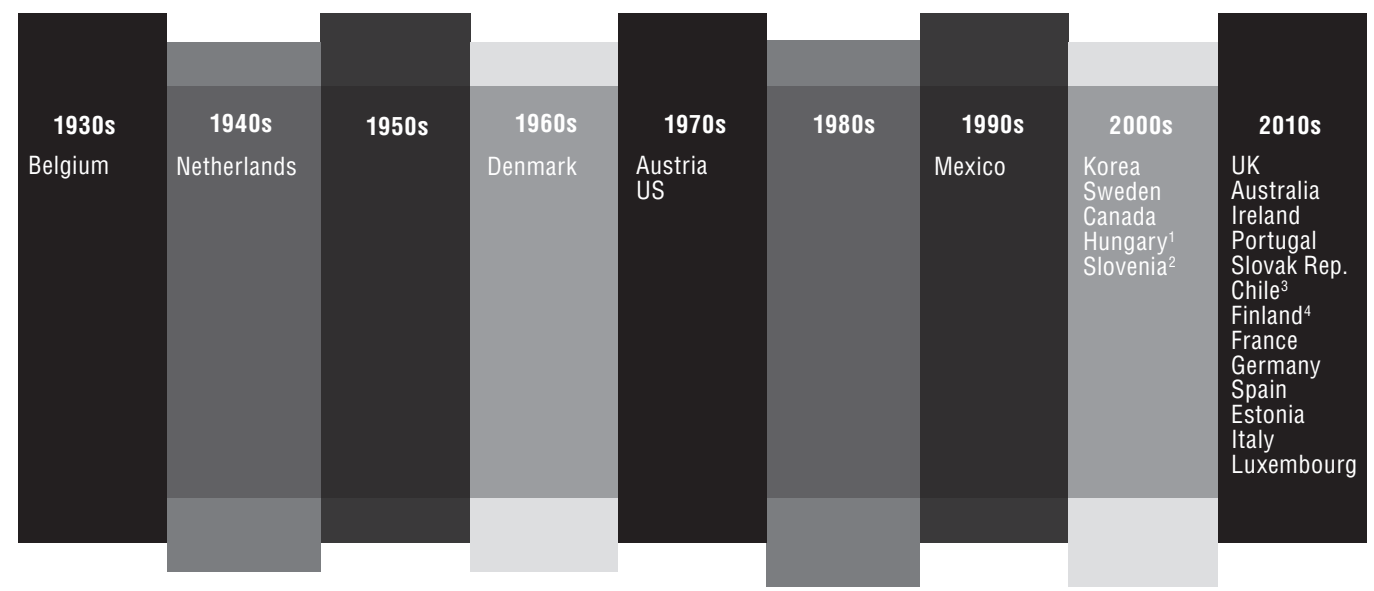

1. Hungary: The Office of the Fiscal Council in Hungary (established 2009) saw its resources significantly reduced at end 2010.

2. Slovenia: A first fiscal council with minimal resources ceased operations in 2012. A new fiscal council is in the process of being established.

3. Chile: A Fiscal Advisory Council was established in April 2013. Its members were replaced following elections. There have been proposals for reform to bring the council more in line with international standards.

4. Finland: In addition to the National Audit Office Fiscal Policy Evaluation Unit, a new Economic Policy Council was established in 2014 with a mandate to give ex ante policy advice.

Despite their growing popularity, IFIs across OECD member countries face similar challenges, particularly in their early years. While it may be in countries' long-term interest to establish an IFI, politicians may be tempted to constrain the actions of an IFI to avoid criticism in the short term. On a positive note however, the experience of countries with more long-standing institutions demonstrates that - even if they do not always agree IFIs are viewed in the longer term as important partners for finance ministries and legislative budget committees in promoting credible fiscal policies.

Given how new the majority of these institutions are, it is difficult to formally assess their effectiveness. Moreover, the establishment of an IFI, particularly in those countries with older instructions, may reflect the government's political commitment, underpinned by the electorate's preference, for discipline (Kopits, 2011). Nevertheless, several points in the OECD principles have been reaffirmed as key features of effective fiscal councils, for example, strict operational independence and a strong presence in the public debate, as well as a role in fiscal rule monitoring and production or assessment of forecasts (OECD, 2012 and IMF, 2013 and 2014). 


\section{Institutional models}

IFIs within the OECD are a heterogeneous group - there is no one size fits all model. They vary considerably in terms of their governance provisions, breadth of their mandate and functions, leadership and staff arrangements, and budget. This underlines the importance of local needs and the local institutional environment (including, in some cases, capacity constraints) to their design, even for those bodies that were set up to meet the same European requirements (see OECD principles 1.1 and 1.2). One area where fiscal councils differ is their institutional independence. Belgium provides an example of a fiscal council with more limited independence as the High Council of Finance is formally chaired by the Minister of Finance and has a secretariat under the authority of the federal government. An example of a fiscal council with stronger independence is the United Kingdom's Office for Budget Responsibility (OBR) which is a legally separate armslength entity with its own oversight board.

Over half of the institutions (56\%) can be described as under the statutory authority of the executive or standalone (although they may, like the UK OBR, have dual lines of accountability to the executive and the parliament). This tends to be institutions that follow the fiscal council model, although even within this model, there are subsets, for example, some countries have chosen small, largely academic councils (e.g. Sweden, Ireland). Others have followed more of a corporatist tradition in which a larger set of council members may be proposed by different stakeholders or interest groups (e.g. Austria, Belgium, Denmark, France).

Another third (33\%) of the institutions in the case studies follow the parliamentary budget office model (Australia, Canada, Italy, Korea, Mexico, United States) with a stronger focus on assisting parliamentary oversight of the budget and supporting the work of the main budget committee. PBOs are also more likely to have a costing role.

The remainder have been established as autonomous units connected to the national audit institution (Finland, France). It should be noted that several also have links to the Central Bank. For example, Oesterreichische Nationalbank provides staff for Austria's Fiscal Advisory Council and funding for the Council for Budget Responsibility in the Slovak Republic is drawn from the National Bank of Slovakia.

\section{Leadership}

IFIs may have an individual or collegial leadership structure. With the exception of Italy, those that fall into the parliamentary budget office model tend to have an individual leadership structure (Australia, Canada, Korea, Mexico, United States), as do the Netherlands and Spain. Others set up in line with the fiscal council model are typified by a collegial leadership structure with the Chair taking a more or less strong role (e.g. Austria, Belgium, Denmark, Ireland, Portugal, Slovak Republic, Sweden, United Kingdom).

The OECD Principles for IFIs recommend that the position of head of the IFI should be a remunerated and preferably full-time position (principle 2.4). All those institutions set up along the parliamentary budget office model to date have full-time leadership that is remunerated. However, as previously mentioned, under the fiscal council model half of the institutions have part-time leaders. These tend to be those institutions in smaller European countries, institutions which can draw on the work of other institutions, and some of the older institutions with more of a corporatist tradition and a larger number of council members (for example, Austria, Belgium and Denmark which all have ten or more 
Figure 2. Leadership arrangements by institutional model

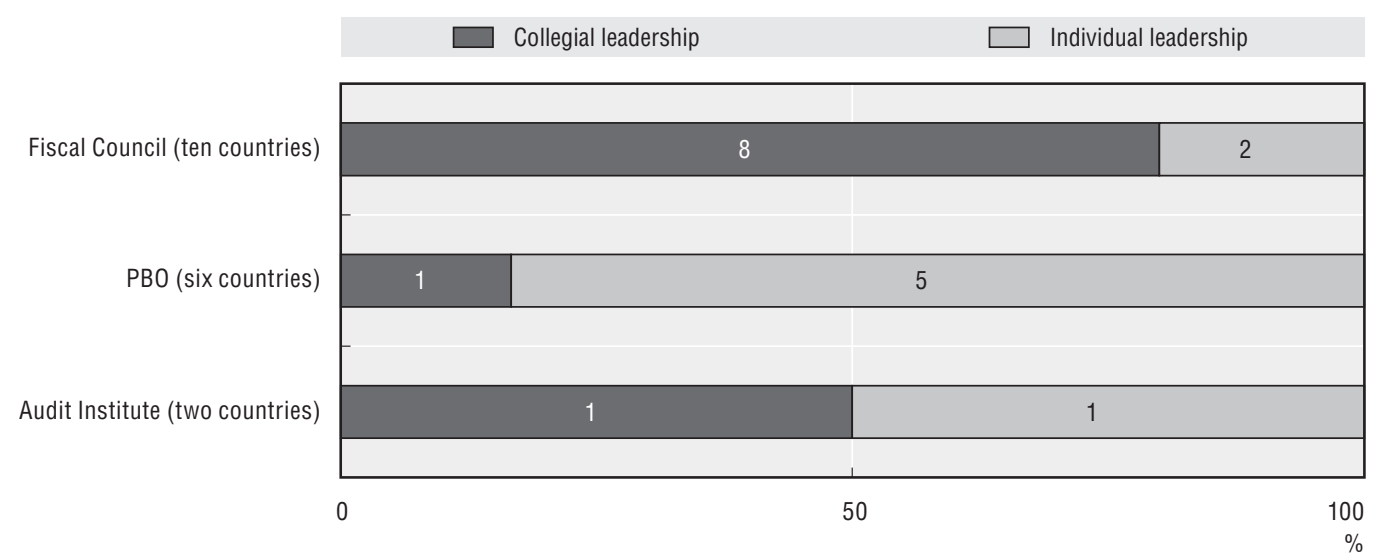

part-time council members). In some cases a position as a council member might be best described as honorary and is not remunerated.

In most OECD countries, leaders are appointed by the government or parliament although they may be proposed by other stakeholders. As noted earlier, a number of countries, particularly within the EU have more of a corporatist tradition in which council members may be proposed by different stakeholders or interest groups. In Finland, the leader of the Fiscal Policy Evaluation Function is assigned by the Auditor General. Several countries (e.g. Ireland, Portugal, and Sweden) allow for non-nationals to serve as council members, thus increasing the pool of qualified candidates and reducing the risk of "groupthink". This design choice may serve to bolster independence.

Some OECD countries have procedures in place within the appointment process to provide assurance that leadership appointments are non-partisan. For example, in the United Kingdom, appointments to the OBR's Budget Responsibility Committee are made by the Chancellor of the Exchequer subject to the consent of the House of Commons Treasury Select Committee and in Spain the Council of Ministers nominated candidate for AIReF Presidency must appear before the Congress of Deputies Finance and Public Administrations Committee to be assessed for suitability prior to being appointed. Similarly the government may not dismiss the leadership without the approval of the parliament as is the case in Ireland, Spain and the United Kingdom (see principle 5.1).

Where leadership appointments are made by parliament, additional safeguard procedures can still be put in place. For example, the appointments may also be subject to the approval of relevant committees (as is the case in Australia and Italy) or the full parliamentary chamber (as is the case in Mexico). In the US, the CBO Director and deputy are appointed by the Speaker of the House of Representatives and the President pro tempore of the Senate after considering recommendations received from the Committees on the Budget of the House and the Senate.

The OECD Principles also recommend that the leadership of an IFI should be selected on the basis of merit and technical competence, without reference to political affiliation (principle 2.2) and this principle has been strongly adhered to in OECD member countries. The leadership of IFIs across the OECD is drawn from a variety of backgrounds including academia, government (particularly the Ministry of Finance), audit institutions, the central bank and the private sector. Almost a quarter of leaders have spent time in academia prior to joining the IFI. 
Figure 3. Leadership background (where known)

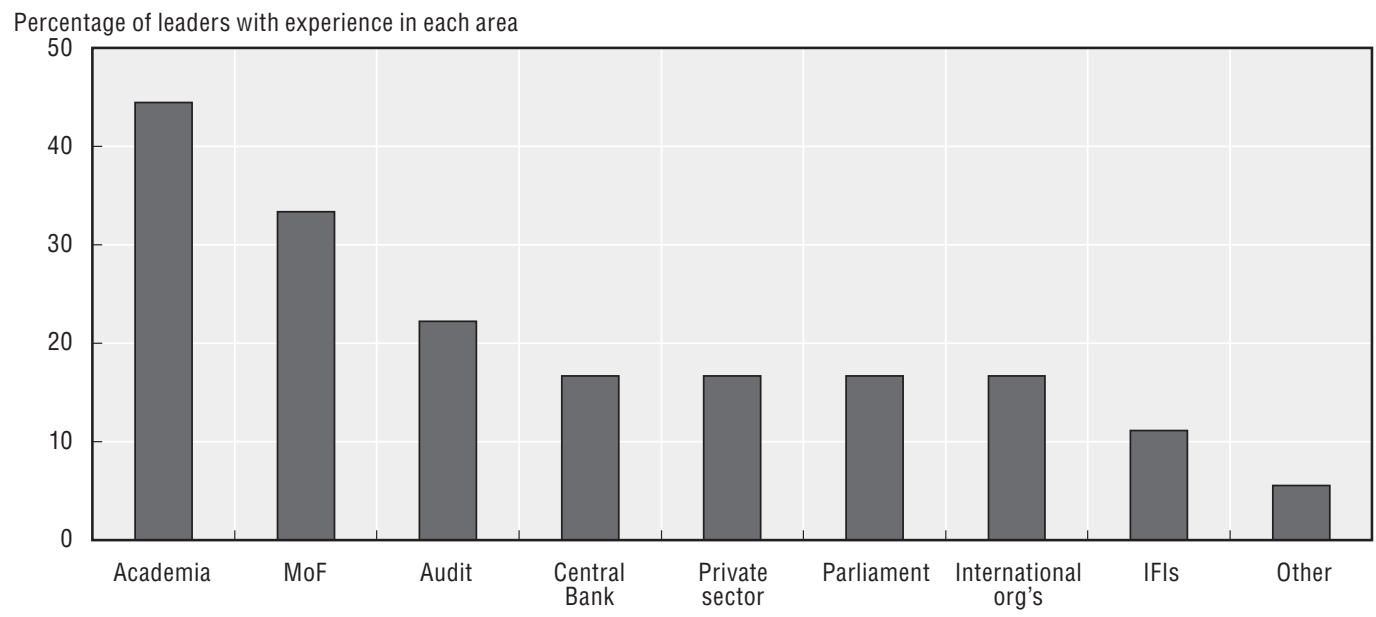

The OECD Principles for IFIs recommend that term lengths and the number of terms that the leadership may serve should be clearly specified in legislation (principle 2.3). In almost all of the IFIs across OECD member countries leaders have clearly defined term lengths. The exception is the Korean National Assembly Budget Office (NABO) where there is no defined term or term limit for the chief. In practice, every two years the NABO chief resigns when there is a change of House Speaker.

The OECD Principles also recommend that the criteria and process for dismissal of leaders should be clearly stated in legislation (principle 2.3). There are clearly defined criteria for the dismissal of leaders in almost three-quarters (72\%) of the IFIs. Exceptions include Austria, Belgium and Sweden, where the situation is not clearly defined or legislation does not explicitly prescribe a particular process for the removal of the leadership. Another exception is Canada, where the Parliamentary Budget Officer is appointed for a five-year term renewable once "during pleasure", meaning that he or she can be removed at the discretion of the Governor in Council (essentially at the discretion of the Prime Minister) and without cause. The final exception is Korea where the House Speaker has the power to dismiss the chief.

A further recommendation in the OECD Principles is that the leadership of the IFI should have full freedom to hire and dismiss staff in accordance with applicable labour laws (principle 2.5). The vast majority of the IFIs (78\%) have full control over the hiring process for staff. Exceptions include Austria, Belgium and France where staff are provided by the National Bank and Ministry of Finance and Court of Auditors, respectively. In Ireland the

\section{Figure 4. Strength of leadership arrangements}

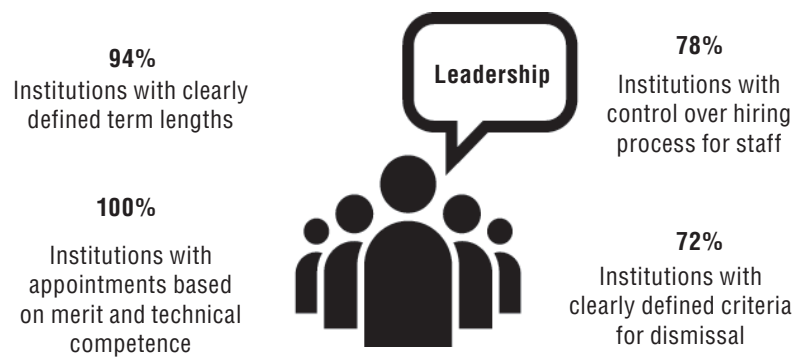


Fiscal Advisory Council has the flexibility to hire staff, although prior approval is needed from the government, which can be seen as a limit on its administrative independence. In Korea senior staff (above division chiefs) are appointed and dismissed by the Speaker of the National Assembly, whereas other staff are appointed and dismissed by the NABO chief.

\section{Resources}

The OECD Principles for IFIs recommend that the resources allocated to IFIs must be commensurate with their mandate in order for them to fulfil it in a credible manner (principle 4.1). The three IFIs with the greatest budget and staffing resources are highlighted in the table below:

Table 1. Highly resourced institutions

\begin{tabular}{llc|lll}
\hline \multicolumn{2}{c|}{ Budget } & \multicolumn{3}{c}{ Staff } \\
\hline 1 & US (CBO) & $46.8 \mathrm{~m}$ USD & 1 & US (CBO) & 246 \\
2 & Netherlands (CPB) & $13 \mathrm{~m} \mathrm{EUR}$ & 2 & Korea (NABO) & 138 \\
3 & Korea (NABO) & $13.6 \mathrm{~m} \mathrm{USD}$ & 3 & Netherlands (CPB) & 117 \\
\hline
\end{tabular}

This reflects the breadth and scope of their mandate and activities. For example, the United States CBO, the Korean NABO, and the Netherlands CPB all have a role in policy costing, a resource-intensive task that requires staff with specific programme knowledge. The Korean NABO also has a broad mandate for budget analysis and evaluation. In particular it prepares a wide range of evaluations each year, on topics ranging from infrastructure projects to government assistance to autonomous public institutions. A small number of institutions have around 30-60 staff and a budget of USD 3-7 million (Australia, Denmark, Italy, Mexico, Spain). The remaining institutions (50\% of IFIs) operate with fewer than 30 staff and these institutions tend to have a budget of less than USD 3 million. In general, institutions within this group tend to have a narrower remit. For example, a number of institutions in the lower half of the staff count focus on activities such as assessing or endorsing the government's forecasts and monitoring compliance with fiscal rules only.

\section{Figure 5. Institutions grouped by general scale of resources}

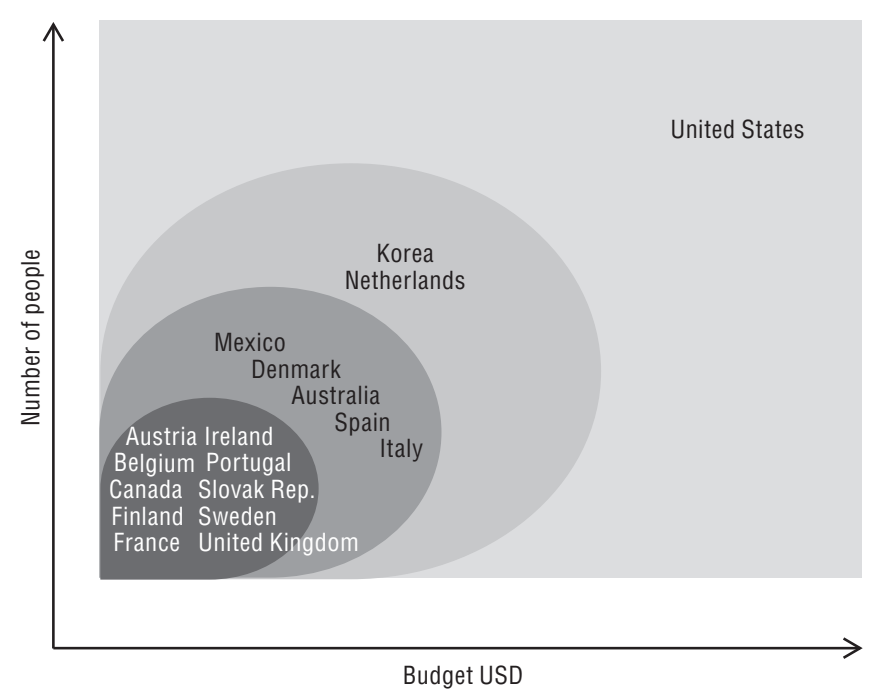


Those institutions in the upper half of the staff count may have some additional functions, such as a (limited) role in policy costing (Canada, Slovak Republic, United Kingdom). The smallest institutions, France, Ireland and Sweden operate for fewer than one million euros with 5 or less secretariat staff.

The OECD Principles for IFIs recommend that certain protections be put in place regarding IFI budgets, such as appropriations being published and treated in the same manner as other independent bodies and multi-annual funding commitments (principle 4.1). Less than half of the IFIs (44\%) have their budget outlined as a separate line item and fewer still (25\%) have budgets with multi-annual funding commitments, a practice which can enhance independence and help insulate the institution from political pressure (e.g. Australia and United Kingdom). However, a small number of institutions have their funding levels set out in legislation (e.g. Ireland and Italy). While in Italy, the budget can only be amended through the annual budget legislation, in Ireland the funding is not subject to annual authorisation through the budget process and so new legislation would be required to modify or withdraw funding, affording it a very high level of protection. Certain protections are in place in other OECD countries too. For example, the Portuguese Public Finance Council does not have its budget set out in legislation, but it is stated in legislation that their funding can only be reduced in duly justified exceptional circumstances.

\section{Mandate, functions and work programme}

Certain typical core functions can be found across IFI models. A large percentage of institutions engage in macroeconomic and/or fiscal forecasting (83\%). Their role in the forecasts takes several forms. For example, the Netherlands CPB and the UK OBR have been tasked with producing the official economic and fiscal forecasts used by government. Some institutions produce alternative forecasts (e.g. Canada, Denmark, Korea, Mexico, United States), while others provide an opinion on, or endorsement of, the government's forecasts (e.g. Austria, Finland, France, Ireland, Italy, Portugal, Spain, Sweden) and still others were set up with no forecasting role at all (e.g. Australia, Belgium, Slovak Republic).

With the exception of the Netherlands $C P B,{ }^{10}$ all of the fiscal councils in OECD member countries within the EU are tasked with monitoring compliance with fiscal rules (although some of the older EU institutions, such as Austria and Denmark, only took on this role recently to meet new EU requirements). None of the institutions in OECD member countries that are outside of the EU have this task, although it has been proposed for the Australian Parliamentary Budget Office.

Many institutions have a role in the analysis of long-term fiscal sustainability (89\%). This may, for example, involve analysis of the impact of demographic trends, public policy and debt levels on long-term public finances.

Half of the institutions in OECD member countries (50\%) have a costing role, with this function found across all parliamentary budget offices and a number of fiscal councils. However, there is notable diversity in the type of costing work undertaken. The US Congressional Budget Office costs virtually every bill reported by congressional committees (between 500 and 700 annually). The Canadian PBO undertakes policy costings, but is selective when doing so given its limited resources. It prioritises requests based on materiality and contribution potential. A project or request is material if it can reasonably be expected to have a substantive impact on the government's finances, estimates or the Canadian economy. The Slovak Council for Budget Responsibility may publish opinions, particularly 
in terms of implications for the general government budget and long-term sustainability, on draft legislation submitted to the National Council at its own initiative or at the instigation of a parliamentary group. A number of institutions also have a role in scrutinising policy costings. For example, the UK OBR scrutinises the costings of budget measures produced by government departments.

While the function of costing of election platforms has generated considerable interest within the OECD membership, only the Netherlands CPB and Australian PBO have this function. The reasoning behind giving the PBO this role was that while the government and opposition enjoyed access to the Ministry of Finance and Treasury to cost their election commitments, similar access was not afforded to smaller political parties or independents. The mandate of the PBO has also evolved to include a report after a general election on the budget impact of election commitments of designated parliamentary parties. Additional resources are given to the $\mathrm{PBO}$ when carrying out this function. The Netherlands has been costing election platforms and coalition agreements (the Netherlands typically has coalition governments) since the 1980s and, although voluntary, all major parties now ask for such costings. The scope of such evaluations has to include the long-term effects and the impact of the proposals on the distribution of income and unemployment. Most major political parties also ask the CPB to cost major sectoral policy topics, like education, mobility, environment and the housing market. Over the years, this higher scrutiny has had the advantage of making party manifestos much more specific.

The mandates of IFIs may evolve. This is true even for very young institutions. For example in April 2013 the Irish Fiscal Advisory Council was assigned a new role in endorsing the Department of Finance's macroeconomic forecasts. For others, discussions about potential changes are under way, such as the proposal to have the Australian PBO prepare annual medium-term (ten-year) budget projections. ${ }^{11}$ The Korean NABO had its mandate revised in 2014 to give it a strengthened role in the costing of legislation- NABO now has sole authority to prepare cost estimates for bills introduced by members. As noted earlier, some of the older institutions have taken on a new role in monitoring compliance with fiscal rules (e.g. Austria and Denmark).

IFIs should have the autonomy to determine their own work programme within the bounds of their mandate. Similarly, they should have the scope to produce reports and analysis at their own initiative, provided that these are consistent with their mandate (principle 3.2). All of the IFIs have this autonomy although the extent to which the work programme is guided by legislation varies and in some instances it must also be approved externally. For example the Korean NABO work programme must be approved by the Speaker of the National Assembly and the Mexican CEFP must submit its work programme to the Chamber of Deputies' Committee for Review. An exception is the French High Council for Public Finances (HCFP). The organic law establishing the Council establishes the timings for its reports and prohibits it from undertaking work on its own initiative beyond what is provided for in the law.

\section{Relationship with the legislature}

The OECD IFI Principles recognise that legislatures perform critical accountability functions in country budget processes (principle 5.1). As noted earlier, many legislatures play a role in the appointment and dismissal process for IFI leadership. Almost all institutions $(94 \%)$ send their key reports to the legislature (and all make their reports public so technically accessible to the legislature) and participate in parliamentary hearings (again, 94\%). The 


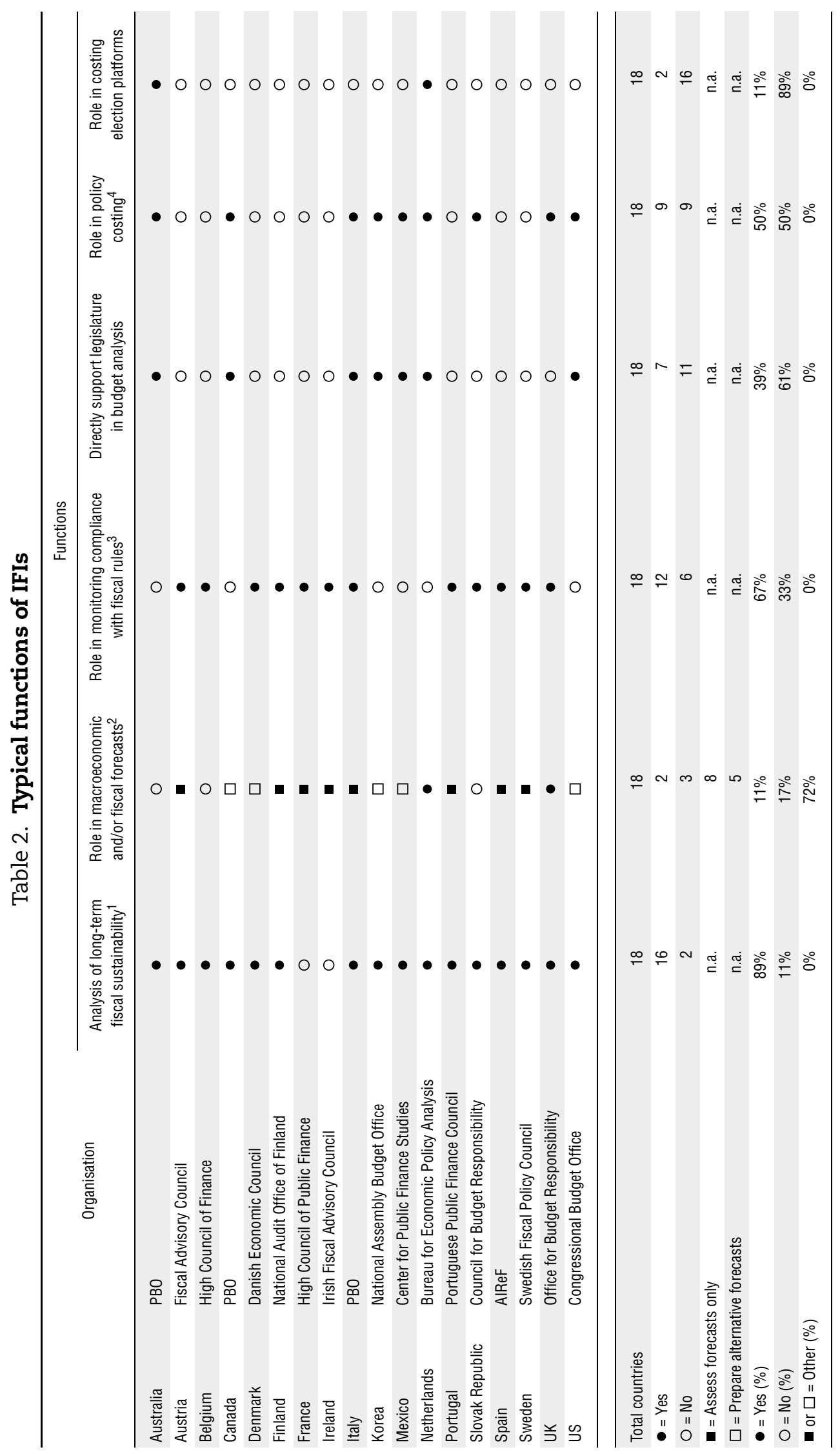




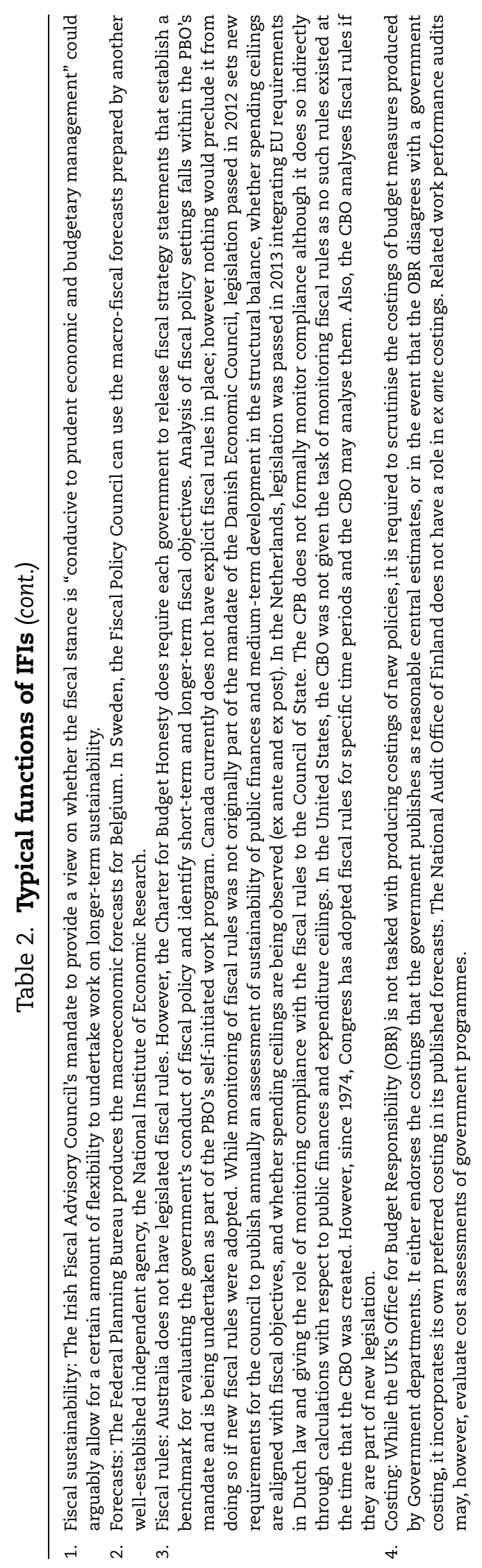


Belgian High Council of Finance is the only institution that does not do this. However, while it has no formal relationship with the legislature, theoretically parliamentary committees could invite the chairs of the sections to discuss budgetary issues.

\section{Access to information}

Accessing government information is crucial to the work of IFIs. In this context, the OECD Principles for IFIs recommend that access to information is guaranteed in legislation and, if necessary, reaffirmed through protocols or memoranda of understanding (principle 6.1). A Memoranda of Understanding (MoU) can help to manage expectations by establishing mutually agreeable processes for information requests and responses, including indicative timeframes for responses, what to do when requests are not complied with, and provisions regarding the treatment of confidential data. Just over $60 \%$ of institutions in OECD member countries have access to information underpinned by legislation, and at least half of these have access to information underpinned by both legislation and MoU (Canada, Finland, Italy, Portugal, Slovak Republic, and United Kingdom). Others are negotiating MoUs (e.g. Spain). However, one in five institutions (22\%) still have no underpinning to their access to information (Austria, Denmark, Netherlands and Sweden). The extent to which access to information is underpinned by different agreements is not always a perfect indicator for the ease with which institutions obtain information. For example, in the Netherlands access to information has no underpinning, but being a government "insider", the CPB has relatively easy access to non-published information held by the ministries and information is received in a timely manner. On the other hand, Canada has access to information underpinned by both legislation and memoranda of understanding, but the PBO initially experienced difficulties obtaining information requested.

\section{Figure 6. Access to information}

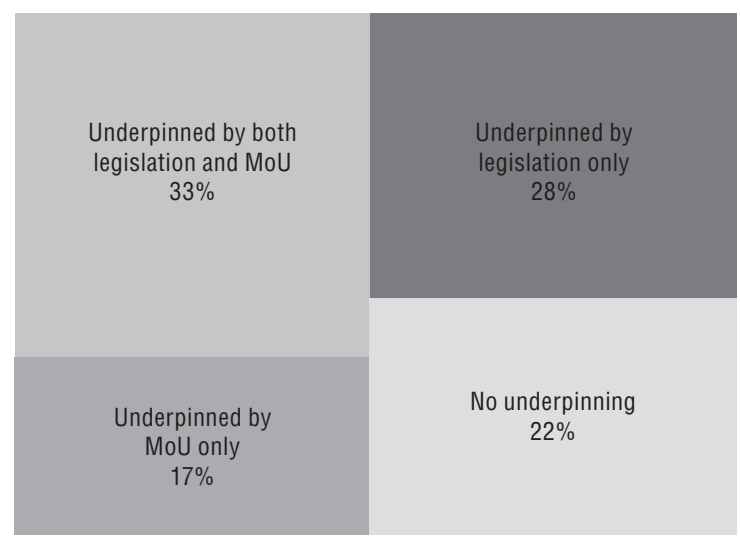

\section{Advisory support and evaluation}

The OECD Principles for IFIs recommend that IFIs develop a mechanism for external evaluation of their work (principle 9.1). Almost half (44\%) of the IFIs across OECD member countries have an external advisory panel in place, or in development, in order to enhance the credibility of their work (Finland, Italy, Korea, Netherlands, Slovak Republic, Spain, United Kingdom and United States).

Advisory panels can be in place for a number of reasons, for example, to make suggestions in relation to an institutions' programme of work and topics of concern or to 
provide methodological or technical advice. Korea's NABO has a panel of outside advisors whose main role is to advise the chief on NABO's duties or other topics of concern and the Netherlands CPB has an advisory board (the Central Planning Commission) that advises the management on its work programme. The Slovak Republic's Council for Budget Responsibility has an Advisory Panel that provides advice on methodological issues. In Spain, AIReF have an Advisory Board of professionals, divided into two panels focusing on the two key areas covered by AIReF's remit: economic analysis and budgetary and institutional analysis. The UK OBR has a nine-person panel of experts who help develop and scrutinise the OBR work programme and methods and in the United States the CBO has a Panel of Economic Advisers and a Panel of Health Advisers who provide advice to further the reliability, profession quality and transparency of the CBO's work. The Italian PBO and the National Audit Office of Finland are also planning to establish expert panels to provide technical advice.

A small number of IFIs also engage in peer review both formally and informally. For example, the Australian PBO uses peer review processes as required for its major reports. Peer reviewers are familiar with the data, methodologies and estimation techniques and have in the past been sourced from independent think tanks, academia, international organisations, private sector economists and other IFIs. In each case their identity has been made public. The Canadian PBO has also actively sought to have its work peer reviewed for external validation and to ensure the rigour of the methodology and the results. To do this, it regularly collaborates with other institutions such as universities, think tanks, the Canadian Association for Business Economics, the United States CBO and the IMF.

A full external evaluation of an IFI can serve to legitimise the institution relevant to its environment, resources, products and perceptions of its legislated and non-legislated stakeholders. At present just two IFIs (11\%) have a process for external evaluation incorporated into legislation (Australia and United Kingdom). The first evaluation of the Australian PBO was completed by the Australian National Audit Office in June 2014, which had as its objective to "assess the effectiveness of the Parliamentary Budget Office in conducting its role since being established in July 2012". The first evaluation of the United Kingdom OBR was completed by a team from the University of Ottawa, which included the former Canadian Parliamentary Budget Officer, and published in September 2014. In June 2015, the Chancellor to the Exchequer asked Sir Dave Ramsden, Chief Economic Adviser to HM Treasury, to complete a government review of the OBR. The intention was for this to build on the work of the first external evaluation, focusing on the existing regime and framework of the OBR and its role in enhancing UK fiscal credibility. A number of other institutions have been pro-active in the area of external evaluation. The Netherlands CPB has the longest experience with external review: every five years the work of the CPB is evaluated by academic peers (on scientific value) and by clients (on policy relevance). Nearly all of the academics for the scientific review are non-Dutch, which enhances objectivity, The Irish Fiscal Advisory Council published their first external review in 2015 and have indicated willingness for external evaluation to take place on a regular basis, and in Spain the President of AIReF has committed to conduct a mid-term independent assessment of AIReF activity. 


\section{Figure 7. Advisory support and evaluation}

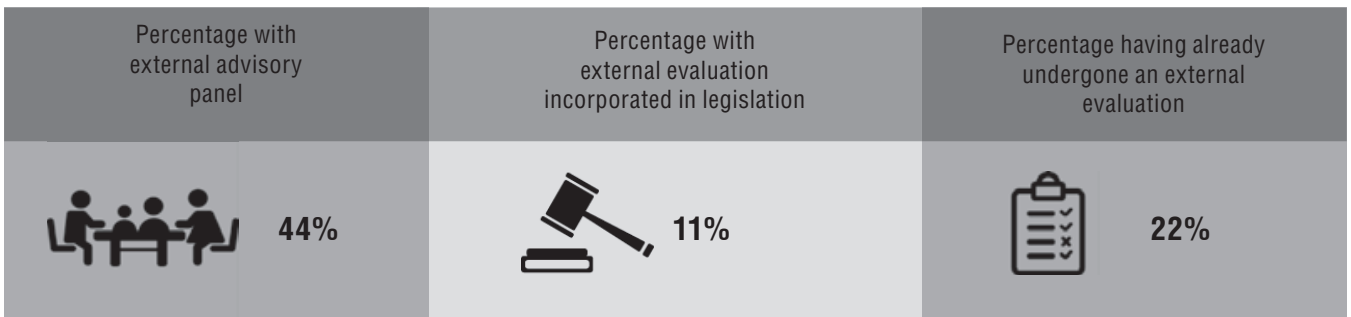

\section{Notes}

1. Over two years of extensive consultation took place within the PBO, the Working Party of Senior Budget Officials (SBO) and the Public Governance Committee (PGC).

2. As part of the preparatory work for the principles in 2012, the OECD undertook a study of 15 institutions. This was then expanded to include four new institutions (Finland, France, Italy and Spain) and a study of the now defunct Slovenian Fiscal Council was removed. The original case studies have been updated here where possible, as several of the institutions covered have undergone evolutions in their mandates and functions since 2012.

3. The potential positive role of IFIs is also recognised in the OECD Recommendation on Budgetary Governance (2015), which calls on governments to consider "how the credibility of national budgeting - including the professional objectivity of economic forecasting, adherence to fiscal rules, longer-term sustainability and handling of fiscal risks - may also be supported" through the work of IFIs.

4. Except where noted the data in the introduction pertains to the 18 case studies presented in Part 3.

5. References for further reading are provided for each country case study.

6. New IFIs are planned for example in Iceland, Greece (which recently proposed to strengthen the mandate of the existing Parliamentary Budget Office), and Slovenia (to replace the now defunct Fiscal Council).

7. Similar requirements can be found in the so-called "two-pack". Regulation No. 473/2013 that requires all euro-zone members to establish an IFI.

8. The Five Presidents' Report is available at http://ec.europa.eu/priorities/economic-monetary-union/docs/ 5-presidents-report_en.pdf.

9. A parallel trend in many OECD countries has been for legislatures to increase their budget analysis capacity whether through a fully-fledged independent parliamentary budget office or by strengthening internal research units.

10. This task has been given to the Council of State.

11. See Australian Parliament Joint Committee of Public Accounts and Audit Report No. 446: Review of the Operations of the Parliamentary Budget Office - www.aph.gov.au/Parliamentary_Business/ Committees/Joint/Public_Accounts_and_Audit/PBO/Report_446.

\section{Bibliography}

Calmfors, L. and S. Wren-Lewis (2011), "What Should Fiscal Councils Do?", Economic Policy, Vol. 26, Issue 68, pp. 649-695, http://dx.doi.org/10.1111/j.1468-0327.2011.00273.x.

Debrun X. and T. Kinda (2014), "Strengthening Post-Crisis Fiscal Credibility: Fiscal Councils on the Rise A New Dataset”, IMF Working Paper, WP/14/58, IMF, www.imf.org/external/pubs/ft/wp/2014/wp1458.pdf.

Hagemann, R. (2011), "How Can Fiscal Councils Strengthen Fiscal Performance?", OECD Journal: Economic Studies, Vol. 2011/1, http://dx.doi.org/10.1787/eco_studies-2011-5kg2d3gx4d5c.

International Monetary Fund (IMF) (2013), The Functions and Impacts of Fiscal Councils, IMF, www.imf.org/ external/np/pp/eng/2013/071613.pdf. 
Kopits, G. (2011), “Independent Fiscal Institutions: Developing Good Practices”, OECD Journal on Budgeting, Vol. 11/3, http://dx.doi.org/10.1787/budget-11-5kg3pdgcpn42.

OECD (2012), "Draft principles for independent fiscal institutions Annex: Draft country notes", www.oecd.org/gov/budgeting/D2-AM\%20-\%20SBO\%20Hand-Out\%201\%20ANNEX\%20-\%20Country\%20 Notes\%20-\%20revised\%2029\%20May.pdf. 


\section{Recommendation of the Council on Principles for Independent Fiscal Institutions}

What follows is a reproduction of C(2014)17 Recommendation of the Council on Principles for Independent Fiscal Institutions, adopted by the OECD Council on 13 February 2014.

HAVING REGARD to Article 5b) of the Convention on the Organisation for Economic Co-operation and Development of 14 December 1960;

NOTING the growth of independent fiscal institutions within Member countries and the diversity of existing institutions;

HAVING AGREED that, for the purpose of the present Recommendation, independent fiscal institutions are publicly funded, independent bodies under the statutory authority of the executive or the legislature which provide non-partisan oversight and analysis of, and in some cases advice on, fiscal policy and performance, and that these institutions have a forward-looking ex ante diagnostic task;

RECOGNISING that independent fiscal institutions have the potential to enhance fiscal discipline, promote greater budget transparency and accountability and raise the quality of public debate on fiscal policy, while recognising also that alternative institutional arrangements may serve some countries equally well;

RECOGNISING that budget transparency is a key element of good governance and that the OECD has played a leading role in the international community in promoting budget transparency through the OECD Best Practices for Budget Transparency (OECD, 2002);

On the proposal of the Public Governance Committee;

I. RECOMMENDS that Members which have chosen to establish or are considering establishing an independent fiscal institution take into account the Principles for Independent Fiscal Institutions which are set out in the Annex to this Recommendation of which it forms an integral part.

II. INVITES Members and the Secretary-General to disseminate this Recommendation.

III. INVITES non-Members who have chosen to establish or are considering establishing an independent fiscal institution to take account of and to adhere to this Recommendation.

IV. INVITES relevant international organisations to take account of this Recommendation and to collaborate with the OECD to exchange good practices and data on independent fiscal institutions.

V. INSTRUCTS the Public Governance Committee to monitor the implementation of this Recommendation and to report thereon to the Council no later than three years following its adoption and regularly thereafter. 



\title{
ANNEX
}

\section{Principles for Independent Fiscal Institutions (IFIs)}

\begin{abstract}
$\mathrm{T}_{\mathrm{r}}$ he twenty-two Principles for Independent Fiscal Institutions (fiscal councils and independent parliamentary budget offices) proposed below are grouped under nine broad headings: (1) local ownership; (2) independence and non-partisanship; (3) mandate; (4) resources; (5) relationship with the legislature; (6) access to information; (7) transparency; (8) communication; and (9) external evaluation.
\end{abstract}

\section{Local ownership}

To be effective and enduring, an IFI requires broad national ownership, commitment, and consensus across the political spectrum. While a country seeking to establish an IFI will benefit from the study of existing models and experiences in other countries, models from abroad should not be artificially copied or imposed. Regional or international authorities may provide valuable support and protection.

Local needs and the local institutional environment should determine options for the role and structure of the IFI. Design choices may also have to take into account capacity constraints, particularly in smaller countries. ${ }^{1}$ The basic characteristics of an IFI, including specific protections, should be informed by the country's legal framework, political system, and culture. Its functions should be determined by the country's fiscal framework and specific issues that need to be addressed.

\section{Independence and non-partisanship}

Non-partisanship ${ }^{2}$ and independence are pre-requisites for a successful IFI. A truly non-partisan body does not present its analysis from a political perspective; it always strives to demonstrate objectivity and professional excellence, and serves all parties. This favours that IFIs should be precluded from any normative policy-making responsibilities to avoid even the perception of partisanship.

The leadership 3 of an IFI should be selected on the basis of merit and technical competence, without reference to political affiliation. The qualifications should be made 
explicit - including professional standing and relevant government or academic experience. Qualifications should include proven competence in economics and public finances and familiarity with the budget process.

Term lengths and the number of terms that the number of terms that the leadership of the IFI may serve should be clearly specified in legislation as should be the criteria and process for dismissal for cause. The leadership's term should optimally be independent of the electoral cycle. Independence may be enhanced by defining the term span beyond the electoral cycle.

The position of head of the IFI should be a remunerated and preferably full-time position. ${ }^{4}$ Strict conflict- of-interest standards, particularly for institutions with council members employed on a part-time basis, should be applied equally vis-à-vis other employment in the public or private sector.

The leadership of the IFI should have full freedom to hire and dismiss staff in accordance with applicable labour laws.

Staff should be selected through open competition based on merit and technical competence and without reference to political affiliation. Conditions of employment should be along the lines of that of the civil (or parliamentary) service. ${ }^{5}$

\section{Mandate}

The mandate of IFIs should be clearly defined in higher-level legislation, including the general types of reports and analysis they are to produce, who may request reports and analysis, and, if appropriate, associated timelines for their release.

IFIs should have the scope to produce reports and analysis at their own initiative, provided that these are consistent with their mandate. Similarly, they should have the autonomy to determine their own work programme within the bounds of their mandate.

Clear links to the budget process should be established within the mandate. Typical tasks carried out by IFIs might include (but are not limited to): economic and fiscal projections (with a short- to medium-term horizon, or long-term scenarios); baseline projections (assuming unchanged policies); analysis of the executive's budget proposals; monitoring compliance with fiscal rules or official targets; costing of major legislative proposals; and analytical studies on selected issues. ${ }^{6}$

\section{Resources}

The resources allocated to IFIs must be commensurate with their mandate in order for them to fulfil it in a credible manner. This includes the resources for remuneration of all staff and, where applicable, council members. The appropriations for IFIs should be published and treated in the same manner as the budgets of other independent bodies, such as audit offices, in order to ensure their independence. Multiannual funding commitments may further enhance IFIs independence and provide additional protection from political pressure.

\section{Relationship with the legislature}

Legislatures perform critical accountability functions in country budget processes and the budgetary calendar should allow sufficient time for the IFI to carry out analysis necessary for parliamentary work. Regardless whether an independent fiscal institution is under the statutory authority of the legislative or the executive branch, mechanisms should be put in place to encourage appropriate accountability to the legislature. These 
may include (but are not limited to): 1) submission of IFI reports to parliament in time to contribute to relevant legislative debate; 2) appearance of IFI leadership or senior staff before the budget committee (or equivalent) to provide responses to parliamentary questions; 3) parliamentary scrutiny of the IFI budget; and 4) a role for parliament's budget committee (or equivalent) in IFI leadership appointments and dismissals.

The role of the IFI vis-à-vis parliament's budget committee (or equivalent), other committees, and individual members in terms of requests for analysis should be clearly established in legislation. Preferably, the IFI should consider requests from committees and sub-committees rather than individual members or political parties. This is particularly relevant for those IFIs established under the jurisdiction of the legislature.

\section{Access to information}

There is often asymmetry of information between the government and the IFI - no matter how well an IFI is resourced. This creates a special duty to guarantee in legislation and if necessary to reaffirm through protocols or memoranda of understanding - that the IFI has full access to all relevant information in a timely manner, including methodology and assumptions underlying the budget and other fiscal proposals. Information should be provided at no cost or, if appropriate, sufficient resources should be provided in the IFI budget to cover analysis obtained through government actuarial services.

Any restrictions on access to government information should also be clearly defined in legislation. Appropriate safeguards may be put in place ${ }^{7}$ as regards protection of privacy (for example, taxpayer confidentiality) and of sensitive information in the areas of national defence and security.

\section{Transparency}

Given that promoting transparency in public finances is a key goal of IFIs, they have a special duty to act as transparently as possible. Full transparency in their work and operations provides the greatest protection of IFI independence and allows them to build credibility with the public.

IFI reports and analysis (including a full account of the underlying data and methodology) should be published and made freely available to all. As noted in 5.1, all IFI reports and analysis should be sent to parliament in time for legislative debate ${ }^{8}$ and the leadership of the IFI should be given the opportunity to testify before parliamentary committees.

The release dates of major reports and analysis should be formally established, especially in order to co-ordinate them with the release of relevant government reports and analysis. ${ }^{9}$

IFIs should release their reports and analysis, on matters relating to their core ongoing mandate on economic and fiscal issues, in their own name.

\section{Communications}

IFIs should develop effective communication channels from the outset, especially with the media, civil society, and other stakeholders. Given that the influence of IFIs in fiscal policy making is persuasive (rather than coercive by means of legal sanctions or other punitive measures), media coverage of their work assists in fostering informed constituencies that may then exercise timely pressure on the government to behave transparently and responsibly in fiscal matters. 


\section{External evaluation}

IFIs should develop a mechanism for external evaluation of their work - to be conducted by local or international experts. This may take several forms: review of selected pieces of work; annual evaluation of the quality of analysis; a permanent advisory panel or board; or peer review by an IFI in another country.

Relevant body:

Public Governance Committee

\section{Notes}

1. Several countries (e.g. Ireland, Portugal, and Sweden) allow for non-nationals to serve as council members, thus increasing the pool of qualified candidates and reducing the risk of "groupthink". As such, this design choice may also serve to bolster independence.

2. Non-partisanship should not be confused with bi-partisanship. Whereas bi-partisanship suggests a balance between political parties, non-partisanship necessitates an absence of political influence.

3. The title may differ - director, president, or chair - depending on its design. The institution may be under individual or collective (council) leadership.

4. There are exceptional cases in which a part-time position may be considered sufficient, for example if the IFI has a strictly defined and limited work programme or if another institution provides complementary functions which impact on the workload of the IFI. In Sweden, the Fiscal Policy Council can use the macro-fiscal forecasts prepared by another well-established independent agency, the National Institute of Economic Research.

5. Given the small size of the majority of IFIs, staff may be provided with career mobility within the broader civil service. However, care should be taken to avoid conflict of interest.

6. Other functions are carried out by well-established IFIs, such as costing of election platforms by the Netherlands Bureau for Economic Policy Analysis, or programme evaluation by the Korean National Assembly Budget Office.

7. For example, security clearance for IFI staff.

8. There may be cases where an IFI provides confidential estimates as part of the legislative process. For example, the US Congressional Budget Office provides estimates early in the legislative process kept confidential only until the legislative proposal becomes public - in order to help craft legislative proposals.

9. Care must be taken to avoid the perception that the timing of the release of the IFI reports favours the government or the opposition parties. 


\section{Australia}

\section{Parliamentary Budget Office (PBO)}

Established: By legislation in December 2011; appointment of first Parliamentary Budget Officer in July 2012.

Enabling legislation: Parliamentary Service Act 1999 as amended by the Parliamentary Service Amendment (Parliamentary Budget Officer) Act 2011.

Mandate: To inform the parliament by providing independent and non-partisan analysis of the budget cycle, fiscal policy and the financial implications of proposals.

Budget: AUD 29.7 million over four years (2014); this includes short-term funding to address demands during election periods.

Staff: 38, the budget allows for the employment of approximately 40 staff. 


\section{Context}

The establishment of a parliamentary budget office (PBO) in Australia has been debated at various times since the 1980s. The primary impetus for establishing a PBO was a perceived need for greater fiscal transparency and accountability regarding the cost of election promises. In particular, while the government and opposition enjoyed access to the Ministry of Finance and Treasury to cost their election commitments, similar access was not afforded to smaller political parties or independents. As well, there was a view among some stakeholders that parliament would benefit from specialised research and analysis pertaining to fiscal and economic policy.

The idea became a reality in 2010 when, following the federal election, the minority government agreements signed by the Australian Labor Party with the Coalition, Australian Greens and independent members of parliament included a commitment to establish a PBO. That commitment formed part of the "Agreement for a Better Parliament: Parliamentary Reform", which also called for a special committee of the parliament to decide on the "structure, resourcing and protocols for such an office".

Subsequently, the parliament convened the Joint Select Committee on the Parliamentary Budget Office ( $\mathrm{PBO}$ ) to examine the possible structures for a $\mathrm{PBO}$ and the range of services a PBO could provide. The Joint Committee membership included senators and MPs of the Australian Labor Party, the Liberal Party of Australia, the Nationals, the Australian Greens and an Independent Member of Parliament. The Joint Committee issued a media release and sought submissions from the public, as well as leaders of major and minor political parties, independent members of parliament, the Treasurer, the Minister for Finance and Deregulation, the Department of Parliamentary Services, the Department of the House of Representatives, the Department of the Senate, the Clerks of the New South Wales Parliament and a number of international parliamentary budget offices. As part of the inquiry, the Joint Committee also held three public hearings during February 2011. Its report was submitted on 23 March 2011. The 28 recommendations reflected a consensus among all committee members.

In May 2011 the government also announced in a press release that it would provide AUD 24.9 million over four years to establish the PBO and that the PBO would be established as a separate entity headed by an independent statutory officer - the Parliamentary Budget Officer. This funding was subsequently included in the Portfolio Budget Statements for 2012-13, along with an outline of the corresponding planned performance related outcomes. The government tabled its initial response to the Joint Committee on 1 August 2011, which agreed with 23 of the Joint Committee's recommendations, and "agreed-inprinciple" with the remaining five recommendations.

On 22 August, Shadow Treasurer Joe Hockey introduced the Parliamentary Budget Office Bill, 2011, as a private members bill, along with the Charter of Budget Honesty Amendment Bill, 2011 (the latter to remove the provisions for costing federal opposition election commitments). This was immediately followed by the introduction of a government 
bill on 24 August, the Parliamentary Service Amendment (Parliamentary Budget Officer) Bill, to establish the Parliamentary Budget Office.

The opposition raised concerns that the government's proposed legislation lacked several key features, which included:

- stronger powers to access government information, consistent with those held by the National Audit Office, rather than authority to establish non-statutory arrangements with the head of a Commonwealth of Australia body to obtain information required to support the mandate;

- the ability to undertake confidential work during the caretaker period, rather than the requirement that policy costings requested and prepared during this time be published; and

- the inclusion of independent economic and fiscal forecasting in the PBO's mandate.

The government's bill passed the House of Representatives without amendment in September 2011 and was introduced in the Senate where it again passed without amendment in November 2011. The Act received Royal Assent in December 2011 and was proclaimed in February 2012.

In March 2013, the Parliamentary Service Amendment (Parliamentary Budget Officer) Bill 2013 was passed to require the $\mathrm{PBO}$ to produce a post-election report on the cost of parties' election commitments within 30 days of the end of the caretaker period for a general election. The $\mathrm{PBO}$ was provided with additional funding to implement this requirement and to enhance the PBO's fiscal policy analysis and costings capabilities.

\section{Relationship with the executive and the legislature}

The PBO is one of four parliamentary departments. The Parliamentary Budget Officer must report to the President of the Senate and Speaker of the House (i.e. the "Presiding Officers") on matters pertaining to operations and management. At the same time, the enabling legislation stipulates that the Parliamentary Budget Officer has full independence regarding the performance of their functions (i.e. the precise manner in which the mandate is carried out, $64 \mathrm{~N})$.

Beyond explicit authorities granted within its enabling legislation, the PBO's independence is further reinforced by the procedures for appointment and termination. In the case of the former, the Presiding Officers can only appoint a Parliamentary Budget Officer following approval by the Joint Committee of Public Accounts and Audit (JCPAA, 64X). Regarding the latter, the Parliamentary Budget Officer can only be removed from office prior to the end of their four-year term with a majority vote by both the House of Representatives and the Senate, or in the case of insolvency (64XE).

Parliamentary oversight of the PBO is exercised through two principle measures: annual scrutiny and approval of the annual budget; and, the corresponding work plan. In the case of the latter, the enabling legislation requires that the Parliamentary Budget Officer must consult with the JCPAA to establish priorities for the coming fiscal year. In addition, the legislation also provides that the JCPAA may request an independent review of the operations of the PBO following each general election (64T, see also Section 11). The National Audit Office completed an independent performance audit of the administration of the PBO in June 2014. This audit fulfilled the JCPAA's requirement for an independent review. 
Given that the primary clients of the PBO are parliamentarians, it is anticipated that ongoing oversight will also be exercised through consideration of testimony by PBO staff at Senate committee hearings and related confidential and public reports.

The $\mathrm{PBO}$ is designed to complement existing specialised financial and economic expertise available to parliamentarians. While some of the PBO's functions are similar to those within the Ministry of Treasury and/or Finance, particularly those pertaining to policy costing, the statute provides the $\mathrm{PBO}$ with the exclusive mandate to provide these services to all parliamentarians. Furthermore, the PBO's ex ante analysis regarding the cost of contemplated and proposed expenditure and revenue measures is distinct from the ex post analysis of the National Audit Office.

\section{Box 1. Role of the legislature in the budget process}

Australia has a Westminster parliamentary system of government. This includes a bicameral parliament comprised of a House of Representatives (lower house) and a Senate (upper house). The 150 members of the House of Representatives are elected by preferential ballot. The 76 members of the Senate are elected through proportional representation. Legislation that seeks to authorise expenditure or impose taxation must originate in the House of Representatives by the government. At the same time, the Senate retains the right to request amendments to financial legislation that does not pertain to "ordinary annual services" and it can also refuse to pass any bill.

The Australian government's fiscal year runs from July to June. The budget is generally introduced by the Treasurer in the House of Representatives in early May, providing the parliament with approximately eight weeks to scrutinise and approve the proposal. The budget itself is comprised of several parts, including an overall economic and fiscal outlook, proposed new measures, and the proposed resourcing for individual agencies and departments that will be sought through annual appropriation acts. There are generally three main appropriation bills introduced annually, which provide for the "ordinary annual services of government", "new policy measures", and "funding for parliamentary departments", respectively. In addition, a second cohort of supplementary appropriation bills ("additional estimates") are typically introduced in February for items subsequently announced post-Budget or other required adjustments to the expenditure plan.

The requirement that the government must initiate expenditure and taxation proposals curtails parliamentary power to amend the budget or appropriation acts. Legislators can only vote to reject or reduce proposed expenditures. However, in the Westminster system, financially-related votes are typically seen as confidence issues. As such, the limited powers to amend proposed legislation are seldom exercised by members of the House. Consequently, the House of Representatives tends to focus on the broader macroeconomic and fiscal policy outlined in the budget, rather than scrutinising individual expenditure items.

In contrast, the Senate has a well-articulated committee structure designed to examine the budget and proposed appropriations. This is, in part, attributable to the structure of the electoral system that often provides the government with a majority in the House of Representatives, but a minority in the Senate. Each Senate committee will scrutinise one or more departmental portfolios and hold hearings on the proposed spending. During these hearings, committee members question ministers and public servants regarding policy and operational considerations, especially the effectiveness and efficiency of various programmes. Meetings are generally held in public, but can occasionally be held in camera. Following these meetings, each committee will draft a report that is made public enumerating any concerns and/or recommendations. 


\section{Box 1. Role of the legislature in the budget process (cont.)}

Prior to 2012, the primary source of technical support on finance and economic issues for members of the House and Senate was the Library of Parliament. More broadly, legislators also benefitted from specialised staff working with the Department of the Senate and House of Representatives, as well as political party secretariats or individual members. It is anticipated that the $\mathrm{PBO}$ will complement this existing capacity.

\section{Legal basis for establishment}

The Parliamentary Service Amendment (Parliamentary Budget Officer) Act 2011 amended five pieces of legislation, including:

- The Parliamentary Service Act 1999: To establish the legal entity of the PBO as a department of the parliament, as well as set forth the legal mandate and administrative powers of the $\mathrm{PBO}$.

- The Charter of Budget Honesty Act 1998: To, among other things, extend the provision of policy costings during a caretaker period to the leader of a minority party. ${ }^{1}$

- The Freedom of Information Act, Long Service Leave (Commonwealth Employees) Act 1976, and Remuneration Tribunal Act 1973: To implement other consequential amendments.

\section{Mandate}

Section 64B of the Parliamentary Service Act 1999 (the act) provides the PBO a broad mandate "to inform the parliament by providing independent and non-partisan analysis of the budget cycle, fiscal policy and the financial implications of proposals". Minor language changes aside, the mandate is in accordance with recommendation two of the Joint Committee.

Specific functions of the Parliamentary Budget Officer are also laid out in section 64E of the act as well as three limitations: the PBO's functions do not include preparing economic forecasts or budget estimates, and the PBO must rely on the fiscal and economic forecasts contained in the most recent reports released by the government (Section 64E [2 and 3]).

Under the Parliamentary Service Act, the PBO is able to cost policy proposals at the request of parliamentarians or parliamentary parties, on a confidential basis outside the caretaker period for a general election, and on a public basis for requests made by parliamentary parties and independent parliamentarians during the caretaker period for a general election. The PBO can respond to requests for information on or analyses of the budget on a confidential basis at any time, including during the caretaker period. In addition, the PBO may undertake at its own initiative research and analysis on issues related to the budget and fiscal policy.

The ability of the PBO to prepare costings on a confidential basis outside of the caretaker period for a general election may, at first glance, seem at odds with the PBO's objective of achieving greater fiscal transparency and accountability regarding the cost of election promises. However, the ability to work with the PBO on a confidential basis provides parliamentarians and parliamentary parties with the opportunity to develop and cost their policies in a more measured fashion in the lead up to an election. They are then able to publicly release fully costed policies before an election in the knowledge that the costings have been professionally prepared by the PBO. This can be expected to result in greater disclosure of election commitments prior to an election and place greater 
accountability on the parliamentarians and parliamentary parties concerned. The ability to access costing services on a confidential basis is particularly valuable to non-government parliamentarians and parliamentary parties who did not have access to these services prior to the establishment of the PBO.

As noted earlier, the PBO's mandate was enhanced with the Parliamentary Service Amendment (Parliamentary Budget Officer) Bill 2013 which requires the production of a post-election report on the cost of parties' election commitments within 30 days of the end of the caretaker period of a general election.

Apart from the post-election report, the current mandate does not refer to specific reports, or timings for reports, that must be presented during the year. However, the reference to the budget cycle clearly provides some expectations in terms of timing of analysis. In addition, the $\mathrm{PBO}$ can expect increased workloads during election periods.

There may be scope for the PBO's mandate to be further enlarged. The National Commission of Audit established by the Abbott coalition government in late 2013 recommended that the government adopt a high-level fiscal strategy with fiscal rules, and that the $\mathrm{PBO}$ report the government's progress against the fiscal rules following the release of the final budget outcome each year. ${ }^{2}$ The government has responded that the issue of reporting against fiscal rules will be considered following the 2014-15 budget. ${ }^{3}$

\section{Functions}

The Parliamentary Service Act 1999 provides the PBO with the following functions:

1. outside the caretaker period for a general election, to prepare policy costings on request by senators and members, with the requests and the PBO's responses to be kept confidential if so directed by the requestor;

2. during the caretaker period for a general election, to prepare costings of publicly announced policies on request by authorised members of parliamentary parties or independent members;

3. to prepare responses (other than policy costings) to requests relating to the budget from senators and members, with the requests and the PBO's responses to be kept confidential if so directed by the requestor;

4. to prepare submissions to inquiries of parliamentary committees, on request by such committees, with the requests and the PBO's responses to be made publicly available;

5. after a general election, to report on the budget impact of election commitments of designated parliamentary parties; and

6. to conduct, on his or her own initiative, research on the budget and fiscal policy settings, with the results of this work to be made publicly available.

As noted in the "PBO's Summary Guide to Policy Costings", there are two categories of "costing" work:

1. outside the caretaker period for a general election, policy costings on request by senators and members, with requests and the PBO's responses to be kept confidential if so directed by the requestor;

2. during the caretaker period for a general election, policy costings of publicly announced policies on request by authorised members of parliamentary parties or independent members. 
With respect to its costing methodology, the PBO uses the "Charter of Budget Honesty Costing Guidelines" (the guidelines). The guidelines specify the various methodologies that could be used to address a costing request, including: assumptions, sensitivity analysis, accounting treatments and relevant scope of analysis. Examples and case studies are also provided regarding certain types of costing requests. Consistent with the guidelines, the PBO prepares a fiscal impact analysis for the current financial year and three subsequent years. Overall, this ensures that cost estimates generated by the Australian public service or $\mathrm{PBO}$ will be prepared on a comparable basis. All policy costings prepared by the $\mathrm{PBO}$ have a "best-before" date, indicating that the estimates are only valid within a certain period of time, typically the subsequent budget update. ${ }^{4}$

PBO costings also include a reliability rating, to reflect the degree of uncertainty surrounding the estimated budget impact. Reliability ratings serve as an indicator of the uncertainty inherent in preparing costings and aim to reflect how much the actual future outcome may be expected to differ from the point estimate. This uncertainty arises due to the quality, detail and availability of data and the need to make assumptions. The PBO is refining the reliability ratings with a view to making the indicators more objective, and intends to publish material explaining how its reliability ratings are determined and what they mean for the validity of costings.

The published self-initiated research undertaken by the PBO focuses on the sustainability of the budget over the medium term and also aims to improve budget transparency and promote a better understanding of the budget and fiscal policy settings. As of early 2014, the PBO had released three reports as part of its self-initiated work programme: Estimates of the structural budget balance of the Australian Government 2001-02 to 2016-17, published 22 May 2013; Australian Government spending, Part 1: Historical trends from 2002-03 to 2012-13, published 10 December 2013; and Trends in Australian Government receipts 1982-83 to 2012-13, published 15 April 2014. It also published a chart pack on 10 June presenting a graphical summary of the 2014-15 budget and forward estimates relative to the 2013-14 Mid-year Economic and Fiscal Outlook report, showing the impacts of policy decisions and other factors. Over the next few years, the self-initiated work programme will focus on the following broad areas: trends in Australian government expenditure and revenue, sensitivity of expenditure and revenue estimates to economic shocks, Commonwealth/state fiscal issues, distributional impacts of policies, approaches to the costing of policy proposals, budget reporting, fiscal responsibility frameworks and capital budgeting.

The Charter of Budget Honesty requires each government to release a "fiscal strategy statement" with, or prior to, the tabling of its first budget and each subsequent budget (Section 6). This statement must be based on principles of sound fiscal management set out in the Charter. A key purpose of these statements is to "establish a benchmark for evaluating the government's conduct of fiscal policy", identify short-term and longer-term fiscal objectives, as well as explain the broad strategic priorities on which the budget will be based. Analysis of fiscal policy settings falls within the PBO's mandate and is being undertaken as part of the PBO's self-initiated work programme. As noted in Section 4, the National Commission of Audit recommended that the Charter be amended to require the $\mathrm{PBO}$ to report the government's progress against its medium-term fiscal strategy following the release of the final budget outcome each year.

In enumerating the functions of the Parliamentary Budget Officer, the act (64E) explicitly identifies items outside the purview of the Officer's legislative mandate, including the 
preparation of economic forecasts or budget estimates. The act also mandates that the Officer must use the "economic forecasts ..., fiscal parameters ... and fiscal estimates" contained in the budget, Intergenerational Report and Pre-election Economic Fiscal and Outlook Report. As explained in a statement made by the Parliamentary Budget Officer to parliamentarians in 2012, this ensures that duplication is avoided amongst the Ministry of Finance, Treasury and PBO. Finally, the Parliamentary Budget Officer has also stated that the PBO does not "have a policy advisory role and it will not make policy recommendations".

\section{Work programme}

The act stipulates that the Parliamentary Budget Officer must develop an annual work plan in consultation with the JCPAA that delineates its priorities and planned resource allocations $(64 \mathrm{Q})$. The act also requires that the work plan must be made publicly available; the Work Plans for 2012-13 and 2013-14 are published on the PBO's website. ${ }^{5}$

Beyond the global priority-setting mechanism for work, the Parliamentary Budget Officer announced in the 2012-13 work plan that emphasis in the PBO's inaugural year would be placed on:

- setting the PBO on a fully operational footing; fully-staffed, with appropriate policy and administrative frameworks; and,

- gaining the parliament's trust as a valued source of budgetary and fiscal analyses, as well as policy costings.

The PBO work plan for 2013-14 identified three key priorities for the PBO: continue to fulfil the PBO's mandate as a responsive and effective independent institution of the Parliament; prepare policy costings and budget analyses in response to requests from individual parliamentarians; and publish self-initiated research focusing on budget sustainability and transparency and fiscal issues of interest to broader parliamentary and public audiences.

The legislative mandate provides for a balance of directed work, such as policy costings, as well as self-initiated projects that include research and analysis of budget or fiscal policy. The PBO has announced that outside of the caretaker period, priority is given to responding to requests from members, senators and parliamentary committees. During the caretaker period (i.e. following dissolution of the parliament, during an election) priority is granted to responding to requests for publicly announced policies to be costed by the PBO.

Given the priority assigned to policy costing work, the majority of resources are allocated toward this task. The PBO aims to provide responses to policy costings in a timely manner. The timeliness of the PBO's responses is impacted by the complexity of the costings and the extent to which information needs to be sought from other agencies, or if further information is required from parliamentarians about the request. The recent report of the National Audit Office noted that the PBO's average response times have improved over time, taking an average of 54.6 business days in September 2012 and an average of 15 business days in the last quarter of 2013 (ANAO, 2014).

In the year leading up to the September 2013 general election, the PBO completed around 1000 costings for parliamentary parties and individual parliamentarians, with the non-government parties making most of the requests. The demand for PBO costings and budget analyses has continued since the election period. 
In October 2013, the PBO released its post-election report of election commitments for the 2013 general election. This report provided costings of all election commitments made by the major political parties, and indicated that there had been a high level of accuracy in the statements by the political parties on the costs of their election commitments.

Notwithstanding the priority placed on responding to costing requests, the PBO has also allocated significant dedicated resources for its self-initiated work programme.

\section{Budget}

In the 2011-12 budget, the Gillard government committed to provide AUD 24.9 million over four years to establish the PBO. This was in line with recommendation 26 of the joint committee which called for "ongoing funding of no less than AUD 6 million per annum with consideration being given to additional resourcing for election years". 6 Subsequently, Section 64D of the Parliamentary Service Amendment (Parliamentary Budget Officer) Act 2011 provided for a first appropriation from the consolidated revenue fund for "the purposes of the Parliamentary Budget Officer and the Parliamentary Budget Office in the financial year starting on 1 July 2011, to the extent of AUD 6000 000" and the 2012-13 budget provided for an appropriation of AUD 6.1 million in the first full year of operations.

The PBO's annual appropriation for 2014-15 is AUD 7.0 million and is expected to remain at around this level for the next four years except for 2015-16 when the PBO will receive an additional AUD 0.5 million to assist it to meet expected increased demand associated with the next general election. This is in line with recommendation 26 of the Joint Committee on the Parliamentary Budget Office, which called for "ongoing funding of no less than AUD 6 million per annum with consideration being given to additional resourcing for election years". In addition to its annual appropriation, the PBO has access to a special appropriation of AUD 6 million (the prior year's unspent funding, as provision for costs related to the PBO's permanent accommodation and secure IT network project). An additional budget measure in 2013-14 provided the PBO with AUD 4.5 million over five years to enhance capability and functions and to produce the Post-Election Report (this includes the aforementioned AUD 0.5 million for additional costing capability for the 2015-16 election period) (ANAO, 2014).

Sections 64R and 64S of the act also follow recommendation 27 of the Joint Committee on the Parliamentary Budget Office. Section 64R stipulates that "the Joint Committee on Public Accounts and Audit may request the Parliamentary Budget Officer to submit to the committee draft estimates for the Parliamentary Budget Office for a financial year before the budget for that financial year" and "the Parliamentary Budget Officer must comply with the request in time to allow the committee to consider the draft estimates and make recommendations on them before the budget". Section 64S lays out the duties of the JCPAA including considering and making recommendations to both houses of the parliament and the Presiding Officers on the PBO's draft estimates, as well as the PBO's overall resources.

\section{Staffing}

\subsection{Leadership}

Section 64XE of the act outlines the process for appointing the Parliamentary Budget Officer as an independent statutory officer of the parliament. As noted earlier, the appointment is made for a four-year term by the Presiding Officers, following approval by the JCPAA. The four-year term is longer than the three-year electoral cycle. A Parliamentary 
Budget Officer holds the paid position on a full-time basis and is eligible for reappointment, but cannot hold the position for more than eight years.

The legislation is silent regarding the requisite qualifications of the Parliamentary Budget Officer or how the recruitment process should proceed. That said, the position was publicly advertised through the Australian public service jobs website in March 2012 and listed the following qualifications:

- extensive senior experience in public policy, policy costings or similar work;

- exceptional strategic leadership capacities and the ability to inspire a small workforce to fulfil a very specific range of functions;

- excellent stakeholder relationship management abilities;

- high integrity and credibility;

- well-developed strategic and analytical skills;

- an understanding of the Commonwealth budget and the role and operations of Parliament in Australia's federal system;

- Australian citizenship and ability to satisfy required security clearances.

The inaugural Parliamentary Budget Officer, Mr. Phil Bowen, was appointed in May 2012 and began work in July. He brought over several decades of professional experience, including senior positions in the Finance Department directly relevant to the role of Parliamentary Budget Officer, including five years as head of the Budget Group. Prior to his appointment, he was the Australian Director on the board of the Asian Development Bank.

Section 64XE of the act provides for removal of the Parliamentary Budget Officer from office by the Presiding Officers if "each House of the Parliament, in the same session of the Parliament, presents an address to the Presiding Officers praying for the removal of the Parliamentary Budget Officer on the ground of misbehaviour or physical or mental incapacity" or if the "Parliamentary Budget Officer becomes an insolvent under administration". Should he or she wish to resign, the Parliamentary Budget Officer must give written notice to the Presiding Officers (section 64XD).

\subsection{Staff}

The PBO's organisation structure is directly aligned with its core functions. A sixperson senior management team reports to the Parliamentary Budget Officer. The top structure (see Figure 1) comprises a Fiscal Policy Analysis Division (two senior executives), a Budget Analysis Division (three senior executives) and a Corporate Strategy Branch (one senior executive).

The Fiscal Policy Analysis Division is responsible for developing and managing the PBO's self-initiated programme of published research on the budget and fiscal policy. The Budget Analysis Division is responsible for preparing analyses of the budget, and undertaking costings of revenue and expenditure proposals. The Corporate Strategy Branch is responsible for formulating corporate strategies and policies; delivering corporate services, including accommodation, personnel, finance, procurement and IT services; and ensuring that the $\mathrm{PBO}$ meets its reporting and other compliance obligations.

As noted in the Parliamentary Budget Office work plan for 2012-13, the ability of the PBO to fulfil its mandate depends on the "skills base, experience and commitment of its staff". The PBO is funded for approximately 40 full-time staff; as of the end of July 2014 it had a complement of 38 staff. Further recruitment action is underway. ${ }^{7}$ The PBO's staff 
Figure 1. PBO organisation chart

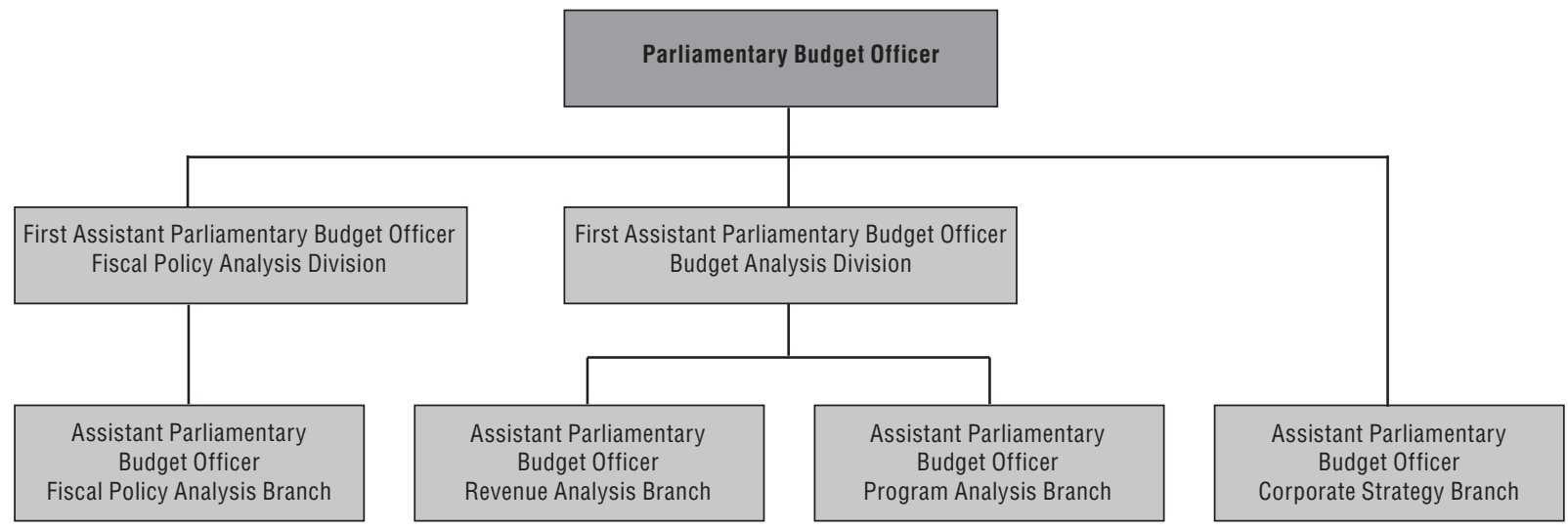

principally comprises technical specialists in economics, accounting, commerce and public administration. Almost two-thirds of $\mathrm{PBO}$ staff hold post-graduate qualifications and virtually all staff have direct experience in costing, fiscal analysis and budgeting gained in the Australian public service (APS). Their mean age is 36 , which is lower than the comparable figure in the APS (43).

As the PBO is a parliamentary department, all staff are employed under the terms of the Parliamentary Service Act 1999, which stipulates that their loyalty rests with the parliament rather than the government. In general, this legislative framework provides for wages, benefits and employment conditions that are similar to the APS. There are also provisions that ensure mobility between the APS and the parliamentary departments (Section 26 of the Parliamentary Service Act). Administratively, management of staff and human resources rests with the Parliamentary Budget Officer, who holds the authority to hire or terminate staff.

The PBO will use outside consultants where there is a requirement for specialised expertise that is not available in-house, or where it would not be cost effective to maintain such expertise on a permanent capacity. It is anticipated that this type of support will be short-term in nature and linked to specific projects undertaken by the PBO.

\section{Access to information}

The Parliamentary Service Act does not give the PBO statutory information-gathering powers. However, consistent with recommendation 13 in the Joint Select Committee on the Parliamentary Budget Office, the act provides that the Parliamentary Budget Officer may make an arrangement with the head of any Commonwealth body to obtain relevant information and documents (64F). Further, the arrangement may make provision for confidentiality of documents, as required. Any such arrangement must be in writing and be publicly available.

Shortly after the first Parliamentary Budget Officer was appointed, he negotiated a memorandum of understanding (MoU) $)^{8}$ with the heads of Commonwealth bodies regarding information access. While initially concluded with the Secretaries from the Department of Finance and Department of Treasury, there are now 28 Secretaries and heads of agencies that are party to the agreement. Other Commonwealth bodies may opt to negotiate independent arrangements with the Parliamentary Budget Officer, in 
consultation with the Treasury and Finance Secretaries. The PBO also benefits from strong informal collaboration with other agencies on technical issues.

The Parliamentary Budget Officer has publicly noted that the MoU is intended to have a clear "pro-disclosure" bias. While the MoU is not legally binding, it clearly enumerates the obligation of parties to maintain a co-operative working relationship that encourages the timely flow of information and data relevant to the Parliamentary Budget Officer's mandate. This specifically identifies the:

- process to request information and documents from a department;

- appropriate procedures to respond to these requests (including an indicative timeframe for response: urgent within five days, routine within 10 days, and during the caretaker period within 3 days);

- requirement to explain in writing why a Commonwealth body is unable to comply with a request;

- provisions regarding the confidentiality of requests and the treatment of confidential data; and

- monitoring and evaluation mechanism.

Finally, the MoU includes a dispute-resolution mechanism that commits the parties to attempt to resolve any disputes at the "lowest, most informal, level practicable". If this cannot be achieved, the MoU provides that either party may request the appointment of a mediator to resolve the dispute, with the mediator to be agreed to by both parties. Regardless of any disagreement on a specific information request, all signatories agree to continue to perform their obligations under the MoU pending resolution of the dispute.

In addition to the MoU, the government issued the "Australian Government Protocols governing the engagement between Commonwealth bodies and the Parliamentary Budget Officer" (the protocols). The protocols highlight the Australian government's intent to support the Parliamentary Budget Officer in the performance of his or her functions. As described in the introduction to the protocols, they are "government policy and promote the government's basis for heads of Commonwealth bodies and their staff to manage their interactions with the PBO. They also seek to facilitate and promote the ready and open exchange of views and information between Commonwealth bodies and the PBO, and to ensure a high-level of consistency and transparency across government."

The Parliamentary Service Amendment (Parliamentary Budget Officer) Bill 2013 mentioned earlier, in addition to requiring the $\mathrm{PBO}$ to prepare a post-election report, also amended the Taxation Administration Act 1953 to allow the PBO to have access to confidential taxpayer data from the Australian Taxation Office for use in performing its statutory functions.

To help assure parliamentarians that they can deal with the PBO on a confidential basis, the PBO was exempted from the provisions of the Freedom of Information (FOI) Act. Subsequently, the Freedom of Information Amendment (Parliamentary Budget Office) Act 2012 amended the FOI Act and the Privacy Act 1988 to extend the FOI exemption to information held by government departments and agencies that relates to a confidential request to the $\mathrm{PBO}$. One important related aspect of the protocols is that they mandate that ministers and their staff will not ask heads of Commonwealth bodies for any information which would disclose the nature of a confidential request from the Parliamentary Budget Officer. 
The PBO monitors and reports on information requests sent and responses received, both in its annual report and in reports to the Senate Finance and Public Administration Legislation Committee. Overall, Commonwealth bodies have generally responded to formal information requests in a reasonably timely and thorough manner, although in a few instances there have been long delays in the provision of information to the PBO. For the period of September 2012 to April 2014 the PBO made 679 requests for information, with the peak number of requests during the election period. The median response time was nine business days, although 18 responses took more than 51 business days (ANAO, 2014, p. 66). The length of time taken by an agency to respond to a PBO request depends on a number of factors, including the ease of extracting information, the magnitude of the request and competing work priorities (this can be an issue leading up to the government's budget and mid-year update).

The recent report of the National Audit Office indicates that, for the 20 agencies surveyed, all found the MoU effective and that the PBO's stakeholder management was effective. None had any concerns about the PBO's use of confidential information and none reported any dispute with the $\mathrm{PBO}$. However, while only a few reported being unable to meet $\mathrm{PBO}$ requests, 17 indicated that they had difficulties meeting the timeframes and all reported that information requests had an effect on their agencies resources, with several claiming to have spent hundreds of hours on PBO information requests (ANAO, 2014).

The ANAO report concluded that the PBO has so far been able to access the information that it needs to conduct its work and that at present there is no need to change the arrangements made under the MoU and the protocols. It cautions however that:

... the PBO's lack of statutory information access powers are not aligned with the OECD's recommendation that an IFI's access to information should be guaranteed in legislation, and any restrictions to access should also be clearly defined in legislation. Due to the importance of the PBO's information access, this will be a matter for close monitoring. This will be particularly important in the future if there are unreasonable delays in obtaining information, or there are a large number of costings the PBO cannot undertake due to lack of access to information, including information about the Contingency Reserve ${ }^{9}$ (ANAO, 2014).

Finally the ANAO report made one recommendation linked to confidentiality of information, to which the PBO agreed:

Recommendation No. 1

In the interests of greater transparency, the ANAO recommends that the Parliamentary Budget Office includes in all costings, estimates of administrative expenses, where significant. (ANAO, 2014)

The Public Accounts Committee subsequently endorsed this recommendation calling for the PBO's information gathering powers to be strengthened.

\section{Transparency}

The report of the Joint Select Committee on the Parliamentary Budget Office made four recommendations to encourage $\mathrm{PBO}$ transparency (16 to 19). The first provided overarching guidance that "wherever possible ... the work of the PBO (should) be made publicly available". Recommendations 17 and 18 provide that work should be kept confidential upon request of a client, but where possible the work that has gone into the preparation of a client request should be included in other public reports. Finally, recommendation 
19 empowered the Parliamentary Budget Officer to make public statements, especially where they consider the work of the PBO to be misrepresented in the public domain.

The Act generally reflects these recommendations, stipulating that requests during the caretaker period must be released publicly (64L (2)), and that requests outside of the caretaker period may be treated confidentially if stipulated by the parliamentarian (64M). In the case of confidential requests, the Act further delineates the specific responsibilities of the Parliamentary Budget Officer and $\mathrm{PBO}$ employees regarding the management of confidential requests.

In practice, the $\mathrm{PBO}$ has adopted a model that reflects the spirit of the Committee's recommendations and the Act. At the request of the PBO's primary parliamentary stakeholders, much of the PBO's work is undertaken confidentially with parliamentarians able to disclose the analysis at their discretion. At the same time, the Parliamentary Budget Officer publishes all self-initiated work on the PBO's website, including the methodology, assumptions and data that underpin any analyses and research. Publication in this case is simultaneous for parliamentarians and the public.

Although the $\mathrm{PBO}$ is expected to inform the public debate on budgetary and fiscal policy issues, the Act is silent with respect to external communications between the PBO and media and general public. The PBO does not have a documented communications strategy; however, the Parliamentary Budget Officer has adopted an approach that aligns with the intent of the Joint Committee recommendation. While the Parliamentary Budget Officer is available to provide factual briefings to the media on request, emphasis is placed on letting the work "speak for itself". In practice, this means that the Parliamentary Budget Officer will generally only make formal public statements in the form of guidance material placed on the PBO website, public speeches, on-the-record comments before parliamentary committees and rebuttals to correct the record when the work of the PBO is being misrepresented. The PBO announces new publications posted on the PBO website via e-mail and Twitter. The PBO monitors media coverage of its work but does not have a formal process to analyse such coverage.

\section{Governance, advisory support, monitoring and evaluation}

Consistent with the recommendations of the Joint Committee report (1 and 10), the act created both a PBO and a Parliamentary Budget Officer (64A and 64C). As a department of the parliament, the $\mathrm{PBO}$ is subject to oversight by the Presiding Officers with respect to administrative and financial matters. The Parliamentary Budget Officer is also required to develop the PBO's annual work plan in consultation with the JCPAA (64Q). However, the act stipulates the processes by which the Parliamentary Budget Officer fulfils their functions, and consequently exercise of the mandate of the Parliamentary Budget Officer is not subject to direction by the Presiding Officers (64P) or the JCPAA (64S).

Since June 2013, the PBO maintains an audit committee to provide independent assurance and advice to the Parliamentary Budget Officer on the risk management arrangements of the PBO and on external accountability responsibilities. This committee is comprised of two external appointees and the Assistant Parliamentary Budget Officer for the Corporate Strategy Branch. PBO staff form the secretariat to the committee. The Chief Finance Officer, representatives of the internal audit provider and the ANAO attend as observers.

As noted in the PBO work plan for 2012-13, peer-review processes will be used as required, depending on the complexity and nature of the project. The three major reports 
released to date under the self-initiated work programme have all been peer-reviewed by external experts familiar with the data, methodologies and estimation techniques. Peer reviewers have been sourced from independent think tanks, academia, international organisations, private sector economists and other IFIs. In each case, the identity of the peer reviewers has been made public. The PBO anticipates maintaining this peer-review process on an ongoing basis.

Joint Committee recommendations 24 and 25 outlined a triennial evaluation process that was subsequently incorporated in the act (64T). Statute provides that within nine months following a general election, the JCPAA may request the Parliamentary Budget Officer to cause an independent review of the PBO to be undertaken. The request must specify who should perform the review, its scope, methodology and the requirement that the results be provided to the Joint Committee. The act also indicates that the request for a review must be conscious of the resources of the PBO. Following receipt of the report, the JCPAA is required to submit it to the Senate and the House of Representatives.

As described earlier, a performance audit of the administration of the PBO was completed by the Australian National Audit Office in June 2014. The ANAO audit objective was to "assess the effectiveness of the Parliamentary Budget Office in conducting its role since being established in July 2012". The audit focussed on the governance of the PBO, access to information issues and the functions of the PBO, particularly its costing role, as well as the post-election report and self-initiated research.

This audit fulfilled the JCPAA's requirement for an independent review. The ANAO's report, entitled "The Administration of the Parliamentary Budget Office", was highly positive, with one formal recommendation to improve the transparency of agency administrative expenses, where applicable, in policy costings. Among other things, it concluded that the PBO "is already well regarded as an authoritative, trusted and independent source of budgetary and fiscal policy analysis", with stakeholders reporting that "for the first time, all parliamentarians have access to independent policy costing and information request services during all periods of the parliamentary cycle", that the costings prepared by the PBO were of "high quality", that the "PBO was professional to deal with" and that the "PBO's work has improved the transparency around election commitments and facilitated a more informed public debate about budgetary matters". The ANAO identified a limited number of administrative improvements for the PBO to consider going forward and highlighted potential issues around access to information and potential expansion of the PBO's current mandate to include a role in monitoring progress against fiscal targets (ANAO, 2014).

It should be noted that the PBO has taken special initiatives to improve performance, for example, an "After Action Review" of its operations related to the 2013 election which made 21 recommendations all agreed by the PBO executive. The ANAO expects that implementation of these recommendations will enable the $\mathrm{PBO}$ to address several issues raised in the ANAO report (ANAO, 2014).

Since the review, the Public Accounts Committee has made a number of recommendations to:

- strengthen the PBO's information gathering powers;

- require the PBO to prepare annual medium term (10 year) budget projections;

- include 10 year medium term projections in the post-election report of election commitments. 
In addition, opposition policy is for $\mathrm{PBO}$ to also prepare: Independent economic forecasts, annual structural budget balance analysis and an intergenerational report every five years.

\section{Concluding remarks}

Stakeholders recognise that the work of the Australian PBO has helped to level the playing field for non-government parties and independent parliamentarians by giving them access to costing and budget information services that previously were not available to them. The PBO's first full year of operation saw a very strong demand for its services, in particular during the months leading up to the 2013 general election.

The accuracy of publicly announced election commitment costings has also improved markedly with no "black holes" having been identified in the 2013 election commitments. This is the first time that this has been the case for many years.

Budget transparency has increased as a result of the public release of the PBO's postelection report and the research papers that the PBO has published. For instance, the PBO's paper on the structural budget balance was the first paper to be released on this topic since a Treasury paper in 2010. Since the release of the PBO's paper in May 2012, each budget update has included a Treasury analysis of the structural budget balance.

The PBO has not only survived the test of a first change of government, its mandate was enhanced to include a new function - the production of a post-election report on the cost of parties' election commitments - and discussions are underway as to whether it should take on an additional roles in monitoring progress against fiscal targets and other areas.

The Australian PBO, although having commenced operations less than two years ago, has a track record of success demonstrated by its ability to recruit highly skilled personnel and attract substantial demand by a plurality of parliamentarians for its primary product: policy costings. This is due, in part, to adoption of many of the OECD's Principles for Independent Fiscal Institutions in the legislation and operating model, including:

- a non-partisan and independent PBO, Parliamentary Budget Officer and staff;

- a clearly articulated mandate that is set within legislation, including clear links to the budget process;

- adequate resources that are commensurate with its mandate; and

- a process for external evaluation of the PBO.

As the Parliamentary Budget Officer has stated publicly, "the establishment of the PBO as an independent and non-partisan institution of the Parliament represents a significant strengthening of Australia's public sector governance framework. It has the potential to provide all parliamentarians with a more level playing field from which to access analyses of the budget and fiscal policy, and costings of policy proposals. If used effectively, the PBO can work with the Parliament to help improve the integrity of the policy development process, better inform public policy debates and strengthen budget transparency." The medium-term challenges will be to maintain and enhance the perception of the PBO as a trusted independent and non-partisan source of relevant, high quality and timely information, for all political constituencies; to ensure ongoing good access to information; and to continue to facilitate a more informed public debate. 


\section{Notes}

1. The Charter for Budget Honesty Act legislates a high level of budget transparency and specific disclosures. The Charter provides a comprehensive legal framework for the formulation and conduct of fiscal policy in general. Its provisions can be divided into two groups: a regime for setting fiscal objectives, and an extensive system of fiscal reporting to monitor the consistency of the government's fiscal actions with its stated fiscal objectives (OECD, 2008).

2. The commission's report was released publicly on 1 May 2014. See recommendations 1 and 2 at www.ncoa.gov.au/report/phase-one/recommendations.html.

3. See www.financeminister.gov.au/media-release/2014/05/13/our-response-national-commission-audit-report.

4. To assist parliamentarians with their engagement with the $\mathrm{PBO}$, the $\mathrm{PBO}$ has provided senators and members with guidance documents that are accessible on the PBO's website. See: www.aph.gov.au/About_Parliament/Parliamentary_Departments/Parliamentary_Budget_Office/guidance.

5. See for example, the PBO's Work Plan for 2013-14: www.aph.gov.au/About_Parliament/Parliamentary_ Departments/Parliamentary_Budget_Office/corporate_publications/workplan13-14.

6. During the Joint Committee's inquiry, the Department of Parliamentary Services provided three estimates for the PBO's budget. The third (and the lowest) was for AUD 6 million per annum, providing for "employment of up to 20 staff and employment of external experts on demand" and allowing for the $\mathrm{PBO}$ to "undertake client requests and publications, but with limited research capacity".

7. Initially a number of temporary staff were seconded from the Australian public service. Permanent recruitment commenced in late 2012.

8. "Memorandum of Understanding between the Parliamentary Budget Officer and the heads of Commonwealth bodies in relation to the provision of information and documents".

9. Currently the $\mathrm{PBO}$ does not have access to the details of provisions for individual items included in the contingency reserve and PBO guidance for costings indicates that PBO costings are prepared without this information.

\section{Bibliography}

Australian Government (2015), Parliamentary Budget Officer Job Announcement, www.apsjobs.gou.au/ SearchedNoticesView.aspx? Notices=10565893\%3A1\&mn=SESSearch.

Australian National Audit Office (2014), The Administration of the Parliamentary Budget Office, Commonwealth of Australia, Canberra.

Australian Parliamentary Budget Office (2015), www.aph.gov.au/About_Parliament/Parliamentary_ Departments/Parliamentary_Budget_Office.

Blöndal, J.R. et al. (2008), "Budgeting in Australia”, OECD Journal on Budgeting, Vol. 8, No. 2, OECD, Paris.

Bowen, P. (2012), “The Parliamentary Budget Office: An Independent and Non-partisan Institution of the Australian Parliament", keynote address to the Certified Practising Accountants Congress, Commonwealth of Australia, Canberra.

Department of the Parliamentary Budget Office (2013), “Portfolio Budget Statements 2012-13", Budget Related Paper No. 1.20D, Commonwealth of Australia, Canberra.

Joint Select Committee on the Parliamentary Budget Office (2011), "Inquiry into the proposed Parliamentary Budget Office", Commonwealth of Australia, Canberra.

Ministry of Finance and Deregulation (2012), "Charter of Budget Honesty Costing Guidelines", Commonwealth of Australia, Canberra.

PBO (Parliamentary Budget Office) (2012), "Parliamentary Budget Office Work Plan for 2012-13", Commonwealth of Australia, Canberra.

PBO (2012), "Memorandum of Understanding between the Parliamentary Budget Officer and the Heads of Commonwealth Bodies in relation to the Provision of Information and Documents", Commonwealth of Australia, Canberra.

PBO (2012), "Summary Guide to Policy Costings: Procedures, Information Requirements and Methodology", Commonwealth of Australia, Canberra. 
PBO (2012), “Parliamentary Budget Office: Australia”, presentation to the Fourth Annual Meeting of OECD Parliamentary Budget Officials and Independent Fiscal Institutions, Commonwealth of Australia, Canberra.

PBO (2013), "Parliamentary Budget Office Work Plan for 2013-14", Commonwealth of Australia, Canberra.

Legislation

Charter of Budget Honesty Act 1998, No. 22, 1998, Commonwealth of Australia, Canberra.

Parliamentary Service Amendment (Parliamentary Budget Officer) Act 2011, No. 170, 2011, Commonwealth of Australia, Canberra. 


\section{Austria}

\section{Fiscal Advisory Council (Fiskalrat)}

Established: As Government Debt Committee in 1970, succeeded by the Fiscal Advisory Council in 2013.

Enabling legislation: Federal Law on the Establishment of the Government Debt Committee (Bundesgesetz über die Errichtung des Staatsschuldenausschusses) 8 January 2002; Federal Law on the Establishment of the Fiscal Council (Bundesgesetz über die Errichtung des Fiskalrates), 31 July 2013 (www.ris.bka.gu.at or www.fiskalrat.at/en/tasks.html; Federal Law Gazette I No. 149/2013).

Mandate: Assess the current fiscal situation and compliance with the national fiscal rules with an outlook for the future; analyse the macroeconomic effects of debt financing operations; analyse the sustainability and quality of public budgets; make recommendations on fiscal policies in the context of economic conditions; present an annual report on the recommendations and on the result of studies to the federal minister of finance; fulfil specified EU-monitoring obligations; and promote public debate in relation to the above.

Budget: Not disclosed.

Staff: 15 council members (including three without voting rights), six secretariat staff. 


\section{Context}

The precursor to Austria's Fiscal Advisory Council (or FISK for "Fiskalrat"), the Government Debt Committee ${ }^{1}$ (GDC) was initially created to advise the government on debt management issues. This role was introduced as part of a 1969 reform of the stateowned Postal Savings Bank initiated by the government of the Austrian People's Party. The establishment of the GDC was a small and uncontroversial element of this reform. The GDC was initially attached to the Postal Savings Bank; however in 1997, due to the privatisation of the Postal Savings Bank, the secretariat was transferred to the Austrian Central Bank.

In the early 1990s, Austria breached the 60\% debt-to-GDP ratio enshrined in the Treaty of Maastricht. With the aim to qualify for monetary union, the focus of the GDC evolved to include budget policy more broadly. This organic change found formal expression in the 2002 revision of its legal framework, which substantially broadened the mandate of the GDC. These changes came ahead of a more wide-ranging set of budget reforms later in the decade (Blöndal and Bergvall, 2007; Steger, 2010; Ministry of Finance, n.d.).

In 2001, the conservative coalition government of the Austrian People's Party and the Freedom Party of Austria initiated changes to the legal framework of the GDC. A contentious issue was a change in the composition of the committee. Under its previous legal framework, the committee had a total of 13 members. The government appointed three members and the "social partners" (organised business and labour) five each. The new provisions gave the government powers to appoint half of the members with voting rights. The report of the Finance Committee on the draft law, adopted by majority vote, insisted that these changes are not meant to limit the independence of the committee. However, the opposition parties disagreed and voted against the legislation.

The work of the GDC took place in a context of increasing commitment to numerical fiscal rules and targets. Austria is subject to the fiscal framework of the European Union (EU) for preventing and correcting excessive government deficits in the Member countries. According to the so-called six-pack (e.g. update of the Stability and Growth Pact), the Treaty on Stability, Co-ordination and Governance in the Economic and Monetary Union, and Regulation (EU) No. 473/2013 (the two-pack) compliance with prudent fiscal policy-making should be supported by country-specific numerical fiscal rules, transparency requirements, standards for budgetary frameworks, common timelines and independent bodies at the national level. Independent fiscal councils are seen as one cornerstone of the strengthened EU budgetary surveillance framework.

To aid fiscal policy co-ordination in a federal country like Austria, the fiscal rules and targets for the general government have been complemented with national "Stability Pacts" between the different levels of government. The current "Austrian Stability Pact 2012" entered into force without a time limitation. It defines multidimensional fiscal rules in line with the EU regulations at the federal and sub-national level and provides for improvements of budgetary co-ordination. A debt brake rule sets upper limits for the 
headline and structural deficits of the federal government, states (Länder) and municipalities and an expenditure rule limits annual expenditure growth for all levels of government. Further provisions require a gradual reduction of the government debt ratio and set upper limits on contingent liabilities. Moreover, since 2009 the federal budget operates within rolling and legally binding four-year expenditure ceilings (Steger, 2010).

To meet the amended EU requirements, new legislation was passed in Austria on 31 July 2013 to transform the Government Debt Committee into a Fiscal Advisory Council (Fiskalrat) and to expand its mandate. The new FISK law stipulates, inter alia, that the FISK members are not permitted to request or take any instructions from the body by which they have been appointed or from any other organisation. Furthermore, the new Parliamentary Budget Office (see Annex) has the right to participate in the meetings of the Fiscal Council in an advisory capacity, public authorities must reply to inquiries of the FISK, and Statistics Austria must provide the FISK with budget data electronically and budgetary out-turns according to the Austrian Stability Pact 2012. The right of information and the participation of the Parliamentary Budget Office were assigned by an amendment of the Social Democrats and the People's Party. The FISK law was adopted by majority vote and was in principle also supported by the Green Party. The new legislation came into force on 1 November 2013.

\section{Relationship with the executive and the legislature}

The council's staff is provided by the Oesterreichische Nationalbank, and the council is organised as an independent and autonomous unit. The FISK is obliged to report to the Federal Minister of Finance and to inform the public, inter alia, if circumstances lead to strong deviations from the fiscal targets, like the activation of the correction mechanism within the framework of the national fiscal rules. The Federal Minister of Finance is required to forward the FISK's annual report to the National Council and to the federal government. In the past, the parliament considered the report only at the committee level.

The secretariat of the former GDC highlighted its role as a "support and co-ordination committee" for the Federal Ministry of Finance. It aimed to co-ordinate and integrate the different interests of the social partners, the authorities and the economists that were represented in the GDC and continue to be represented in the FISK. This approach also explains why the recommendations of the GDC, whenever possible, were adopted unanimously.

Both the Oesterreichische Nationalbank and the Federal Minister of Finance have the power to order a meeting of the FISK, which must convene "without delay". However, according to legislation, Council members are not permitted to request or take instructions from the body by which they have been appointed or from and other organisation.

While the GDC had no direct relationship with the Austrian Parliament, the 2013 law provides for a representative of the Parliamentary Budget Office to participate in an advisory capacity in all FISK's meetings. The Oesterreichische Nationalbank is similarly represented. The Federal Minister of Finance must forward the FISK's annual report to the lower house, as well as the government. Typically, the parliament considers this report at the committee level, however, neither the government nor the parliament are required to respond to any of the reports or recommendations of the FISK. The critical new role of the FISK in the context of the EU surveillance process concerning the numerical fiscal rules will probably strengthen the direct communications with the parliament as well as with the executive. 
The watchdog function of the FISK is mainly carried out through communication with the public (e.g. news conferences, studies, workshops) and by meetings with public officials of all levels of Austria (central, regional and local).

Other institutions provide technical macroeconomic analysis. By convention, the Austrian Institute of Economic Research (WIFO) provides short-term to medium-term macroeconomic forecasts for the Ministry of Finance (Blöndal and Bergvall, 2007).

The committee, now council, experienced numerous changes in government over the past four decades, and it faces no serious existential threats from a political party or major interest group.

\section{Legal basis for establishment}

The Federal Law on the Establishment of the Government Debt Committee (Bundesgesetz über die Errichtung des Staatsschuldenausschusses) was published on 8 January 2002. Its origin dates back to a 1969 Law on the Postal Savings Bank, which included a provision that tasked the then state-owned bank with advising the government on debt management issues and required the formation of a committee for this purpose (paragraph 12). A previous revision to the legal framework, necessary in 1996 due to the privatisation of the Postal Savings Bank, transferred the administration of the GDC to the Austrian central bank, the Oesterreichische Nationalbank (amended in 1997, 1998 and 2000). In July 2013, the Federal Law on the Establishment of the Government Debt Committee was amended to formally establish an independent Fiscal Advisory Council (Bundesgesetz über die Errichtung des Fiskalrates; Federal Law Gazette I, No. 149/2013, www.fiskalrat.at/en/tasks.html).

\section{Mandate}

The mandate of the FISK is clearly defined in the 2013 law (article 1[1], 1.1-1.8) as:

1. assessing the current fiscal situation with an outlook for the future against the backdrop of Austria's fiscal policy objectives and development trends in the money and capital markets;

2. analysing the economic effects of financial operations in connection with the indebtedness of all public authorities on the basis of the research activities under No. 1;

3. analysing the sustainability and the quality of budgetary policies of all public authorities;

4. providing written recommendations on the fiscal policies of the public authorities in Austria, taking economic conditions into consideration;

5. preparing an annual report on the recommendations made to the Federal Minister of Finance, including the results of studies and analyses under Nos. 1 to 3, which the Federal Minister of Finance is to present to the National Council and federal government;

6. tasks according to Article 3 of the Treaty on Stability, Co-ordination and Governance in the Economic and Monetary Union, Federal Law Gazette III No. 17/2013, article 6 of Directive 2011/85/EU and according to article 5 of Regulation (EU) No. 473/2013 ("two-pack"); this specifically includes:

a) providing recommendations on the medium-term budget objectives according to EU Regulation 1466/97;

b) providing recommendations on the adjustment path to reach medium-term budget objectives; 
c) monitoring rule-compliance under article 5 of EU Regulation 1466/97 as amended by EU Regulation 1175/2011 in a timely fashion;

d) observing circumstances and submitting recommendations that activate, extend or end corrective measures according to article 7, Federal Law Gazette I No. 30/2013;

7. other tasks requested by the fiscal equalisation partners;

8. contributing to shaping public opinion in connection with the tasks of the Fiscal Advisory Council as well as organising information events.

Previously, the equivalent provisions in the 1996 law limited the GDC's tasks to studying money and capital markets, and to making recommendations related to the macroeconomic impact of the government's financing operations. The 2002 reform represented a significant expansion of the committee's mandate from debt management advice to a much broader watchdog function that included fiscal policy analysis and monitoring. This also entailed an extension of the institutional coverage from the central to all levels of government. The FISK law of 2013 further extends the mandate. It aims to comply with new EU requirements while supporting compliance with the multidimensional national fiscal rules through monitoring ongoing fiscal developments, adherence to country-specific numerical fiscal rules (Österreichischer Stabilitätspakt 2012) and providing its own fiscal forecasts, assessments and recommendations.

The FISK has no direct role in the budget process. The legal framework does not specify any particular limitations, and leaves substantial discretion to the council in deciding which aspects to emphasise in any particular report. The FISK has to submit an annual report to the Federal Minister of Finance. The 2002 law did not stipulate a particular deadline for the submission of this report, nor does the 2013 law.

\section{Box 1. Role of the legislature in the budget process}

Austria is a federal country with a parliamentary system of government. The parliament consists of two chambers. According to the constitution, the lower house, the National Council, has exclusive competence in budget matters. The upper house, or Federal Council, is a regional chamber representing the interests of the nine Länder in the legislative process. It has no role in decisions on the federal finances. There are no restrictions on the National Council's power to amend the budget. However, legislative activism has tended to be limited in practice.

Since 2009, the federal government must submit a draft medium-term expenditure framework (MTEF) law in April for discussion and approval by the National Council. It proposes binding four-year expenditure ceilings for five broad headings (clusters of ministries), as well as more detailed ceilings for about 30 chapters (based on ministries) that are binding for the upcoming budget and indicative for the following years. The MTEF is discussed and approved by the National Council. The budget is submitted in late October, about two months prior to the start of the fiscal year, and has to comply with the previously approved ceilings.

The Budget Committee has sole responsibility for examining the federal budget, but its proceedings include input from relevant sectoral committees on individual chapters. Only the first committee session, which considers overall budget policy, is open to the public.

Since 2007, Austria has undertaken a comprehensive federal budget reform (Steger 2010). This includes the establishment and strengthening of a number of administrative 


\section{Box 1. Role of the legislature in the budget process (cont.)}

and independent institutions responsible for fiscal and budgetary control. The role of the National Council in the budget process changed significantly from 2013. Its role has shifted from scrutinizing over 1000 detailed appropriations to a focus on the medium-term expenditure framework, global budgets and new performance information. To support this new role, the parties in the parliament proposed the establishment of a parliamentary budget office. For the first time in Austrian history, a parliamentary committee has access to expert staff (see Annex).

\section{Functions}

The annual report of the former GDC and now the FISK provides an overall assessment of fiscal policy in the context of economic conditions and the EU requirements. The annual report is about 100 pages long, excluding appendices, and gives a detailed picture of fiscal developments in the federal, regional and local levels in Austria. It contains a review of economic developments, an assessment of the country's fiscal position in relation to the requirements of the Stability and Growth Pact, a review of domestic and international debt trends, the debt management strategy of the Österreichische Bundesfinanzierungsagentur (Austrian Treasury) and an outlook based on the most recent stability programme submitted to the European Commission. The biannual recommendations are much shorter, about five pages on average. They contain qualitative comments, including policy recommendations that are meant to support the drafting of the budget (July) or its implementation (December). While the annual reports and recommendations may be critical of aspects of fiscal policy, they rarely contain dissenting opinions.

An important focus is on assessing Austria's compliance with the fiscal rules of the Stability and Growth Pact, including in the medium term. This can be linked to normative policy recommendations. For example, in its December 2011 recommendations, the GDC urged the rapid adoption of a constitutional "debt brake" that had been proposed by the government. Formally, recommendations and reports only required majority support; but in practice unanimous approval has been the norm with "very few exceptions" (Chaloupek, 2011). The FISK is entrusted with monitoring and supporting compliance with country-specific numerical fiscal rules and has to evaluate and to endorse fiscal forecasts of the government (e.g. Austria's stability programme) and compliance with the multidimensional national fiscal rules. These assessments, along with its own fiscal forecasts will be published in separate reports (the fiscal rules report in May and the assessment report on budget developments in $\mathrm{t}$ and $\mathrm{t}+1$ in November). The FISK's own budget forecasts, prepared twice a year, serve to check Austria's official budget plans for plausibility. The FISK has no formal macro-forecasting function.

The FISK does not produce detailed costings of individual laws or policies and has no role in evaluating the fiscal impact of election platforms produced by the different political parties.

\section{Work programme}

The FISK mandate is broad and comprehensive: The council is formally entitled to comment and make recommendations on all matters of fiscal policy and on other matters of the general orientation of economic policy insofar as it is related to fiscal policy. Hence, 
the FISK decides its own work programme within the bounds of its mandate. It is required to present an annual report on its recommendations to the Federal Minister of Finance, who has to pass it on to the National Council and the federal government. In practice, the council publishes recommendations twice a year, in July and December, and submits its annual report in July. The July recommendations highlight issues relevant to the preparation of next year's budget, while the December recommendations focus on the execution of the budget approved by parliament. As of 2014, the FISK will also produce a medium-term fiscal outlook based on Austria's stability programme and the draft budgetary plan with its own calculations regarding compliance with fiscal rules and assessments based on its own fiscal forecasts (likely in May and October each year).

The FISK meets on the invitation of its Chair as often as required, but at least once every quarter. In practice, the council or its subcommittees meet about eight times a year in total. Upon the written request of at least three members, a meeting of the committee must be called within one week. The FISK also has to convene when requested to do so by the Federal Minister of Finance or the Oesterreichische Nationalbank.

The council undertakes analyses at its own initiative. For example, in recent years it has held workshops on topics such as fiscal policy councils (January 2011), expenditure rules (September 2005) and budget policy and growth (April 2003). It also publishes papers on various topics. In 2011, these included analyses of changes to the EU fiscal governance framework (December) and of budget trends in Austria's nine provinces (March). For example, in 2013 the FISK published a study on "Government Guarantees for Nonpublic Entities in Austria - How Effective Are the New Guarantee Ceilings in Limiting Guarantee Risk?" (Hauth and Grossmann, 2013). These contributions aim to make public and political debates more objective, by injecting relevant factual information.

\section{Budget}

The budget of the FISK is set by the Oesterreichische Nationalbank, which is legally obliged to provide the necessary resources, in consultation with the chair of the council. The budget is not disclosed to the public. Its expenditures mainly cover the personnel costs of the secretariat, as members of the council are only reimbursed for expenses. The budget of the Oesterreichische Nationalbank is set annually. Apart from the addition of new secretariat staff, the budget has been contained in recent years, in line with resource trends for other parts of the Oesterreichische Nationalbank. The secretariat regards the current funding level as sufficient for carrying out the activities of the FISK.

\section{Staffing}

\subsection{Leadership}

The 2013 law regulates the composition of the FISK and the appointment process for its Chair, two Vice-Chairs and all other members as follows (the provisions of the 2013 law on the appointment process remain largely unchanged from the 2002 law). Council members must be "recognized experts in the fields of fiscal and budgetary matters" (Article 1[2]). The federal government nominates six members; the Austrian Chamber of Commerce, in agreement with the Presidium of the Chambers of Agriculture, three members; and the Federal Chamber of Labour three members. In addition, the following organisations nominate one member each, but without any voting rights: the Austrian Association of Municipalities, the Association of Austrian Cities and the Conference of Provincial Governors. 
The government appoints the Chair of the FISK, while Vice-Chairs are nominated by the Chamber of Commerce (Vice-Chair for the first half of the year) and the Federal Chamber of Labour (Vice-Chair for the second half of the year). Seven members constitute a quorum. In case of a tie, the Chair has a deciding vote. A representative of the Oesterreichische Nationalbank and the Austrian Parliamentary Budget Office (since 2013) are entitled to take part in each meeting of the Fiscal Advisory Council (with no voting rights). Since 1970, the FISK and its predecessor have had four presidents, all of them university professors of economics.

Members of the FISK must be eligible for election to the National Council, the lower house of the Austrian Parliament, which requires that they have Austrian citizenship and are at least 18 years of age. The most important practical implication of this requirement is that non-nationals cannot be appointed. Moreover, members of the FISK may not be serving members of the legislature or the government at the federal or regional levels. In practice, the appointment of the government's six members is based on proposals of the parties that make up the governing coalition.

Members are appointed for six-year ${ }^{2}$ renewable terms. In comparison, the maximum electoral term for the parliament was increased from four to five years in 2008. If a member of the FISK resigns before the end of their term, the relevant nominating organisation appoints a new member for the remainder of the term. In addition, each organisation has to appoint a deputy for each member, who can substitute for the member in case he or she cannot attend a meeting. The law does not explicitly regulate the removal of the Chair or of any member following their appointment.

Service on the council is strictly honorary; members do not receive a salary, although they are entitled to be reimbursed for expenses incurred as part of their duties. Most members have full time jobs in academia, chambers, government or the private sector.

\subsection{Staff}

The number of secretariat staff has increased in line with the broadening of the FISK's role. As of 2013, the secretariat was comprised of six staff members: the head of the Secretariat, four economists, and a research assistant who fall under the formal authority of the Oesterreichische Nationalbank and its regulations. Like the 2002 law, the 2013 law requires the Oesterreichische Nationalbank to bear the costs of the FISK, including the provision of sufficient personnel and administrative expenses (article 1[17]). The council's staff (secretariat) is provided by the Oesterreichische Nationalbank and located in the building of the Oesterreichische Nationalbank. However, the committee itself is "strictly independent from the National Bank's governing bodies" (Chaloupek, 2011). Staff typically have Masters degrees and are specialists in fiscal policy and budgeting.

The law allows the committee to draw on the services of outside experts. For instance, the annual report on public finances in 2012 lists a dozen external experts from the Federal Ministry of Finance, the Oesterreichische Nationalbank, the Austrian Treasury, the Court of Audit, academic and research institutions and organised labour, as well as two large banks. The law does not regulate potential conflicts of interest. Rather, the committee is seen as bringing together the different interests and views of the government, the "social partners" and economists.

Until recently, the FISK and its predecessor the GDC, did not have regular interaction with similar institutions abroad, although its workshops sometimes involved international 
participants. For instance, it has hosted a workshop on independent fiscal councils that included representatives from other such bodies. Secretariat employees are regular contributors to domestic discussions, for instance in federal working groups on administrative reform, the Public Finance/Maastricht Working Group at Statistics Austria, or the annual budget workshop of the Austrian Institute of Economic Research. Since 2013 contacts with international organisations and the bilateral meetings have increased.

\section{Access to information}

Access to relevant information is facilitated by the fact that the government appoints half of the members with voting rights on the FISK, including the chair. Moreover, the secretariat of the committee is run by the Oesterreichische Nationalbank, which has extensive access to fiscal and economic information from domestic and international sources. The 2002 law did not specifically deal with access to information, nor did it impose any restrictions in this regard. The 2013 law (Article 1 [15a]) states that: "Regional administrative authorities must reply to inquiries of the Fiscal Advisory Council for information necessary to fulfil the tasks under Article 1 within a reasonable time frame. Statistics Austria must provide budget data in electronic form of regional administrative authorities and the reports on budget results according to the Austrian Stability Pact of 2012."

The secretariat of the FISK does not recall instances where the government has threatened or attempted to limit its access to relevant information.

\section{Transparency}

All of the committee's recommendations and annual reports, as well as any other publications and workshop materials, are made publically available on the FISK website. The committee organises news conferences at least three times a year, in conjunction with the publication of the fiscal rules report in May, its annual report around the beginning of July, and its budget assessment report for year $t$ and $t+1$ including recommendations in December. These news conferences take place in the building of the Oesterreichische Nationalbank and include a presentation by the Chair of the FISK. The reports and recommendations typically gain attention in the media, and members are also sometimes quoted in their personal capacities. In the past, apart from these two news conferences, media coverage of the former council's opinions throughout the year tended to be relatively low. The exception has been statements of the chairman on current political issues which are often reported in the media. Due to the amended mandate, the FISK increased communications with the media and the public by providing information to the press between news conferences and by co-operating with other IFIs.

\section{Governance, advisory support, monitoring and evaluation}

The FISK does not have a formal oversight board or advisory panel. However, its work is subject to peer review in so far as all draft documents (produced by the secretariat) are heavily discussed during its meetings not only with the nominated members but also with the outside experts and accordingly redrafted in the meeting or afterwards.

\section{Concluding remarks}

The precursor to the FISK, Austria's GDC, has a history spanning more than four decades, which has seen a significant evolution of its work from a focus on debt management to a broader function as budget policy watchdog. This role is well established, 
but also limited to advice and commentary. Its impact on actual budget figures is uncertain, but it is regarded as having some influence on the direction and focus of public debate on the budget and fiscal policy (Kronberger, 2011). It remains to be seen whether its transformation to the FISK and its new functions will further enhance its relevance and influence.

\section{Notes}

1. Staatsschuldenausschus.

2. Previously under the 2002 legislation, the term length was four years.

\section{Bibliography}

Austrian Fiscal Advisory Council or Fiskalrat (formerly the Government Debt Committee or Staatsschuldenausschuss) (2015), www.fiskalrat.at.

Austrian Parliament (2015), www.parlament.gu.at.

Blöndal, J.R. and D. Bergvall (2007), "Budgeting in Austria", OECD Journal on Budgeting, Vol. 7, No. 3, OECD, Paris, pp. 39-75.

Chaloupek, G. (2011), “The Government Debt Committee in Austria”, Wirtschaftspolitische Blätter, Vol. 58, No. 1, Austrian Chamber of Commerce, Vienna, pp. 37-43.

Federal Ministry of Finance (n.d.), "Haushaltsrechtsreform" (links to further information on the reform of the legal framework for budgeting), www.bmf.gu.at/Budget/Haushaltsrechtsreform.

Kronberger, R. (2011), "Comment on the Swedish Fiscal Policy Council, the High Council of Finance in Belgium and the Government Debt Committee", Wirtschaftspolitische Blätter, Vol. 58, No. 1, Austrian Chamber of Commerce, Vienna, pp. 93-96.

Steger, G. (2010), “Austria's Budget Reform: How to Create Consensus for a Decisive Change of Fiscal Rules", OECD Journal on Budgeting, Vol. 2010, No. 1, OECD, Paris, pp. 7-20.

\section{Legislation}

Federal Law on the Restructuring of the Legal Framework of the Postal Savings Bank (Bundesgesetz zur Neuordnung der Rechtsverhältnisse der Österreichischen Postsparkasse), 26 November 1969.

Federal Law on the Establishment of the Government Debt Committee (Bundesgesetz über die Errichtung des Staatsschuldenausschusses), 20 December 1996.

Federal Law on the Establishment of the Government Debt Committee (Bundesgesetz über die Errichtung des Staatsschuldenausschusses), 8 January 2002.

Federal Law on the Establishment of the Fiscal Council (Bundesgesetz über die Errichtung des Fiskalrates), 31 July 2013. 


\section{Austrian Parliamentary Budget Office (PBO)}

\section{Parliamentary Budget Office (Budgetdienst)}

Established: 2012.

Enabling legislation: Established by the President of the National Council according to the statutory basis governing the parliamentary organisation (Federal Constitutional Law, Federal Law on the Rules of Procedure of the Austrian National Council).

Mandate: The mandate of the PBO is to support the parliament (National Council) in the budgetary process, in debating and approving the budget and exercising its oversight role.

Budget: Not disclosed.

Staff: Plan for a full staff component of six academic experts and two assistants. 


\section{Context}

Despite long-term efforts to provide independent budgetary expertise directly to parliament, the National Council did not have a specialised budget research unit until 2012. The establishment of the Parliamentary Budget Office (PBO) was closely connected to a comprehensive federal budget reform begun in 2007. The reform introduced a number of completely new elements to the budgetary process such as performance budgeting (including the requirement that each ministry set at least five key goals that are approved by parliament), a new budget structure with lump-sum budgets, accrual budgeting and accrual accounting.

Since 2013, the role of the National Council in the budget process has also changed significantly, shifting from scrutinising over 1000 detailed appropriations to a focus on the medium-term expenditure framework, global budgets and the new performance information. As the new budget rules assign additional powers to the government in respect of budget allocation, more stringent parliamentary control of the budget execution is indispensable. To support this new role, all political parties represented in the National Council unanimously agreed on the establishment of an independent PBO. In July 2012 the PBO was established by the President of the National Council according to the statutory basis governing the parliamentary organisation.

\section{Relationship with the Executive and the Legislature}

The PBO is a unit of the parliamentary administration within the Department of Legal, Legislative and Research Services. However the PBO has a specific mandate to support and consult the Budget Committee directly. For the first time in the history of the Austrian Parliament, a parliamentary committee has direct access to expert staff.

The PBO co-operates with government, especially with the Ministry of Finance and the Performance Management Office of the Federal Chancellery, to obtain current and accurate information on budgetary issues. Furthermore the head of the BPO participates in meetings of senior budget officials of the line ministries.

The PBO has already established good relationships with independent institutions and the scientific community such as the Austrian Institute of Economic Research, the Institute of Advanced Studies, the National Statistical Institute and the Fiscal Advisory Council (formerly the Government Debt Committee). According to the new legislation on the Fiscal Advisory Council, the PBO is entitled on a statutory basis to participate in the meetings of the council in an advisory capacity.

The PBO also maintains close working relations with the Court of Audit. The PBO frequently uses reports of the Court of Audit (especially on the federal financial statements) as a basis for analytical work and refers to important recommendations from the court. 


\section{Legal basis for establishment}

The PBO was established by the President of the National Council in July 2012 as part of the parliamentary administration according to the statutory basis governing the parliamentary organisation. As agreed among all political parties represented in the National Council and according to a statement of the Budget Committee of the Austrian Parliament of 10 November 2011 (1510 d.B. XXIV. GP) the PBO shall work independently and objectively and directly support the Budget Committee.

\section{Mandate}

The mandate of the PBO is to support the National Council in the budgetary process, in debating and approving the budget and exercising its oversight role. Its key tasks are:

- to support the Budget Committee in the form of written expertise, analysis and short studies on budgetary matters presented by the government according to budget law;

- to support other parliamentary committees regarding impact assessment ${ }^{1}$ of new legislation;

- to consult especially on performance and gender budgeting;

- to provide short analyses at the request of members of the Budget Committee.

As of the new legislative period on 29 September 2013, the Budget Committee decided to invite the head of the PBO to participate in all meetings as an expert.

\section{Functions}

The PBO provides independent and objective analysis to the parliament generally and to the Budget Committee specifically, thereby strengthening the parliament's position relative to the government.

The PBO prepares responses to budget related questions from the Budget Committee and its members and impact assessments of new legislation when specifically requested by other parliamentary committees.

The independent analyses of the PBO cover all budget-related documents presented by the government in accordance with the new federal organic budget law 2013. They are focussed on fiscal policy, development of income and expenditure, tax revenue and the adequacy of the budget allocations in light of economic forecasts, performance information and gender budgeting.

In its first year, the PBO produced a number of brief and in-depth analyses of budgetrelated documents such as the draft medium-term expenditure framework, the updates of the medium-term projections of the stability programme, the budget proposal for 2013, impact assessment of new legislation (e.g. tax legislation), and several reports of the Minister of Finance (e.g. on budget implementation, public debt, contingent liabilities and guarantees, subsidies, and financial and economic results of off-budget public entities). Regarding the MTEF, the PBO analysis focussed, for example, on: expenditure and income development and its structural changes, macroeconomic developments and fiscal sustainability, challenges and risks for implementation and recommendations for improvements in the format of budget documents (e.g. more transparent budget and reporting formats) under the new budget law.

The PBO also provides concise information on budget-related issues (e.g. on new EU legislation or reports on budgetary developments in EU member states or on the recommendations of international bodies like the OECD or IMF) and macroeconomic developments (e.g. on new economic forecasts). For that purpose the PBO maintains an 
e-mail information service for the Budget Committee on economic and fiscal data. The PBO will likely play a role in the forthcoming evaluation of the Austrian budget reform.

PBO staff attend Budget Committee meetings and the head of the PBO appears before the committee.

\section{Work programme}

According to the aforementioned statement of the Budget Committee of the Austrian Parliament, the political parties have agreed on a list of duties and products for the PBO, further specifying the key tasks of the PBO. The envisaged services include ongoing analyses on important budget related drafts (e.g. mid-term expenditure framework, budget law and accompanying legislation) and government reports (e.g. on current budget execution, performance information, public debt, contingent liabilities and guarantees, and subsidies). Analyses shall focus on:

- the financial and macroeconomic impact (e.g. on economic growth, employment)

- economic, environmental and social sustainability

- distributive effects

- evaluating the costings provided by the government on new legislation and programmes

- effects on gender equality and

- scrutiny and monitoring of the implementation of performance budgeting.

According to the provisions in the statement, the head of the PBO shall agree a detailed catalogue of deliverables and products with the leading party representatives on the Budget Committee. Based on this agreement, the PBO will define its annual work programme.

Current analyses have been provided on the PBO's own initiative (in practice for the majority of tasks) and cover especially the draft fiscal framework and the draft budget as well as the reports of the Ministry of Finance according to the new budget rules.

The PBO prepares brief notes (two pages) and short studies (five pages) upon request. Requests may be made by the Budget Committee as a whole, parliamentary groups represented on the committee, or individual committee members. Requests are handled on a first-come-first-served basis. To prevent individual requests overloading the $\mathrm{PBO}$, individual requests are limited to three questions per month for each parliamentary group.

The PBO will compile a description of the products and services provided in a yearly activity report, along with a summary of its main findings and conclusions.

\section{Budget}

The PBO does not have a separate budget. The expenses are funded from the budget of the parliamentary administration. The main costs incurred are for staff salaries and general office expenses. A parliamentary amendment to the 2012 budget provided additional funding for the establishment and subsequently the ongoing operation of the PBO. This amendment was adopted with unanimous support from all political parties in the National Council.

\section{Staffing}

\subsection{Leadership}

The head of the PBO is a civil servant in the parliamentary administration appointed by the President of the National Council following a hearing before the leaders of the 
different party groups represented on the Budget Committee. The first head of the PBO was formerly a senior civil servant in the Court of Audit.

\subsection{Staff}

Staff members are employed by the parliamentary administration and appointed by the President of the National Council. As such, while the Head of the PBO is consulted in the hiring process, he/she does not have the power to hire or dismiss staff. In total, the PBO is expected to have a staff of six academic experts and two assistants at full capacity. Currently, seven staff members have been appointed. The academic experts have backgrounds as budget experts, economists and lawyers. Their professional experience includes assignments in the Ministry of Finance, the Federal Chancellery, universities or as private consultants. Staff are subject to the rules of conduct for civil servants.

\section{Access to information}

There are no special provisions regarding access to budgetary information, however, the Budget Committee has agreed to evaluate this in due course. In practice, necessary information has been provided to the PBO by government authorities. However, it will be important to agree upon more detailed procedures for information exchange with government in future.

\section{Transparency}

According to the aforementioned statement of the Budget Committee, the PBO shall be based on the following principles:

- PBO shall work independently and ensure high-quality expertise.

- PBO shall submit analysis to all political parties.

- PBO shall ensure transparency and publish all requests and all studies, reports and brief notes prepared by the PBO on the parliament's website.

As the $\mathrm{PBO}$ is a unit within the parliamentary administration, it does not have its own website but its work is released on the "Budget-Analysen" page of the parliament's website. ${ }^{2}$ Similarly, the PBO's relationship with the media is largely handled by the parliament's Press Information Service.

\section{Governance, advisory support, monitoring and evaluation}

According to the statement of the Budget Committee, the PBO must produce a yearly activity report. The $\mathrm{PBO}$ receives feedback on an ongoing basis from the Budget Committee on $\mathrm{PBO}$ services and products. $\mathrm{PBO}$ products are also open to public scrutiny when they are published online. The PBO is a new institution in its start-up phase. As such, it is currently too early to consider a performance or impact evaluation. The parliamentary administration, including the PBO, is subject to audit by the Austrian Court of Audits. The PBO does not have a panel of outside advisors.

\section{Concluding remarks}

The Austrian PBO is already an established element of the new Austrian Fiscal Governance Framework. The creation of the PBO has been an important step in providing additional independent know-how and expertise to the parliament - thus reducing information asymmetries and strengthening the position of the parliament vis-à-vis the 
government in budgetary matters. The analytical work of the PBO has been well received by parliamentarians and $\mathrm{PBO}$ analyses are seen as supporting a fact-based and problemfocussed debate in the Budget Committee.

The PBO's continued success will depend in large part on its ability to develop good working relations and procedures with the Budget Committee and other committees (regarding impact assessments of new legislation), as well as with government. So far the Budget Committee has indicated that the products provided by the PBO have been very valuable for the members in the budget debate and that the establishment of the PBO was a major step to strengthen parliamentary budget control. As noted earlier, at the beginning of the new legislative period on 29 September 2013, the Budget Committee decided to invite the head of the PBO to participate as an expert in all of its meetings.

It is expected that PBO scrutiny, in co-ordination with the Budget Committee, will lead to improved quality and the relevance of Ministry of Finance reports. As a consequence of the new budget law, and with analytical support from the PBO, the debate in the parliament is shifting from parochial interests in minor individual budget allocations to a higher-level policy discourse (e.g. development of public deficit and public debt, enhancement of economic growth, proactive measures against unemployment, education and research policies, and development assistance).

The PBO also provides the parliament with a vital link to the Fiscal Advisory Council where previously only a very weak relationship existed. This further strengthens the parliament's access to independent budget assessment and fact-based recommendations.

The PBO is still in its start-up phase; its main objectives for the near future are the finalisation of a catalogue of deliverables and products and the integration of new staff members. In the longer term, the PBO plans to create a specialised database on fiscal and economic issues to communicate with the members of parliament and the public.

\section{Notes}

1. This may include budgetary, economic, social and environmental impacts. The PBO may also perform evaluations of government costings as part of the impact assessment process.

2. See: www.parlament.gu.at/PAKT/BUDG/.

\section{Bibliography}

Austrian Parliament (2015), www.parlament.gu.at.

Blöndal, J.R. and D. Bergvall (2007), "Budgeting in Austria”, OECD Journal on Budgeting, Vol. 7, No. 3, OECD, Paris, pp. 39-75.

Parliament of Austria, Nationalrat, Jahresbericht 2012, "Budgetdienst: Stärkeres Parlament durch unabhängige Beratung”, Parliament of Austria, Vienna, pp. 24-25.

Berger, H. (2012), "Für ein starkes Parlament”, Verwaltung INNOVATIV, Vol. 2012, No. 3, Federal Ministry for Education, Arts and Culture, Vienna, p. 6.

\section{Legislation}

Federal Law on the Establishment of the Fiscal Council (Bundesgesetz über die Errichtung des Fiskalrates), adopted by the National Council on 5 July 2013. 


\section{Belgium}

High Council of Finance: (Hoge Raad van Financiën/Conseil supérieur des Finances)

Established: 1936, with major reforms in 1989. A 13 December 2013 co-operation agreement enhanced the responsibilities of the HCF (Section Public Sector Borrowing Requirements) in line with the EU fiscal compact.

Enabling legislation: Royal Decree on the High Council of Finance (Koninklijk besluit betreffende de Hoge Raad van Financiën/Arrêté royal relatif au Conseil supérieur des Finances), 3 April 2006.

Mandate: The Council is responsible for advising the Minister of Finance and the Minister of Budget in the development of fiscal, financial and budgetary policy.

Budget: Unavailable. No separate budget line.

Staff: One Chair (Minister of Finance), two Deputy Chairs and 24 council members; 12 secretariat staff, 2 secretariat administrators. 


\section{Context}

The High Council of Finance (HCF) is one of the oldest fiscal councils. It was first established by a 1936 royal decree in an effort to consolidate five previously created advisory bodies (High Council of Finance, n.d.). ${ }^{1}$ In the run-up to the Second World War, the Council's work arguably became too broad. It ventured beyond a purely advisory role and started to generate policy prescriptions, which may explain why post-war Ministers of Finance were reluctant to convene it. As a result, the council fell into disuse and did not convene from the Second World War until 1969. The council was revived in 1967 and new members appointed in 1969, following a recommendation by a government commission on the financial problems of economic expansion. It was reformed again in 1981, when the membership of the council was expanded.

The structure and mandate of the HCF changed fundamentally in 1989 in the context of a constitutional reform process towards a federal state. At the time, a widely shared concern was the need to reconcile macroeconomic and budgetary stability with increased subnational fiscal autonomy. This reform included the creation of the Section for "Public Sector Borrowing Requirements" (PSBR) and specific competences for intergovernmental fiscal co-ordination. The structure and mandate of the HCF were updated in 2006. This reform abolished the Section "Financial Institutions and Markets", which had become obsolete due to the existence of other institutions with related functions, and expanded the mandate of the Section "Taxation and Social Security Contributions" to include tax revenues collected by the federal government on behalf of local governments. The council, and in particular its section for PSBR, continues to play an important role in the effort to promote fiscal discipline in a federal setting.

In December 2013, under a co-operation agreement, the HCF Section Public Sector Borrowing Requirements was officially designated as Belgium's "independent fiscal institution" under the new European fiscal framework and its mandate was enhanced. The co-operation agreement is between the federal, regional and community governments, and was ratified by the parliaments of each of these entities.

The European Union's fiscal rules provide an important reference for the development of the budget. Belgium is subject to the $3 \%$ deficit and $60 \%$ debt limits in the Stability and Growth Pact. In accordance with the pact, Belgium has drawn up a stability programme each year since 1998 to set out medium-term budget targets that guide annual budgets. This approach has relied on the co-operation between the federal and sub-national governments, through agreements that specify borrowing targets for each region and community on a multi-annual basis, taking into consideration the recommendations of the HCF and a burden-sharing agreement for the consolidation efforts. Local authorities are subject to a balanced budget rule based on a 1982 royal decree; this rule, however, takes into account the electoral investment cycle. This subsector has had more or less balanced finances in the past two decades, although with variations across individual municipalities and the electoral cycle (Van Meensel and Dury, 2008). In recent years, the balanced budget 
is more challenging for local authorities due to growing pension costs and an increase in social assistance expenditure as a result of the economic crisis and population ageing.

\section{Relationship with the executive and the legislature}

The HCF is an advisory body for the executive with limited institutional independence. The secretariat of the HCF is part of the Federal Public Service Finance, under the authority of the federal government, and formally the Minister of Finance chairs the council. Article 2 of the 2006 decree describes the council as a "technical and advisory" body that works to support the Minister of Finance and the Minister of Budget. There is no requirement on the government to respond to the reports of the HCF, although the budget documents make reference to the recommendations of the council.

The HCF has no formal relationship with the federal or sub-national parliaments. Legislative committees do not generally discuss the council's reports, although individual members of parliament may refer to them. On some occasions, staff from the HCF secretariat have participated in discussions held by committees in the sub-national parliaments. Theoretically, parliamentary committees could invite the chairs of the sections to discuss budgetary issues, but this rarely happens. When recommendations of the PSBR section reflect a political consensus, such discussions could also be perfunctory. Overall, the role of the council is well established and it has operated under many governments of different political compositions. It faces no existential threat.

As noted earlier, the co-operation agreement of 13 December 2013 in effect formalised the recommendations of the PSBR section in view of the Stability Programme. The opinion of the section on the multi-annual targets has to be, as of 2014 , submitted to the Concertation Committee. Based upon these recommendations, the governments of the federal level and the regions and communities have to seek an agreement on the budgetary path for the Stability Programme. In practice, if the governments elect a different budgetary path then the one recommended by the PSBR section, they have to defend their choice ("comply or explain").

The HCF is not the only advisory body that plays a role in the budget process. The National Accounts Institute (NAI) was created in 1994 in order to ensure the quality and the independence of the main economic statistics and macroeconomic forecasts upon which the budget is based. It has no resources of its own, but serves as a vehicle to bring together Statistics Belgium, the National Bank of Belgium and the Federal Planning Bureau. Bogaert et al. (2006) describe the relationship between the HCF and the NAI as a division of labour between two fiscal councils, where the latter is limited to "positive economics" in contrast to the more "normative" role of the council.

The Federal Planning Bureau carries out a number of important activities related to public finances that are typical in other IFIs (Bogaert et al., 2006). For instance, it collaborates with the National Bank of Belgium in the preparation of the general government account within the national accounts. The bureau also produces, on behalf of the NAI, the short-term economic forecasts that are used by the federal government for drawing up its budget. The bureau's medium-term economic outlook informs the preparation of the Stability Programme. Moreover, it prepares long-term projections of the budgetary consequences of an ageing population. The origin of the Bureau dates back to 1959 and it currently has about 100 staff members. 


\section{Box 1. The Federal Planning Bureau}

Founded in 1959 as the "Programming Bureau", the Federal Planning Bureau (FPB) is an independent public agency which, in its current form - as stipulated in the Law of 21/12/ 1994 amended by the Law of 04/04/2014 - forecasts, studies and analyses policy measures. Its main mission is to support the political decision-making process. As such, it shares its expertise with the government, parliament, social partners and national and international institutions. The FPB carries out studies and projections on economic, social and environmental policy issues, and on the integration of these policies within a context of sustainable development. FPB analysis is limited to positive analysis.

On behalf of the National Accounts Institute, the FPB provides the federal government, regions and communities with a common forecast (referred to as the "economic budget") that serves as a starting point for their budgetary projections. The FPB also prepares a medium-term economic outlook including a detailed projection of general government accounts (federal, social security, federated entities and local) based on a no-policy-change scenario that is then used by the HCF to make its recommendations. This macroeconomic outlook also serves as a starting point for the elaboration of the stability programme. Finally, the FPB is the seat of the secretariat of the Study Group on Ageing and produces its long-term projections of age-related budgetary expenditures.

To reinforce its independence, the FPB has a policy of being as transparent as possible. It publishes its forecasts, methods, models and data. It also assesses its own forecasting performance. Moreover, any study commissioned by the federal government or any other institution is published under the FPB's name. All FPB publications can be downloaded free of charge from its website. Study results are also disseminated through presentations at workshops and conferences.

Regular staff recruitment is governed by a transparent procedure and the candidates are appointed for a renewable nine-year term on the proposal of the bureau's managing board. Management staff is appointed by the Council of Ministers on the basis of a list of candidates chosen by a selection committee composed of independent experts in the fields of management and economics.

\section{Box 2. Role of the legislature in the budget process}

Belgium is a federal state with a parliamentary system of government and a bicameral legislature. The Chamber of Representatives has 150 members who are directly elected by universal suffrage. The Coalition Agreement of 2011 included reforms to the Senate which were implemented fully in 2014, the first year where senators were not directly elected. The new 60-member Senate is completely composed of members appointed by the community and regional parliaments $\left(50\right.$ members $\left.^{2}\right)$ and "co-opted" senators elected by their peers (six from the Dutch language group and four from the French-language group). The Senate's role in the legislative process has been greatly reduced and will focus on reforms of the state and the royal family.

The Chamber of Representatives has exclusive authority over the state budget. The budget is to be presented no later than 31 October, two months before the start of the fiscal year. In recent years, however, there have been frequent deviations from the normal budget cycle due to political instability. 


\section{Box 2. Role of the legislature in the budget process (cont.)}

Fiscal policy, revenue proposals and interest payments are examined by the Committee on Finance and Budget in the presence of the federal Ministers of Budget and Finance. Sectoral committees examine the expenditure proposals that fall within their particular policy area in sessions that are attended by the relevant minister. They report their findings, orally or in writing, to the Committee on Finance and Budget. These committee sessions are open to the public. Following a final vote in the Committee on Finance and Budget, the spending and revenue bills are discussed in the plenary. Amendments may be filed at each stage of the proceedings and are not circumscribed by constitutional restrictions. In practice, significant amendments without the support of the government are unlikely. The Belgian Parliament does not have a specialised budget analysis unit.

The Court of Audit, which has about 600 staff, examines government accounts and its findings are reported to parliament.

\section{Legal basis for establishment}

The HCF was first created by the Royal Decree of 31 January 1936 Establishing a High Council of Finance. Reforms occurred in 1967 and 1981. The creation of the section PSBR as part of the council was required by article 49, $\S 6$ of the Special Law of 16 January 1989 on the Financing of Communities and Regions. The Royal Decree of 3 April 2006 on the High Council of Finance established its current structure. New tasks were assigned to the PSBR section by the co-operation agreement of 13 December 2013.

\section{Mandate}

Article 2 of the 2006 decree gives the HCF a broad overall mandate: "The Council is responsible for advising the Minister of Finance and the Minister of Budget in the development of fiscal, financial and budgetary policy." In principle, it can act on its own initiative although this is rare in practice. The two Sections and a Study Group that fall under the Council have more targeted mandates:

According to the 1989 Special Law, the PSBR section of the council has to prepare an annual opinion on the financing needs of governments. The section may also give its opinion, on its own initiative or upon request by the federal Minister of Finance or Budget, as to the advisability of restricting the borrowing requirement of one or more authorities should this be necessary in order to protect economic and monetary union or to avoid "a structural derailment of the borrowing requirements". This is one of the main legal competences of the council and the key reason for the creation of the PSBR section in the context of the 1989 state reform. In practice, this option has never been used. Any attempt by the federal government to limit the borrowing of a region or community would be "very likely to cause massive political turmoil" (Coene and Langenus, 2011). In line with the concerns at the time of the creation of this section, its institutional coverage is comprehensive and includes the different levels of government, as well as other institutions if they affect government budgets.

As noted in the OECD Economic Survey of Belgium (OECD, 2015), the responsibilities of the HCF have been enhanced as follows: ${ }^{3}$

"First, in the context of the preparation of the Stability Programme, the HCF delivers an

Opinion with recommended multi-annual budget targets to promote fiscal sustainability 
in the medium and long term. These targets are set in nominal and structural terms for each level of government, taking into account a fair burden-sharing of the fiscal consolidation efforts. On the basis of that Opinion, the federal, regional and community governments have to conclude an agreement on the fiscal path and its breakdown. Second, the co-operation agreement also tightens up enforcement of the fiscal rules by strengthening the Council's monitoring responsibilities. The Council will monitor the different governments' budget outcomes and, in the event of any significant deviation from targets, will trigger a correction mechanism. In such cases, the government in question will have to implement additional consolidation measures in a limited timeframe to attain its target. The Council will monitor the implementation of these corrective measures."

The second Section on "Taxation and Social Security Contributions" can give advice, either at the request of the federal Minister of Finance or at its own initiative, on issues related to taxation and social security contributions. It also has to give an annual opinion on the tax revenues collected by the federal government on behalf of local governments.

In addition, a Study Group on Ageing was created by the Law of 5 September 2001 Guaranteeing a Continuous Reduction of Public Debt and Creating an Ageing Fund. It has to publish an annual report on the budgetary and social consequences of ageing, which by law should be taken into account by the PSBR section in preparing its recommendations. As noted in Box 1, the secretariat of the Study Group on Ageing is provided by the Federal Planning Bureau.

\section{Functions}

Within the HCF, the PSBR section evaluates compliance with the budgetary targets of the different subsectors of the general government, and recommends borrowing targets for the medium and longer term. Detailed economic analysis of taxation is the role of the Section Taxation and Social Security Contributions section. The work of the Study Group on Ageing has a long-term focus, including projections of the budgetary effects of ageing that cover a 50-year period. The HCF does not produce macroeconomic forecasts, as this role is assigned to the NAI/FPB. Nor does the HCF routinely cost individual policy proposals, carry out regulatory impact assessments, or produce assessments of the fiscal implications of the election platforms of political parties. The reports of the HCF are based on budgetary data and quantitative analyses, complemented with narrative commentary and interpretation.

Since 1989, the council has had a crucial role in assessing compliance with mediumterm budgetary targets. Its PSBR section monitors overall compliance with the targets in the stability programmes for the general government as a whole, as well as the contributions of the different sub-sectors. This includes both an ex post as well as an ex ante focus, which in past years have usually been linked to separate reports. One of the key tasks of the Section is to develop normative recommendations, specifically medium-term deficit targets and their breakdown across the sub-sectors.

The ex ante role of the PSBR section has been formalised by the Co-operation Agreement of 13 December 2013. The Section will continue to recommend a multi-annual budgetary path but as of 2014 the budgetary targets have to be set in both nominal and structural terms. This budgetary path has to be set for all the levels of government, including individual regions and communities. The ex ante opinion is thereafter submitted to the Concertation Committee. Based on this opinion, the governments of the federal level 
and the regions and communities have to seek an agreement on the fiscal path for the stability programme.

The ex post role of the PSBR section has also been significantly enlarged by the Co-operation Agreement of 13 December 2013. The monitoring responsibilities of the section were strengthened in order to comply with the fiscal compact. The section will continue to monitor the budgetary outcomes and their compliance with the targets of the stability programme. However from now on, an automatic correction mechanism will be triggered if the section detects a significant deviation. If this happens, the government or governments in question will have to implement measures to correct this deviation. The PSBR section will be responsible for monitoring the implementation of these corrections measures in a separate report and it will also be the section that determines whether exceptional circumstances apply.

\section{Work programme}

The chair, the deputy chairs of the two permanent sections, a member nominated by the Minister of Finance, a member nominated by the Minister of Budget, a member representing the National Bank of Belgium and the member representing the Federal Planning Bureau form a "Bureau" charged with preparing and organising the work of the HCF. In practice, the two sections and the study group organise their work with a high degree of autonomy.

The HCF organises its work programme in accordance with its mandate. The two sections and the working group each have to report annually. They also have to respond to ad hoc requests from the government, and can act on their own initiative. In practice, the council and its subunits rarely go further than their required regular reports and typically respond only to ministerial requests. The dates of publication for the required reports have varied somewhat.

The PSBR section usually produces more than one report a year. The first is typically published around March and recommends fiscal targets on a multi-annual basis for each level of government in view of the stability programme. In the context of the introduction of the "European semester", this first report contributes to the development of the stability programme. A second report in early summer (June/July) ${ }^{4}$ assesses the compliance of the budgetary outcomes of the previous year with the targets of the stability programme for each level of government including individual regions and communities. This report can involve specific recommendations on the budget balances of individual authorities. The timing of the two reports can sometimes be more erratic due to specific economic circumstances or to changes to the timing of stability programme updates. In addition, if the automatic correction mechanism is triggered, the workload of the PSBR section will likely rise and include additional reports.

\section{Budget}

Unlike the Federal Planning Bureau, the HCF does not have a separate line in the budget. In fact, the council has no significant expenditures of its own. The Federal Public Service Finance provides the secretariat staff, with resources that are allocated as part of the regular budget process. Members do not receive any wages, as they have other full-time jobs and membership only entails attendance at a small number of meetings a year. Hence, unlike in countries where fiscal councils have been threatened with budget cuts when they 
have been perceived as overly critical of the government, this is not a possibility in Belgium. However, there are other circumstances that can disrupt its work, in particular delays in the appointment of its members.

\section{Staffing}

\subsection{Leadership}

Article 4 of the 2006 decree stipulates that the federal Minister of Finance is the Chair of the HCF. The federal Ministers of Finance and Budget also designate two Deputy Chairs who can replace the chair in case of absence. In practice, the Deputy Chairs chair the meetings and are in charge of organising the work programme. They propose the main guidelines for the Opinions and represent their Section in various meetings and institutions. The HCF consists of 24 members with five-year renewable terms (Articles 5 and 6). All also have full time positions in other institutions. In principle the appointment of non-nationals is possible.

The PSBR section consists of 12 members. Six members must be experts in budgeting and economics. Three of these are nominated by the National Bank of Belgium, one by the Minister of Finance, one by the Minister of Budget and one (the Deputy Chair) is nominated jointly by the Ministers of Finance and Budget. The Ministers of Finance and Budget nominate another six members who are experts in finance and economics on the basis of proposals from the governments of the communities and regions, including: two members proposed by the government of the Flemish Community; one by the government of the French Community; one by the government of the Walloon Region; two by the government of the Brussels-Capital Region, with one each representing the French and Dutch language communities.

Twelve members are nominated in the Section Taxation and Social Security Contributions Section. They must be experts in the area of taxation. These include six members of which one is proposed by the government of the Walloon Region if desired, one by the government of the French Community if desired, two by the Flemish government if it wishes and two by the government of the Brussels-Capital Region if it wishes, with one each representing the French and Dutch language communities. Another six members are nominated by the Minister of Finance, two of which are proposed by the Minister of Budget, one by the Minister of Social Affairs, one by the Federal Planning Bureau and two by the Minister of Finance.

Technically, the King appoints the members of the council. In practice, he always appoints the proposed individuals. Resolutions of the HCF require a two-thirds majority and the Minister of Finance does not have voting rights. Members do not receive compensation, except a modest attendance fee (about EUR 40 a meeting) and reimbursement of travel-related expenses.

In practice, the membership of the council has to reflect a carefully crafted political balance. Appointments have to be "carved up" among the traditional political parties and strike a balance in terms of regional-federal and linguistic representation, as well as gender. This can delay appointments. Following the 2004 regional elections, it was especially difficult to reach an agreement on the composition of the HCF, which led to a two-year hiatus that interrupted the work of the council. The mandates of the previous members expired in the fall of 2011 and the sections have been reconstituted since March 2012 with the appointment of the current members for a period of five years. 
Strictly speaking, the decree on the HCF does not provide for the dismissal of a council member. In practice, the replacement of a member might become necessary if, for instance, he or she takes up a new position that is incompatible with work on the council.

\subsection{Staff}

The work of the two sections of the HCF is supported by a secretariat consisting of 12 staff plus two administrators, appointed by the federal Minister of Finance. The Federal Planning Bureau provides separate administrative support to the Study Group on Ageing. In practice, secretariat duties are interpreted in a very broad manner and include the drafting of the Council's reports.

The secretariat is located on the premises of the Federal Public Service Finance. Its staff are civil servants and full-time members of the Research and Documentation Department of the Federal Public Service Finance, which carries out preparatory analytical work and drafts documents in support of political decisions in the field of public finance. This ensures that the council has access to staff with relevant qualifications, mostly in economics. Traditionally, they work part-time on HCF business and part-time on other business, depending on the particular workload of the council at a given time. Recently, due to the Section PSBR becoming the official IFI, Section PSBR secretariat staff work essentially full time.

The use of external experts is also possible, but rare in practice. Informally, some members may draw on expertise of staff in those organisations that nominated them, for instance to provide comments on draft reports.

\section{Access to information}

The HCF is chaired by the Minister of Finance, who also appoints the staff of the secretariat from amongst the staff of the Federal Public Service Finance. This ensures timely access to information the council may require for the preparation of reports. Some members of the council may also have access to the expertise within their nominating organisations, such as the National Bank of Belgium and the Federal Planning Bureau. Unlike in some other countries, the HCF has not been threatened with limits on access to information in response to critical reports. This is an unlikely scenario in Belgium given the importance of political factors in establishing the composition of the council.

The co-operation agreement of 13 December 2013 also clearly stimulates that the HCF should be granted access to all information it needs to carry out its missions and particularly the new missions of the PSBR section.

\section{Transparency}

All reports of the council are published on the HCF website ${ }^{5}$ in both French and Dutch. The PSBR section also publishes an executive summary in English of their reports on the website. The reports are of a technical nature and include discussions of methods and assumptions where appropriate. New reports are announced on the website of the Federal Public Service Finance. Occasionally, the publication of a report is accompanied by a news release. Since 2007, the chair of the PSBR section has held more regular news conferences to accompany publications. The publications of the council receive media attention and are also referenced in the budget documents that the government tables in the Belgian 
Parliament or in the stability programme. As the reports are of a technical nature and not always easily understood by the media and non-specialists in general, the council regularly prepares a summary of its opinion in less technical language.

\section{Governance, advisory support, monitoring and evaluation}

The HCF work programme is overseen by its "bureau". The HCF does not have an oversight board or panel of advisors to guide its work. Nor is its work systematically subjected to peer review. However, it has received some positive evaluations in the academic literature and by international financial institutions. There is also some informal interaction between the secretariat of the HCF, and the relevant technical staff of the Federal Planning Bureau and the National Bank of Belgium.

\section{Concluding remarks}

The HCF is an advisory and consultative body. It has limited institutional independence from the Federal Public Service Finance, which provides the necessary staff and offices, and which finances the operation of the council from its budget. This is evolving however as the staff working for the Section PBSR have essentially become full-time and potential reforms are being discussed which would supplement the PSBR secretariat with experts from the regions and communities.

The Council nonetheless is regarded as an important forum for intergovernmental fiscal co-ordination in Belgium (Spahn, 2007). It is part of a set of fiscal institutions that ensures the separation of normative functions from more technical functions such as forecasting (Bogaert et al., 2006). This role is widely recognised and the continued existence of the council is not in doubt. However, commentators point out that the influence of the PSBR section was most visible in the first decade after its creation. Debrun, et al. (2009) summarise that its recommendations "were followed closely as long as its views were aligned with political priorities", in particular in the run-up to the adoption of the euro. However, its recommendations "seem to have been followed less closely" during the past decade. This view is confirmed by a study that assesses the council's effectiveness in promoting fiscal discipline, including whether the government adopted and complied with the recommendations (Coene and Langenus, 2011). However, it is impossible to say with certainty to what extent the recommendations merely reflect an existing consensus, or serve to establish one.

It remains to be seen whether the council can regain its former level of influence. It did play a useful role during the political crisis of 2010 and 2011, when Belgium's political parties failed to form a new government and a caretaker administration was in charge. The latter sought the opinion of the HCF in devising a consolidation plan for the 2011 to 2014 stability programme. At the time, the council's input gave the budgetary targets a degree of legitimacy, although the targets for the years after 2012 remain contested by some regions. Through its successive opinions the PSBR section also provided valuable input to the development of the Sixth Reform of the State, especially regarding the contribution of the regions and the communities to the consolidation efforts. The new missions given to the PSBR section will no doubt further strengthen the role of the section in the Belgian budgetary framework.

\section{Notes}

1. These included: A Treasury section, a section on banks and stocks, a section of industrial and commercial finance, a section on budgetary legislation and technology and a tax section. 
2. Of the 50, 29 are appointed by the Flemish Parliament (and the Dutch-speaking group of the Brussels-Capital Region Parliament), ten appointed by the Parliament of the French Community, eight appointed by the Parliament of the Walloon Region, two appointed by the French-speaking group of the Parliament of the Brussels-Capital Region and one appointed by the Parliament of the German-speaking Community.

3. The Federal Planning Bureau was appointed as the independent fiscal council for macroeconomic forecasts (see Box 1).

4. As of 2015, the Section PSBR has decided to bring forward the report on compliance with the budgetary outcomes to better fit with the European semester. If a significant deviation is detected this new timing should allow governments to take measures for the next budget. The previous report timing in autumn came too late for governments to apply new measures to the next budget.

5. The HCF website has been temporarily merged with that of the Ministry of Finance due to budgetary reasons.

\section{Bibliography}

Belgian Chamber of Representatives (2015), www.dekamer.be.

Belgian Federal Planning Bureau (Federaal Planbureau/Bureau Fédéral du Plan) (2015), www.plan.be.

Belgian High Council of Finance (Hoge Raad van Financiën/Conseil supérieur des Finances), http:// financien.belgium.be/nl/over_de_fod/hoge_raad_van_financien.

Belgian Senate (2015), www.senate.be/english.

Bogaert, H., L. Dobbelaere, B. Hertveldt and I. Lebrun (2006), "Fiscal Councils, Independent Forecasts and the Budgetary Process: Lessons from the Belgian Case", Working Paper 4-06, Federal Planning Bureau, Brussels.

Coene, L. and G. Langenus (2011), "Promoting Fiscal Discipline in a Federal Country: The Mixed Track Record of Belgium's High Council of Finance", Wirtschaftspolitische Blätter, Vol. 58, No. 1, Austrian Chamber of Commerce, Vienna, pp. 11-35.

Debrun, X., D. Hauner and M.S. Kumar (2009), "Independent Fiscal Agencies", Journal of Economic Surveys, Vol. 23, No. 1, John Wiley and Sons, pp. 44-81.

High Council of Finance (n.d.), Institutionele Geschiedenis van de Hoge Raad van Financiën: Opdracht, Samenstelling en Activiteiten, High Council of Finance, Brussels.

OECD (2015), OECD Economic Surveys: Belgium 2015, OECD, Paris, http://dx.doi.org/10.1787/eco_surveys-bel2015-en.

Spahn, P.B. (2007), "Intergovernmental Fiscal Relations and Structural Problems of Federalism in Belgium", International Monetary Fund, Washington, DC.

Van Meensel, L. and D. Dury (2008), "The Use and Effectiveness of Fiscal Rules and Independent Fiscal Institutions", National Bank of Belgium Economic Review, Vol. 2008, No. 2, National Bank of Belgium, Brussels, pp. 69-84.

\section{Legislation}

Co-operation Agreement between the federal government, the communities, the regions and the community commissions concerning the execution of article $3 \S 1$ of the Treaty on Stability, Co-ordination and Governance in the Economic and Monetary Union (Samenwerkingsakkoord tussen de federale overheid, de gemeenschappen, de gewesten en de gemeenschapscommissies betreffende de uitvoering van art. $3 \S 1$ van het Verdrag inzake Stabiliteit, Coördinatie en Bestuur in de Economische en Monetaire Unie/Accord de coopération entre l'État fédéral, les communautés, les régions et les commissions communautaires relative à la mise en œuvre de l'art. $3 \S 1$ du Traité sur la Stabilité, la Coordination et la Gouvernance au sein de l'Union économique et monétaire), 13 December 2013.

Royal Decree on the High Council of Finance (Koninklijk besluit betreffende de Hoge Raad van Financiën/ Arrêté royal relatif au Conseil supérieur des Finances), 3 April 2006.

Royal Decree on the High Council of Finance (Koninklijk besluit betreffende de Hoge Raad van Financiën/Arrêté royal relatif au Conseil supérieur des Finances), 20 June 1989. 
Special Law of 16 January 1989 on the Financing of Communities and Regions (Bijzondere wet betreffende de financiering van de Gemeenschappen en Gewesten/Loi spéciale relative au financement des Communautés et des Régions), 16 January 1989.

Royal Decree Establishing a High Council of Finance (Koninklijk besluit houdende instelling van een hoogen raad van financiën/Arrêté royal instituant un Conseil supérieur des Finances), 31 January 1936.

Note: The High Council of Finance has published a detailed institutional history, in Dutch, that provides further details on the evolution of the council's legal framework. The document is available on the council's website, http://finance.belgium.be/en/about_fps/high_council_finance/ 


\section{Canada}

\section{Parliamentary Budget Officer}

Established: By legislation in 2006; first Parliamentary Budget Officer appointed in March 2008.

Enabling legislation: The 2006 Federal Accountability Act (FedAA) and resulting amendments to the Parliament of Canada Act.

Mandate: To provide independent analysis to the parliament on the state of the nation's finances, the government's estimates and trends in the Canadian economy; and upon request from a committee or parliamentarian, to estimate the financial cost of any proposal for matters over which the parliament has jurisdiction.

Budget: CAD 2.8 million.

Staff: 17 


\section{Context}

Canada's Conservative Party's 2006 election platform proposed the creation of an independent parliamentary budget authority to provide the parliament with objective analysis on the state of the nation's finances and trends in the Canadian economy. This proposal was then included in the Federal Accountability Act (FedAA) ${ }^{1}$ - the first act of business of the newly formed Conservative minority government - introduced in April 2006 and passed in December 2006. The FedAA included a broad package of reforms around conflict of interest rules, restrictions on election financing and various measures to enhance administrative transparency, oversight and accountability. Ultimately it made substantive changes to 45 statutes and amended over 100 others (the Parliament of Canada Act was amended to include provisions for the Parliamentary Budget Officer - PBO). The reforms were enacted over a period of several years and Canada's first Parliamentary Budget Officer was appointed in March 2008.

Among the rationales for the establishment of a PBO were concerns (particularly among parliamentarians) about the credibility of government forecasts which had consistently underestimated budget surpluses. This was seen as hindering full parliamentary and public debate on fiscal options. Indeed, Finance Canada commissioned two separate studies ${ }^{2}$ of its estimation methodology and forecasting performance in 1994 and 2005 which looked at various options for improvement (Beaumier, 2006; Levy, 2008; Jeffrey, 2010).

Concerns were also raised around significant cost overruns in several government programmes, and lack of budget transparency more generally. The "sponsorship scandal", a significant factor in the lead-up to the 2006 elections, provided additional incentive to find mechanisms to promote budgetary transparency and accountability (Jeffrey, 2010). Moreover, Parliament, lacking the financial expertise and resources to properly scrutinise the government's increasingly complex budgets and estimates, and the budgetary impact of government programmes and legislation, was struggling to fully carry out its constitutionally mandated oversight function (Page and Yalkin, 2012). ${ }^{3}$

The PBO was not among the more controversial aspects of the FedAA (Levy, 2008; Jeffrey, 2010) or the resulting amended section of the Parliament of Canada Act. The government's proposals for a new section on the PBO in the Parliament of Canada Act were amended by the parliament to include: 1 ) a provision that the $\mathrm{PBO}$ have access to government data without charge ${ }^{4}{ }^{2}$ ) the removal of a subsection requiring the $\mathrm{PBO}$ to estimate the costs of private members' bills - instead the PBO is mandated to cost any matter that falls within the jurisdiction of the parliament if requested by a member of a committee; 3) provisions within the PBO's mandate to help committees better consider the estimates; and 4) increasing the term length of the Parliamentary Budget Officer from three to five years. Although the legislative provisions establishing the $\mathrm{PBO}$ received broad cross-party support, ${ }^{5}$ differing interpretations of these same provisions soon led to disagreements on the exact nature of the PBO's independence, mandate, reporting relationships and management authority when it came to the practical implementation of the PBO. 
The above was largely linked to the fact that the PBO was housed in the Library of Parliament rather than provided with separate offices. As an officer of the Library of Parliament charged with providing independent analysis, the Parliamentary Budget Officer was subject to administrative levers that effectively curtailed his ability to fully establish his office and carry out his work programme as originally planned. In early 2009, the PBO was informed that he would not receive his planned operating budget. The Joint Standing Committee on the Library of Parliament also initiated an inquiry into the operations of the PBO within the Library of Parliament. Chaired by Liberal senator Sharon Carstairs and Conservative MP Peter Goldring, the Joint Committee heard evidence throughout March and April 2009 and released its report in June 2009. While the Joint Committee called for the PBO's planned budget to be re-established, the recommendations in the report accepted almost all of the arguments made by the Parliamentary Librarian and "instructed the PBO to undertake a number of activities to comply with various human resource and procedural directives" (Jeffrey, 2010). The Joint Committee also asked that the PBO prepare an action plan describing how his offices would comply with the Joint Committee's recommendations. This was duly done but several questions, most critically that of the PBO's budget, remained unresolved for some time.

\section{Relationship with the executive and the legislature}

Although independent of the executive, ${ }^{6}$ the Parliamentary Budget Officer is appointed by the Governor in Council (on the advice of the Prime Minister - see Section VIII for a full description of the appointment process). The PBO holds office "during pleasure", meaning that he or she can be removed at the discretion of the Governor in Council and without cause, although there would likely be political costs attached to such a move. ${ }^{7}$

The parliament is the PBO's main client. While the PBO has an independent mandate, as an officer of the Library of Parliament (rather than a full officer of parliament) with offices located within the parliamentary library, the $\mathrm{PBO}$ is not truly administratively independent. All of the PBO's work is provided to the parliament and the Parliamentary Budget Officer regularly gives evidence before parliamentary committees. The PBO's enabling legislation identifies three parliamentary committees as the PBO's primary clients within the parliament: the Standing Committee on National Finance of the Senate, the Standing Committee on Finance of the House of Commons and the Standing Committee on Public Accounts (PAC) of the House of Commons. Other legislative committees and individual parliamentarians can also request analysis from the $\mathrm{PBO}$. One such example is the Standing Committee on Government Operations and Estimates of the House of Commons, which by virtue of the confluence of mandates (i.e. regarding estimates), has made the committee a regular client of the $\mathrm{PBO}$.

The PBO's work is complementary to that of the Auditor General (AG) and both the PBO and the AG work closely with the PAC, however the PBO's work is distinct in that it focuses on the ex ante part of the budget cycle. The PBO works with external partners with similar expertise, for example in the private sector, universities, think tanks, and "sister" institutions in other countries in both the legislative and executive branches. 


\section{Box 1. Role of the legislature in the budget process}

Canada has a Westminster-based parliamentary system of government with a bicameral parliament comprised of the House of Commons (directly elected for a four-year term subject to an earlier dissolution of parliament) and the Senate (105 appointed members who serve until the age of 75). Constitutionally, the House of Commons enjoys preeminence in budgetary matters.

The legislative budget review and approval process takes place from March through June; the fiscal year starts on 1 April. It should be noted that the Minister of Finance seeks prior advice from parliamentary committees during the budget preparation phase (JuneSeptember) and, following the release of the Budget Consultation Papers covering the economic and fiscal outlook and prospective fiscal and expenditure targets in October, the Minister of Finance begins consultations with the Standing Committee on Finance (FINA) among other stakeholders. Following a series of public hearings held in different locations throughout Canada in October and November, FINA submits a pre-budget report with recommendations in early December. While FINA's recommendations are not binding, they provide an opportunity for parliament to influence the budget.

The Canadian constitution grants the government the exclusive power to initiate expenditure proposals. The parliament is tasked with scrutinising and approving the government's proposed budget - parliament's "power of the purse" means no public monies can be raised or spent without the consent of the House of Commons. In practice however, parliamentarians, expert observers, and citizens believe that the parliament plays this role ineffectively. Several reports commissioned by parliament have explored this issue (1998 and 2003) and, as recently as February 2012, the House of Commons standing committee on government operations and estimates announced that it will study ways to give MPs more control over spending (Good, 2005; Curry, 2012; The Globe and Mail, 2012).

Parliament's amendment powers are limited. It can only amend the budget to decrease the level of funding. It cannot increase funding for items in the government's budgetary proposals or propose new expenditure. The influence of the parliament on the budget is further limited by strong party discipline and the political tradition of the confidence convention: a vote on any "money bill" is considered a vote of confidence in the government. In practice this means the parliament rarely exercises its amendment powers and the government may withdraw certain aspects of its budget framework if majority support for them is not certain (Blöndal, 2001).

In the House of Commons, FINA considers the budget overall while sectoral committees consider individual appropriations in their specific areas. In the Senate, the Standing Committee on National Finance is solely responsible for scrutinising the budget (von Trapp, 2011). Committee meetings are generally open to the public and their reports are published. Committees have the formal power to summons "persons, papers and records" necessary to carry out their scrutiny role and may consult or employ outside experts. The PBO now provides the main technical support available to the parliament as a whole during the budget process; however some additional support may also be available through the Parliamentary Information and Research Service's "estimates cluster" in the parliamentary library, specialised staff in political party secretariats, or an individual member's staff. 


\section{Legal basis for establishment}

The 2006 Federal Accountability Act (FedAA) created the PBO by amending the 1985 Parliament of Canada Act. There is no separate, enabling legislation pertaining to the $\mathrm{PBO}$ as there is, for example, for other officer (or "agent") of parliament positions.

\section{Mandate}

Section 79.2 of the Parliament of Canada Act gives the PBO a broad mandate in legislation to:

a) provide independent analysis to the Senate and to the House of Commons about the state of the nation's finances, the estimates of the government and trends in the national economy;

b) when requested to do so by any of the following committees, undertake research for that committee into the nation's finances and economy:

i) the Standing Committee on National Finance of the Senate or, in the event that there is not a Standing Committee on National Finance, the appropriate committee of the Senate,

ii) the Standing Committee on Finance of the House of Commons or, in the event that there is not a Standing Committee on Finance, the appropriate committee of the House of Commons, or

iii) the Standing Committee on Public Accounts of the House of Commons or, in the event that there is not a Standing Committee on Public Accounts, the appropriate committee of the House of Commons;

c) when requested to do so by a committee of the Senate or of the House of Commons, or a committee of both Houses, that is mandated to consider the estimates of the government, undertake research for that committee into those estimates; and

d) when requested to do so by a member of either House or by a committee of the Senate or of the House of Commons, or a committee of both Houses, estimate the financial cost of any proposal that relates to a matter over which the parliament has jurisdiction.

The mandate does not make reference to specific reports or timings for reports that must be presented during the year; however the reference to the estimates clearly provides some expectations in terms of timing of analysis. Apart from the priority accorded to various committee requests, the mandate allows for the PBO to largely undertake work at its own discretion.

\section{Functions}

The PBO Operational Plan defines three basic types of PBO products and services (committee requests, regular products and independent research) and three basic formats for the office's regular analytical products:

1. fact sheets - short background summaries, up to two pages; a format that so far has not been produced;

2. briefing notes - somewhat more detailed analysis, up to five pages; and

3. independent, in-depth economic and financial analysis reports and research working papers. 
Currently the office of the $\mathrm{PBO}$ provides the parliament with comprehensive analysis of the government's budget proposals. Although the office of the $\mathrm{PBO}$ has no legal obligation to produce forecasts, it has produced two alternative forecasts a year in spring and fall, released just before the government's forecasts. These forecasts take a medium-term (five-year) perspective. The fiscal forecasts are based on the office's own model and assumptions but, unlike the private sector, the office uses the same accounting basis as the government. In terms of economic projections, for the first two years of its existence, the office of the PBO used the average forecasts of its own survey of private sector economists and Finance Canada's survey of private sector economists, but is now making its own economic projections. The office also typically produces a short analysis of the government's forecasts. Since 2010, the office of the PBO has also released a "Fiscal Sustainability Report" (FSR) with long-term projections of up to 75 years. While the scope of the 2010 FSR was limited to the federal government, the 2011 report expanded the analysis to include provincial-territorial governments on a consolidated basis. Previously the government did not produce long-term estimates, but began to do so for the federal government in 2012.

The office of the $\mathrm{PBO}$ also undertakes costings but is selective when doing so given its limited resources. Often the office chooses instead to scrutinise Treasury's costings, putting them through "tests of reasonableness". To date, the office has carried out several highprofile cost assessments on, for example; Canada's mission in Afghanistan, Aboriginal education infrastructure, the "Truth in Sentencing Act", the proposed acquisition of the F-35 Lightening II Joint Strike Fighter and several private members bills.

The office of the PBO can undertake analysis and other projects at its own initiative. In 2011, with a view to enhancing parliamentary oversight throughout the fiscal year, the PBO introduced the Integrated Monitoring Database (IMD). The IMD is a searchable database of budgeted and in-year expenditures listed by vote for each federal department and agency and updated every three months. As such, it attempts to ensure congruence between the estimates and in-year financial reporting. The IMD uses non-confidential government data and is adjusted for supplementary estimates throughout the year to allow parliamentarians to track the increase (or decrease) of authorised expenditures over the course of a fiscal year, as well as compare this evolution to previous years.

As Canada does not currently have fiscal rules, the office of the PBO does not monitor compliance with fiscal rules although nothing would preclude it from doing so if new fiscal rules were adopted. As a non-partisan body, the office does not make normative policy recommendations nor does it have a role in costing election platforms.

\section{Work programme}

Apart from the priority accorded to Finance Committee and PAC requests, the mandate allows for the $\mathrm{PBO}$ to largely set the work programme at his or her own discretion. While the mandate is not specific on timelines for providing analysis, in practice the $\mathrm{PBO}$ typically produces two forecasts a year in spring and fall, just before the government's forecasts and provides analysis of the government's draft budget in time for legislative debate. Given resource limitations, the PBO has set additional priority setting parameters for requests for costings and other analysis in its operational plan ${ }^{8}$ based on "materiality" and "contribution potential". Of these two concepts, materiality is the PBO's primary overriding principle for setting priorities. 
Materiality is defined as a project or request that can reasonably be expected to have a substantive impact on the government's finances, estimates or the Canadian economy. Materiality is relative to total annual programme spending and the size of the economy (PBO, 2008c). Contribution potential is defined as a project or request has the potential to increase budget transparency and/or inform parliamentary and public dialogue towards implementing sound budget policy and financial management by: strengthening fiscal discipline; better allocating the government's resources to priorities; and/or increasing operational efficiency (PBO, 2008c). For requests that meet materiality and contribution potential thresholds, further priority is given to requests supported by a consensus of committee members, followed by requests from individual parliamentarians. The PBO also can and does undertake analysis at its own initiative.

\section{Budget}

The PBO's current operating budget is CAD 2.8 million. It is included in the overall budget for the Library of Parliament, although it does not appear as a separate line item. ${ }^{9}$ The library's budget process is as follows: it submits documentation (business cases including that of the PBO, summary budget and estimate) to the Speakers of the Senate and the House of Commons for their consideration. Once agreed, the library's budget becomes part of the estimates for the parliament. ${ }^{10}$ The estimates are sent to the President of the Treasury Board, who submits them in the House of Commons along with the government's departmental estimates for the fiscal year.

The PBO's budget came under threat early on. The government provided for a budget of CAD 1.8 million to cover office set-up costs with the understanding that the PBO would receive a full operating budget of CAD 2.8 million in its second year (2009-10). The PBO planned based on this understanding. However, in December 2008 the PBO was informed that the office's 2009-10 budget allocation would only be slightly higher than its start-up budget, around CAD 1.9 million. This decision was widely seen by outside observers as an attempt to constrain the office of the $\mathrm{PBO}$ and its work following tensions with the government over critical PBO reports (in particular a report analysing the cost of Canada's military mission in Afghanistan released during the sensitive October 2008 election period). ${ }^{11}$ The $\mathrm{PBO}$ argued that the budget reduction put existing staff commitments at risk and severely limited his office's capacity to fulfil its mandate. Many opposition MPs called for an immediate restoration of the promised funding and the dispute over the PBO's budget was widely reported in the media. The PBO's budget allocation figured prominently in the Joint Committee on the Parliamentary Library's June 2009 report which ultimately recommended an increase to the originally planned for CAD 2.8 million but on the condition that the PBO comply with all of the report's other recommendations. ${ }^{12}$ As noted in Section I, the committee also asked that the PBO prepare an action plan describing how they would comply with these recommendations. The PBO duly did so while pointing out that it would be impossible to comply while operating under the start-up budget.

In July 2009, over 130 economists, including seven current Canada Research chairs, added their support by signing an open letter calling on parliamentarians across parties to ensure that the office of the PBO received adequate funding to carry out its mandate. ${ }^{13}$ However, it wasn't until the start of the 2010-11 fiscal year that the PBO's planned budget of CAD 2.8 million was restored without conditions. This budget, while fairly modest, is commensurate with the office of the PBO's mission, provided that it can continue to set its own workload priorities based on "materiality" and "contribution potential". 


\section{Staffing}

\subsection{Leadership}

Section 97.1(2-3) of the Parliament of Canada Act outlines the appointment process for the Parliamentary Budget Officer. The Parliamentary Librarian forms and chairs a review committee to search for a suitable candidate. The committee identifies a shortlist of three names which are submitted in confidence through the Leader of the Government in the House of Commons to the Governor in Council (GiC). The GiC (acting on the advice of the Prime Minister) selects and appoints the Parliamentary Budget Officer from these three names. The PBO is appointed for a five-year term renewable once ${ }^{14}$ "during pleasure", meaning that he or she can be removed at the discretion of the GiC (essentially at the discretion of the Prime Minister) and without cause. The parliament plays no role in approving the appointment or dismissal.

The legislation is not explicit in terms of potential candidates' qualifications, restrictions on who can be appointed, or exactly how the recruitment process should proceed, although there are precedents for GiC appointments. The position of the $\mathrm{PBO}$ is subject to the Terms and Conditions of Employment for Full-Time Governor in Council Appointees. ${ }^{15}$ This includes specific statutes and guidelines that govern the conduct and actions of GiC appointees while in office, namely: the Conflict of Interest Act, the Ethical Guidelines and Statutory Standards of Conduct and the Guidelines for the Political Activities of Public Office Holders. The PBO's remuneration and expenses are set by the GiC.

After a lengthy appointment process (December 2006 to March $2008^{16}$ ), Kevin Page became Canada's first Parliamentary Budget Officer, bringing nearly 25 years of experience in the executive branch of the Canadian government, most in a fiscal capacity. The first PBO's term ended in March 2013 and he did not seek renewal. ${ }^{17}$ The process to find a successor, which came under criticism as lacking transparency, dragged on for a further five months leading some to speculate as to the future of the office. During this period the new Parliamentary Librarian was asked to serve as interim PBO. The appointment of Canada's second PBO, an economist with 27 years of service in the Library of Parliament, was announced in 30 August 2013.

\subsection{Staff}

Although the PBO's operational plan calls for a staff of 17, in its first few years the office typically maintained 13 to 15 full-time staff, including two administrative support staff. The PBO may also use outside consultants. Until the office received its full operating budget several staff members were seconded from government departments. Despite being located in the Parliamentary Library, in practice the Parliamentary Budget Officer has had full responsibility for hiring and dismissing PBO staff. Conditions of employment are those of the Library of Parliament.

PBO staff hold advanced degrees (MA, MSc, MBA or PhD) and designations (CA, CMA, CFA) in economics, econometrics, accounting, finance and financial analysis with relevant experience either in the public or private sectors, or in academia (Page and Yalkin, 2012). The majority of the staff have significant experience working in the executive branch with Finance, Treasury, the Privy Council or the Bank of Canada. More generally, the office of the PBO seeks individuals that are entrepreneurial and willing and able to innovate in obtaining data, developing and using tools and forming productive partnerships with external resources. (Page and Yalkin, 2012). 


\section{Access to information}

The PBO's right to information necessary to perform its mandate is covered by s. 79.3(1) of the Parliament of Canada Act which states that:

Except as provided by any other Act of Parliament that expressly refers to this subsection, the Parliamentary Budget Officer is entitled, by request made to the deputy head of a department within the meaning of any of paragraphs (a), (a.1) and (d) of the definition "department" in Section 2 of the Financial Administration Act, or to any other person designated by that deputy head for the purpose of this section, to free and timely access to any financial or economic data in the possession of the department that are required for the performance of his or her mandate.

The act provides for several exceptions, including personal information, which is restricted under Section 19 of the Access to Information Act, and information deemed to be a cabinet confidence.

The office of the PBO developed its own information protocol which includes a template for its information requests (all of which are published along with departmental responses), request categories (urgent, normal, or low priority) and a suggested timeline for departments to respond based on those categories ( 24 to 48 hours, five working days and 30 working days respectively). The protocol also lays out actions the PBO will take when denied access to requested information, or when there what is considered an unreasonable delay in providing information. First, the PBO proposes to report the matter to parliament. In cases of deadlock and as a last resort, the PBO reserves the right to seek a legal remedy in the Federal Court of Canada. For cases when access to information is denied because the department deems it to be a cabinet confidence, the PBO may request that the Clerk of the Privy Council certify this position in writing.

The PBO has often reported difficulties getting the information it requires and federal officials have complained that they are overburdened by requests for information (Plecash, 2012). Disagreements over the PBO's right of access to information on savings measures in the 2012 budget led the PBO to file an application with the Federal Court of Canada seeking a judgment clarifying his mandate. While the PBO's reference to the Federal Court of Canada was dismissed on a technicality, the judge's obiter dictum upheld both the right of the $\mathrm{PBO}$ to seek, from the government, the details regarding the CAD 5.2 billion in spending cuts from the 2012 budget and the right to take the government to court for the refusal to release such requested information.

The Judge's obiter dictum also included potential solutions that the PBO could have attempted, noting that complaints could have been made to the Chief Librarian, the two Speakers, the Joint Committee, and perhaps to Parliament as a whole, before taking recourse with the Court. Shortly after he took office on 3 September 2013 the second PBO, Jean-Denis Fréchette, decided to implement a protocol along these lines. On 24 March 2015, the Joint Committee on the Library of Parliament - after being asked by the Speaker of the House of Commons and the Speaker of the Senate to look into the access to information issues faced by the PBO - agreed to the following motion:

It was agreed, - That the Committee direct the Co-Chairs to write to the Speaker of the Senate, the Speaker of the House of Commons, the Parliamentary Librarian of Canada, and the Parliamentary Budget Officer with the following message in response to the letter from the Speakers dated November 25, 2014, concerning a Parliamentary process for the Parliamentary Budget Officer to obtain information: 
The Committee agrees with the assessment that there needs to be a Parliamentary process for obtaining information required to ensure the Parliamentary Budget Officer fulfils the mandate set out in the Parliament of Canada Act. Section 79.2 of that Act establishes the role of providing independent advice to the Senate and the House of Commons, as well as undertaking research for House and Senate Committees.

This Committee believes that in the event the Parliamentary Budget Officer is unable to obtain documents or records with the information required to act on the duty to provide advice to Parliament, the Parliamentary Budget Officer may write to the chairs of the Committees outlined in Section 79.2 of the Act, and ask them to use their considerable powers to send for papers and records. As noted in House of Commons Procedure and Practice, 2nd edition, on page 979, "The House has never set a limit on its power to order the production of papers and records", while noting that there are cases where insisting on production of some documents may not be appropriate, such as items touching on national security and foreign relations.

This Parliamentary recourse will allow the Parliamentary Budget Officer to ensure that Parliamentarians are sufficiently informed of the matters for which the office was created. ${ }^{18}$

This new process has the advantage of helping to ensure full parliamentary ownership of such information requests.

\section{Transparency}

During the PBO's 2008 stakeholder consultation, parliamentarians and others were overwhelmingly supportive of the PBO's proposal to use a "fully transparent, open publishing model" and the PBO committed to having all analysis openly reported to committees and parliamentarians and freely accessible to the public on the PBO's website in the office's operational plan. This is in line with good practice in other countries with similar institutions.

While the PBO's open publishing model is accepted today, initially it created what might best be described as an organisational cultural dissonance with the model of the Parliamentary Library which guarantees the confidentiality of the questions submitted to it by parliamentarians and of the support services it provides to parliamentary committees. During the 2009 Joint Committee inquiry into the operations of the PBO within the Library of Parliament, the PBO's open publishing model was questioned and the Joint Committee made two recommendations: 1) "that a response to a request made by a parliamentarian or a parliamentary committee in accordance with the legislated mandate shall remain confidential, until the confidentiality is lifted by the parliamentarian or the parliamentary committee making the request" (see rec. 6) and 2) that "the Parliamentary Budget Officer [is] not to release any report during a general election" (see rec. 7).

To date, all of the PBO's reports and analysis are published on their website along with data sets and methodologies or models. ${ }^{19}$ Types of publications include: economic and fiscal assessments, reports and briefing notes, committee appearances, presentations, and letters. Regarding the latter, correspondence with government departments and agencies is made available on the website to the extent that it is not classified. In line with the Joint Committee's recommendation, the PBO does not publish communications from parliamentarians or parliamentary committees without permission, nor do they usually publish letters from the public. The $\mathrm{PBO}$ also publishes information requests to government departments, status updates on these information requests, and copies of responses. 
Finally, the PBO publishes contact information for all PBO staff, as well as "proactive disclosures" on staff travel expenses, hospitality expenses, and any contracts over CAD 10000.

The $\mathrm{PBO}$, and more importantly the office's work, have received substantial media coverage from the outset. The first Parliamentary Budget Officer chose to proactively engage with the media, speaking on behalf of the office during press conferences and in interviews. Tensions between the government and the first PBO regularly played out in the media, sometimes devolving into unfortunate personal attacks against the PBO. Although the PBO's staff does not include a press officer or liaison, every effort is made to make the PBO's work relevant and accessible to the media including, for example, trainings for the media on how to understand and use PBO reports and databases.

\section{Governance, advisory support, monitoring and evaluation}

As part of the Library of Parliament, the PBO is subject to oversight by the Speakers of both houses who are assisted by the Joint Standing Committee on the Library of Parliament. The Parliament of Canada Act mandates the Speakers, assisted by the Joint Committee, to direct the day-to-day functioning of the library, and, with the approval of both houses, make orders and regulations to govern how the library is managed and how its budget is spent (see Parliament of Canada Act s. 74(1), Subsection 75(2), and s. 74[2]). The Joint Committee also plays a role in assuring that the library officers and other staff "discharge their official duties faithfully" (s. 78 of the Parliament of Canada Act) and, according to the rules of procedure of both houses undertake studies or inquiries on orders of reference from the two houses.

The PBO regularly collaborates with other institutions (e.g. universities, think tanks, the Canadian Association for Business Economics, the United States Congressional Budget Office (CBO) and the IMF) and has actively sought to have its work peer reviewed for external validation and to ensure the rigour of the methodology and results. For example, the independent peer review panel for the PBO's March 2011 report entitled "An Estimate of the Fiscal Impact of Canada's Proposed Acquisition of the F-35 Lightning II Joint Strike Fighter" included experts from the Strategic and Defence Studies Centre, Australian National University, Queen's University and the United States CBO.

\section{Concluding remarks}

Despite a difficult "birthing process", the limitations inherent in its current legislative framework and its small size, the office of the PBO quickly built a reputation domestically and internationally as a highly credible independent institution whose work has increased budget transparency and enriched the parliamentary and public debate on the public finances. The Economics Department at the OECD noted in their 2010 economic survey of Canada that "the PBO has proved useful at providing an independent, sometimes discordant, opinion on the federal government's fiscal forecasts, which can only improve the transparency and debate around federal fiscal policy" (OECD, 2010). It further recommended that "the federal government should continue to support the Parliamentary Budget Office, and provinces should consider establishing similar independent fiscal agencies that can assess compliance relative to objectives and reinforce accountability" (OECD, 2010). ${ }^{20}$ The IMF concluded that the "PBO has earned a reputation for good quality independent analysis for its research, costings, and forecasting work" (IMF, 2013). 
The office of the PBO faces several tests, one being its first change in leadership. This arguably got off to a rocky start with a much criticised delayed appointment process and the departure during the transition period of one of the two Assistant PBOs. Such departures can be difficult for small fiscal organisations particularly when the pool of available talent is limited in the first place. However, things have quickly stabilised.

It remains to be seen how the office of the $\mathrm{PBO}$ will fare if there is a change to the party in power despite the fact that the opposition parties are generally supportive. The Conservative government which established the office of the PBO (and which has remained in power during the office's short lifetime) is among its fiercest critics. Weak separation of powers in a Westminster-based system like Canada's increases the risk that during majority governments parliamentarians in the majority will be politically reluctant to champion a parliamentary budget office when government is not supportive.

Given past difficulties and future uncertainty, the parliament may wish to take advantage of the upcoming transition period to consider amendments to clarify the PBO's current enabling legislation and enhance the PBO's independence. As has been suggested in several private members bills, ${ }^{21}$ this could be accomplished by changing the PBO's status to that of a full officer of Parliament who serves during good behaviour and by providing the PBO with clear administrative independence including full control over the office's financial and human resources.

\section{Notes}

1. Full title of the FedAA: "An act providing for conflict of interest rules, restrictions on election financing and measures respecting administrative transparency, oversight and accountability." Concurrently the government issued an Action Plan which pledged to seek to: "Ensure truth in budgeting with a Parliamentary Budget Authority by creating the position of a Parliamentary Budget Officer to provide objective analysis to Members of Parliament and parliamentary committees concerning the state of the nation's finances, trends in the national economy, and the financial cost of proposals under consideration by either house." The action plan also pledged to provide quarterly updates to government fiscal forecasts.

2. The first was a "Review of the Forecasting Accuracy and Methods of the Department of Finance" by Ernst \& Young in 1994 and the second was a "Report of the Review of Canadian Federal Fiscal Processes and Systems" by Dr Tim O'Neill in 2005.

3. The United States Congressional Budget Office (CBO) was the main model for the PBO, despite questions as to whether such a model would work in Canada's very different Westminster-based parliamentary system.

4. Similar to the provisions contained in the Auditor General Act.

5. Clear cross-party support was necessary as the government did not have a majority in the House of Commons and could not simply use party discipline to guarantee support in the legislature.

6. It should be noted that Canada's Westminster-based parliamentary system features a high degree of integration between the legislative and executive branches, particularly during the terms of majority governments. Party discipline is strong and when a party enjoys a majority in the parliament, the Prime Minister and the cabinet may effectively control the parliament.

7. The Parliamentary Librarian is also appointed by the Governor in Council and holds office "during pleasure". This is in contrast for example to other officers of parliament, for example, the Auditor General Act (S.3 [1]) states that the Auditor General "holds office during good behaviour" and "may be removed for cause."

8. In the summer of 2008, the PBO undertook a series of stakeholder consultations with senators, members of parliament, key parliamentary committees, retired and current senior bureaucrats, think tanks, academics and peer organisations in other jurisdictions. These consultations contributed to the development of the PBO's first Operational Plan (December 2008) outlining the office of the PBO's operating principles and goals for the first two years of operations and its plan 
and proposed resource allocation to achieve these goals. This framework continues to guide much of the office's work, although some provisions are under review following the Joint Committee's June 2009 report.

9. Other service areas within the Library of Parliament's budget include the office of the Parliamentary Librarian, the Parliamentary Information and Research Service, Information and Document Resource Service, Learning and Access Services, Corporate Services, and the Information Technology Directorate.

10. The parliament's total budget includes the Senate, the House of Commons, the Library, the Office of the Conflict of Interest and Ethics Commissioner, and the Senate Ethics Officer's budgets.

11. At the same time, the Parliamentary Library sought to bring the PBO more strictly under its administrative control.

12. See recommendation 8: www.parl.gc.ca/content/hoc/Committee/402/BILI/Reports/RP3993042/bilirp03/ bilirp03-e.pdf.

13. For a copy of the letter and a list of signatories see http://supporttheopbo.blogspot.com/2009/07/openletter-in-support-of-opbo.html.

14. Not linked to the electoral cycle.

15. See www.pco-bcp.gc.ca.

16. An overview of the first appointment process can be found below:

- December 2006, the Parliamentary Librarian drafted a job description which was sent for approval to the Privy Council Office.

- July 2007, the Privy Council Office classified the PBO position as a GCQ-5, one level below the Parliamentary Librarian (GC-6). It should be noted however that the "Q" indicates a quasijudicial function, an additional level of independence not subject to performance pay.

- January 2007, the Parliamentary Librarian formed a discussion group nominated by the Canadian Association of Former Parliamentarians and representatives of all parties in both Houses, and recruited Allan Darling, a retired official as a senior adviser to help define the skills and experience that candidates should possess.

- August 2007, the Library of Parliament entered into a contract with an executive search firm, Ray and Berndtson, to conduct a national search process for qualified candidates.

- November 2007, the Parliamentary Librarian convened the selection committee required by the Parliament of Canada Act to review eight of the 24 candidates identified during the executive search process. The committee identified an additional six candidates to be approached for the position.

- December 2007, the committee held interviews and chose a short list which the Parliamentary Librarian forwarded to the Government House Leader. However, no candidate was willing to accept the position.

- February 2008, the House and Senate Standing Committees on Finance, concerned about the delays, heard evidence on the appointment process.

- March 2008, Kevin Page, an economist with almost three decades of experience in the federal public service, notably with Finance Canada, the Treasury Board Secretariat and the Privy Council Office, accepted the appointment as Canada's first Parliamentary Budget Officer as a GCQ-6.

17. The position of Parliamentary Librarian was also open and a new Parliamentary Librarian was recruited.

18. www.parl.gc.ca/HousePublications/Publication.aspx?DocId=7918081\&Language=E\&Mode=1\&Parl=41\&Ses=2.

19. Parliamentarians are provided with hard copies upon request.

20. In September 2013, the province of Ontario set up a Financial Accountability Officer (FAO) mandated to provide Ontario's parliamentarians with independent forecasting and fiscal analysis.

21. A private member's bill was again defeated in Parliament in June 2013. 


\section{Bibliography}

Blöndal, J.R. (2001), "Budgeting in Canada”, OECD Journal on Budgeting, Vol. 1, No. 2, OECD, Paris, pp. 39-82.

Beaumier, G.A. (2006), “The Accountability Act and the Parliamentary Budget Officer”, Parliamentary Information and Research Service, Library of Parliament, Parliament of Canada, Ottawa.

CBC News (2009), "Fund Me or Axe Me, Parliamentary Budget Officer Says", 3 November, Canadian Broadcasting Corporation, www.cbc.ca/news/canada/story/2009/11/03/parliamentary-budget-officerkevin-page-funding.html.

Clark, C. Scott and P. DeVries (2010), "A Sad Farewell to the Parliamentary Budget Officer", The Globe and Mail, 14 September, The Globe and Mail, Toronto, www.theglobeandmail.com/globe-debate/a-sadfarewell-to-the-parliamentary-budget-officer/article4325812/.

Curry, B. (2012), "MPs Seek to Bolster their Powers of Public-Spending Oversight", The Globe and Mail, 16 February, The Globe and Mail, Toronto, http://m.theglobeandmail.com/news/politics/ottawanotebook/mps-seek-to-bolster-their-powers-of-public-spending-oversight/article2338539/?service=mobile .

Curristine, T., H. Jason and J. Seiwald (2013), "Case Studies of Fiscal Councils - Functions and Impact", IMF Supplement, July 16, 2013, International Monetary Fund, Washington, www.imf.org/external/np/ pp/eng/2013/071613a.pdf.

Department of Finance Canada (2015), www.fin.gc.ca/fin-eng.asp.

Good, D.A. (2005), "Parliament and Public Money: Players and Police", Canadian Parliamentary Review, Vol. 28, No. 1, Commonwealth Parliamentary Association Canadian Region, Ottawa, pp. 17-21.

Government House Leader (2008), “Government House Leader Announces Appointment of Canada's First Parliamentary Budget Officer", news release, 14 March, Office of the Leader of the House, Ottawa, www.lgc.gc.ca/eng/content/archive-goverment-house-leader-announces-appointment-canadas-firstparliamentary-budget.

House of Commons, Standing Joint Committee on the Library of Parliament (2009), "Report on the Operations of the Parliamentary Budget Officer within the Library of Parliament", Parliament of Canada, Ottawa, www.parl.gc.ca/content/hoc/Committee/402/BILI/Reports/RP3993042/bilirp03/bilirp03-e.pdf.

Globe and Mail (2012), "It's Time for our MPs to Reclaim the Power of the Purse", The Globe and Mail, 17 February, http://m.theglobeandmail.com/news/opinions/editorials/its-time-for-our-mps-to-reclaim-thepower-of-the-purse/article2342750/?service=mobile.

Levy, G. (2008), "A Parliamentary Budget Officer for Canada", Canadian Parliamentary Review, Vol. 31, No. 2, Commonwealth Parliamentary Association Canadian Region, Ottawa, pp. 39-44.

Jeffrey, B. (2010), “The Parliamentary Budget Officer Two Years Later: A Progress Report”, Canadian Parliamentary Review, Vol. 33, No. 4, Commonwealth Parliamentary Association Canadian Region, Ottawa, pp. 37-45.

OECD (2010), OECD Economic Surveys: Canada 2010, OECD, Paris, http://dx.doi.org/10.1787/eco_surveys-can2010-en.

Office of the Parliamentary Budget Officer of Canada (2015), www.parl.gc.ca/pbo-dpb/.

Page, K. (2009), “The Canadian Experience”, presentation at the OECD Parliamentary Budget Officials (PBO) annual meeting, Rome, 26 February.

Page, K. (2010), "Establishing and Operating a Legislative Budget Office: The Canadian Experience 2008-09", presentation at the OECD Parliamentary Budget Officials (PBO) annual meeting, Berne, 12 February.

Page, K. and Tolga R. Yalkin (2013), “Canada: Oversight with Qualified Independence”, in G. Kopits (ed.), Restoring Public Debt Sustainability: The Role of Independent Fiscal Institutions, Oxford University Press, Oxford, pp. 166-188.

Parliament of Canada (2015), www.pbo-dpb.gc.ca.

Parliamentary Budget Officer (2008a), "Stakeholder Consultation Summary", 15 August, Parliament of Canada, Ottawa, www.parl.gc.ca/PBO-DPB/documents/PBO_Stakeholder_Consultations.pdf.

Parliamentary Budget Officer (2008b), "Information Protocol", December, Parliament of Canada, Ottawa, www.parl.gc.ca/PBO-DPB/documents/Information\%20Protocol.pdf.

Parliamentary Budget Officer (2008c), "Operational Plan", December, Parliament of Canada, Ottawa, www.parl.gc.ca/pbo-dpb/documents/Operational_Plan.pdf. 
Plecash, C. (2012), “РBO Page Challenges Finance Department to Deliver on Promise to Release LongTerm Fiscal Report", The Hill Times online, 20 February, www.hilltimes.com/news/news/2012/02/20/ pbo-page-challenges-finance-department-to-deliver-on-promise-to-release-long-term/29659.

Privy Council Office of Canada (2015), www.pco-bcp.gc.ca.

von Trapp, L. (2011), "Committee Structures for Budget Oversight", survey background note for the Parliamentary Budget Officials Network Annual Meeting, OECD, Stockholm, 28-29 April, GOV/PGC/ SBO(2011)6.

\section{Legislation}

Access to Information Act 1985 (Act current to 07/02/2012 and last amended on 16/11/2011).

Federal Accountability Act 2006.

Parliament of Canada Act 1985. 



\section{Denmark}

\section{Economic Council (Økonomiske Råd)}

Established: 1962.

Establishing legislation: Law No. 302 on Economic Co-ordination (Lov om $\varnothing$ konomisk Samordning) of 5 September 1962; Law No. 574 on the Economic Council and the Environmental Economic Council (Lov om Det Økonomiske Råd og Det Miljøøkonomiske Råd), 6 June 2007 (amended by Law No. 167 on 12 June 2012).

Mandate: To monitor economic development, analyse long-term development prospects and contribute to the co-ordination of the various economic interests.

Budget: DKK 27.4 million (2014).

Staff: Four co-chairs and 21 other members; $30-35$ secretariat staff (30 in fulltime equivalent terms). 


\section{Context}

The initial idea behind the creation of the Economic Council in 1962 was to bring together various economic interests in a forum that could be used for wage negotiations and settlements. The council never played an effective role in this regard; but its structure survived and over the years it developed into an independent voice on economic policy.

The law establishing the Economic Council was adopted with the votes of the governing parties, the Social Democrats and the Danish Social Liberal Party. The opposition voted against the legislation, except two members of the Conservative Party who voted in favour. In total, 91 parliamentarians voted in favour, 72 against and 12 abstained. The small centrist Social Liberal Party had proposed the creation of a similar institution in 1957, but at that time the Social Democrats opposed the initiative. The idea to create such a body was fostered by a parliamentary commission on co-ordination (Samordningsudvalget) in 1956. The term "co-ordination" had several meanings: co-ordination between different government agencies (ministries), between the government and the central bank, and unions and employer organisations discussing and co-ordinating cost developments.

Fiscal policy in Denmark is subject to international fiscal rules and domestic political commitments. Denmark has to comply with the 3\% deficit and $60 \%$ - debt limits in the Stability and Growth Pact, and regularly produces the required convergence programmes. It has generally adhered to these rules and has so far only been in breach of the deficit limit once, in July 2010. Periodically since the 1990s, Danish governments have produced medium-term fiscal plans that set out a number of rules and commitments.

Although the impact of the global economic crisis has been less severe than in many other European countries, government policy reflects the need to respond to the crisis. The programme of the government that took office in October 2011 contains four major fiscal commitments: the structural budget balance must be at least zero by 2020 , compliance with the EU recommendation of a structural improvement of the budget balance by $1.5 \%$ over the period 2011-13, a positive sustainability gap as measured by the so-called S2 indicator (European Commission, 2006) and debt levels well below the EU's 60\% limit.

In addition, the coalition government of the Social Democrats, the Danish Social Liberal Party and the Socialist People's Party, which took office in October 2011, introduced statutory and binding multi-annual expenditure ceilings as part of the 2012 Danish Budget Law for the state, municipalities and regions to help ensure increased budgetary discipline. ${ }^{1}$ The Budget Law also states that the structural deficit must not exceed $.05 \%$ of GDP and gives direction on how to correct fiscal policy in case ceilings are breached/higher deficits. The reform also entailed a formal role for the Economic Council in monitoring adherence to the announced ceilings (Sørensen, 2011; Jensen and Davidsen, forthcoming). These ideas go back to proposals published by the previous coalition government of the Liberal Party and the Conservative People's Party in April 2011 and the initiative is expected to have broad political support in the parliament. The proposals have also been endorsed by international organisations (OECD, 2012). Reference was made to the example of the 
Swedish Fiscal Policy Council in the public debate on these proposals and the formal "Remarks" that accompanied the amendment to the law on the Economic Councils.

\section{Relationship with the executive and the legislature}

The Economic Council is an independent body that advises the executive and the legislature. It was under the formal authority of the Ministry of Economic and Business Affairs until 2011, when changes to Danish government ministries gave responsibility to the Ministry of Economic and Internal Affairs (Økonomi og indenrigsministeriet), and now the Ministry of Finance. Its reports are submitted to the government, which has no legal obligation to respond. In practice, there is substantial media interest in the work of the council and its analyses are referred to in the budget documents and political debates. Since its creation in 1962, the council has existed under a number of different governments; its role is well established and it currently faces no existential threat. ${ }^{2}$ It has its own offices, which are separate from those of the Ministry of Finance. The legal framework of the council also provides a formal mechanism that protects its independence. Although the Minister of Finance formally appoints the chairmanship, the incumbent co-chairs nominate the individuals.

The Finance Committee of the parliament traditionally discusses the reports of the council in a two-hour session that is not open to the public. The committee values the council as an independent, politically neutral source of expert advice.

The Economic Council has no formal relationship with other official institutions. However, there are professional interactions with institutions which work in related areas, such as the National Bank of Denmark, Statistics Denmark, researchers at universities and economists at different private institutions and organisations, including those that are members of the Economic Council. There are also several think tanks that analyse economic policy, such as Arbejderbevægelsen Erhvervsråd, Kraka, Concito and Cepos. However, most of these have a particular political stance. At the international level, the secretariat of the Economic Council participates in the Association of European Conjuncture Institutes (AIECE), which consists of about 40 forecasting institutions in 20 countries.

\section{Box 1. Role of the legislature in the budget process}

Denmark has a parliamentary system of government and a unicameral parliament, the Folketing, with 179 members. Of these, 175 members are elected in Denmark, two in the Faroe Islands and two in Greenland. There are no constitutional restrictions on the Folketing's authority to modify the budget, and several hundred amendments are typically proposed. In aggregate, however, the impact of any changes is modest. The budget is typically presented in the parliament at the end of August, more than four months ahead of the beginning of the new fiscal year. It is immediately referred to a 17-member crossparty Finance Committee, which holds a two-day technical review of the proposals in early September. Members of the committee are assigned different parts of the budget and formulate questions, which are put to the relevant ministers in a series of short hearings. The first reading allows the Minister of Finance to explain the budget and the different political parties to outline their views. This is followed by elaborate and less public political negotiations. The second reading of the budget takes place in the beginning of November, but this is a perfunctory event. At this time, the Finance Committee publishes a report clarifying any technical aspects of the budget and listing all significant changes between 


\section{Box 1. Role of the legislature in the budget process (cont.)}

this budget proposal and the budget currently in effect. Sectoral committees have no formal role in the process, but some conduct hearings on relevant parts of the budget and exert informal influence. Committee meetings are held behind closed doors unless a committee decides otherwise. All changes to the budget are approved in the third reading in December. The 2012 Budget Law gave the parliament a new role in establishing spending ceilings on an annual basis.

The Finance Committee is also actively involved in approving about 200 in-year adjustments each year, often to move money between different items. A small team of researchers - currently one economist and two students - support budget-related discussions. Moreover, the Danish National Audit Office, or Rigsrevisionen, is an organisation under the Folketing with 270 staff. The Danish Auditor General assists the Public Accounts Committee in its review of the accounts and carries out examinations at its request.

\section{Legal basis for establishment}

The legal origin of the Economic Council was Law No. 302 on Economic Co-ordination (Lov om Økonomisk Samordning) of 5 September 1962. The legal framework was then updated by Law No. 574 on the Economic Council and the Environmental Economic Council (Lov om Det Økonomiske Råd og Det Miljøøkonomiske Råd) of 6 June 2007. This reform created the Environmental Economic Council and integrated it into the structure of the Economic Council. Formally, the new structure is known as The Economic Councils (De Økonomiske Råd), which is made up of the Economic Council and the Environmental Economic Council. In the following text, the singular "council" refers to the Economic Council, whereas the two bodies collectively are referred to as the "councils". The main focus in the context of this publication is the work of the Economic Council.

The law governing the Economic Council was amended by Law No. 167 in 2012 in part to address increased demands for fiscal discipline post-crisis and to ensure that Denmark implemented its obligations under the European fiscal compact (although Denmark is not a member of the Euro zone). These changes came into force on 1 January 2014.

\section{Mandate}

The 2007 law provided a broad mandate for the Economic Council. Its mission is to monitor economic development, analyse long-term development prospects and contribute to the co-ordination of the various economic interests (Article 1). The mandate of the Environmental Economic Council is to analyse the interaction between economic performance and the environment and assess the effectiveness of environmental policies (Article 1a). The 2007 law does not spell out any more specific tasks or specific deadlines for any reports. It does require the Economic Council to meet at least twice a year, while the Environmental Economic Council has to meet at least once a year. Effectively, this leaves ample scope for the Economic Council to determine its work programme and to choose its priorities. The Council's mandate also imposes no particular limits with regard to the institutional coverage of its work; it is not restricted to central government.

The 2012 law further expanded the Economic Council's mandate to include an annual assessment of: the sustainability of public finances and medium-term development of the structural balance, whether expenditure ceilings are aligned with fiscal objectives and 
whether expenditure ceilings have been respected in terms of planning ex ante and when financial statements are available ex post.

\section{Functions}

Perhaps the central role of the Economic Council has been the production of independent short-term and medium-term macroeconomic forecasts, although these have no formal role in the budget process. It is well known for the development of the Simulation Model of the Economic Council, or SMEC (Andersen, 1991), which it uses for its macroeconomic forecasts. SMEC is one of the main macroeconomic models in use in Denmark, although the Ministry of Finance has used other models (Andersen and Madsen, 1992). The council also uses several other models, for example a microeconomic simulation model that allows it to study the effect of tax changes on labour supply.

Further tasks carried out by the Economic Council include analyses of the current fiscal stance, long-run fiscal sustainability and trends in income distribution. It also makes recommendations on short-term fiscal stabilisation policy as well as structural policy questions with an emphasis on labour market policy, tax policy and pension reform (Sørensen, 2011). More recent is the work of the Environmental Economic Council, which includes analyses of the economic consequences associated with reaching given energy targets, the environment or climate policy objectives. Reports are based on rigorous quantitative analysis in combination with narrative information.

The Economic Council does not play a role in evaluating or costing the fiscal component of the election platforms of political parties, nor does it cost individual pieces of legislation for the legislature or the executive. However, its work on the budget and fiscal policy has expanded in recent years. For example, the spring 2010 report of the Economic Council contained a special focus on long-term developments in public finances and the council has continued to do this in every spring report since. ${ }^{3}$ The council assessed the development of the budget deficit to be worse than in the convergence programme of the government. It urged spending restraint in order to contain public consumption relative to the size of the economy. The introduction of statutory and binding multiannual expenditure ceilings has led to a further expansion of its public finance work and, for the first time, the Economic Council has a formal role in fiscal surveillance. A new division in the secretariat was created to focus on the analysis of public finances; the head of this new division commenced work in March 2012.

The council can and does make normative policy recommendations, which can have an influence on public debate. These recommendations are grounded in objective and technically competent analyses of relevant issues. According to Sørensen (2011), the council has over the years produced several policy recommendations that were rejected at first but ended up being implemented later on. For instance, it first recommended labour market reform in 1988, but actual changes occurred only from 1994 and more recently in 2010. It also recommended the introduction of an earned-income tax credit in 1998, which was implemented in 2004. It repeatedly advocated retirement reform since the mid-1990s, which followed in 1998, 2006 and 2012.

\section{Work programme}

Paragraph 3 of the 2007 law requires that the Economic Council meets at least twice a year to discuss a report prepared by the co-chairs. The Environmental Economic Council is 
required to meet at least once a year. A meeting takes place at the request of the four co-chairs or a minimum of three other members. The council, specifically the co-chairs, have substantial discretion in determining the work programme and the focus of particular inquiries. Draft reports are circulated to council members in the form of a discussion document that is confidential until a formal meeting. Members' comments are included with the final report, but the report itself does not change even if some of them disagree with certain aspects.

The Economic Council publishes a report entitled "Danish Economy" (Dansk Økonomi) twice a year, in spring (May or June) and the autumn (traditionally October or November, however it will likely be October from now on so that the report can be used in the negotiations on the budget). These reports assess international economic developments and the outlook for the domestic economy. Each report also covers certain special topics. In recent years, these have covered a wide variety of subjects, such as the distribution of income, early retirement and the retirement age, tax evasion, productivity, and the longterm evolution of public finances. The Ministry of Finance has responsibility for the preparation of the economic assumptions for the budget. However, the scrutiny of the budget by Parliament's Finance Committee entails a review of the economic assumptions and a comparison against forecasts produced by other institutions such as the Economic Council and the National Bank of Denmark (Blöndal and Ruffner, 2004).

\section{Budget}

The secretariat of the Economic Council is financed mainly through the national budget. To a limited extent, it can supplement its appropriation with research grants from external sources. The allocation for the Economic Council has been part of the budget of the Ministry of Economic and Business Affairs, the Ministry of Economic and Internal Affairs, and now the Ministry of Finance, and is decided during the regular annual budget process. The Economic Council has its own sub account within the Ministerial budget. In 2014, the budget was DKK 27.4 million with actual operating expenditures of DKK 26.8 million. In its 2010 annual report, the council reported a budget of DKK 24.9 million and actual operating expenditures of DKK 23.5 million. The respective budgets for 2008 and 2009 were DKK 24.2 million and 25.2 million and actual spending totalled DKK 22.8 million (2008) and 22.9 million (2009). During these years, externally generated income never exceeded two per cent of total operating income. The Economic Council does not receive multi-annual funding commitments.

In general, funding has been commensurate with the tasks of the council, and it has also not been threatened with budget cuts. In fact, there have been occasions where it was exempted from general cuts in the central government budget. The relatively benign treatment of the council's budget is reflected in the steady rise of the number of staff employed at its secretariat. This has grown from 5.5 in 1963, to 10 in 1972, 12 in 1987, approximately 15 in 1995 and about 30 full-time equivalent staff in 2007. In anticipation of the council's new role in fiscal surveillance, it was granted an increase in funding of DKK 4 million in 2012 and onwards. The explicit role as a "fiscal watchdog" is only new in a formal sense as the council has for many years assessed fiscal policy both in terms of stabilisation as well as long-term sustainability. However, an explicit mandate in fiscal surveillance requires it to devote further resources to this topic, which is reflected in this increase. 


\section{Staffing}

\subsection{Leadership}

The Economic Council and the Economic Environmental Council are presided over by a common "chairmanship" consisting of four co-chairs who are academic economists - the so-called "wise men". Formally, the Minister of Finance appoints the co-chairs for a period of up to six years, which is longer than the four-year electoral term of the government. In practice, the government always appoints the persons nominated by the incumbent cochairs, following an informal tradition that has not been broken in at least 25 years. One of the co-chairs acts as head chair. The position does not carry any additional formal powers, but this individual acts as the primary spokesperson. This does not preclude any of the other co-chairs from also interacting with the media. It should be noted that reports and recommendations therein are the responsibility of the chairmanship; other members might agree or disagree.

The law does not rule out multiple terms and in practice some members have been appointed as members or co-chairs several times. The minister cannot dismiss a co-chair prior to the expiry of their term of office. An individual appointed as co-chair cannot hold a seat in parliament. In practice, they must also be independent of interest groups. In principle, the appointment of non-nationals is a possibility. In practice, this would also require knowledge of the Danish economic and institutional context, and foreign appointments are rare. In fact, this possibility has only been used once, when it proved important for accessing relevant expertise in environmental economics. Of four incumbents, three are Danish nationals and one is Norwegian. All of them are men. They have full-time jobs as professors in economics and exercise their function as co-chairs on a part time basis.

In addition to the four co-chairs, the Economic Council can have up to 22 other members appointed by the Minister of Finance for up to three years. One of these represents the minister, who also appoints up to three further members, one each of these upon the recommendation of the Research Council, a research funding body, and the Rectors' Conference of Danish universities. Of the remaining 18 members, one each is nominated by: the Minister for Business and Growth, the National Bank, the Employers Confederation, the Confederation of Commercial Transportation and Service Industries, the Construction Association, the Confederation of Professional Associations, the Employees Association, the Economic Council of the Labour Movement, the Confederation of Danish Industries, the Crafts Council, the Agricultural Council, the Danish Chamber of Commerce, the Consumer Council, the Bankers Association and local government. The Confederation of Trade Unions nominates the remaining three members. There is currently a discrepancy between the total of 22 ordinary members provided for in the law and the actual total of 21 . This is due to the merger, in 2008, of two of the nominating organisations: the Confederation of Commercial Transportation and Service Industries and the Confederation of Danish Industries. Similarly, the Economic Environmental Council has 20 other members to represent various interests relevant to environmental affairs. In practice, the leaders or high-ranking officials of the relevant nominating organisations attend full meetings of the Economic Council or the Economic Environmental Council.

All of the co-chairs are remunerated. The head chair receives a remuneration of around DKR 300 000, while the other co-chairs receive around DKR 200000 . None of the other members of the Economic Council or the Environmental Economic Council receive remuneration. 


\subsection{Staff}

Paragraph 4 of the 2007 law requires a secretariat to support the work of the Economic Council and the Environmental Economic Council by conducting research and drafting documents. The current organisation of the secretariat reflects four main areas of analyses: macroeconomics, public finances, structural economics and environmental economics. The secretariat employs mainly professional economists, plus several administrators and a number of students. It has an overall staff total of about 30 to 35 (30 in full-time equivalent terms). It is not uncommon for staff to move from the Ministry of Finance to the Council, or vice versa, but not as secondments. Based upon a recommendation of the co-chairs, the Minister of Finance appoints a director who has operational responsibility for the management of the secretariat and its staff. This individual may not be a member of parliament and has to be independent of the different interest groups that are represented on the council. In practice, the incumbent is typically a professional economist. The current director (2012) worked in the secretariat of the Economic Council for about a decade and a half before his appointment to the position.

The staff members of the secretariat are paid according to standard collective agreements between the central government and the relevant unions. These agreements leave ample room for individual wage elements as well as different policies regarding promotions. Overall, wages are comparable with other public institutions. The secretariat does not make temporary appointments, but it does employ outside consultants for specific purposes, for example, for setting up and using an energy model, for building a model on traffic and congestion and for the analysis of biodiversity. On a regular basis, the secretariat uses the DREAM model, which is designed to analyse fiscal sustainability and other long-term demographic issues. The use of this model is very specialised and is "bundled" with consultant-like services. Total expenditure on consultants can vary greatly between years, but on average it is around DKR 500000 annually.

\section{Access to information}

The Councils have access to all publicly accessible economic data and government information. In practice, relevant government bodies such as the Ministry of Finance or the National Bank of Denmark are usually very willing to provide any information that may be required. There are no specific statutory guarantees or memoranda of understanding, nor specific restrictions, and the Councils have not been threatened with limits on access to information by the government. At present, there is no explicit agreement on the exchange of information relating to the Economic Council's new role as a fiscal watchdog. However there is a clear understanding that the secretariat should have access to the relevant information and data in order to fulfil the new task.

\section{Transparency}

All of the reports of the Economic Council are published in electronic form and in hard copy. The official website contains a complete archive of its reports going back to 1962, the first year of its existence. An English summary has been included with the reports since 1982. The website also contains descriptions of several economic models that are used by the council, including links to working papers that contain a description. The release of a report is accompanied by a news conference. The council publishes various supplementary materials on the website, including the submissions it received from its members, as well 
as background notes and data. In addition, members of the council and the secretariat publish a number of opinion pieces and academic contributions each year; the website contains an archive of these contributions. The co-chairs of the Economic Council also frequently comment on economic developments and policy in their personal capacities.

\section{Governance, advisory support, monitoring and evaluation}

The governance of the councils relies on the guidance of the four "wise men". This arrangement helps to create a buffer between the interest groups represented by the other members, as the co-chairs have overall responsibility for giving direction to the work and any recommendations. There is no formal process of peer review for reports. However, the projections of the Economic Council are regularly compared to those of other institutions, which creates a degree of peer pressure and competition. Moreover, the co-chairs have an incentive to ensure that the councils produce high-quality work, as substandard reports would damage their academic credentials and reputation.

\section{Concluding remarks}

The Economic Council has an institutional history of half a century, which involved a considerable evolution of its role towards becoming an economic policy watchdog. Its structure reflects an organic process and is difficult to replicate outside its particular context. Over the past decades, the council has on several occasions brought policy options into public discussions that have contributed, sometimes with considerable time lags, to actual reforms. The work of the council is widely respected as technically competent and politically neutral. Since the council has no formal powers over economic policy, its influence depends on the quality of its analysis and the independence of its chairmanship.

In recent years, the council developed into an "implicit fiscal council" (Andersen, 2010); the 2012 legislation made this explicit giving the council a formal mandate to assess fiscal policy in relation to a set of expenditure ceilings. The fact that the council is envisaged to play a key role in fiscal surveillance is evidence of its achievements. On the other hand, such a new role also has potential risks, as it brings the council much closer to political debates. A key challenge for the council will be to maintain its hard-earned reputation for political neutrality.

\section{Notes}

1. Up until three years ago, the Danish state budget was in a surplus for many years. However, local governments - which account for considerably more than half of public spending - have, as a whole, had difficulty keeping expenditures within the limits agreed with the central government.

2. The first decade of the council's existence was somewhat more turbulent. On several occasions, members of the council were upset with the chairmanship's analysis and recommendations. In the winter of 1972/73 there were discussions in the parliament and the Fiscal Affairs Committee whether the council should be dissolved. Then Minister of Economic Affairs Per Hækkerup argued in favour of dissolution, but there were no formal legislative proposals to do so.

3. This topic was also analysed several times prior to 2010.

\section{Bibliography}

Andersen, T.M. (2010), "Danish Economic Council”, presentation at the Swedish Fiscal Policy Council's Conference on Fiscal Policy Institutions, 18 November, Stockholm. 
Andersen, K.V. and P.K. Madsen (1992), "Expelled from the Garden of Eden: The Politics of Economic Modeling in Denmark", Informatization and the Public Sector, Vol. 2, No. 3, IOS Press, Amsterdam, pp. 233-58.

Andersen, E. (1991), "Danish Experience with Macroeconometric Models", Scandinavian Journal of Economics, Vol. 93, No. 2, Wiley-Blackwell, Hoboken, pp. 315-322.

Blöndal, J.R. and M. Ruffner (2004), "Budgeting in Denmark", OECD Journal on Budgeting, Vol. 4, No. 1, pp. 49-79.

Bohlbro, P. and N. Hoffmeyer (2013), "The Danish Budget Law", presentation prepared for the Meeting of OECD Parliamentary Budget Officials, Ottawa, www.pbo-dpb.gc.ca/files/files/D1-AM\%20-\%20Round table\%20-\%20Peter\%20Bohlbro\%20-\%20DEN_EN.pdf.

Danish Parliament (2015), www.thedanishparliament.dk.

European Commission (2006), “The Long-term Sustainability of Public Finances in the European Union", European Economy, Vol. 2006, No. 4, European Commission, Brussels.

Jensen, L. and S. Davidsen (forthcoming), "The Global Financial Crisis in Denmark and Sweden: A Case of 'Crisis Management Lite'”, in J. Wanna et al. (eds.), The Global Financial Crisis and the Impact on Government Budgets and Debt: Responses, Reforms and Resilience in OECD Countries, Edward Elgar, Gloucestershire.

Organisation for Economic Co-operation and Development (2012), OECD Economic Surveys: Denmark 2012, OECD, Paris.

Økonomiske Råd (2011), Årsrapport 2010, Økonomiske Råd, Copenhagen.

$\varnothing$ konomiske Råd (various editions), Dansk Økonomi, Økonomiske Råd, Copenhagen.

Sørensen, P.B. (2011), “Independent Fiscal Watchdogs: Rationale and Danish Experience”, Presentation at the Joint Conference on Controlling Public Spending in Advanced Economies organised by the IMF Fiscal Affairs Department and the Italian Ministry of Economy and Finance, 14-15 November, Rome.

The Economic Councils of Denmark (De Økonomiske Råd) (2015), www.dors.dk.

\section{Legislation}

Law No. 302 on Economic Co-ordination (Lov om Økonomisk Samordning), 5 September 1962.

Law No. 574 on the Economic Council and the Environmental Economic Council (Lov om Det Økonomiske Råd og Det Miljøøkonomiske Råd), 6 June 2007.

Law No. 167 on Amending the Law on the Economic Council and the Environmental Economic Council (Lov om ændring af lov om Det Økonomiske Råd og Det Miljøøkonomiske Råd), 12 June 2012. 


\section{Finland}

\section{National Audit Office of Finland - Fiscal Policy Evaluation}

Established: Independent monitoring and evaluation of fiscal policy function established as of January 2013.

Enabling legislation: Constitution of Finland (1999), Act on the National Audit Office of Finland (2000, amended 2012), Act on the Implementation and Application of the Provisions of the Treaty on Stability, Co-ordination and Governance in the Economic and Monetary Union and on the Requirements of the Frameworks of Public Finances (2012).

Mandate: To monitor compliance with the Fiscal Policy Act (869/2012) and its provisions, including setting and compliance with the fiscal policy rules, the quality of macro-economic forecasts, and the adequacy and effectiveness of corrective fiscal policy measures in case of correction mechanism.

Budget: EUR 0.7 million (2015).

Staff: Four assigned to the IFI function (2015). 


\section{Context}

As a member state of the European Union and the euro area, Finland is bound by the fiscal rules set in the European Stability and Growth Pact and the Fiscal Compact, including the medium-term objectives established in the stability programmes. Finland has also a system of national fiscal rules in place: an expenditure rule which sets a cap for central government spending for the electoral period ${ }^{1}$ which has been complemented by balanced budget and deficit targets. ${ }^{2}$ Both European commitments and the national fiscal rules informed the debate on establishing an independent fiscal institution (IFI).

The tasks of independent monitoring and evaluation of fiscal policy, and oversight of fiscal policy rules and the automatic correction mechanism were assigned to the National Audit Office of Finland (NAOF) ${ }^{3}$ as part of Finland's implementation of the new EU requirements. In this regard, Finland sought to meet its obligations and to ensure longterm sustainability of public finances and credibility of fiscal policy. A key issue raised by the parliament was the quality of the European Commission's economic forecasting and analyses. The parliament's Finance Committee was concerned about the significant uncertainty associated with estimates of the structural balance, in particular that the estimation method used by the European Commission may not properly take into account the unique features of the Finnish economy. The Finance Committee requested that the NAOF assess the structural balance using the European methodology and to assure the quality of the European Commission calculations. In addition the Finance Committee emphasised the need to have an open dialogue with the European Commission in order to confirm that the commission's methodology provides an unbiased assessment of the structural features of the Finnish economy. It was in this context that the Finance Committee indicated that a fiscal council appointed by the government would be useful (Finance Committee Report VaVM 38/2012). ${ }^{4}$

Although the legislation establishing the NAOF as the Finnish independent fiscal institution was passed in the context of Finland's European commitments, the mandate of the NAOF to provide independent monitoring and evaluation of fiscal policy also grew out of the need to monitor national fiscal rules and to improve accountability and increase the credibility of fiscal policy. Finland has had a system of national fiscal rules in place since the early 1990s, the most significant of which are the "spending limits" (expenditure rule). The spending limit system was reformed in 2003 following the 2002 OECD review of budgeting in Finland. In 2006, the Ministry of Finance appointed an expert working group to explore further reforms. Referring to the experience of the Swedish National Institute for Economic Research, the Danish Economic Councils and the Belgian High Council of Finance, the working group recommended the independent external evaluation of the implementation of the spending limits. External monitoring was deemed desirable provided it was backed by solid expertise in macroeconomics, the budget and public finances. Without such expertise, the working group feared that a system of external monitoring could lead to erroneous statements, which would cause "confusion, unfounded 
mistrust in the functioning of the spending limits system". ${ }^{5}$ The Ministry of Finance considered the NAOF had sufficient knowledge and expertise to carry out this external monitoring role (Ministry of Finance, 2007).

The NAOF launched an ongoing annual audit programme which audits compliance with the expenditure ceilings, as well as the accuracy of the information on the governmental fiscal policy. Since 2008, the results of these audits are presented to the parliament each spring. The NAOF also developed broader "effectiveness audits" with a macroeconomic orientation and, in early 2011, launched "fiscal policy audits". Also in early 2011, the NAOF presented a first "electoral period report" on the effectiveness of the expenditure ceilings as a fiscal policy governance tool. Electoral period reports aim to provide an external assessment of the government's fiscal policy before parliamentary elections, thus implementing OECD recommendations on budget transparency. The parliament has welcomed this new approach.

Finally, the establishment of an IFI has entered the debate in part due to feedback from international organisations. The 2010 and 2012 OECD economic surveys in particular recommended establishing an IFI to reinforce a long-term perspective in fiscal policy. Finland has historically fairly low or manageable levels of government debt compared to many other European countries. But debt surged during a serious recession in the early 1990s and in 2009 the Finnish economy took a serious hit from the external shock following the financial crisis (with GDP reduced by 8\%). A key medium-term and long-term issue for public finances is a clear sustainability gap following mainly from the comparatively rapid ageing of the population. Productivity and efficiency in the public sector are also important issues given the large size of Finland's public sector. ${ }^{6}$

There is broad support in parliament for independent monitoring of fiscal policy and that part of the legislation was adopted unanimously. The act itself was controversial, however, due to fundamental disagreements over the nature and merits of the European Fiscal Compact, with one major opposition party coming out against the ratification of the Fiscal Compact. The NAOF is under the constitutional authority of the parliament. However, an alternative arrangement was proposed in debates: that a fiscal council, comprised mainly of academics, be established under statutory authority of the government with tasks such as providing policy recommendations and costings of electoral platforms. This proposal was widely discussed in academic circles and in economic periodicals and culminated in a group of leading economists presenting a proposal to the Ministry of Finance for such a fiscal council with a broad mandate.

The NAOF has also called upon the government to establish a fiscal council in several fiscal policy audit and evaluation reports and opinions (see, for example, the NAOF Special Report to the parliament on the effectiveness of spending limits, K 21/2010). Ultimately, Finland decided to separate independent monitoring and assessment functions from broader and more academic ex ante policy recommendations (or policy advice) to Government. Independent monitoring and evaluation is assigned to the NAOF under the statutory authority of the legislature, while the Economic Policy Council has a mandate to give ex ante policy advice. The government appointed the first Economic Policy Council, comprised of academics, in spring 2014 for a five year term. The council's first report was published in January 2015. The NAOF co-operates and co-ordinates its work with the Economic Policy Council in order to avoid duplication. 
In November 2014 the NAOF reorganised its work on fiscal policy evaluation and monitoring. The IFI function - "Fiscal Policy Evaluation" - was separated from the audit departments in order to clarify and strengthen it in accordance with international best practices and to give a distinct identity to its role and products. It is an independent function in the National Audit Office of Finland headed by the Executive Director for Fiscal Policy Evaluation.

\section{Relationship with the executive and the legislature}

The NAOF is an independent institution under constitutional authority of the parliament. It is part of the legislative and supervisory powers of the parliament but has functional independence. Section 90(2) of the constitution guarantees the independence of the NAOF and the act on the NAOF provides further protections regarding the independence of the function of the Auditor General (head of the NAOF). ${ }^{7}$

The NAOF presents an Annual Parliamentary Report to the parliament at the same time that the government presents its budget proposal. The legislation governing fiscal policy monitoring seeks to ensure that the NAOF forwards all reports on the structural balance and all opinions on the adequacy and sufficiency of government measures to parliament. The NAOF may also present Special Parliamentary Reports to the parliament at its own discretion. The parliament has a statutory right of access to all work carried out by the NAOF as necessary for its oversight functions. The NAOF regularly provides evidence and expert opinions to parliamentary committees.

Parliament's Audit Committee scrutinises the financial statements and management reports of the NAOF and prepares a report on them for the plenary. Parliament's Audit Committee also provides the plenary with an assessment of the Annual Parliamentary Report and other work of the NAOF. The NAOF special Reports on Fiscal Policy Evaluation (the Annual Fiscal Policy Evaluation Report and the Electoral Period Reports which present the mid-term review and end of the electoral period review) are also discussed by the Parliament's Finance Committee which gives an opinion on them to the Audit Committee. According to the constitution, the parliament may steer or instruct the NAOF only by a general act of the parliament that respects the criterion for independence set in the constitution and other constitutional laws.

The government is required to respond publicly to NAOF reports and recommendations and does so in practice. In addition, the government responds to observations or recommendations made by the parliament on the basis of NAOF Parliamentary Reports.

As noted above, the NAOF co-operates and co-ordinates its work with the Economic Policy Council. In addition, the council will be subject to audit, oversight and evaluation by the NAOF. Finland has several private economic research institutes which prepare economic forecasts. Some, along with the Bank of Finland, provide sustainability analyses and all provide some level of policy advice on, and monitor the effects of, economic and fiscal policies. 


\section{Box 1. Role of the legislature in the budget process}

Finland has a parliamentary system of government with a unicameral parliament known as the Eduskunta. The government's budget proposal is presented in September and approved before 25 December. Parliament can amend the budget proposal as it sees fit; however, revenue based on acts of Parliament may only be amended by legislative amendments. The parliament uses its amendment powers in practice, each year making changes that signal politically important topics; but overall the amount of these changes is only around $0.1 \%$ of the total budget (for example, EUR 50.1 million compared to the budget total of EUR 54 billion). While the vote on the budget is not considered a confidence vote, significant rejection of the overall economic policy line of the government would in practice be a vote of confidence.

The budget details and taxation legislation are referred to the Finance Committee for action, but the implementing legislation is referred to the respective sectoral committees. The budget is adopted in a single reading by the parliament and the vote is based on a report prepared by the Finance Committee. Committee hearings on the budget typically call on several hundred experts, including ministers, senior public servants, representatives from trade unions and civil society, experts and local government officials. A small team in the Research Services office provides some analytical support on economic and budgetary questions.

\section{Legal basis for establishment}

The National Audit Office of Finland is established by Section 90(2) of the Constitution of Finland and its access to information is provided in Section 90(3) of the constitution. Monitoring of fiscal rules is partly based on this general external audit and evaluation mandate and partly on the specific new role assigned in the Act on the National Audit Office of Finland (14.7.2000/636, amended by Act 21.12.2012/870) and the Act on the Implementation and Application of the Provisions of the Treaty on Stability, Co-ordination and Governance in the Economic and Monetary Union and on the Requirements of the Frameworks of Public Finances (21.12.2012/869), the Fiscal Policy Act of 2012.

The NAOF establishes its own rules of procedure (by decree issued by the Auditor General) and working methods in accordance with the constitutional independence provided in Section 90.

\section{Mandate}

The parts of the NAOF mandate linked to its function as an IFI are: independent monitoring and evaluation of fiscal policy, oversight of fiscal policy rules, and the audit and the evaluation of the information basis for, and effectiveness and governance of, fiscal policy including the quality of official macro-economic forecasts and sustainability of public finances.

While the mandate is expressed in broad terms in the Constitution, it is clearly defined in Section 5 of the act to implement the EMU requirements which specifies monitoring and evaluation of adherence to the fiscal rules and obligations under the fiscal compact. In addition, the legislation specifies that the NAOF shall, in the case of exceptional circumstances referred to in the Fiscal Compact, assess in a public opinion whether the policy measures taken by the government to improve the structural balance of the general government are adequate and sufficient. 
The broad Constitutional mandate allows NAOF Fiscal Policy Evaluation to study the appropriateness and relevance of the European Union fiscal policy rules to the long term needs of Finland's national economy and the sustainability of public finances. This is included in the NAOF Fiscal Policy Evaluation work programme.

Monitoring includes:

- oversight of the setting of the fiscal rules required by the Fiscal Compact and the Budgetary Frameworks Directive 2011/85/EU;

- assessment of the quality of the macro-economic forecasts;

- assessment of whether the government has fulfilled its obligations to propose and take measures to improve structural balance; and

- assessment of whether fiscal policy is exercised in accordance with medium-term objectives.

An automatic correction mechanism is triggered in the event of significant observed deviations from the medium-term objective or the adjustment path towards it. The NAOF has several obligations related to this process, in particular to evaluate if the actions taken by the government are sufficient to correct the observed imbalance in the public finances.

Institutional coverage includes the whole general government, including state finances, the central bank and state transfers to actors in other sectors of the economy. It does not cover the resources of local government or the social security funds. Extra-budgetary funds, state-owned enterprises and decentralised agencies are within the audit mandate.

The legislation leaves the timing of reporting mainly to the discretion of the NAOF, apart from the Annual Parliamentary Report in autumn.

\section{Functions}

The main functions of NAOF fiscal policy evaluation are:

- Evaluating, from a macroeconomic and governance perspective, the quality and reliability or accuracy of information used to prepare and take decisions on fiscal policy (including tax policy), and the quality and accuracy of reporting on the implementation and results of fiscal policy. This includes potential risks to meeting fiscal policy objectives, whether fiscal policy was effective in achieving stated policy objectives, the sustainability of public finances and economic stability in the long-term, and the specific objectives established by the parliament and the government;

- Evaluating adherence to, and the effectiveness of, fiscal policy rules in terms of macroeconomic stability and the sustainability of public finances;

- Policy analyses, opinions and assessments related to fiscal policy;

Fiscal policy evaluation is subject to NAOF methodological guidelines for independent multi-disciplinary evaluations. Assessments generally combine both qualitative and quantitative analyses, as well as risk assessments where possible.

NAOF fiscal policy audits, which support the work done at NAOF Fiscal Policy Evaluation, look at the volume and trends of government spending and revenue in relation to the spending limits. They draw on statistics and other relevant information. In addition, the NAOF assesses the monitoring by the Ministry of Finance and compares the results. In assessing the structural balance, the NAOF evaluates Ministry of Finance estimates and then prepares its own independent analysis of the long-term structural balance. 
The sustainability of public finances is an ongoing audit and evaluation question. The NAOF provides qualitative analysis of Ministry of Finance sustainability analyses, as well as the ministry's policy scenarios, assumptions and application of the assumptions. NAOF analysis is benchmarked against sustainability analyses performed by other actors and expert opinions in the literature.

In addition, the NAOF undertakes alternative sustainability analyses in co-operation with an independent economic research institute. These analyses test different assumptions and policies using a dynamic general equilibrium model that includes actual health statistics and stochastic population forecasts. This model is used to highlight potential uncertainties associated with variables that affect the sustainability of public finances and to provide a quantitative stochastic assessment of the scale of these different scenarios.

The NAOF does not prepare forecasts. It can, however, assess the quality of the government's economic forecasting (and the quality of tax revenue estimates) and did so in the first electoral period report to the parliament. ${ }^{8}$ The NAOF does not have a role in ex ante policy advice, costings and costings of electoral programmes. Related work performance audits may, however, evaluate cost assessments and the impact of individual government proposals.

The NAOF regularly gives opinions and expert testimonies to parliamentary committees (most frequently to the Audit Committee, Constitutional Law Committee and the Finance Committee, although they also receive requests from sectoral committees). It may also give opinions to government when asked; provided it has the resources and that the request falls under its mandate.

\section{Work programme}

The NAOF prepares a work programme for fiscal policy audits and evaluation covering each electoral period (for example, 2011-14). This allows for the timing of the work programme to be aligned with the government programme, which is the most important steering document for fiscal policy. Moreover, spending limits and other targets are set by electoral period. The general electoral period plan for fiscal policy audit and evaluation is then translated into the annual audit and activity plan of the NAOF for four years. The Executive Director for Fiscal Policy Evaluation is responsible for approving the electoral period plan and proposing the concrete audit and action plan to be integrated into the larger NAOF Audit Plan approved by the Auditor General.

The plan is decided in part based on systematic risk analyses and working environment analyses. An important tool in this regard is the national economic and central government finances risk analyses which identifies and reviews trends, challenges and risks for the national economy and economic policy affecting central government finances and fiscal policy.

The NAOF has complete independence in its choice of topics for analysis. Nevertheless, it has established general principles for choosing topics: assessment tasks following from European treaties and legislation concerning fiscal policy rules and fiscal policy objectives; the economic significance of a topic to national economy and government finances; accuracy, relevance, materiality and importance of information to the parliament; and the significance of information to the general public debate on fiscal policy issues.

The NAOF responds to parliamentary requests, and government ministries and agencies regularly ask NAOF representatives to participate as experts in various working 
groups. As long as participation in these working groups does not create conflicts of interest or serious resource constraints, NAOF accepts these invitations.

The NAOF Advisory Board is consulted on the NAOF work programme, and more informal consultations are held with various other stakeholders such as parliamentary committee chairs, the Prime Minister's Office, Ministry of Finance and other ministries and academia.

Key products for fiscal policy evaluation are as follows:

- End of electoral period: the electoral period review report to the parliament (Special Parliamentary Report) serves in part to inform fiscal policy objectives in the coalition agreement negotiations.

- The mid-term electoral period report to the parliament (Special Parliamentary Report) which is timed to serve as an input to the government's mid-term review of its programme at the end of February before decisions on the General Government Fiscal Plan and adjustments to fiscal policy are made in March. The General Government Fiscal Plan includes fiscal targets for all general government sectors as well as macro guidance for local governments and the central government spending limits.

- Once a year Fiscal Policy Evaluation submits a report to the plenary of the Parliament. The report covers compliance with national and EU fiscal policy rules, as well as an assessment of whether the objectives set for the fiscal policy have been reached, transparency in Government reporting on fiscal policy, and an assessment of reporting on sustainability.

\section{Budget}

Approximately EUR 0.7 million of the NAOF total budget of EUR 15.3 million is allocated directly to Fiscal Policy Evaluation. The Fiscal Policy Audit in the NAOF Performance and Fiscal Policy Audit Department supports the work of the IFI function (Fiscal Policy Evaluation). Their work is co-ordinated throughout the electoral period and in the annual work programmes prepared and approved by the Executive Director for Fiscal Policy Evaluation in concert with the Deputy Auditor General for Performance and Fiscal Policy Audit. The NAOF budget is set annually as part of the decision on the parliament's budget and is funded solely from the appropriation for the parliament. Funding in overall terms falls short in light of the broad mandate of the NAOF and in comparison to international benchmarks.

\section{Staffing}

\subsection{Leadership}

The Auditor General is elected by the parliament in a secret vote for a six-year, renewable term, following an assessment of candidates by the Audit Committee. Candidates are chosen through an open competition and must have a higher university degree, strong knowledge of public finances and state administration and proven leadership skills and experience. The Auditor General may be removed only by a decision of the plenary of the parliament for reasons specified by law (incapacity to perform in his or her functions and grave violations of official duties).

The Auditor General has full freedom to hire and dismiss staff within applicable legal constraints and the NAOF rules of procedure. ${ }^{9}$ NAOF staff are part of the parliamentary service under the Act on the Civil Servants of the Parliament 1197/2003. The Auditor General makes all decisions "on presentation" which means that they are co-signed by a 
rapporteur who is responsible for the substantive preparation of the decision and legality of the action. By law the appointments shall be merit-based.

The head of the IFI function at the NAOF is, pursuant to the NAOF rules of procedure, the Executive Director for Fiscal Policy Evaluation and is responsible for reports and opinions and leadership of work in this area. The Executive Director for Fiscal Policy Evaluation also acts as the rapporteur-general for the relevant reports presented to the plenary of the parliament. The Executive Director for Fiscal Policy Evaluation is a Member of the NAOF Executive Board and the Economic Counsel of the NAOF Executive Board. The Executive Director for Fiscal Policy Evaluation is a permanent civil servant, but his or her leadership function is assigned by the Auditor General.

According to the NAOF rules of procedure, the Executive Director for Fiscal Policy Evaluation must have: a higher university degree in a relevant field; strong knowledge of economics, audit, public finances and budgeting, and evaluation or scientific research activities, as well as proven leadership experience. The position can only be terminated if there is a restructuring of the organisation wherein no other task can be assigned for economic reasons, for inability to perform duties or for serious breaches of official duties (for example, not meeting objectives on a permanent basis). Procedures for dismissal are regulated in law and involve hearings of the persons concerned. The Executive Director for Fiscal Policy Evaluation is a full-time, paid position.

\subsection{Staff}

The NAOF maintains a staff of approximately 140, but only four (including the Executive Director for Fiscal Policy Evaluation) are assigned to its IFI functions. Staff are recruited according to the processes in place for parliamentary civil servants and salaries and benefits are in line with those of the parliamentary service. In practice, salaries are higher than those of the government civil service.

Staff serving the IFI function all have a higher university degree or PhDs. They have backgrounds in economics, budgeting, finance, financial auditing and management and policy analysis and have held previous positions in academia and the Bank of Finland. The average age is around 40 years old. This team is supported by several administrative assistants, who have lower university or polytechnic degrees, and by the NAOF Head of Communications. Other departments within the NAOF also provide expertise to the team responsible for fiscal policy evaluation.

The NAOF may accept staff from government agencies or universities for temporary assignments provided they are qualified and their positions can be financed from the NAOF budget. The NAOF also co-operates with universities and research institutes in its analyses. For example, the NAOF carried out with a university a joint research project on spending limits. The NAOF also has had a joint research programme with an economic research institute using a dynamic general equilibrium model to analyse the sustainability of public finances, as well as fiscal policy rules and the structural balance. The NAOF Fiscal Policy Evaluation plans to commission studies or develop joint studies supporting the evaluation of fiscal policy on an annual basis.

Staff are governed by the general rules in the Administrative Code and in the Act on Parliament's Civil Servants regarding conflicts of interests. In addition, the NAOF has its own internal ethical rules to avoid conflicts of interest based on international standards on auditing. 


\section{Access to information}

Access to government information is guaranteed in Section 90(3) of the Constitution of Finland regardless of and over-riding secrecy provisions. The NAOF also has a specific right to information from the central bank guaranteed in law. In practice, access to information from the Ministry of Finance has been smooth and, particularly on the budget, even confidential internal analyses and data have been made available in a timely manner. The NAOF has a memorandum of understanding with Statistics Finland. One issue is that social security funds in Finland are, for the most part, provided by private insurance companies and neither the NAOF nor the Ministry of Finance have direct access to their information.

In addition, econometric and other statistical analyses for certain policy issues require access to secret data underlying the statistics (unit-level data on subjects used in statistical models which fall under statistical secrecy as defined in the EU law on the confidentiality of the unit level input data for statistics). In cases concerning entities not subject to the NAOF constitutional oversight, and where Statistics Finland is the source of information, the NAOF's access is no different than that of any researcher. This data concerns private companies and individuals and the procedures for granting research permission can make it difficult to get data in time. So far, this has not been an issue in the area of fiscal policy evaluation.

Access to statistical background data is unlikely to present a problem in macroeconomicoriented work.

\section{Transparency}

All final NAOF reports are published on its website. Draft reports are sent to the executive (i.e. relevant government ministry) for comment prior to finalisation and then final reports are sent to the government and the parliament's Audit Committee and, for information, to other relevant parliamentary committees. The Fiscal Policy Evaluation reports tabled to the plenary of the Parliament are public by Constitution. NAOF methodologies are published and general manuals are available online. Preliminary studies are also public documents and available to any member of public upon request. The NAOF endeavours to make available its calculations on the structural balance and other significant working documents underlying its reports in accordance with the principles of open data.

The NAOF regularly issues a news release on all fiscal policy evaluation and parliamentary reports and holds news conferences or other types of information events (i.e. briefing breakfasts) for representatives of the media for electoral period reports and other reports of public interest. NAOF media policy calls for executives and members of staff to respond positively to requests for interviews to provide factual and objective communication. The Auditor General is regularly interviewed in the media, and responsible NAOF experts frequently comment on work published.

The function as IFI presents a challenge to the NAOF to demonstrate its credibility and reputation in this field through good-quality work that is well communicated. Given that the media often focus on NAOF criticisms of government, the NAOF will also be challenged to ensure that positive messages are also picked up and to demonstrate continually the non-partisan nature of its work. Background meetings and briefings are an important tool for communicating the results of NAOF analyses. This is true for the media as well as the academic community. The NAOF will continue to expand its interaction with the broader research community. 
Parliamentary hearings, background briefings and meeting with government representatives are not made public, with the exception of the hearing of the Auditor General on the Annual Parliamentary Report which includes discussion on macroeconomic aspects and the sustainability of public finances from NAOF analyses. While reports are public there is broad consensus that confidential discussions between the NAOF and government ministries are necessary to tackle difficult issues. NAOF representatives have participated in Ministry of Finance-led expert assessments of the spending limits system and in drafting the recommendations for fiscal policy governance. They have also participated in projects led by the Prime Minister's Office to prepare recommendations on the strategic management of government. The NAOF considers this kind of more confidential work to be critical to its overall objectives to promote the sustainability of public finances and ensure reliable information for parliamentary decision-making and the public debate.

\section{Governance, advisory support, monitoring and evaluation}

The NAOF is planning to establish a Scientific Council to provide technical advice on, and evaluation of, NAOF work, in particular on methodological issues. The proposed role of the Scientific Council is described in the methodology manual on fiscal policy as assessing the quality of the work done and providing advice on preliminary studies and the work plan.

The audit manuals of the NAOF require the NAOF to seek systematic feedback on the quality and relevance of its work from those it has audited and other stakeholders. As part of its stakeholder relations, the NAOF maintains a statutory Advisory Board composed of: five MPs from the biggest parliamentary groups; two Permanent Secretaries of ministries; the Budget Director and the government Controller-General from the Ministry of Finance; one chief executive of a government agency; one professor representing university research; the Director-general of the Government Economics Research Institute; the Auditor General; and one member elected to represent the NAOF staff. The Advisory Board has a maximum term of three years.

All NAOF work is subject to international peer review in accordance with international standards for government auditing. The last peer review was concluded in 2012 and concentrated on the application of the international standards and best practices in quality assurance and in audit manuals. The peer review concluded that the fiscal policy audit manual and the quality assurance system are in line with internationally accepted standards.

According to the fiscal policy audit manual, fiscal policy work should be subject to regular peer reviews by experts, including for example external experts from academia. All draft analyses are also subject to internal peer review by another member of the staff before being presented for comments or decision-making. The NAOF monitors whether its recommendations have been implemented and reports to the parliament on implementation.

\section{Concluding remarks}

While the NAOF is a well-established, long-standing institution with a good reputation, fiscal policy auditing and evaluation are new functions. With only limited resources and a very small staff, the NAOF faces many challenges as it attempts to build credibility in this new area and establish a reputation for robust, quality work.

Monitoring compliance with fiscal policy rules and assessing the effectiveness of fiscal policy touch on issues at the heart of the political agenda. This creates an additional challenge in terms of demonstrating high-quality work and integrity and communicating 
the work in a sufficiently clear manner, while avoiding being perceived as political. For example, structural balance (structural deficit) appears to be a natural indicator for analysis of sustainable policy. But in an economy that is subject to structural changes, estimation of the potential output is difficult and controversial and so a seemingly neutral and technical task is actually one of the most hotly contested macroeconomic issues. Moreover, when analysing the sustainability of public finances, it has been challenging to communicate risk assessments and a stochastic view to political and policy debates which too often focus on trying to determine a "single true figure".

The NAOF must also determine where to draw the line in terms of policy recommendations. While the NAOF does not traditionally give ex ante policy recommendations, with its new function it is broadly expected to give forward-looking recommendations based on its assessments. What is appropriate in this respect, for example, when pinpointing the adjustment measures and needs in detail? How can the NAOF maintain the established division of the tasks between policy preparation (the role of government) and supporting the parliament through monitoring and evaluation (the role of the NAOF)? In particular, how can the NAOF credibly assess the effectiveness of policies that it itself has recommended?

\section{Notes}

1. The expenditure ceiling is only adjusted to reflect changes in price levels and structural changes in the budget. It is set in the Government Programme and is constitutionally subject to a vote in the parliament. The expenditure cap covers approximately four-fifths of the central government budget.

2. A useful overview of Finland's fiscal policy rules and objectives in force up to 2015 can be found in, the Fiscal Transparency Evaluation of Finland IMF 2015. See in particular Table 2.5 on p. 46.

3. The office's names in Finland's official national languages are valtiontalouden tarkastusvirasto finanssipolitiikan valvonta and statens revisionsverk - tillsyn över finanspolitiken The National Audit Office has a long history in Finland. Established in 1695, and functioning continuously since 1824, it began conducting fiscal policy audits and evaluations in 2008 and was assigned a specific fiscal policy audit and evaluation function in 2011.

4. See the parliament's web pages: www.eduskunta.fi/FI/vaski/mietinto/Documents/vaum_38+2012.pdf.

5. Ministry of Finance: Kehyksen puitteissa 2007. The full English version of the report is on the Ministry of Finance website at: www.2014.um.fi/vm/en/04_publications_and_documents/ 01_publications/08_other_publications/20070213Fiscal/name.jsp (accessed in January 2012, no longer available online).

6. General government expenditure in Finland is approximately $56 \%$ in comparison to GDP.

7. The Auditor General is elected by the parliament in a secret vote, following an assessment of candidates by the Audit Committee. Candidates are chosen through an open competition.

8. The NAOF has, on occasion, included qualitative or quantitative comparisons on the accuracy of the economic forecasts in fiscal policy audit reports.

9. In practice, hiring includes a panel of several experts and other quality assurance measures.

\section{Bibliography}

Jón R. Blöndal, Jens Kromann Kristensen and M. Ruffner (2003), "Budgeting in Finland", OECD Journal on Budgeting, Vol. 2/2, http://dx.doi.org/10.1787/budget-v2-art12-en.

Economic Policy Council of Finland (2015), www.talouspolitiikanarviointineuvosto.fi/index.php/en/.

Eduskunta (2012), Finance Committee Report VaVM 38/2012, www.eduskunta.fi/FI/vaski/mietinto/ Documents/vaum_38+2012.pdf. 
IMF (2015), Fiscal Transparency Evaluation of Finland, www.imf.org/external/pubs/ft/scr/2015/cr1560.pdf.

Ministry of Finance of Finland (2007), Fiscal Policy Rules and the Reform of Spending Limits in Finland, Ministry of Finance, Budget Department, Helsinki, www.2014.um.fi/um/en/04_publications_and_ documents/01_publications/08_other_publications/20070213Fiscal/kehykset_enkku_sopus.pdf.

Ministry of Finance of Finland (2015), http://vm.fi/en/frontpage.

National Audit Office of Finland (2011), National Audit Office's separate report to Parliament: Effectiveness of the central government spending limits procedure as a fiscal policy instrument, Helsinki, www.vtu.fi/files/2862/FIPO_R_21_2010_netti.pdf.

National Audit Office of Finland (2014), "Valtiontalouden Tarkastusviraston Työjärjestys", National Audit Office, Helsinki, www.vtu.fi/files/4546/Tarkastusviraston_tyojarjestys_1.11.2014_dnro_ 16.00.2014.pdf.

National Audit Office of Finland (2015), www.vtu.fi/en/nao/organisation/auditor_general.

OECD (2010), OECD Economic Surveys: Finland 2010, OECD Publishing, Paris, http://dx.doi.org/10.1787/ eco_surveys-fin-2010-en.

OECD (2011a), "Parliamentary Budget Officials Network Survey Background Notes: Committee Structures for Budget Approval and Oversight and Interim Financial Reporting", Annual Meeting of OECD Parliamentary Budget Officials, OECD, Stockholm, 28-29 April, www.oecd.org/dataoecd/7/30/ 48089653.pdf.

OECD (2011b), "Budgeting Features that Strengthen Fiscal Policy in OECD Countries: Results from the OECD Budget Practices and Procedures Database", Annual Meeting of Senior Budget Officials Network on Performance and Results, OECD, Paris, 9-10 November, www.oecd.org/officialdocuments/ displaydocumentpdf? cote $=$ GOV/PGC/SBO(2011)11\&doclanguage $=e n$.

OECD (2012), OECD Economic Surveys: Finland 2012, OECD Publishing, Paris, http://dx.doi.org/10.1787/ eco_surveys-fin-2012-en.

Parliament of Finland (2015), www.eduskunta.fi.

\section{Legislation}

Constitution of Finland (11.6.1999/731), www.finlex.fi/fi/laki/ajantasa/1999/19990731.

Act on the National Audit Office of Finland (14.7.2000/636, amended by Act 21.12.2012/870), www.finlex.fi/fi/laki/ajantasa/2000/20000676.

Act on the Implementation and Application of the Provisions of the Treaty on Stability, Co-ordination and Governance in the Economic and Monetary Union and on the Requirements of the Frameworks of Public Finances (21.12.2012/869), www.finlex.fi/fi/laki/smur/2012/20120869. 



\section{France}

\section{High Council for Public Finances (Haut Conseil des finances publiques, HCFP)}

Established: 2013.

Enabling legislation: 17 December 2012, Organic Law on the Planning and Governance of Public Finances (Loi Organique du 17 Décembre 2012 relative à la Programmation et à la Gouvernance des Finances Publiques).

Mandate: To provide an opinion on: the government's macroeconomic forecasts underlying draft financial laws (programming legislation, finance laws, financing of social security and stability programmes); ex ante compliance of these draft financial texts with the multi-year structural balance trajectory; and ex post compliance with the structural balance trajectory.

Budget: EUR 800000 (2014).

Number of Staff: Ten council members and four to five secretariat staff (all parttime). 


\section{Context}

Over the past 30 years, France has failed to bring its public finances to sustainable levels. The last government surplus was in 1974. Since then, while public finances have gone through a number of recovery phases (1976-80, 1988-90, 1997-2000 and 2004-06) each recovery was followed by setbacks, and France entered the 2008 financial crisis with a deficit of nearly 3\% of GDP and public debt (as defined by Maastricht) of 65\% of GDP. In 2014, the government deficit was $4 \%$ and public debt amounted to $90 \%$ of GDP. Though successive governments have promised a return to fiscal balance none have been successful. France has systematically failed to adhere to the stability programmes submitted to the European authorities, a problem compounded by over-optimistic macroeconomic assumptions.

Nevertheless, in the latter half of the 2000s, France gradually strengthened its budgetary framework. Today the state budget is structured around several instruments:

- so-called "zero volume" spending standards (increase in state spending from one year to the next is limited to inflation) and "zero value, excluding debt and pensions" (increase in state spending is frozen from one year to the next);

- three-year ceilings on spending for the state's general budget missions, set every two years for a three-year period;

- a freeze (in volume and then in value) on government financial assistance to local authorities (collectivités territoriales);

- so-called cross-cutting rules, which apply to certain expense categories: e.g. replacing only one out of every two retiring government workers (staff costs), multi-year objectives to reduce operating expenditures, etc.

These rules were added in 2008 to the Public Finance Programming Laws (LPFP), which are approved every two years and cover a period of at least three years. While they are not formal legal constraints, the Court of Auditors (Cours de Comptes) assesses ex post compliance with them when it audits implementation of the Finance Law.

Since 1997, social security expenditures have typically been voted as part of the social security financing laws. This legislation includes a National Objective for Health Insurance Expenditures (ONDAM), which is an effective tool for regulating health insurance spending. An "early warning committee" was formed in 2004 to alert the government if changes in health insurance spending make it incompatible with the national objective approved by the parliament.

The creation of an independent fiscal institution was the subject of intense debate in early 2010 within an group of experts and parliamentarians chaired by economist Michel Camdessus which was set up to examine ways to improve fiscal governance and anchor a fiscal rule in the constitution. Many reservations were expressed, notably by parliamentarians. There were, for example, concerns about how an independent fiscal institution would fit into the current institutional framework - would its functions overlap with those of the Court of Audit? Would it undermine or supplant the role of the parliament in budget oversight? 
March 2012, however, brought a change of perspective as France ratified the new European Treaty on Stability, Co-ordination and Governance (TSCG or Fiscal Compact) and the government began looking at how to translate the European requirements into French law, including the requirement that an independent institution monitors compliance with the national fiscal rules.

The first option considered was the establishment of an ad hoc institution, separate from the government and the parliament, as well as from the Court of Auditors, which would focus exclusively on ex post monitoring of public finances. The Court of Auditors, concerned about conflicting mandates, proposed a second option in which it would continue to monitor compliance with fiscal objectives and the new fiscal council would analyse the macroeconomic projections and underlying assumptions used to prepare the budget. As the European Commission indicated in its September 2011 Report on Public Finances, the Court of Auditors already performed a number of the tasks typically assigned to a fiscal council. In particular, it examined public finance developments and stances, verified compliance with fiscal rules, and issued opinions and recommendations on fiscal policy. However, the court did not have jurisdiction to produce or endorse macroeconomic forecasts, a function unrelated to its historical role.

A compromise was finally announced by the President of the Republic on 7 September 2012: the creation of the High Council of Public Finances (HCFP), the "indisputable authority" tasked with monitoring and ensuring the application of fiscal rules as well as verifying the assumptions on which the budget would be based.

The government presented a draft organic law on the planning and governance of public finances to the parliament on 19 September 2012. After lively debates in both chambers, which focussed mainly on the composition and tasks of the HCFP, the organic law was passed by a large majority. Some members of parliament did speak out, however, to condemn what they saw as a new technocratic framework divesting the parliament of its prerogatives in the budget process.

The organic law, which translates the provisions of the Fiscal Compact into French law, contains a number of provisions in addition to the creation of the HCFP:

- It defines the content of public finance programming laws that set, with a view to achieving the government's medium-term objective, successive annual structural balance trajectories and actual balance trajectories for the public accounts and the structural adjustment effort for each fiscal year of the programming period.

- It expands finance laws and budget settlement laws, which previously covered only state finances expressed in cash-based accounting, to include an "introductory article" (article liminaire) outlining the forecasted structural and actual public balance, expressed in national accounting, for all public administrations. This provision should allow for the Constitutional Council to monitor compliance with the trajectory.

- It introduces a correction mechanism in which the HCFP plays a central role.

\section{Relationship with the executive and the legislature}

The HCFP is an independent body alongside the Court of Auditors. This means that it is fully independent from both the government and the parliament, and that it has a special separate status from the Court of Auditors. The tasks of the Court of Auditors with regard to budgetary oversight have been adapted to prevent duplication with those conferred by law to the HCFP. It was thought that the HCFP would benefit from being 
attached to the Court of Auditors due to the court's well established reputation for independence and its high level of credibility within France's institutional landscape, in particular the trust placed in it by the parliament. The court and the HCFP maintain close ties in order to guarantee the consistency of their tasks. The HCFP is presided over by the First President (Premier président) of the Court of Auditors, and the Chief of Staff (Rapporteur général) is also a magistrate of the Court.

While the strong links between the Court and the HCFP may risk giving the perception that the HCFP is essentially a part of the Court, the organic legislation makes several provisions in order to guarantee the complete independence of the members of the HCFP. For example, members of the HCFP are appointed by six different authorities, which include representatives from the opposition. In France, the National Assembly and Senate Finance Committees are chaired by opposition members. And council members cannot receive or solicit any instructions from the government or any other organisation.

The HCFP's enabling legislation provides the basis for the relationship between the parliament and the HCFP. The Presidents of the National Assembly and the Senate and the Presidents of the Finance Committees in both chambers appoint four of the ten council members who make up the council (collège). The parliament also reviews and approves the HCFP's budget. Given the parliament's constitutional mandate to approve and oversee the national budget, all opinions rendered by the HCFP are sent to the parliament for consideration during budgetary and related debates on financial legislation. Finally, the Finance Committees of either chamber can request a hearing with the President of the HCFP at any time (Article 20).

HCFP opinions on the texts specified in the HCFP mandate are not binding on the government. However, given that HCFP opinions are public, are in the parliamentary debate, and receive media attention, the government runs a reputational risk if it chooses to disregard them.

\section{Box 1. Role of the legislature in the budget process}

France has a bicameral legislature comprised of the National Assembly and the Senate. The 577 members of the National Assembly are elected in a two-round, first-past-the-post ballot, in which the candidate is elected with an absolute majority in the first round (i.e. more than 50\%) or a relative majority in the second round. The 348 Members of the Senate are elected by a college of approximately 150000 members, comprised of the members of the National Assembly, municipal and regional councillors, and their delegates.

Constitutionally, legislation that seeks to authorise expenditure or impose taxation must originate in the National Assembly by the government. The parliament is constitutionally prohibited from changing overall revenues or expenditures in the government's proposed budget. Parliamentarians are also prohibited from creating new "missions" or programmes, or from proposing amendments to revenue measures. However, the parliament has full freedom to amend proposed expenditure within these restrictions by shifting the amounts allocated among programmes within the same "mission". Total amendments tend to be very small; in 2013 they were less than 0.1 per cent of the total budget.

The French fiscal year runs from January to December. The 2001 Organic Budget Law (LOLF) provides that around the end of each spring, the government tables a report on economic and fiscal developments which is subsequently debated by parliamentarians. The results of this debate inform the development of the budget law, which must be submitted 


\section{Box 1. Role of the legislature in the budget process (cont.)}

to the parliament by the first Tuesday of October. There are time limits set out in statute regarding debate in the National Assembly (40 days) and Senate (20 days), as well as an overall limit of 70 days from introduction of the proposed law to a final vote. This includes time for scrutiny by legislative committees. The constitution provides that if a final vote is not taken within 70 days, the previous year's budget takes effect for a limited period.

The Finance Committees take the lead in budget scrutiny, co-ordinating a process in which sectoral committees can make recommendations which the Finance Committees then review and accept or reject. They are supported by a sizeable staff (over 20).

The LOLF requires that the budget law be accompanied by several documents, including an overall economic and fiscal outlook covering at least four years, proposed new measures and their relationship with existing policies, performance-related information for programmes, as well as estimates of tax expenditures. This overall "budget package" is presented as a collection of roughly 50 major public policies ("missions"), which in turn are comprised of approximately 170 specific programmes linked to objectives and performance indicators. The parliament is required to vote on each individual "mission", which typically includes planned expenditures across several ministries or agencies. Apart from expenditure limits on human resources, allotments approved by the parliament can then be redistributed among different types of expenditure provided that the limits for each programme are respected. Supplementary budget laws (i.e. "rectifying laws") are typically submitted to the parliament at least once a year to modify the initial revenue and expenditure figures.

Parliamentarians also exercise in-year oversight regarding execution of the budget law. More specifically, the government is required to apprise the Presidents of the National Assembly and Senate Finance Committees of proposed reallocations between programmes (maximum $2 \%$ ) or expenditure reductions (maximum 1.5\%). The LOLF also vests these Finance Committees with authority to "monitor execution of the budget acts and evaluate public finance issues ... [via] ... documentation or on-the-spot investigation". These committees can compel testimony from any witness deemed pertinent to this work.

The High Council on Public Finance is expected to complement the support provided by the French Court of Accounts, which can assist both Finance Committees throughout the year in their scrutiny and evaluation of spending. In addition, the National Assembly Finance Committee will continue to rely on its Monitoring and Evaluation Task Force to support analysis and propose reforms to public policies, programmes and services.

\section{Box 2. Role of the Court of Auditors in the oversight of the public finances}

The 4 October 1958 Constitution and the 2001 Organic Law on Financial Legislation (LOLF) give a key role to the court in oversight of public finances. As such, the court is already considered a "budget watchdog". It controls ex post government budget implementation and the implementation of social security funding legislation. It controls the public accounts ex post, certifying government accounts and the overall social security system. Finally, it monitors the status of and outlook for public finances throughout the year. A sub-report on this topic is prepared in February as part of the court's annual report, and again in June, as part of the report on the status of and outlook for the public finances. 


\section{Legal basis for establishment}

The HCFP was established by Law No. 2012-1403 on the planning and governance of the public finances on 7 December 2012. In its Decision No. 2012-653 DC of 9 August 2012, the Constitutional Council determined that the implementation of the Treaty on Stability, Co-ordination and Governance did not require the constitution to be revised. However, in the absence of constitutional amendments, it also decided that an organic law was necessary to establish the rules regarding the medium-term objective and the budgetary adjustment trajectory of public administrations, the correction mechanism and the independent bodies involved in the budget process. An organic law, under French law, is higher-level legislation and has quasi-constitutional standing. An organic law therefore takes precedence over finance laws and social security financing laws. Article 21 of the organic law states that the HCFP shall establish and publish its own rules of procedure. Article 18 of these rules for procedure calls for an information-sharing protocol to be developed between the HCFP and the government.

\section{Mandate}

The mandate of the HCFP is different from many of its European counterparts in two key ways. First, the HCFP is directly involved in the budget process - it must be consulted before any draft financial texts are presented in the parliament. However, its opinions are not binding on the government. Secondly, its mandate is strictly defined and does not include an overall assessment of the status and outlook - or sustainability - of public finances. This last task remains under the responsibility of the Court of Auditors.

The HCFP is an advisory body tasked with providing fully independent opinions on all financial texts presented by the government, including the following:

- public finance programming laws, passed every two years, which set the annual successive structural and actual balance trajectories of public administration accounts (medium-term objective) for a minimum of three years;

- draft finance laws and social security financing laws, passed every year in December, which will now include a structural balance objective and an actual balance objective for all public administrations;

- amended finance laws and amended social security laws, which may arise throughout the year to modify laws previously approved by the parliament;

- budget settlement laws passed in May of the year following the year to which they refer, which now outline results with regard to the structural balance and actual balance for the year in question; and

- stability programmes presented each year in April to the European Commission and the European Council.

While the HCFP must assess numerous laws, its opinions are limited to:

- assessing the soundness of the macroeconomic forecasts on which the draft finance law and stability programme are based;

- examining potential output and the output gap in the programming laws;

- analysing ex ante whether the annual objectives in the finance law are coherent with the multi-year structural balance trajectory; and 
- identifying ex post any significant deviations from the medium-term objective or the adjustment path towards it as defined in the programming law.

HCFP tasks are strictly defined in its enabling legislation which states that the HCFP may not discuss or issue opinions on anything above and beyond the topics provided for in the organic law.

\section{Functions}

The HCFP does not prepare its own macroeconomic projections - this is the prerogative of the government. Its role is to examine the robustness and accuracy of key macroeconomic forecasts: GDP components, inflation, payroll, etc. The HCFP assesses their accuracy based on the information at its disposal, as well as alternative projections from international organisations and other economic bodies. As part of this work, it carries out riskassessment-type analyses.

The organic law provided for a "coherence review" (examen de la cohérence) without detailing what was expected in practice. At one end of the spectrum this could simply mean ensuring that the figures match. A more ambitious approach taken by the HCFP is to analyse both revenue and expenditure projections. The short time frame within which the HCFP prepares its opinion means it will most likely have to focus its analysis on key revenue and expenditure lines and whether they have optimistic or pessimistic biases.

The HCFP does not have the authority to analyse the long-term sustainability of public finances. It has no role in policy costings or costings of electoral platforms and does not provide normative policy recommendations. The Court of Auditors continues to play the main ex post assessment role, but the HCFP is responsible for the ex post evaluation regarding structural balance projections.

\section{Work programme}

The organic law establishes the timings for main HCFP reports in September, April and May, and in response to government reports that may be presented during the year. Article 21 of the organic law prohibits the HCFP from undertaking work on its own initiative beyond what is provided for in the law.

\section{Budget}

The HCFP has its own budget line as part of the appropriations for the budget of the Court of Auditors in the finance law. The HCFP annual granted budget is approximately EUR 800000 , of which $45 \%$ is intended to finance staff costs and $55 \%$ is for operations and the use of external expertise. Effective expenses excluding wages have so far been very limited (less than EUR 30 000). In addition, the Court of Auditors provides logistical support.

\section{Staffing}

\subsection{Leadership}

The HCFP is chaired by the First President of the Court of Auditors and consists of a council and a permanent secretariat responsible for preparing proposals to be discussed by the council. The First President of the court is a magisterial appointment and he or she cannot be dismissed. The HCFP President speaks on behalf of the council. 
In addition to its President, the council has ten members:

- four Court of Auditors magistrates are appointed by the First President of the Court;

- five recognised experts in economics and public finance, appointed by the Presidents of the National Assembly and the Senate, the Presidents of the National Assembly and Senate Finance Committees and the President of the Economic, Social and Environmental Council (Conseil économique, social et environnemental); and

- the director general of the National Institute of Statistics and Economic Studies (Institut national de la statistique et des études économiques or INSEE).

The members of the HCFP are appointed for a five-year term. Half are renewed every 30 months (two and one-half years). The terms of the Court of Auditors magistrates are renewable once. The terms of the outside experts are non-renewable. Membership is parttime and unremunerated; only expenses (e.g. travel) associated with their work are reimbursed. The council must maintain a gender balance with an equal number of men and women. Although council members are part-time, they are restricted from holding elected office. There is no provision prohibiting the appointment of a foreign national to the HCFP.

Council members can only be removed by the institution that appointed them and after the majority of two-thirds of the other members has been notified. Cause for dismissal includes cases of permanent physical incapacity or serious breach of duties (violation of deliberative secrecy, etc.). Council members must make a declaration of interests to the First President of the Court of Auditors. These declarations are also published on the HCFP website.

\subsection{Staff}

The permanent secretariat is headed by a Rapporteur General who acts as chief economist and is supported by a small team. The Rapporteur General has two assistants, one to synthesise macro-economic and public finance data and one handling administrative issues. The Rapporteur General can recruit secondees to the HCFP secretariat from among the magistrates in the Court of Auditors (magistrates may work part-time on HCFP business and maintain duties within the Court of Auditors) and public employees. The HCFP can also recruit experts from academia or other organisations. The first Rapporteur General was a former general director of INSEE, former director of forecasting at the Ministry for the Economy and Finance and former chief economist of the OECD. The second Rapporteur General had over 40 years of experience at the Court of Auditors and in the Ministry of Finance. The HCFP can also draw on outside experts, particularly from academia, to enhance the quality and credibility of its work.

\section{Access to information}

The organic law states that the government must respond to requests for information from the HCFP. In practice, information has not always been forthcoming. The HCFP has attempted to develop a memorandum of understanding with the relevant administrative actors (budget directorate, treasury, social security administration). Where relevant, the HCFP has strongly underlined the problems posed by incomplete information in its opinions.

\section{Transparency}

The HCFP publishes all its opinions on its website, as well as information on its participation in parliamentary hearings and other news on its work. Opinions are sent first 
to the government and rendered public when they are presented in the National Assembly. Preparatory work, however, remains confidential as, in keeping with French legal tradition, the HCFP is not authorised to publish dissenting opinions.

The HCFP bases its assessment on the government its GDP projections on the estimates of the government, the most recent economic information available, and forecasts produced by other organisations (a list of which is made public). Official contacts between the President of the HCFP and government officials are made public. Similarly, working conditions agreed between the permanent secretariat and the administration will be made public in the memorandum of understanding.

While the establishment of the HCFP and its initial work have already received significant media coverage, it has faced challenges in terms of distinguishing the HCFP from the Court of Auditors which has a very high profile in the media. Given the sensitive nature of HCFP work, communications are handled by the President of the HCFP with the support of the permanent secretariat. A further challenge, faced by many IFIs, is that the subject matter covered by the HCFP is not always easily accessible for the general public. The HCFP has organised and participated in seminars on topics related to its work.

\section{Governance, advisory support, monitoring and evaluation}

The HCFP may consult outside experts or organisations for its analyses, but it does not have an oversight board or advisory panel.

\section{Concluding remarks}

The HCFP faces a number of challenges as a new institution with an unprecedented role in the French budget process. First, it has been established in a particularly difficult economic period which means that extreme caution has to be used when assessing government macroeconomic projections.

Secondly, although its placement alongside the Court of Auditors means that it benefits from the court's solid reputation for independence, it has to build up its own macroeconomic credibility.

Finally, the HCFP depends heavily on information on the public finances provided by the government and on whether such information is accurate and easily accessible. The HCFP and the executive will have to build trust over time in order to work together productively on public finances.

\section{Bibliography}

Camdessus, M. (2010), "Réaliser l'Objectif Constitutionnel d'Équilibre des Finances Publiques", Rapport du groupe de travail présidé par Michel Camdessus, 21 June, Directorate of Legal and Administrative Information, Paris.

Constitutional Council (2012), "Decision No. 2012-653 DC of 9 August 2012 on the Treaty on Stability, Co-ordination and Governance in the Economic and Monetary Union, Constitutional Council, Paris, www.conseil-constitutionnel.fr/conseil-constitutionnel/english/case-law/sample-of-decisions-inrelevant-areas-dc/decision/decision-no-2012-653-dc-of-9-august-2012.115501.html.

Court of Auditors (Cours de Comptes) (2015), www.ccomptes.fr.

Directorate-General for Economic and Financial Affairs (2011), Public Finances in EMU - 2011, European Commission, Brussels, http://ec.europa.eu/economy_finance/publications/european_economy/2011/pdf/ ee-2011-3_en.pdf.

Economic, Social and Environmental Council of France (2015), www.lecese.fr/en. 
French Ministry for the Economy and Finance (2015), www.economie.gouv.fr/welcome-to-the-frenchministry-for-the-economy-and-finance.

French National Assembly (2015), www2.assemblee-nationale.fr/langues/welcome-to-the-english-websiteof-the-french-national-assembly.

French National Institute of Statistics and Economic Studies(2015), www.insee.fr/.

French Senate (2015), www.senat.fr/lng/en/.

High Council for Public Finances of France (2015), www.hcfp.fr.

\section{Legislation}

La Constitution du 4 octobre 1958, www.conseil-constitutionnel.fr/conseil-constitutionnel/francais/laconstitution/la-constitution-du-4-octobre-1958/la-constitution-du-4-octobre-1958.5071.html.

Les Règles Relatives aux Membres du Haut Conseil des Finances Publiques et au Rapporteur Général, www.legifrance.gouv.fr/affichTexte.do?cidTexte=JORFTEXT000027243862.

Loi Organique du 17 Décembre 2012 Relative à la Programmation et à la Gouvernance des Finances Publiques, http://legifrance.gouv.fr/affichTexte.do?cidTexte=JORFTEXT000026785259\&fastPos=2\&fast ReqId $=503057187 \&$ categorieLien $=i d \&$ oldAction $=$ rechTexte.

Loi organique $\mathrm{n}^{\circ}$ 2001-692 du $1^{\mathrm{er}}$ août 2001 relative aux lois de finances, www.legifrance.gouv.fr/affichTexte. do?cidTexte=LEGITEXT000005631294\&dateTexte=vig . 


\section{Ireland}

\section{Irish Fiscal Advisory Council (IFAC)}

Established: 31 December 2012 (in 2011 and 2012, IFAC operated on an interim basis).

Enabling legislation: Fiscal Responsibility Act 2012 (FRA).

Mandate: The council is required to monitor and assess the government's compliance with the budgetary rule. The council is also required to assess the official forecasts of the government and to provide a view on the fiscal stance.

Budget: EUR 800000 (2013, ceiling set in the FRA).

Staff: Five council members (part-time) and a five-person, full-time secretariat. 


\section{Context ${ }^{1}$}

The establishment of the Irish Fiscal Advisory Council (IFAC) on an interim basis in July 2011 was part of a larger package of reforms. Previously, Ireland's traditional budget framework was cash-based and focussed on managing annual budget spending. During 2006-08, some reforms were undertaken including the introduction of a pre-budget outlook and a unified budget (whereby central government revenue and expenditure policy decisions were announced together on budget day and social welfare spending was integrated with the estimates of departmental spending). During 2008-10, as the financial and fiscal crises in Ireland deepened, budget management came under closer scrutiny, both within Ireland and internationally. With the underlying general government deficit rising sharply and burgeoning public debt, there was a need to accelerate the budget management reforms as part of a comprehensive set of measures.

In late 2010, the government commitments aiming at reducing the high fiscal deficits and restoring the sustainability of public debt were set out in the annual budget for 2011 and the National Recovery Plan 2011-14 (Government of Ireland, 2011b). The planned measures to improve budget management included: establishing a medium-term expenditure framework with multi-annual ceilings on expenditure, creating a budget advisory council and preparing a draft fiscal responsibility law to put key reform measures on a statutory basis.

At the same time, Ireland officially requested financial assistance from the "troika" of the European Commission, the European Central Bank (ECB) and the International Monetary Fund (IMF). An agreement for 2010-13, including a joint financing package of EUR 85 billion, was reached and adopted in December 2010. In line with the proposal in the government's National Recovery Plan 2011-14, the agreement included the "establishment of a budget advisory council to provide an independent assessment of the government's budgetary position and forecasts" as a structural benchmark to be completed in 2011 . $^{2}$

At the European Union (EU) level, proposals were being developed to strengthen fiscal frameworks. All EU member states were encouraged to put in place stronger fiscal frameworks, including an effective medium-term planning horizon, numerical fiscal rules and clear and credible budget forecasts. The establishment of an independent fiscal institution was also recommended. As such, the EU/IMF programme, and anticipated reforms of economic governance at the EU level, accelerated Ireland's budget framework reforms.

In parallel, the Joint Committee on Finance and the Public Service of the parliament (Oireachtas) analysed different options for establishing an independent fiscal institution and recommended establishing two independent councils: an economic advisory council and a separate budgetary review council. It was proposed that the first would have a shortterm focus (the annual budget) and the second would focus on the medium-term, including monitoring compliance with fiscal rules (Oireachtas, 2010). The Department of Finance on the other hand favoured creating a single council with a mandate to consider fiscal policy "in the round". 
There was broad support across political parties for the establishment of the IFAC. The December 2010 agreement to set up the council was made by the coalition government in which Fianna Fáil was the main party. In January 2011, when the junior coalition partner, the Green Party, withdrew its support for the government, the February 2011 elections resulted in a new coalition government being formed by the Fine Gael and Labour parties. This new government also supported establishment of IFAC, as well as many of the measures described above, but through their own Programme for Government. In July 2011, the new Minister of Finance announced the establishment of the Irish Fiscal Advisory Council on an interim basis, until it could be formally established through the Fiscal Responsibility Act. Although no one particular model was followed, Sweden's Fiscal Council was influential in the design of IFAC, as it was seen as economical with part-time council members, a strong leaning towards choosing academics as council members and does not make its own forecasts or projections. ${ }^{3}$

To get the council established and operating quickly in its interim form, support services and accommodation were provided by the Economic and Social Research Institute (ESRI), an independent research institute that is partly funded by government. These arrangements have continued following the adoption of the FRA, with the ESRI being reimbursed from the IFAC budget for the services provided. During this interim period, the council had a somewhat unique opportunity to contribute to the debate around its final design. In January 2012, it published a report outlining its views entitled "Strengthening Ireland's Fiscal Institutions". The majority of its recommendations were accepted.

The council was formally established as an independent statutory body under the Fiscal Responsibility Act 2012 (FRA) which came into force in December. The FRA also sets out the fiscal framework, including providing the legal basis for the medium-term budget framework and fiscal rules consistent with EU rules.

\section{Relationship with the executive and the legislature}

The IFAC is independent from both the government and the Oireachtas in its operations. However, the Minister of Finance is responsible for appointing council members. The Minister can also dismiss council members for cause but must have the approval of the lower house. The council can hire staff and lease premises but must have the "prior consent of the Minister, following consultation with the Minister for Public Expenditure and Reform", which does potentially limit administrative independence.

Concerning the Oireachtas, in November 2011, upon invitation of the Oireachtas Joint Committee on Finance, Public Expenditure and Reform, the Chair of the IFAC presented the council's first Fiscal Assessment report to this committee (see presentation to Oireachtas committee), which was followed by questions from committee members and discussions on the report. To maintain close relations with the Oireachtas, IFAC has continued to appear before this committee and posts transcripts of these appearances on its website. It may also appear before other committees as requested.

Under the FRA, the council is required to produce an annual report for the Minister who then forwards a copy to the parliament "as soon as reasonably practicable" (Article 13). The Office of the Comptroller and Auditor General is responsible for auditing the Fiscal Advisory Council's accounts which are sent to the parliament (Article 10). Dáil committees can also request that the Chair give evidence on the accounts, and committees in both houses 
can request that the Chair account for the performance of the functions of the council (Articles 11[1-2]).

To assess government's fiscal and economic projections, the council needs to understand recent budget outcomes and the modelling approaches used by the Department of Finance (DOF). The council is therefore reliant on access to information from the DOF, the Central Statistics Office and the National Treasury Management Agency (NTMA). IFAC (2012) has suggested that it might be useful to have written memoranda of understanding with some of these bodies to ensure an appropriate flow of statistical and other information. The council continues to maintain close ties with ESRI.

\section{Box 1. Role of the legislature in the budget process}

Ireland has a parliamentary system of government. The parliament (The Houses of the Oireachtas) is bicameral with a 166-seat lower house, Dáil Éireann whose members are elected by proportional representation and a 60-seat upper house, Seanad Éireann whose members are nominated or elected indirectly.

The Oireachtas must give legislative effect to budget measures announced by the government. The Dáil has greater budgetary powers than the Seanad. "Money bills" (the Finance Bill and Appropriations Bill) can only be initiated in the Dáil. The Seanad can make recommendations on such bills, but cannot amend them. On budget day (in mid-October in line with euro area rules) the Minister of Finance and the Minister for Public Expenditure and Reform announce new tax and revenue measures and new expenditure measures respectively in statements to the Dáil. Most attention at this stage is paid to changes to taxation and social welfare. On budget day, financial resolutions are passed by the Dáil, which give immediate effect to some of the budget's revenue-raising measures. These relate mainly to any tax changes which take effect immediately. The financial resolutions passed on budget day are confirmed by the passing of the Finance Bill within four months. The Finance Bill includes the other tax changes announced on budget day as well as technical changes to tax legislation.

The estimates of expenditure included in the budget documents set out the government's proposed allocations for each department and the main state agencies. A more detailed breakdown of the proposed allocations - the revised estimates - is presented to the Dáil in December. Debate by the legislature on these estimates usually takes place in February and March (via the relevant Dáil sectoral committees), after which the Dáil votes to authorise the spending. During this time spending may continue under the reversionary budget rules. The Oireachtas committees invariably invite the Ministers in charge of a spending area to assist them to carry out their scrutiny role. Since 2011, the traditional estimates have been reformatted on a programmatic basis, incorporating some performance information. However, the committees "consider" the estimates without recommendation, and the Dáil cannot amend the spending estimates. It can only approve or reject proposed expenditure. The Dáil is further constrained by the convention that the vote on the budget (in October) can be considered a vote of confidence in the government. The annual budget cycle is completed when the Appropriation Bill is passed in the following December, giving formal legislative effect to the earlier Dáil votes on the estimates. Supplementary Estimates are presented where additional expenditure above Dáil approved expenditure is expected in a Department/agency or where within an Estimate virement for a new purpose occurs.

Traditionally the budget process has been a secretive affair, with the precise allocations brought forward by the government tending to be a fait accompli with little input from the 


\section{Box 1. Role of the legislature in the budget process (cont.)}

parliament ex ante. In 2011, as part of its Comprehensive Expenditure Review 2012-2014, the government proposed as of 2012 an opening up "of the budget process to greater parliamentary oversight, scrutiny and active participation". This proposal took into account recommendations which it cited from two earlier Oireachtas reports: 1) the 2005 Second Report of the Public Accounts Committee (PAC): Proposals for Alterations in the Way that Estimates for Expenditure are Considered by Dáil Éireann, which called for the annual estimates process to be brought forward to allow a more substantive role for Dáil Éireann and its committees in contributing to the expenditure planning process before the precise allocations for the year in question were determined; and 2) the 2010 Joint Oireachtas Committee on Finance and the Public Service report on Macroeconomic Policy and Effective Fiscal and Economic Governance which called for the introduction of multiannual budgeting, and for the reformatting of estimates to show all costs, administrative overheads and activities against each project or programme to allow for more meaningful Dáil scrutiny (Government of Ireland, 2011a). There are some signs of increased parliamentary engagement ex ante. In recent years, the parliament has devoted resources to some Committees for greater scrutiny of the Estimates on a programmatic basis.

Ex post, the Standing Committee of Public Accounts (PAC) plays a key role in ensuring that there is accountability and transparency in the way government agencies allocate, spend and manage their finances. The PAC examines and reports on the reports of the Comptroller and Auditor General (C\&AG), notably those relating to departmental expenditure and other accounts, as well as the C\&AG's value-for-money reports. Hearings of parliamentary committees are open to the media and the public, and their proceedings are usually published.

Technical support on the budget is available to the Oireachtas from the staff of its Library \& Research Service and some parliamentary committees have devoted staff time to help scrutinise the Estimates; but, overall, such support is limited.

Note: A total of 43 are elected by serving politicians (both national and local), to five panels to represent vocational interests (culture and education, agriculture, labour, industry and commerce, and public administration), three are elected by graduates of the National University of Ireland and three by graduates of the University of Dublin (Trinity College), and 11 are nominated by the Taoiseach.

Source: Oireachtas Library and Research Service (2011), www.oireachtas.ie/parliament, www.president.ie, http:// per.gov.ie/public-expenditure.

\section{Legal basis for establishment}

The FRA 2012 provides the legal underpinnings for the establishment of IFAC as an independent body. Further EU regulations (July 2013) resulted in the council being assigned the role of endorsing the macroeconomic forecasts produced by the Department of Finance on which budgets and stability programmes are based (implemented by Ministers and Secretaries Amendment Act $2013^{4}$ ). The process of this additional function is outlined in the Memorandum of Understanding between the Council and the Department of Finance. ${ }^{5}$

\section{Mandate}

The mandate of the Irish Fiscal Advisory Council is:

- To assess the official forecasts produced by the Department of Finance. These are the macroeconomic and budgetary forecasts published by the department twice a year - in the stability programme update in the spring and in the budget in the autumn. ${ }^{6}$ 
- To assess whether the fiscal stance of the government is conducive to prudent economic and budgetary management, including by reference to the EU Stability and Growth Pact.

- To monitor and assess compliance with the budgetary rule as set out in the Fiscal Responsibility Act. The budgetary rule requires that the government's budget is in surplus or in balance, or is moving at a satisfactory pace towards that position.

- In relation to the budgetary rule, to assess whether any non-compliance is a result of "exceptional circumstances". This could mean a severe economic downturn and/or an unusual event outside the control of the government which may have a major impact on the budgetary position.

- To endorse, as it considers appropriate, the macroeconomic forecasts prepared by the Department of Finance on which the budget and stability programme update are based.

The endorsement function represents an evolution in the IFAC mandate and an amendment to the FRA. In April 2013, the Irish government announced that the IFAC would be assigned the role of independently endorsing the macroeconomic forecasts on which the 2014 budget was based.

The council's mandate to provide a view on whether the fiscal stance is "conducive to prudent economic and budgetary management" could arguably allow for a certain amount of flexibility to undertake work on longer-term sustainability, fiscal risks or other issues.

The council submits its assessment reports to the Minister for Finance and within ten days releases them publicly. If the government does not accept the council's assessment of its compliance with the requirements of the budgetary rule (as set out in the FRA), the Minister for Finance must lay a statement before Dáil Éireann outlining the government's reasons for not accepting it.

\section{Functions}

Consistent with its mandate, IFAC began publishing assessments of the government's medium-term fiscal outlook in October 2011. It currently publishes two assessment reports a year. Typically these reports have four substantive parts, notably the assessments of: macroeconomic forecasts (including a comparison of the growth forecasts of the Central Bank of Ireland, the EU and the IMF); budgetary forecasts; compliance with fiscal rules; and the fiscal stance.

The council has developed a fiscal-feedback model for assessing the potential impacts of macroeconomic/budgetary developments and changes in the fiscal policy stance. The model was used to assess whether the targets for the general government deficit would be achieved. The council has also adopted the use of fan charts to illustrate uncertainty. Furthermore, the fiscal feedback model has been extended beyond the 2015 horizon.

Given its macro-fiscal focus, the council does not scrutinise each new budgetary policy proposal presented by the government to the Oireachtas in its annual finance bill and detailed spending estimates for each fiscal year. It is outside the council's mandate to conduct detailed costing of policy proposals, including the fiscal component of election platforms of the various political parties or of the coalition agreements of incoming governments. ${ }^{7}$ The council does publish analytical notes and working papers on its own initiative. 


\section{Work programme}

The council is responsible for setting its own work programme in accordance with its mandate. The council regulates its own quorum and generally meets once a month, although much of its work is done via e-mail or phone. Among the priorities are to prepare two fiscal assessment reports. These reports are published in June and November after the Stability Programme Update and the budget respectively. The council also prepares Annual Reports, and the first such report (for FY 2013) has been published. The content of the Annual Reports include a summary of IFAC activities in the previous 12 months. The council can undertake analysis at its own initiative (for example, it commissioned a consultant to prepare a study on Fiscal Rules for Ireland, which was timed to provide input to the fiscal rules sections of the FRA). Separate research papers are published on the council's website.

\section{Budget}

For HY 2011 and FY 2012, the council was funded through a grant-in-aid provided by the government, capped at EUR 650000 in 2012. As of FY 2013, the council's budget is guaranteed under the FRA and paid directly out of the state's central fund (similar to independent institutions such as the judiciary and the parliament). Unlike most other public expenditure, this type of funding stream ("non-voted" expenditure) is not subject to annual voting and authorisation by the Dáil on the proposal of the government, and as such provides a very high level of protection, as well as multi-annual stability of funding. New legislation would be required to modify or withdraw funding. The budget allocation under the FRA provides a ceiling of EUR 800 000, indexed to the rate of inflation. While the level of funding has been sufficient to date, there is some question as to whether the council's role will evolve and accordingly should be reviewed in future. Early on, several council members worked voluntarily and remaining members received a stipend. This was seen as unsustainable and council members now receive a time buy-out. IFAC has full flexibility on how to spend its funds within the ceiling provided; however it has faced some challenges, for example, Ireland's effective hiring limits in the public service have made hiring additional secretariat staff somewhat more difficult than anticipated in practice.

\section{Staffing}

\subsection{Leadership}

The five members of the council are appointed by the Minister for Finance. The Minister also designates the Chair from the council members. The FRA specifies that when choosing council members, due regard should be paid to competence and experience in domestic and international macroeconomic or fiscal matters and that, to the extent practicable, there be "an appropriate balance between men and women in the membership". Council members cannot hold or stand for political office.

The FRA provides for a four-year term, renewable once. This is decoupled from the election cycle of five years for the parliament. Initially, the interim council members were appointed on terms with staggered durations ranging from two to four years.

Council members may be removed from their posts by the Minister prior to the end of their terms, but only if Dáil Éireann passes a resolution providing for the removal and stating the grounds for it (article 4[3]). The FRA (article 4[2]) defines potential reasons for dismissal as follows: 
a) the member has become incapable through ill-health of effectively performing the functions of the office;

b) the member has committed stated misbehaviour;

c) the member has a conflict of interest of such significance that, in the opinion of the Minister, the member should cease to hold the office; or

d) the removal of the member appears to be necessary for the effective performance by the Fiscal Advisory Council of its functions.

A council member can also be disqualified from holding office if he or she:

a) is adjudicated bankrupt;

b) makes a composition or arrangement with creditors;

c) is convicted on indictment of an offence, or is convicted outside the State of an offence consisting of acts or omissions which would constitute an offence triable on indictment if done or made in the State;

d) is convicted of an offence involving fraud or dishonesty; or

e) has a declaration under Section 150 of the Companies Act 1990 made against him or her or is subject or is deemed to be subject to a disqualification order by virtue of Part VII of that Act. (Article 4[4]).

A member of the Fiscal Advisory Council may also resign on their own accord by sending a letter of resignation to the Minister of Finance. Where there is a vacancy (however occasioned) in the membership of the council, the Minister shall, if it is reasonably practicable to do so, appoint a replacement before the end of the period of 6 months (Article 1[4]).

The first council is comprised of the Chair and four members, all appointed by the Minister for Finance in July 2011 after a search for qualified people and a government decision. The first Chair is a university professor with extensive experience in economics and public finance. Other members of the first council had backgrounds serving in ESRI, the IMF, the OECD and academic institutions. Council members are not required to be Irish nationals and one member of the first council is not an Irish citizen. An international presence on the council is thought to enhance its objectiveness. Three of the five original members resided outside of Ireland.

The work of the council entails a very significant, on-going time commitment, despite being part-time, especially as its members generally have substantial other professional responsibilities. The council adopted a principle that full-time employees of the Irish public sector or international organisations of which Ireland is a member and whose budget it contributes to, should not gain financially from their membership on the council. Arrangements are in place to compensate members' full-time employers for the time commitment necessary to fulfil the council's mandate. If a member's employer does not come within these categories or there is no relevant employer, the fee is payable to the member concerned. On this basis, fees payable are as per Category 2 Non-commercial State-sponsored Bodies, set by the Department of Public Expenditure and Reform. Fees per annum are: EUR 20520 for the Chair and EUR 11970 for the members.

\subsection{Staff}

Initially IFAC had three full-time secretariat staff all of which were hired on a secondment basis. The council has since added two additional staff to further develop its 
modelling and forecasting capabilities. ${ }^{8}$ The IFAC has benefited from secondments from, for example, the Central Bank of Ireland, the National Treasury Management Agency, the Department of Public Expenditure and Reform and the ESRI. The budget in the FRA provides the council with the flexibility to hire staff, although as noted earlier, prior approval for new hiring (more specifically the number of posts, not the individuals recruited to the posts) is needed from the government, which can be seen as a limit on its administrative independence.

Council members and staff are subject to the Code of Practice for the Governance of State Bodies and have developed their own Code of Business Conduct which includes a section on conflict-of-interest.

\section{Access to information}

While the FRA is not explicit regarding the right of IFAC to information to perform its duties, article 8(7) endows it with "all such powers as are necessary for, or incidental to, the performance of its functions". The FRA does make provisions prohibiting the disclosure of confidential information. Confidential information is defined as, "information that is expressed by the Fiscal Council or, in the case of information supplied to the Fiscal Council by the Minister, by the Minister to be confidential either as regards particular information or as regards information of a particular class or description". It may be useful in future to clarify, or make more explicit, the parameters by which either the Minister or the council might decide to designate information as confidential so as to avoid even the perception of lack of transparency. The council has developed a Memorandum of Understanding with the Department of Finance, given its endorsement function.

To date, the council reports that it has been provided with reasonable access to government information, although there have been some cases where slow responses have delayed IFAC analysis. In general, delays have been due to the information requested not being easily accessible.

\section{Transparency}

The council seeks to be highly transparent in its activities. Its main reports have been published on its website, as well as official communications and information on its meetings with government, the Oireachtas and other agencies (see fiscal advisory council external meetings).

IFAC will also continue to be transparent concerning its methodology used for assessments. For example, Box 3.2 of IFAC (2011) describes the council's fiscal feedback model. This was further developed and explained in a second assessment report (IFAC, 2012c).

News conferences are held for each of its two annual fiscal assessment reports. To date, there has been extensive media interest in council publications. For special studies, the council decides on the most appropriate outlet for presentation. ${ }^{9}$ The Chair and some council members have participated in interviews with the media. Finally, the positive role of the council was highlighted early on (and continues to be) in respected periodicals and its work on measures of output has received significant attention (e.g. The Economist in 2013).

\section{Governance, advisory support, monitoring and evaluation}

As noted earlier, being a state-funded institution, the council is subject to audits by the Comptroller and Auditor General. The council's Annual Report includes audited IFAC 
financial statements. The relevant committee of the Oireachtas may choose to scrutinise the audit report.

Besides oversight by the external auditor and the Oireachtas, the council has suggested strong accountability arrangements for its activities. More specifically, IFAC (2012a) proposed that a peer review take place on a regular basis (e.g. every four years) and that for transparency, the peer review would be published on the council's website.

A three-member independent peer review group, including a former Chair of the Swedish Fiscal Policy Council, was appointed in early 2015 to provide an independent evaluation of IFAC outputs in line with the IFAC Strategic Plan 2014-16. The terms of reference for the independent evaluation ${ }^{10}$ stated that the peer review group would: "assess the performance of the Council with respect to its mandate and obligations under the FRA"; consider its context, inputs, outputs and impact; and refer to the OECD Principles for Independent Fiscal Institutions. The reviewers would also seek the views of key stakeholders such as the Department of Finance/Department of Public Expenditure Reform, the Oireachtas Joint Committee on Finance and Public Expenditure and Reform, the academic community and the media. Its final report was submitted to IFAC and sent by the council to the Minister for Finance and the Oireachtas Joint Committee on Finance and Public Expenditure and Reform and published on the IFAC website in June 2015. The overall assessment of IFAC in the evaluation was a positive one.

\section{Concluding remarks}

As a still relatively new organisation, the Irish Fiscal Advisory Council has already established a track record as an independent voice advising the government, the parliament and the public on short-term and medium-term fiscal adjustment and debt sustainability issues. It is also beginning to receive considerable media coverage. It continues to improve its communications, focussing on accessibility of key messages. Initially, government reactions to IFAC reports were limited; but the government now includes detailed responses to IFAC analyses in its economic publications (including its stability programme updates). The council's mandate (and capacity) have evolved as a result of its new role in independently endorsing the macroeconomic forecasts. Another area where the council's role is evolving is in looking at long-term sustainability issues or other issues directly linked to its mandate of assessing the "prudence" of national fiscal policy. The external evaluation also noted that proposals for a new role in the costing of election manifestos and budget proposals, going beyond the costing of individual proposals which is already done by the Department of Finance and looking at the overall impact of a package of proposals (Junong, Begg and Tutty, 2015).

The first peer review has been useful not only in assessing the mandate (and related capacity) and quality of work so far, but also its institutional arrangements, for example, to ensure access to information and the council's continued independence.

\section{Notes}

1. This section has benefited greatly from Section 1 of Department of Finance (2011), which provides details on the budgetary and economic context of fiscal reform. Haugh (2011) also provides useful background. In this text, "Department of Finance" is used generically, covering both the present Department of Finance and the new Department of Public Expenditure and Reform that was created in 2011 when the previous Department of Finance was split. 
2. For further information on the economic adjustment programme for Ireland, see http://ec.europa. eu/economy_finance/assistance_eu_ms/ireland/index_en.htm.

3. In May 2011, the experience of Sweden's Fiscal Council was presented and discussed at a Department of Finance seminar, along with other international perspectives from the UK Office for Budget Responsibility and the OECD. See www.finance.gov.ie/viewdoc.asp?DocID=6868).

4. See www.fiscalcouncil.ie/wp-content/uploads/2011/07/en.act_.2013.0029.pdf.

5. See www.fiscalcouncil.ie/wp-content/uploads/2011/07/IFAC_MoU_Readable.pdf.

6. Up to 2012, the annual budget had traditionally been presented in early December. From 2013, in line with euro area rules, the budget has been brought forward to October each year.

7. The function of providing costings for policy proposals of political parties, in particular in the context of general elections, is carried out by the Department of Finance. Protocols are in place to ensure that these costings are treated by the department as confidential, although political parties may disclose them publicly if they wish.

8. It should be noted that the Department of Finance only maintains a small forecasting unit, only slightly larger in size.

9. For example, IFAC (2012a), which is a formal response to the Department of Finance (2011), was presented by the Chair of the council at an economics conference in Dublin in late January.

10. The terms of reference have been published on the council website at www.fiscalcouncilie/wpcontent/uploads/2015/03/Terms-of-Reference_website.pdf.

\section{Bibliography}

Department of Finance (2011), Reforming Ireland's Budgetary Framework: A Discussion Document, March, Department of Finance, Dublin.

Economic and Social Research Institute (2015), www.esri.ie.

Ferris, T. (2012), "Highlighting the Need for Greater Fiscal Responsibility", Public Affairs Ireland, No. 81, PAI, Dublin, pp. 4-5, www.publicaffairsireland.com/journal.

Government of Ireland (2010), The National Recovery Plan 2011-2014, Government Publications Sales Office, Dublin, www.budget.gov.ie/The\%20National\%20Recovery\%20Plan\%202011-2014.pdf.

Government of Ireland (2011a), “Comprehensive Expenditure Report 2012-14”, Government Publications Sales Office, Dublin, www.budget.gov.ie/budgets/2012/Documents/CER\%20-\%20Estimates\%20Final.pdf.

Government of Ireland (2011b), "Programme for Government 2011", Department of the Taoiseach website, Dublin, www.taoiseach.gov.ie/eng/Publications/Publications_Archive/Publications_2011/ Programme_for_Government_Publications.html.

Haugh, D. (2011), “Getting Back on Track: Restoring Fiscal Sustainability in Ireland”, OECD Economics Department Working Papers No. 909, OECD, Paris.

IFAC (2011a), Fiscal Assessment Report, November, Irish Fiscal Advisory Council, Dublin, www.fiscal council.ie/wp-content/uploads/2011/10/FiscalAssessReport_V1.1.pdf.

IFAC (2011b), Memorandum of Understanding between the Council and the Department of Finance, www.fiscalcouncil.ie/wp-content/uploads/2011/07/IFAC_MoU_Readable.pdf.

IFAC (2012a), Strengthening Ireland's Fiscal Institutions, January, Irish Fiscal Advisory Council, Dublin.

IFAC (2012b), Fiscal Assessment Report, April, Irish Fiscal Advisory Council, Dublin.

IFAC (2012c), Fiscal Assessment Report, September, Irish Fiscal Advisory Council, Dublin.

IFAC (2013), Code of Practice for the Governance of State Bodies, Irish Fiscal Advisory Council, Dublin, www.fiscalcouncil.ie/wp-content/uploads/2013/02/codepractstatebod09.pdf.

IFAC (2013), Code of Business Conduct, Irish Fiscal Advisory Council, Dublin, www.fiscalcouncil.ie/wpcontent/uploads/2013/03/IFAC-Code-of-Business-Conduct2014.pdf

International Monetary Fund (2010), "Ireland: Request for an Extended Arrangement - Staff Report", IMF Country Report No. 10/366, December, IMF, Washington, www.imf.org/external/pubs/ft/scr/2010/ cr10366.pdf.

Irish Fiscal Advisory Council (2015), www.fiscalcouncil.ie. 
Junong, Lars, Begg, Iain, and Tutty, Michael G. (2015), How is the Irish Fiscal Advisory Council Performing? An Independent Evaluation of the First years of IFAC, Irish Fiscal Advisory Council, Dublin, www.fiscalcouncil.ie/wp-content/uploads/2012/01/PeerReview_Formatted_23062015.pdf

Kopits, George (2011), "Independent Fiscal Institutions: Developing Good Practices", OECD Journal on Budgeting, Vol. 11, No. 3, OECD, Paris, www.oecd.org/gov/budgeting/Independent\%20Fiscal\%20 Institutions.pdf.

OECD (Forthcoming), "Review of Budget Oversight by Parliament: Ireland", OECD Journal on Budgeting, Vol. 15/3.

Oireachtas (2010), "Report on Macroeconomic Policy and Effective Fiscal and Economic Governance, Houses of Oireachtas", Joint Committee on Finance and Public Service, Fourth Report, November, Oireachtas, Dublin.

Oireachtas Library and Research Service (2011), “Economic Indicators”, No. 7, November, Oireachtas, Dublin.

\section{Legislation}

Fiscal Responsibility Act 2012.

Memorandum of Understanding between the Council and the Department of Finance, www.fiscal council.ie/wp-content/uploads/2011/07/IFAC_MoU_Readable.pdf.

Ministers and Secretaries Amendment Act 2013, www.fiscalcouncil.ie/wp-content/uploads/2011/07/en.act_. 2013.0029.pdf. 


\section{Italy}

Parliamentary Budget Office (Ufficio parlamentare di bilancio, Upb)

Established: 2013, operational in 2014.

Enabling legislation: Law No. 243 of 2012, which implemented Constitutional Amendment Act No. 1 of 2012.

Mandate: Analysis and monitoring of public finance developments and evaluation of compliance with the budget rules.

Budget: EUR 6 million per annum (EUR 3 million provided by each house of parliament) (2014).

Staff: Three board members and plans to recruit 30 staff for the first three years, ${ }^{1}$ after which the number of staff may be raised to 40 . 


\section{Context}

The law establishing the Italian Parliamentary Budget Office represents the culmination of a decade of debate around the quality of public finance information. ${ }^{2}$ Over time, several proposals have been advanced to reform the institutions providing technical support to decision-makers, particularly the parliament, including proposals for the creation of new independent bodies to assess and verify fiscal developments.

This debate came to a head following Europe's most severe recession (2008-09), which created significant fiscal challenges for many European Union (EU) member countries, including Italy, ${ }^{3}$ exacerbating budget deficits and public debt levels. The economic downturn also highlighted the need to improve co-ordination of fiscal policies among EU member countries, given the potential spillover of economic effects from one jurisdiction to another.

In response to these systemic pressures, the European Union (EU) introduced a package of five regulations and one directive (i.e. the six-pack) to strengthen fiscal and macroeconomic surveillance among EU members, which entered into force on 13 December 2011. The six-pack strengthened the existing Stability and Growth Pact (SGP), which previously set two fiscal targets: the deficit among member countries would not exceed $3 \%$ of GDP and public debt levels would not exceed $60 \%$ of GDP. The six-pack was subsequently complimented by two additional regulations (i.e. the two-pack) intended to further strengthen surveillance mechanisms, which inter alia, stipulated that common budgetary rules at the national level "shall be monitored by independent institutions". The two-pack came into force in May 2013.

The Italian Parliament passed amendments to Italy's constitution in 2012 that reflected the EU reforms. Article 97.1 of the constitution was amended to direct that "general government entities, in accordance with European Union law, shall ensure balanced budgets and the sustainability of public debt". Taking effect in 2014, it reinforced existing fiscal rules followed by Italy pursuant to the SGP pertaining to deficit and debt-to-GDP targets.

Following this, Law No. 243 of 2012 (i.e. the law) was passed in late 2012 to implement the administrative framework for the constitutional amendments. In particular, the legislation stipulated the scope and time period for balanced budgets (Chapter II); corrective mechanisms in the case of a missed fiscal target (Chapter III); how budgets of lower levels of government will be balanced, limits on their borrowing and the establishment of a fund to support local governments in financial difficulties because of unfavourable cyclical developments - all in order to contribute to overall sustainability (Chapter IV); and the establishment of an "Independent Body for the analysis and monitoring of public finance developments and evaluation of compliance with fiscal rules" (i.e. the Parliamentary Budget Office, Chapter VII).

As part of the preparation of the law, the Chairs of the Budget Committees of both chambers formed a technical working group made up of officials from the Senate and Chamber of Deputies, representatives of the Ministry of the Economy and Finance 
(specifically the Office of the State Accountant General and the Treasury Unit), the Office of the Presidency of the Council of Ministers (Unit for Relations with the Parliament), representatives of the Court of Auditors, the Bank of Italy and the National Institute for Statistics (Istat). The working group completed its task on 24 September 2012 and forwarded its findings to the Chairs of the Budget Committees. On the basis of the working group's findings, several parliamentary bills were presented in the two chambers at the end of November 2012.

The Budget Committees considered different models for independent fiscal institutions in other countries, including comparative work available from international organisations such as the OECD. A defining feature of the Italian $\mathrm{PBO}$, and one that was the subject of considerable debate during the consideration of the bill, is its collegial leadership structure, which is more typical of the "fiscal council" models than the "PBO" models found in OECD countries. While it was ultimately decided to establish a governing board, the Chair is accorded a position of seniority over the other members and has considerable discretionary powers over the direction of the office's activities.

The final legislative text was approved by large majorities of both the Chamber of Deputies and the Senate. ${ }^{4}$

\section{Relationship with the executive and the legislature}

The PBO is an independent institution attached to the parliament (Article 16.1 of the law), and is currently located in separate premises within the parliamentary precinct. While attached to Parliament, the law also stipulates that the "office shall enjoy full autonomy and independence in its judgements and assessments" (Article 16.2). This independence is secured in large part through provisions around the appointment process and the discretion of the PBO's board in managing all aspects of their operations.

The parliament plays a role in the appointment process for the PBO governing board, considers the PBO's work plan, budget and financial reports, and provides the appropriation for the PBO. The board of the PBO is responsible for providing the Presidents of the Senate and Chamber of Deputies with an annual preliminary budget for the organisation and an annual financial report; however, the parliament cannot alter the content of these reports. Ongoing accountability is also to be exercised through parliamentary review of the PBO's reports and testimony by the Chair before committees upon request (Article 18.2). The Budget Committees held their first hearings with the PBO in the autumn of 2014; several hearings have taken place in both 2014 and 2015.

One aspect of the PBO's functioning that differs from the majority of its OECD counterparts is the "comply or explain" rule: should the $\mathrm{PBO}$ make assessments that significantly differ from those of the government, then at the request of at least one-third of the members of the Budget Committee of either house, the government must explain its position or accept the assessment of the PBO (Article 18.3). With a view to strengthening the role of the parliament, the legislation provides that the "comply or explain" obligation is not automatically triggered by a mere divergence, even a significant one, between PBO and government assessments; rather, the parliament must trigger this mechanism. This stipulation is not expected to diminish the role of the independent body because the opposition parties have an evident interest in seeking a clear explanation from the government for its actions, and because it helps avoid the risk of overlap between the office's activities and the parliament's constitutionally enshrined function of government 
oversight. Arguably, parliamentary discussion of $\mathrm{PBO}$ assessments that diverge from those of the government is an ideal way of ensuring they receive maximum public visibility and are accorded due importance. Publication of PBO work on its institutional website (Article 18.4) is a useful means of attracting the necessary attention of the general public.

\section{Box 1. Role of the legislature in the budget process}

The Italian parliament is comprised of two houses: the Chamber of Deputies (630 deputies) and the Senate (315 senators) whose members are directly elected for a period of five years. The President of the Republic is elected for a seven-year term by a secret parliamentary ballot requiring a majority of two-thirds of a joint sitting of both houses.

The Italian parliament exercises considerable power over budget deliberations and currently each chamber has equal budget powers. However, a significant reform process is underway which would turn the Senate into a regional assembly with drastically reduced powers, making the Chamber of Deputies pre-eminent in the parliamentary budget process. As such, many of the Senate's powers described below would be modified or eliminated.

While the budgetary proposals originate from the government, either house of the parliament can approve amendments to the final bill. The amendments proposed by the parliament (or by the government) have to comply with the target balances set forth in the Update of the Economic and Financial Document: thus, if they entail a higher expenditure, the amendments must be offset. These principles, which were initially regulated by the budget law reform in 1988 and then enshrined in the parliamentary Rules of Procedure, have been strengthened by the recent introduction of EU regulations governing budgetary process, timelines and content, as well as the current fiscal challenges faced by EU member states requiring fiscal retrenchment - this was reflected in Constitutional Law No. 1 of 2012 and in the relevant implementing Act No. 243 of 2012. Amendments proposed number in the thousands although many were not viable and only a small number were approved. Amendments are often more show than substance and are mainly focussed on operational expenditures. Notwithstanding the formal powers of the legislature to amend the budget, the final vote is considered a matter of "confidence" in the government.

The Italian government's fiscal year runs from January to December. Consistent with the two-pack regulations adopted by the EU) in mid-April the government presents the parliament with an Economic and Financial Document (DEF) that contains two components: a stability programme update that outlines medium-term fiscal plans and the national reform programme that articulates policy priorities for growth and employment for the coming 12 months. The parliament then considers these policy documents for approximately three weeks prior to their required approval before the end of April. The relatively short period between presenting these documents and their approval constrains parliamentary debate and scrutiny.

In mid-September, the government presents an updated DEF in the parliament, which provides revised macroeconomic and public finance forecasts, as well as updated planning targets that integrate comments from the EU Council. This is followed by the tabling of the budget in mid-October, which comprised two components: a stability law that presents qualitative and quantitative measures necessary to achieve the objectives set out in the Update of the Economic and Financial Document (e.g. maximum level of debt to be financed, changes in the tax rates) and a central government budget bill that delineates planned expenditures by policy areas, referred to as "missions". As part of a series of ongoing reforms, the government is planning to merge these two documents into one as of 2017. The budget is approved by the end of December. 


\section{Box 1. Role of the legislature in the budget process (cont.)}

The Chamber of Deputies and the Senate each have a parliamentary committee (currently the Chamber of Deputies' Budget, Treasury and Planning Committee and the Senate's Economic Planning and Budget Committee) with primary responsibility for public finance or budgetary issues, which are the focal point for consideration of the budget bills. However, all parliamentary standing committees examine aspects of the budget pertinent to their area of responsibility. These sectoral standing committees provide opinions on the budget bill and can advance amendments to change allocations within the same "mission". The recommendations of these sectoral committees are then considered by the principal Budget Committees. These proceedings are open to the public. The text approved by the Budget Committee is then examined by the whole house, which has the power to amend it further.

The Budget Committees in both houses are supported by specialised staff (see Box 2).

The PBO has discretion regarding engaging with other entities and institutions that produce macroeconomic or public finance forecasts and assess those of the central government, such as the Central Bank, the EU or international institutions, private research centres, social partners (e.g. Confindustria and trade unions) or local authorities. When the public finance and budgetary documents are presented to the parliament, the parliamentary committees with responsibilities for financial affairs hold hearings with these entities (usually Italian) competent in the field of public finance. These entities appraise the government forecasts and the content of the fiscal measures and express an opinion that may be favourable or critical.

\section{Box 2. Existing specialised budgetary support in the Italian parliament}

In 1989, the Italian parliament established two in-house units that offer specialised, nonpartisan, technical support to legislators. The State Budget Department and the Senate Budget Service were created as part of a larger package of parliamentary reforms to improve fiscal stewardship. While both are available to assist individual legislators and parliamentary committees, their efforts primarily focus on supporting the work of the principal Budget Committees in the Chamber of Deputies and Senate. Both are established pursuant to internal parliamentary protocols.

The State Budget Department exclusively supports the Chamber of Deputies with its assessment of legislative fiscal considerations, in particular the annual budget bill. The department has a staffing complement of approximately 15 lawyers and economists. It produces several types of reports, including: analyses of the executive's budget proposals, cost estimates of other legislation and proposed policies, as well as broader economic analyses. All reports are available on the Chamber of Deputies' website.

The Senate Budget Service exclusively supports the Senate in its assessment of the fiscal impacts of proposed legislation. The service has had approximately nine full-time staff with specialties in law and economics, although this will likely change with the planned reforms to the Senate. It produces four types of reports: analyses of the executive's budget proposals, verification of the executive's cost estimates of proposed policies and legislation, economic analyses and other "policy briefs" that provide short descriptions of complicated budget proposals and concepts. All reports are made available to the public on the Senate's website. 


\section{Box 2. Existing specialised budgetary support in the Italian parliament (cont.)}

It is as yet unclear how these two services will evolve following the reform to the Senate.

The budgets of both organisations are part of the overall appropriations of the Chamber of Deputies and Senate. Nominal resources are available to retain external expertise required to prepare analytical reports.

As noted in Section 9, the PBO has developed two memoranda of understanding (MoU) related to its role in assessing the macroeconomic forecasts and the public finances:

- Framework Agreement between the Office of the Parliamentary Budget and Istat, 7 August 2014.

- Memorandum of Understanding between the Office of the Parliamentary Budget and the Ministry of Economy and Finance, 15 September 2014.

\section{Legal basis for establishment}

The creation of the PBO was provided for by Article 5.1(f) of Constitutional Law No. 1 of 20 April 2012 (with the relevant articles coming into force in January 2014), which required a qualified majority and multiple readings in both houses of the parliament. Its organisational structure and functions are defined in articles 16 to19 of Law No. 243 of 2012. In adopting these legislative forms, Italian legislators have provided an additional safeguard.

\section{Mandate}

The mandate of the PBO is clearly defined under Article 18.1, which stipulates that:

The office shall perform analyses, audits and assessments of:

a) macroeconomic and public finance forecasts;

b) the macroeconomic impact of major legislative measures;

c) public finance developments, including by subsector, and compliance with budget rules;

d) the long-term sustainability of public finances;

e) the activation and use of the corrective mechanism and deviations from targets arising from exceptional events; and

f) other matters of economics and public finances pertinent to the analyses, audits and assessments referred to (above).

Given that the legislation outlines both specific functions (subsections a to e) as well as an open-ended statutory authority to undertake ancillary work on a discretionary basis, the mandate could be considered broad.

While the timing for the production and release of the named reports is not specified in legislation, many are directly linked to the existing parliamentary budget process (see Box 1). This includes the verification of forecasts and estimates presented by the government as part of the annual budget plan. Much of the verification and assessment work performed under the PBO's mandate will be prepared consistent with the budget process.

The constitution stipulates that the balanced budget and debt sustainability principles apply to the general government (Articles 81.6 and 97.1), which includes regional and local 
government entities as well as other government-controlled, arm's-length organisations. Overall, this extended mandate ensures that the $\mathrm{PBO}$ is able to perform a comprehensive assessment of the Italian fiscal context. At the same time, its broad remit may lead to a common problem faced by many PBOs: priority-setting in a context of limited resources.

\section{Functions}

As described above the law (Article 18.1) defines PBO functions, although several aspects leave room for some interpretation by the PBO. For example, in assessing and endorsing macroeconomic and public finance forecasts, the PBO has the freedom to pursue various options including making its own alternative forecasts. For the start-up period, it has chosen to use three independent forecasts as benchmarks, as well as Istat's model, although development of the public finance part of this model is ongoing. In future, the PBO plans to develop its own macroeconomic forecasting model.

Some issues have already arisen regarding the timing of the endorsement process and the availability of information. More specifically, information on the structure of the budget measures, of which the policy scenario is an essential element, was received too near the time of the final validation, creating challenges for discussion between those responsible for producing the policy framework and those called upon to validate it.

The PBO also has a role in monitoring compliance with fiscal rules, assessing longterm sustainability, policy costing and studies on economic and public finance issues at its own initiative. An example of work undertaken on its own initiative is the 2015 study on derivatives which received significant attention in the parliament and in the media. Regarding the fiscal rules, in keeping with the common principles developed by the European Commission for the implementation of the fiscal compact, the PBO also verifies the activation and use of the corrective mechanism to counter significant deviations from the targets set in financial and budgetary planning documents.

The law also requires the $\mathrm{PBO}$ to provide its own assessments of deviations from budget objectives in the case of exceptional events (e.g. severe economic recession or natural catastrophes). The $\mathrm{PBO}$ will not provide normative advice or policy recommendations.

\section{Work Programme}

As noted earlier, the PBO's work programme is framed by its legislative mandate, as well as by European Union laws and regulations that provide key benchmarks for the Italian budget process. For example, the requirement to perform an assessment of "compliance with budget rules" is ostensibly linked to the budget laws presented by the government, which must adhere to EU rules.

Beyond the fulfilment of functions assigned under EU law, the Law No. 243 provides that the PBO will adopt an annual "programme of activities" or work plan (Article 18.4) that will be presented to each of the Budget Committees by the PBO Chair and published on the PBO's website. ${ }^{5}$ The timing will be decided by the PBO which will take into account the budget cycle and the timing of the transmission to the parliament of the relevant public finance documents/bills.

The legislative mandate provided to the PBO permits it to perform both proactive and directed work. At the same time, legislation also provides that parliamentary committees with responsibility for budgeting or public finances can request work from the PBO. This 
raises questions around potential capacity constraints and how the PBO will prioritise work. Currently, the PBO prioritises work as much as possible based on the relevance of the subject to its overall workload.

\section{Budget}

Article 19 of the law sets out the funding levels and funding mechanism for the PBO. As noted earlier, beginning in the year 2014, an appropriation of EUR 3 million will be made by each house of the parliament to underwrite $\mathrm{PBO}$ operations, providing for an annual budget of up to EUR 6 million a year. ${ }^{6}$ This is a permanent financing arrangement designed to give the $\mathrm{PBO}$ adequate stability in preparing its spending programme. Administrative services (e.g. rent and utilities) are provided by the Chamber of Deputies and Senate and are in addition to the PBO's EUR 6 million budget.

Under statute, this appropriation can only be amended through the annual budget legislation, pursuant to advice from the PBO governing board. The law provides that regardless of any amendments (i.e. increases or decreases in budgetary allotments), the funding must be adequate to "ensure effective performance of the [PBO] mandate", hence the budgetary appropriation cannot be cancelled (Article 19.1).

The board of the PBO is responsible for the office's financial management and must provide the Presidents of the Senate and Chamber of Deputies with an annual preliminary budget and a financial report for the previous fiscal year, which are published as annexes to their parliamentary financial reports (Article 19.2). The goal of this provision is to ensure transparency, as the parliament cannot alter the content of the preliminary budget or the financial report.

\section{Staffing}

\subsection{Leadership}

The PBO has a collegial governance structure, or governing board, with three members, one of whom holds the position of Chair (Article 16.2). The Chair has certain prerogatives and responsibilities, including: convening board meetings and setting the agenda; representing the $\mathrm{PBO}$ externally; testifying on behalf of the $\mathrm{PBO}$ at parliamentary hearings; presenting the annual PBO work programme to the Budget Committees; and appointing the PBO Director General from among the PBO staff. The Director General will supervise PBO operations (e.g. hire and arrange secondments for other staff). Similar to members of the board, the Director General is required to have experience in the field of economics and public finances.

The Chair and members of the governing board are selected by the Presidents of the Senate and Chamber of Deputies from a shortlist of ten candidates compiled by their respective committees with responsibility for public finance. This rather novel procedure presented some difficulties in practice, including a rather drawn out first appointment process. Nominees require the endorsement of two-thirds of committee members and are selected based on their "recognised independence and proven expertise and experience in the field of economics and public finances at a national and international level" (Article 16.2).

The members of the board are appointed for six-year non-renewable terms, which is independent of the five-year electoral cycle. This, and the fact that their appointment is non-renewable, helps to protect against political pressures. Once appointed, board members are prohibited from engaging in virtually all other professional endeavours. This includes public office, employment in the public or private sectors or memberships on 
other boards or associations. Given these restrictions, the position is considered to be a full-time activity and remunerated commensurately: the Chair receives a salary equivalent to the Chair of the Italian Competition Authority and other members receive a total salary of $80 \%$ of that level Article 16.2). While the legislation is silent regarding the nationality of appointees, the recent OECD Economic Survey for Italy (2013) did suggest that the governing board could consider including non-Italian members as has been the case for example in Denmark, Ireland, Portugal and Sweden.

If the terms of a board member's appointment are violated (e.g. through acceptance of other employment or affiliations), members can be removed by the Presidents of the Chamber of Deputies and the Senate acting on a motion approved by two-thirds of the members from the two Budget Committees. Again, this procedure may change due to the reforms of the Senate.

The first governing board was appointed on 30 April 2014, four months after the PBO was supposed to be operational. The first Chair (or President) was an academic with experience working with the Ministry of Economy and Finance and international organisations such as the International Monetary Fund. The other two members of the governing board (or "Advisors") include a second distinguished academic with experience working with the Ministry of Economy and Finance and conducting research at the United States Congressional Budget Office, and a key budgetary advisor to the Senate with experience working with the Ministry of Economy and Finance and the OECD.

The governing board is responsible for preparing the initial organisational chart for the PBO, which is to be approved by the Presidents of the houses (Article 16.4). This includes, inter alia: an organisational structure, communications strategy and internal policies and procedures, as well as the legal status and remuneration of staff. Finally, legislation provides that the governing board may establish a Scientific Committee composed of individuals with "proven experience" in "economics and public finance" to offer guidance regarding the operational methodologies of the office (Article 18.5).

\subsection{Staff}

The law stipulates that the "PBO shall act with complete autonomy in the selection of its staff, basing its choices solely on merit and competence and its own operational needs" (Article 17.1). During the first three years of operations, the number of PBO staff cannot exceed 30 people. Thereafter, it cannot exceed 40 (Article 17.4). Office staff will come from several sources, including:

- permanent staff hired through public competition;

- individuals hired on contracts of up to three years, renewable once;

- individuals seconded from Parliament, other general government entities or public bodies such as the Central Bank, Ministry of Finance and Istat.

A year into its operations, the PBO is still operating with a skeleton staff of around five economists and five administrators, although recruitment of another six economists was underway. This first group of staff were almost entirely seconded from the Ministry of Economy and Finance, the national statistical office and the Bank of Italy. One economist had joined the PBO from the in-house budget department of the Chamber of Deputies.

PBO staff are organised into three units covering macroeconomic analysis; public finance analysis and sectoral analysis (with analysts looking at both the tax and expenditure sides). These units are nonetheless highly interconnected. 


\section{Access to information}

The right of the $\mathrm{PBO}$ to access information pertinent to its mandate is provided in its statute (Article 18.6). The law provides that the PBO shall interact with all branches of general government, public bodies and publicly owned entities, requiring them not only to communicate data and information, but also to co-operate in any way that the office deems helpful to the fulfilment of its institutional duties (Article 18.6). To facilitate the office in the performance of its duties, these bodies and entities are required to grant the PBO access to any databases relating to the economy and public finances that they have created and/or maintain. Access to data and information is subject to general restrictions relating to confidentiality and privacy imposed by ordinary law.

The PBO has developed two MoUs to further facilitate access and is working on an agreement with the Ministry of Economy and Finance for more direct access. These are the:

- Memorandum of Understanding between the Office of the Parliamentary Budget and the Ministry of Economy and Finance, 15 September 2014, which covers information necessary for the endorsement of the macroeconomic forecasts and evaluation of the public finances.

- Framework Agreement between the Office of the Parliamentary Budget and Istat, 7 August 2014, which is a co-operation agreement on macroeconomic forecasting models and microsimulation of the effects of tax policies.

The two Budget Committees that the PBO serves are also guaranteed access to relevant information through article 6 of Law No. 196 of 2009 on public finances and accounting. Overall, there are no explicit restrictions placed on the types, timing or procedures regarding information access and access to information has been fairly smooth, but it is still early days.

\section{Transparency}

Consistent with the draft Principles for Independent Fiscal Institutions prepared by the OECD, the law provides that the analyses and reports of the PBO are to be published on the organisation's website (Article 18.4). This extends to the underlying methodologies for these reports, including the structure and assumptions of fiscal forecasting and costing models. The PBO has also undertaken to publish a wide range of information online, for example on its regulations, administrative procedures, staff and budgets. The website is being translated into English.

The PBO has direct contact with the media, with the Chair in the role of spokesperson. The PBO held a news briefing at the start of the 2015 budget session and is developing its contacts with key reporters at major newspapers. Media coverage has been rather limited so far, except in specific cases. The PBO is also planning to engage relevant civil society organisations and to create tools such as accessible infographics to facilitate public engagement.

\section{Governance, advisory support, monitoring and evaluation}

To guarantee the authoritativeness of the analyses carried out by the PBO, Article 18.5 of the reinforced law specifies that the board may set up a Scientific Committee composed of people of proven experience and expertise in the field of economics and public finances at a national, European or international level. The mandate of this committee would be to offer guidance on the operational methodology of the PBO, including technical aspects of analyses. The committee may be composed of academics, experts and senior European 
and international officials, and may also include members of national institutions working in the field of public finance. Plans to set up this committee are underway as of early 2015.

Legislation is silent regarding monitoring and evaluation mechanisms for the PBO. However, as noted earlier, the publication of all reports and analyses will provide an ongoing informal mechanism for stakeholders to track PBO performance. As well, consistent with the PBO role in determining Italian compliance with EU fiscal regulations (i.e. deficit and debt sustainability), it may be that the European Commission will monitor the credibility and quality of $\mathrm{PBO}$ analyses in this area.

The PBO has already established a Board of Auditors charged with verifying PBO financial management and accounting, and giving opinions on the PBO draft annual budget and its implementation during the year, and reporting in the PBO Annual Report. The Board of Auditors may also give opinions on other administrative and accounting matters.

\section{Concluding remarks}

The arrangements for the $\mathrm{PBO}$ reflect the vast majority of the good practices outlined in the OECD's Principles for Independent Fiscal Institutions. If successful, the PBO could play an important role in changing the incentives inherent in the political budgeting system by enhancing the role of the legislature and promoting greater transparency and fiscal discipline.

The PBO complements and expands existing research and analytical capacity available to the parliament. To this end, the $\mathrm{PBO}$ is expected to focus with an economic perspective and approach on macro aspects of proposed budget laws, including sectoral analyses and the evaluation of the economic impact of main measures. This approach toward priority-setting is consistent with the principal impetus for establishing the PBO: to assess compliance with EU directives regarding fiscal management.

Implementation of the PBO has not always been as timely as anticipated. Following a rather lengthy appointment process, the governing board had to quickly begin the recruitment process and write its internal regulations in order to be ready in September 2014 to undertake its first assessment of the forecasts and the fiscal stance. Recruitment of the planned 30 staff was still ongoing in early 2015 with less than a quarter in place. Another key short and long-term challenge is communications, including building a relationship with the media, which is off to a positive start, and further developing communication tools such as its website which is already fairly comprehensive. An English version is under construction.

Over the longer term, the PBO will also need to carefully manage its relationships with other actors in the Italian system of budgetary management. For instance, the law stipulates a discrete, but complementary, role for the Supreme Audit Institution vis-á-vis the $\mathrm{PBO}$ (Article 20). Specifically, the Court of Auditors is expected to perform ex post audits of "budgetary management". As such, both institutions are expected to work in unison to support Article 97.1 of the constitution (i.e. achieving balanced budgets and ensuring public debt sustainability).

More broadly, given the paramount PBO role in assessing Italy's fiscal alignment with EU budgetary directives, it will be essential to ensure that this work is deemed credible by both the European Commission and the executive. The PBO is working with the other European IFI's to ensure better communication and information-sharing with the European Commission. 


\section{Notes}

1. As of early 2015, current staffing was limited to a "start-up" group of around six economists and five administrative staff. Posts for an additional 11 economists were being advertised as part of the PBO's ongoing recruitment.

2. In their discussion of the potential role of an independent fiscal institution (IFI) in Italy, Balasonne, Franco and Goretti (2013) identified the following weaknesses in Italy's fiscal framework that an IFI could help address: "unsatisfactory quality and opacity of data used as input in the decisionmaking process; unreliable baseline estimates, including incomplete disclosure of the underlying assumptions and methodology; lack of authoritative evidence-based analyses to support policy design; poor information systems hindering effective monitoring; and loose protocols delaying reactions when deviations emerge."

3. Since late 2011, Italy has undertaken structural reforms and fiscal consolidation policies aimed at addressing a legacy of weak growth and high public debt (the public-debt-to-GDP ratio is nearing $130 \%$ ), but continues to be impacted by the euro-area crisis (OECD, 2013).

4. There were only three votes against in the Chamber of Deputies and four votes against in the Senate.

5. A first work programme for 2014 has been published on the website.

6. Article 19.3 stipulates: "The operating costs, EUR 6 million per year starting from 2014 as indicated in paragraph 1 , shall be covered by means of a corresponding reduction in the projected value of the special current account fund for 2014, which, for accounting purposes, shall be recognised in the three-year budget for 2012-14 under the 'contingency and special funds' programme, which forms part of the 'Funds to be allocated' mission in the 2012 estimates of the Ministry of the Economy and Finance. Part of the sum, EUR 2 million per year starting from 2014, shall be drawn down from the ministry's appropriation, and the remaining EUR 4 million per year as of 2014 from the appropriation of the Ministry of Labour and Social Policies."

\section{Bibliography}

Ercoli, R. (2010), “Restrictions on Parliament's Role in the Budget Process: The Italian Case”, presentation at the OECD Parliamentary Budget Officials (PBO) Annual Meeting, OECD, Berne, 11 February, www.oecd.org/governance/budgeting/44695302.pdf.

European Commission (2015), http://ec.europa.eu/economy_finance/articles/governance/2012-0314_six_pack_en.htm, http://europa.eu/rapid/press-release_MEMO-13-318_en.htm, http://ec.europa.eu/ economy_finance/eu/countries/italy_en.htm, http://europa.eu/rapid/press-release_MEMO-13-196_en.htm.

Forestiere, C. and R. Pelizzo (2008), "Dynamics in Legislative Budgeting in Italy: 1982-2001", Journal of Legislative Studies, Vol. 14, No. 3, Routledge, London, pp. 279-296.

Balassone, F., D. Franco and C. Goretti (2013), "What Role for Independent Fiscal Institutions in Italy?", in G. Kopits (ed.), Restoring Public Debt Sustainability: The Role of Independent Fiscal Institutions, Oxford University Press, Oxford.

Cabras, D. (2011), "Recent Budget Reforms in Italy: Adjusting the Budgetary Decision-Making System to the new European Economic Governance System", presentation at the OECD Parliamentary Budget Officials (PBO) Annual Meeting, OECD, Stockholm, 28-29 April, www.oecd.org/gov/budgeting/ 47742045.pdf.

Goretti, C. (2013), "Law 243 of 24 December 2012: Provisions for the Application of the Balanced Budget Principle Pursuant to Article 81.6 of the Constitution", prepared remarks at the OECD Parliamentary Budget Officials (PBO) Annual Meeting, OECD, Ottawa, 21 February, www.pbo-dpb.gc.ca/files/files/ Italy\%20-\%20Legge\%20n\%20243\%202012_eng.pdf.

Groppi, T. (2012), "The Impact of the Financial Crisis on the Italian Written Constitution”, Italian Journal of Public Law, Vol. 4, No. 1, IJPL, Milan, www.ijpl.eu/archive/2012/issue-11/the-impact-of-the-financialcrisis-on-the-italian-written-constitution.

Ministry of Economy and Finance (2010), "Law 196 Short Note", Italian Ministry of Economy and Finance, Rome, www.rgs.mef.gov.it/_Documenti/VERSIONE-I/Pubblicazioni/Note-brevi/La-legge-d/ Versione-inglese-La-legge-di-contabilit--e-finanza-pubblica-pdf.

Ministry of Economy and Finance (2011), "Italian Budget Cycle and Macroeconomic Projections", presentation to an Albanian delegation, Italian Ministry of Economy and Finance, Rome, www.dt.mef.gov.it/export/sites/sitodt/modules/documenti_en/analisi_progammazione/eventi/budget_ cycle_macroeconomic_projection.pdf. 
Ministry of Economy and Finance (2013), "Italy's Fiscal Framework", presentation to a conference Fiscal Arrangements in Europe, Berlin, 18 February, Italian Ministry of Economy and Finance, Rome, www.dt.tesoro.it/export/sites/sitodt/modules/documenti_it/analisi_progammazione/eventi/ Italyxs_Fiscal_Framework.pdf.

Ministry of Economy and Finance (2015), www.dt.tesoro.it/en/analisi_programmazione_economico_ finanziaria/documenti_programmatici/sezione3/index.html.

OECD (2011), "Parliamentary Budget Officials Network Survey: Background Note on Committee Structures for Budget Approval and Oversight", presented at the OECD Parliamentary Budget Officials (PBO) Annual Meeting, OECD, Stockholm, 28-29 April, search.oecd.org/officialdocuments/ displaydocumentpdf/? cote $=$ GOV/PGC/SBO(2011)6\&doclanguage $=e n$.

OECD (2013), OECD Economic Survey: Italy 2013, OECD, Paris.

Parliament of Italy (2015), Chamber of Deputies and Senate, www.parlamento.it/home.

Parliamentary Budget Office of Italy (Ufficio parlamentare di bilancio) (2015), www.upbilancio.it/.

Piccardi, Cristina (2012), "The Economic Crisis and the National Parliaments: The Italian Experience", European Centre for Parliamentary Research and Documentation (ECPRD), Working Group on Economic and Budgetary Affairs, ECPRD, 7 June, www.parlamento.it/documenti/repository/ affariinternazionali/ecprd2012/4_Piccardi_EN.pdf.

Scotti, Italo (2009), "Profiles of Italian Parliamentary Budget Institutions", presentation at the OECD Parliamentary Budget Officials (PBO) Annual Meeting, OECD, Rome, 26 February, www.oecd.org/gov/ budgeting/42464643.pdf.

Senate Budget Service (2013), "Establishment of an Italian Parliamentary Budget Office", Nota breve No. 2, April, Senate of Italy, Rome, www.senato.it/application/xmanager/projects/leg17/attachments/ dossier/english_versions/000/000/011/NB02_English_.pdf.

Trezzani, C. (2012), "Fiscal Consolidation and Growth: The Italian Experience", prepared comments at the OECD Parliamentary Budget Officials (PBO) Annual Meeting, OECD, Paris, 23 February, www.oecd.org/gou/budgeting/49788978.pdf.

\section{Legislation}

Constitution of Italy, www.governo.it/Governo/Costituzione/principi.html.

Constitutional Amendment Act No. 1 of 2012, www.normattiva.it/uri-res/N2Ls? urn:nir:stato:legge. constituzionale:2012-04-20;1.

Law No. 196 of 2009 (Accounting and Public Finance), www.normattiva.it/uri-res/N2Ls?urn:nir:stato:legge: 2009-12-31;196.

Law No. 243 of 2012 (Provisions for the application of the balanced budget principle pursuant to Article 81.6 of the Constitution), www.normattiva.it/uri-res/N2Ls?urn:nir:stato:legge:2012-12-24;243 



\section{Korea}

\section{National Assembly Budget Office (NABO)}

Established: 2003.

Enabling legislation: National Assembly Act 1948 (amended 1991, 2005, 2011, and 2014) and National Assembly Budget Office Act 2003.

Mandate: To provide the National Assembly with objective budget analysis and evaluation.

Budget: USD 13.6 million (2015).

Staff: 138 (2015). 


\section{Context}

The establishment of the National Assembly Budget Office (NABO) in 2003 was linked principally to political developments rather than to a need for an independent body to monitor fiscal imbalances. Indeed, Korea has persistently followed a prudent fiscal stance. Even at the time of the Asian crisis in 1997-98, the consolidated fiscal balance for general government remained in surplus. ${ }^{1}$ When NABO was being established, general government gross debt was less than 25 per cent of GDP.

In the 1990s, Korea was deepening the democratisation process that had begun in 1987 under the sixth republic. In 1992, the country's first civilian President in 30 years was elected. The parliament was strengthened and given new capacity including the National Assembly Legislative Budget Office, established in 1994 and part of the parliamentary service. In 2000, this office was reorganised into a Legislative Counselling Office and a Budget Policy Office. Then in 2003, NABO was formally established by law as an independent office.

The main impetus for establishing NABO in 2003 stemmed from the political situation. In December 2002 a candidate from the Democratic Party won the presidency for the first time. However, in the National Assembly, the Grand National Party still held the majority of seats. With divided government, the National Assembly majority had a strong interest in creating an independent budget office to scrutinise the new President's draft budgets. Nevertheless there was broad cross-party consensus for the establishment of NABO and NABO continues to enjoy cross-party support today.

Although divided executive and legislative power in 2003 was the major reason why NABO was formally created, the legislature also struggled with a lack of transparency in the government's budgetary data. The Asian crisis had revealed the problems associated with having a segmented budget system. General and special accounts were presented to the National Assembly, but public funds were outside the purview of the parliament in 1997/98. While efforts had been made to broaden the coverage of the annual budget, in 2000 there was still a need to rationalise extra-budgetary funds and special accounts (which had been growing), to integrate all central government fiscal activities into the budget and to publish consolidated data for general government in a timely manner (IMF, 2001). There was also a debate at political level on the size of public debt, especially as to whether governmentguaranteed debt should be included in the definition of public debt.

Korea looked to the United States Congressional Budget Office (CBO) as a model for its legislative budget office and certain similarities between the two are evident. For example, NABO serves only the legislature and has similar functions and internal structures. However, NABO has an evaluation role that is unique among PBOs in the OECD countries.

\section{Relationship with the executive and the legislature}

NABO exclusively serves the National Assembly. The House Speaker appoints NABO's director. The NABO Act 2003 indicates that NABO must prepare reports for committees and 
members of the National Assembly. However, the law does not contain specific reporting requirements, which provides NABO with some discretion. In practice, each year NABO provides extensive budget-related documents to the National Assembly. Although NABO's main means of communicating with the legislature is by written documents, the NABO chief provides evidence before the two budget-related committees mentioned in Box 1 below. ${ }^{2}$ Appearances of senior NABO staff before parliamentary committees are rare, in part because the committees have their own staff to respond to their budget-related questions.

Both the Board of Audit and Inspection (BAI) (which is also an independent institution under the executive ${ }^{3}$ ) and NABO prepare evaluations of government programmes and projects. However, the BAI and NABO do not typically co-operate on this work, since the BAI focuses on financial audits of government programmes, whereas NABO focuses on describing specific government programmes, analysing their effectiveness and, in some cases, making policy recommendations. ${ }^{4}$

In its operational work, NABO is entirely independent of the executive. For example, NABO's medium-term fiscal projections are prepared completely separately from those of the government. Nonetheless, NABO communicates with government departments to obtain information for its analytical work.

\section{Box 1. Role of the legislature in the budget process}

Korea has a presidential system of government. The presidential and legislative elections are on non-synchronised cycles. The National Assembly is unicameral and 245 of the 299 seats are elected by direct representation ( 54 seats are filled by proportional representation).

The 1948 constitution requires the draft budget to be presented to the National Assembly 90 days before the start of the fiscal year and adopted 30 days before the new fiscal year begins. This provides the National Assembly with 60 days for scrutinising and debating the President's draft budget. The constitution does not allow the National Assembly to introduce amendments to the budget that increase any expenditure item or create a new expenditure item without the consent of the executive. In contrast, the National Assembly can amend revenue proposals without any restriction.

The National Assembly Act 1948 established a Special Committee on Budget and Accounts, with 50 members, whose role is to review the draft annual budget, the draft fund management plan and all budget-related matters. Currently, sectoral committees make recommendations to the Special Committee on Budget and Accounts, which accepts or rejects the recommendations after reviewing them, although this may change somewhat to reflect the National Assembly's wish to institute a more "top-down" format. A Finance and Economy Committee examines tax proposals. Some reports of these two committees are published. Committee meetings where the budget is discussed are generally open to the public. The two budget-related committees have 20 to 30 full-time staff working for them.

In Korea, there are autonomous think tanks that publish studies on budget-related issues and whose reports are complementary to those of NABO. Examples include: the Korea Institute of Public Finance, which analyses tax and expenditure policies and publishes various fiscal studies; and the Korea Development Institute (KDI), which researches economic and social issues. The KDI has analysed public finance issues 
(e.g. medium-term expenditure frameworks) and provides independent forecasts. Since these institutions were set up by the government, they are seen as primarily serving the executive, not the National Assembly.

\section{Legal basis for establishment}

Two laws underpin NABO's creation. First, the National Assembly Act 1948 was amended in July 2003 to establish NABO's autonomy within the National Assembly. Second, the National Assembly Budget Office Act, also adopted in July 2003, elaborates on the duties and organisational arrangements for NABO.

\section{Mandate}

NABO has a broad mandate for budget analysis and evaluation. According to Article 22-2(1) of the amended 1948 legislation, NABO is "to research, analyse and appraise matters concerning the settlement of the budget, and the management of funds and finances of the state as well as to support parliamentary activities". The NABO Act 2003 further identifies five specific duties: budget analysis, costing, forecasting, evaluation, and research. In 2014, the National Assembly Act was amended to strengthen NABO's costing role. ${ }^{5}$ The institutional coverage of NABO's activities in the NABO Act is stated to be the budget and funds. ${ }^{6}$

The National Finance Act 2006 and its subsequent amendments specified new documents that the government must submit to the National Assembly. These include a National Fiscal Management Plan and a Fund Management Plan. Both plans require medium-term and long-term projections. This has expanded NABO's mandate since NABO has a duty to analyse the documents that the government prepares on these issues. NABO has therefore extended the projection period for its own baseline fiscal projections, and analyses more fully the management of autonomous government funds and long-term structural fiscal issues (e.g. future pension fund spending).

\section{Functions}

The 2003 NABO Act identifies five main functions: budget analysis, costing, forecasting, evaluation and research. More specifically, under Article 3, NABO is mandated to conduct:

- research and analysis on the budget bill, the final accounts of the budget, draft plans for the administration of funds and the final accounts thereof;

- estimation of the costs required by bills and other matters involving expenditure from the budget or funds;

- analysis of and prospects for macroeconomic trends and the administration of national finance;

- analysis and evaluation of major national projects and analysis of medium-term and long-term financial requirements; and

- research and analysis on any matters required by a committee or member of the National Assembly.

NABO strives to ensure that its analysis is provided to the National Assembly in a timely manner. For example, for the FY 2011 budget, after the President submitted the draft budget to the National Assembly on 2 October 2010, NABO released its analysis of the budget on 20 October. Similarly, to assist the National Assembly to analyse medium-term 
budget soundness, NABO presented its own projections for revenues, expenditure (both discretionary and mandatory), the fiscal balance and government debt. NABO's medium-term projections covered the same five-year period and used the same conceptual framework as the government to facilitate direct comparison, especially the differences in revenue, expenditure and structural fiscal budget projections, and its analysis of "budget soundness".

Regarding long-term forecasting, since NABO prepares an analysis of the MOSF's updates of the medium-term National Fiscal Management Plan and the Ministry of Strategy and Finance (MOSF) prepares long-term fiscal projections (the 2006 National Budget Act requires the MOSF to prepare such projections), NABO has begun to prepare 50-year projections using the long-term demographic projections of the National Statistics Office. These projections are being refined with a view to publishing long-term fiscal scenarios in 2012. NABO's intention is to update its long-term projections every two to three years. NABO does not, however, cost policies promised in pre-election manifestos of major political parties.

The 2003 NABO law does not restrict it from making recommendations. However, "the independence of NABO's duties must be respected" (Article 2) and making policy recommendations is not one of NABO's explicit duties. In its macro-fiscal analysis, NABO limits itself to general suggestions on the overall fiscal stance, to changes in budget processes or to technical issues. For example, in its 2011-14 Economic and Fiscal Outlook, NABO recommended that an expenditure-based fiscal rule would be needed to restore budget soundness and to reach the government's fiscal objective of achieving a "managed budget" surplus by $2014 .^{7}$

NABO prepares a wide range of evaluations each year, from infrastructure projects to government assistance to autonomous public institutions. ${ }^{8}$ Evaluations often make recommendations for improving a programme's operations and effectiveness. Some evaluations have led to handbooks on a specific issue ${ }^{9}$ to assist the National Assembly in its future budget deliberations. In many countries, such evaluations are performed by the supreme audit institution or by ministries' internal audit units. The main reason for the establishment of a strong evaluation function in NABO is that the BAI, although independent, is perceived by the legislature to be under the government. However, since the BAI focuses on financial audits, the potential for overlap is small.

NABO conducts research and analysis on major taxation issues and suggests appropriate directions for tax policies and revenue systems. To this end, NABO has developed various techniques for estimating tax revenues over five years. These serve as the basis for analysing tax reform bills proposed by members of the National Assembly.

$\mathrm{NABO}$ has seen a steady rise in requests from members for cost analyses. For example, the average number of bills accompanied by NABO cost estimates stood at 62 in 2004 and 865 in 2013. Until recently, cost estimates for bills proposed by members could be carried out by the office of the relevant member or by NABO. This led to several problems as staff in the members' offices often lacked the necessary skills to carry out this task and exploited a loophole which allowed them to instead submit a "Statement of Reasons for No Cost Estimate Attached" when costs were deemed too technically challenging to estimate. ${ }^{10}$

In February 2014, the National Assembly Act was revised to:

- give NABO sole authority to prepare cost estimates for bills introduced by members; ${ }^{11}$

- strengthen requirements for bills amended or replaced during committee deliberations to be submitted with revised cost estimates prepared by NABO; and 
- allow Members proposing legislation to seek opinions from NABO on the costs associated with enforcing that legislation while it is being deliberated in committee.

It is expected that these changes will ensure that costings are objective and reliable and that parliamentary debates will be better informed as to potential fiscal consequences of legislation.

Table 1. Legislative proposals with cost estimates: Trends 2004-14 ${ }^{12}$

\begin{tabular}{|c|c|c|c|c|c|c|c|c|c|c|c|c|}
\hline & \multicolumn{3}{|c|}{ Proposed by NA members } & \multicolumn{3}{|c|}{ Proposed by the government } & \multicolumn{3}{|c|}{ Proposed by NA committees } & \multicolumn{3}{|c|}{ Total } \\
\hline & Numbers & $\begin{array}{l}\text { Cost estimates } \\
\text { attached }\end{array}$ & $\%$ & Numbers & $\begin{array}{l}\text { Cost estimate } \\
\text { attached }\end{array}$ & $\%$ & Numbers & $\begin{array}{l}\text { Cost estimates } \\
\text { attached }\end{array}$ & $\%$ & Total & $\begin{array}{c}\text { Cost estimates } \\
\text { attached }\end{array}$ & $\%$ \\
\hline 2004 & 807 & 149 & 18.5 & 201 & - & - & 50 & - & - & 1058 & 149 & 14.1 \\
\hline 2007 & 1476 & 513 & 34.8 & 319 & 150 & 47 & 192 & 6 & 3.1 & 1987 & 669 & 33.7 \\
\hline 2010 & 2439 & 906 & 37.1 & 406 & 108 & 26.6 & 166 & - & - & 3011 & 1014 & 33.7 \\
\hline 2013 & 4934 & 1258 & 25.5 & 256 & 90 & 35.2 & 297 & - & - & 5487 & 1348 & 24.6 \\
\hline 2014 & 3707 & 867 & 23.4 & 309 & 88 & 28.5 & 330 & - & - & 4346 & 955 & 22.0 \\
\hline
\end{tabular}

It appears that NABO's advisory functions will continue to evolve. Specifically, there has been an initiative to align the National Assembly's budget review process with the topdown budgeting process followed by the government. The plan is to move from a system in which the budget is debated in the relevant standing committees before being forwarded to the Special Committee on Budget and Accounts to a system where the totals for the budget and the national debt are decided by the Special Committee on Budget and Accounts before deliberation in the standing committees. Second, since 2012, the Korean government has prepared a national fiscal management plan with separate categories for mandatory and discretionary spending which lays the groundwork for a pay-as-you-go ("PAYGO") system for mandatory spending (an area of the budget that is expected to grow rapidly in the coming years ${ }^{13}$ ). NABO is working to improve its cost estimates for bills subject to the PAYGO system and to further assist in parliamentary debates through realtime scorekeeping.

\section{Work programme}

NABO's draft annual work plan is prepared by NABO on the basis of each division's work plan and projected workload. The NABO Chief presents the draft work plan to the Speaker of the National Assembly who provides comments and recommendations prior to approving it. Suggested changes to the draft work plan tend to be relatively minor.

Although not specifically required by legislation, NABO produces a number of reports that are provided to the National Assembly budget-related committees in time for the discussion of the draft annual budget and medium-term fiscal framework. Each year, NABO also produces other reports, primarily for the National Assembly. NABO also prepares cost estimates of some proposed legislation. NABO assesses how the new legislation would affect government revenues and expenditures during the coming five years. Also annually, NABO updates its plans for conducting evaluations of major programmes and other specific government policies.

Any committee or individual member of the National Assembly can request NABO to conduct studies that have an impact on the budget. NABO does not refuse such requests, e.g. on the grounds that their impact on the budget is minimal or that the issue is "too 
political". Since the National Assembly's budget-related committees' requests have higher priority, individual members' requests to NABO may be placed on a waiting list which, at times, is quite long (especially during the annual budget discussions in the National Assembly). Although NABO has the freedom to undertake research at its own initiative, nearly all of its work is in response to requests coming from the National Assembly.

\section{Budget}

NABO's budget is part of the overall budget of the National Assembly, which is appropriated independently in the national budget (Article 23 of the National Assembly Act 1948). To this end, the Speaker prepares a written budget request and presents it to the government after it goes through an examination by the House Steering Committee (the committee concerned with the National Assembly's operations and management). Before 30 April of each year, the MOSF provides guidelines to the National Assembly for preparing its budget. By 30 June, the Speaker transmits the National Assembly budget to the MOSF, but only for consolidation purposes. The National Assembly secretariat also provides to the MOSF a medium-term plan that includes new projects to be executed over a five-year period. In these medium-term projections, expenditures are indicative, not binding ceilings.

The publicly available annual budget and medium-term project plans contain the various subcomponents of the National Assembly's administrative budgets, notably those of NABO, the National Assembly's General Secretariat, the Library and the parliamentary Research Service. For NABO, a draft budget is prepared internally and submitted to the Secretary General of the National Assembly, who in turn submits it to the House Steering Committee for approval. Later, when the MOSF submits the consolidated draft budget to the National Assembly, the Special Committee on Budget and Accounts examines the National Assembly's own budget during its budget deliberations, before the budget is approved by the National Assembly in plenary session. In general, the NABO budget is approved at its various stages with little modification.

Since its creation, NABO's annual budget has increased significantly in real terms, mainly reflecting the increase in full-time staff. For example, the budget increased from USD 8.9 million in 2008 to USD 13.6 million in 2015.

\section{Staffing}

\subsection{Leadership}

The National Assembly Act (Article 22-2) indicates that NABO "shall have one director and other necessary staff. The director is appointed and dismissed by the Speaker of the National Assembly with the consent of the House Steering Committee." The NABO Act 2003 requires the Chief of NABO to be a public official in political service ${ }^{14}$ and that "in performing his/her duties, the Chief shall have expertise and maintain neutrality". Article 4 of the NABO Act also specifies the Chief's remuneration is to be the same as that of a vice-minister.

The NABO Act (Article 5) elaborates on the appointment process. Prior to requesting the consent of the House Steering Committee, "the Speaker shall receive recommendations from a Recommendation Committee that is composed of persons who have expertise concerning NABO's duties, maintain political neutrality and make fair recommendations." The members of the seven-person recommendation committee are respected public policy experts who are neither members nor public officials of the National Assembly and who are selected particularly for their objectiveness and non-partisanship. When considering 
choices for a new Chief, the recommendation committee considers around five candidates and then proposes a shortlist of two people to the Speaker, who makes a choice. Apart from "being in political service", "having expertise" and "maintaining neutrality", there are no other written criteria or restrictions (e.g. minimum age, academic qualifications, years of prior experience in public finance, nationality) to guide the committee and the Speaker in making their choices.

There is no defined term or term limit for the NABO Chief. Under the National Assembly Act (Article 9), the Speaker changes every two years, even though parliamentary elections are on a four-year cycle. In practice, every two years the NABO Chief resigns when there is a change of Speaker. A new House Speaker could reappoint the "resigning" NABO Chief for a further two-year period. However, since NABO's creation in 2003, no chief has stayed on for two complete two-year terms. The current practice creates considerable uncertainty as to who will be the new Chief when the House Speaker changes every two years. The House Speaker also has the power to dismiss the Chief. This happened in 2005 when the first NABO Chief was dismissed by the Speaker less than two years into NABO's operations on the grounds that the first Chief was unable to provide the non-partisan stance needed for NABO's activities. ${ }^{15}$

\subsection{Staff}

The National Assembly has an independent parliamentary service with its own entrance examinations and its own salary scales. The majority of NABO staff are part of the parliamentary service, although many staff are recruited on fixed-term contracts. ${ }^{16}$ According to the NABO law, staff above Grade V (division chiefs) are appointed and dismissed by the Speaker of the National Assembly, whereas other NABO staff are appointed and dismissed by the NABO Chief. For mid-career recruitments, NABO requires strong academic background as well as work experience. Such recruitment is based on open competition and vacancies are posted on the NABO website and in newspapers. In its early years, NABO experienced considerable turnover of staff under fixed-term contracts although this has decreased recently. NABO's younger recruits often enter directly into the parliamentary service from university and make a career in NABO. Candidates for professional positions should have a PhD or equivalent education, expertise in their field and a recognised research and publication record. During job orientation sessions for newly hired staff (and in job performance evaluations as well), NABO's Assistant Chiefs emphasise NABO's non-partisan stance.

NABO has a two-track system for remuneration. Those employed under the parliamentary service are paid according to the seniority-based system, whereas those under fixed-term contracts follow an annual merit-based salary system. NABO's base salaries are broadly similar to those of the government's civil service, although NABO has different allowances to those of the government. It is infrequent that civil servants with experience in, for example, the Ministry of Strategy and Finance would transfer "to the other side" and join NABO staff. Similarly it is infrequent for a NABO staff member to be recruited by a government ministry.

With 138 full-time equivalent (FTE) staff in 2015, and potential to grow, NABO is the second largest parliamentary budget office in the world in terms of staff (the CBO in the United States is the largest). In 2000, when the Budget Policy Office (BPO) was split off from the Legislative Counselling Office, the BPO had a staff of 41 (FTE). Substantial recruitment took place when NABO was created in 2003: 92 positions were approved and filled in 2004. 
During 2005-08, the number of NABO staff increased very slowly. During 2009-11 the growth of new positions accelerated, to nearly $10 \%$ per annum. ${ }^{17}$ Administratively, NABO has four main divisions: the Budget Analysis Division (with 51 staff); the Economic Analysis Division (34 staff); the Programme Evaluation Division (30 staff); and the Planning and Management Division (20 staff). ${ }^{18}$ NABO also makes extensive use of outside consultants for its work.

\section{Access to information}

The NABO Act 2003 permits the NABO Chief to request state organs to submit any materials necessary to perform their duties with the permission of the Speaker. Entities that receive such a request are required to comply, unless there is a special reason such as national security concerns. In practice, NABO receives all requested expenditure-related information from the government in a timely manner. However, there have been cases where revenue-related data was not provided in a timely way.

\section{Transparency}

All of NABO's regular analytic reports are published, in both printed and electronic form and are freely available for download on NABO's website. NABO's published documents are particularly useful for the Special Committee on Budget and Accounts and the Finance and Economy Committee, which are NABO's main "clients" in the National Assembly. In 2011, the following macro-fiscal documents were published (NABO, 2012b):

- Medium-term (2011-15) Economic Outlook

- 2011-15 Total Revenue and Fiscal Analysis

- Analysis of Tax Revision Bill

- Analysis of the 2011-15 National Fiscal Management Plan

- Analysis of 2012 Tax Expenditure Budget

- Budgetary Issues on 2012 Revenue Budget Proposal

- Comprehensive Review

The most important reports (e.g. those that analyse the administration's proposed medium-term macro-fiscal strategy and the annual budget) are translated from Korean into English and made available on NABO's English-language website. NABO also publishes the methodology and assumptions that underlie its own fiscal projections.

Each year, NABO publishes over 100 budget analysis reports. ${ }^{19}$ In addition, NABO typically prepares 400 to 500 cost estimates each year of various bills discussed by the National Assembly and makes about 200 estimates of tax proposals by members of the National Assembly. These estimates are not made public immediately. However, after about 25 days NABO asks for the cost estimates to be published. This request is usually granted by the relevant committee of the National Assembly. NABO also publishes annually a "casebook" of selected costings. Finally, NABO also prepares over a thousand on-demand research and analytical notes for individual members of the National Assembly each year. These notes are not published, as the elected members prefer to keep them confidential. ${ }^{20}$

The NABO relationship with the media has been cautious. NABO does not have a dedicated press officer to respond to questions from the media, although it monitors the frequency with which NABO is reported in the media. ${ }^{21}$ When NABO analysis is published, it is accompanied by a written Press Report. The published reports are designed to "speak 
for themselves". Nonetheless, the NABO Chief or senior NABO staff communicate directly with the media on occasion. For example, in August 2011, in an interview with the media, the NABO Chief highlighted various future spending risks (ageing population, low birth rate, possible reunification, etc.) and stated that "the nation needs to restore its fiscal position to balanced finances as soon as possible". ${ }^{22}$

Members of the National Assembly prefer to be at the forefront in direct relations with the media. When members of the National Assembly are interviewed by the media on budget-related matters, NABO may provide them with unpublished background briefing notes. However, NABO has recently initiated "grand conferences" on budget issues which have increased NABO's visibility in the media. These conferences, which are open to the public, have been attended by some 300 people, including members of the National Assembly, government ministries, the public and the media.

\section{Governance, advisory support, monitoring and evaluation}

NABO has a panel of outside advisors composed of one chairperson and 14 members. All are acknowledged experts in public finance and economics from universities, research institutes, government offices or the media. Members of the panel have two-year renewable terms. The panel's main role is to advise the NABO Chief (rather than NABO as an institution) on NABO's duties or other topics of concern.

NABO conducts annual internal audits of its activities. Regarding external oversight, the National Assembly Steering Committee may inspect NABO during its annual investigation of National Assembly activities. In examining the annual settlement of the budget of the legislative branch, the Special Committee on Budget and Accounts and the National Assembly review NABO's budget outcome. NABO is also audited annually by the Board of Audit and Inspection.

\section{Concluding remarks}

NABO celebrated its tenth anniversary in $2015 .{ }^{23}$ Over the years, NABO has established itself as a well-respected independent institution both nationally and internationally with a reputation for providing objective high-quality analysis. In its deliberations, the National Assembly uses NABO analysis of the government's draft budget as well as NABO costings, programme evaluations and other analysis. NABO's voice is heard and it has influenced the assumptions underlying the government's budget projections. NABO makes key analyses available to the public and has increased media and public outreach through news releases and, more recently, through conferences on the public finances which are open to the public. Indeed, media coverage of NABO's work has continued to increase over time.

One of the potential challenges faced by NABO is that the NABO Chief does not have a fixed term limit. The current practice of NABO chiefs resigning voluntarily every two years (when House Speakers are changed) is unusual when compared with other countries. There is a risk that the leadership of NABO may become subservient to, or be perceived as subservient to, the wishes of the Speaker and the political interests that he/she represents.

\section{Notes}

1. General government consolidates central and local governments and social security funds. Public enterprises are excluded. During the Asian crisis years, the fiscal surpluses of social security funds and local government surpassed the central government deficit. Government-guaranteed debt is 
excluded from debt data. For details, see IMF WEO database, www.imf.org/external/pubs/ft/weo/ 2011/01/weodata/index.aspx.

2. This is typically less than ten times a year.

3. The BAI is composed of seven commissioners, including the chair, who is appointed by the President with the consent of the National Assembly. The other commissioners are appointed by the President on the recommendation of the chair.

4. For example, in September 2011, NABO examined the impact of the social welfare subsidy on local governments' finances and made three specific policy recommendations (NABO, (2012a).

5. See amendments to Article 66 and Article 79-2.

6. There are two types of funds: "special accounts" and "public funds". Since 2001, the distinction between them has lessened since the revenues and expenditures of both types of funds are now required to be approved by the National Assembly. For further details, see Lienert and Jung (2004).

7. The government had a target of balancing the central government budget deficit (excluding social security funds) by 2013. NABO (2011) and IMF (2011) called for fiscal rules to achieve medium-term budget targets.

8. See "Program Evaluation Division" for the fields of work of evaluations carried out by five teams. The summary of 29 evaluations prepared in 2011 has been published in English. See NABO (2012a).

9. In 2010, NABO published handbooks on: the Government Grants Programme, the Government Loans Programme, the Government Investment Programme (in specific ministries), Public-Private Partnerships in Infrastructure, Programme Budget Projects, Government Subsidies to Local Government and Finance Programmes in Standing Committees.

10. As noted in a recent NABO publication, for the period between 2008 and 2012, National Assembly Members introduced 3198 bills. NABO provided cost estimates for about 30\% of them, or 973 bills; Members' offices provided cost estimates for $69.6 \%$ or 2225 bills. Of the 2225 bills costed by Members' offices, 85.4\%, or 1900 bills, were proposed without cost estimates attached (NABO, 2014).

11. This was in line with a recommendation from the final report of the National Assembly's Special Committee on Budget and Finance Reform.

12. Cook, 2014.

13. According to NABO's Fiscal Outlook, Mandatory spending is expected to grow at an average annual rate of 7\% from 2013 to 2017 (NABO, 2014).

14. Being a "public official in political service" can require previous experience in the parliamentary service. This is the case with Chief Kyung Bok Cook, for example, who was Senior Staff Director of four parliamentary committees, including the Special Committee on Budget and Accounts. He was also a Professor in the Parliamentary Training Office and an adjunct professor at two Korean universities. Among the final four candidates for the fourth chief, only two have previous work experience relating to the parliament.

15. The dismissal was associated with the results of the by-elections in 2005 when the Grand National Party lost its majority in the National Assembly.

16. In February 2012, 68 NABO staff were employed under parliamentary service rules and 54 staff were on fixed-term contracts.

17. The largest increase was in 2010 when two new units (11 positions) were created: a Tax Counsel and a Public Institutions Evaluation Unit. See information on the April 2010 NABO restructuring.

18. There are also four staff members in the NABO Chief's Office. See NABO's Organisation Chart on their website for the full structure.

19. A summary of NABO's publications in 2011 is contained in NABO (2012a).

20. A survey of satisfaction of the National Assembly members is conducted annually. In the surveys, a majority of members have expressed the view that NABO should not publish on-demand research notes.

21. For example, the number of television and newspaper reports on NABO in 2009 and 2010 amounted to 1363 and 1233 respectively.

22. See "Korea Needs to Return to Balanced Finances" (25 August, 2011, News and Events, NABO website).

23. A special publication commemorating NABO's first decade, Ten Years of the National Assembly Budget Office, provides a detailed history in Korean. 


\section{Bibliography}

Budget Office of the National Assembly of Korea (2015), http://korea.nabo.go.kr.

Cook, Kyung Bok, "Recent Reform of Cost Estimating in Korea and NABO's Role”, presentation prepared for the Meeting of OECD Parliamentary Budget Officials, Jerusalem, 31 March-1 April 2014, www.knesset.gov.il/mmm/oecd/Session3_Kyung_Bok_COOK.pdf.

IMF (2001), "Republic of Korea: Report on the Observance of Standards and Codes - Fiscal Transparency Module", International Monetary Fund, Washington, DC, www.imf.org/external/np/rosc/kor/ fiscal.htm.

IMF (2011), "Republic of Korea: 2011 Article IV Consultation - Staff Report", IMF Country Report 11/246, International Monetary Fund, Washington, DC, www.imf.org/external/country/index.htm.

Korea Development Institute (2015), www.kdi.re.kr/kdi_eng/.

Korea Institute of Public Finance (2015), http://eng.kipf.re.kr.

Lienert, I. and Moo-Kyung Jung (2004), "The Legal Framework for Budget Systems: An International Comparison", OECD Journal of Budgeting, Special Issue, Vol. 4, No. 3, OECD, Paris, www.oecd.org/ dataoecd/48/48/35933542.pdf.

NABO (2011), “2010-14 Economic Outlook and Fiscal Analysis", National Assembly Budget Office, Seoul, www.korea.nabo.go.kr/download.Pub.do?fileSID=615.

NABO (2012a), "Summary of NABO Publications", February, National Assembly Budget Office, Seoul.

NABO (2012b), "2011-15 Economic Outlook and Fiscal Analysis", National Assembly Budget Office, Seoul, www.korea.nabo.go.kr/downloadPub.do?fileSID=785.

NABO (2014), “The Development of Cost Estimating in Korea and NABO's Role”, March, National Assembly Budget Office, Seoul.

National Assembly of Korea (2015), http://korea.na.go.kr/int/org_06.jsp?leftid=AF.

Legislation

National Assembly Act 1948 amended by Act No. 6930, 18 July 2003.

National Assembly Budget Office Act No. 6931, 18 July 2003. 


\section{Mexico}

\section{Centre for Public Finance Studies (Centro de Estudios de las Finanzas Públicas)}

Established: 1998.

Enabling legislation: A resolution in 1998 by the Chamber of Deputies. CEFP's establishment was confirmed in the Organic Law of Congress in 1999.

Mandate: To provide objective, non-partisan, and timely analysis to the congress on the public finances.

Budget: MXN 50.9 million (2009).

Staff: 59 (2011). 


\section{Context}

The Centro de Estudios de las Finanzas Públicas (CEFP) was established in 1998 in the context of increasing democratisation. All political parties represented in the Chamber of Deputies signed the agreement establishing the CEFP and in September 1999, the CEFP was recognised in the Organic Law of Congress.

Elections in 1997 - the first under a set of reforms passed in 1996 to level the electoral playing field - ended the domination of the Partido Revolucionario Institucional (PRI) and marked a transition to a competitive multiparty system. ${ }^{1}$ The PRI lost its absolute majority nationwide and lost control of the Chamber of Deputies (the lower house of the congress). ${ }^{2}$ This period of divided government saw the congress beginning to take a more active role in the budget process, necessitating an increase in the congress's technical capacity for independent budget analysis.

Following the 1997 elections, a delegation of new members of the Chamber of Deputies undertook a study visit to the United States Congressional Budget Office (CBO). Although there are marked differences between the two institutions, the design of the CEFP as a nonpartisan budget analysis unit for the Mexican congress, and its budget-related committees more specifically, was influenced by the CBO model.

Unlike several other countries included in this study, the CEFP's establishment was less driven by concerns around economic issues such as problems with deficit bias or excessive indebtedness. Nevertheless, there was a need to improve the efficiency and transparency of the budget framework (IMF, 2002). Over the past decade, Mexico has undertaken a series of reforms in this regard, in particular the 2006 Budget and Fiscal Responsibility Law (BFRL). The BFRL reiterated and expanded the role of the CEFP with, for example, provisions giving the CEFP greater access to government budget information and requiring the CEFP to assess the budgetary impact of legislation proposed by the congress. ${ }^{3}$

\section{Relationship with the executive and the legislature}

The CEFP is under the jurisdiction of the legislature and, while it provides independent analysis, it cannot truly be categorised as an independent institution. It is overseen by the Chamber of Deputies' Committee on the CEFP. Typically members of this committee may also serve on the Finance Committee or the Budget and Public Accounts Committee. These are the two committees that the CEFP works most closely with, although it also provides analysis to other committees in the Chamber of Deputies such as the Finance Committee, to committees in the Senate and to individual legislators. The congress is responsible for the appointment of the Director of the CEFP; the CEFP budget is a component of the administrative budget of the congress; and CEFP offices are located within the Chamber of Deputies.

Although both report to the congress, the CEFP and the Federal Supreme Audit Office (FSAO) work autonomously from each other. The FSAO is an independent constitutional body with its own legislation. It reports to a dedicated audit committee in the Chamber of 
Deputies. Nevertheless the 1998 resolution establishing the CEFP has a provision allowing the CEFP to request from the FSAO (with permission of the relevant committee) information it deems necessary for its work.

\section{Box 1. Role of the legislature in the budget process}

Mexico has a presidential system of government with a bicameral congress. The President is elected every six years for a six-year non-renewable term. The 500-member Chamber of Deputies, or lower house, is elected every three years and the Senate, or upper house, is elected every six years by a combination of proportional and direct representation. One of the particularities of the congress is that deputies and senators may not be elected for consecutive terms, making the Mexican congress one of the only democratically elected legislatures in the world whose membership is completely renewed at each election. The Chamber of Deputies plays the dominant role in the budget process.

The 2006 Budget and Fiscal Responsibility Law (BFRL) sets out the role of the congress in the budget process and the timetable for legislative approval. Before submitting the budget the executive presents two reports to the congress: the first in April contains the macroeconomic projections for the next fiscal year, the second in June outlines the programme structure of the budget including proposed new programmes. The executive presents its expenditure and revenue budgets to the congress by 8 September. The latter must be approved by the Chamber by 20 October and the Senate by 31 October. The expenditure budget must be approved by the Chamber only by 15 November, well before the start of the new fiscal year on 1 January.

The Chamber has the power to amend the draft budget within certain limitations. It cannot change the programmatic structure submitted by the executive or deny funding for expenditures that the executive is legally or constitutionally obliged to make (e.g. federal transfers or entitlement spending). It may increase expenditure only if it identifies additional sources of revenue. This may be done by increasing revenue estimates and the oil price assumption (within limits defined in law). All amendments must also be consistent with the balanced budget fiscal rule. As Mexico is a presidential system, a vote on the budget is not considered a vote of confidence in the government.

The Budget and Public Accounts Committee of the Chamber of Deputies holds hearings on the expenditure budget and hears evidence from representatives from the Ministry of Finance. It also plays a co-ordinating role with sectoral committees submitting their proposals for amendments to be voted on by the Budget Committee before the Budget Committee votes to submit the whole budget to the plenary for approval. The budget is read and debated twice in plenary session before the final vote. Legislative deliberations on the budget are open to the public and the media.

In addition to the support provided by the CEFP, the Budget Committee also has its own staff to assist it, although they typically do not have the same level of technical expertise.

Note: Before the constitutional reform of 2004, the deadline was 31 December; but this resulted in lengthy lastminute budget negotiations that ran into the new fiscal year. For this reason, the finalisation of the budget was moved back by six weeks. An exception is made in the year of presidential elections (every six years) when the new administration's budget must be adopted by 31 December. Table 3.1 of OECD (2009) shows the key dates of the congressional budget approval cycle.

Source: OECD (2009).

The CEFP operates entirely independently of the executive. However, the CEFP does have formal agreements with several public bodies such as: an agreement to exchange information 
and methodologies for assessing poverty and social policies with the National Council for the Evaluation of the Social Policy (CONEVAL); ${ }^{4}$ an agreement to access information and training databases with the National Institute of Geography and Statistics (INEGI); ${ }^{5}$ and a partnership with the National Institute of Public Administration to promote research on public finances and jointly publish a book.

The CEFP also co-operates informally with certain universities and think tanks. Three times a year, the CEFP holds seminars or conferences in which a leading academics and practitioners are invited to debate current issues in public finance. Moreover, universities promote the CEFP's annual prize (Premio Nacional de Finanzas Públicas) and frequently invite the centre to take part in specialised events. There are several non-governmental and academic organisations that prepare analysis and reports on the budget and public finance and related economic or social issues that may be complementary to the work of the CEFP, for example, the Centre for Analysis and Research (Fundar), the Centro de Estudios y Docencia Económicas (CIDE), the Centro de Estudios Espinosa Yglesias and the relatively new Centro de Investigación Económica y Presupuestaria (CIEP) headed by a former CEFP Director. As an example of their work, Fundar has a "Legislative Watch" subgroup that is in contact with the Chamber of Deputies' Budget Committee. For the 2012 Revenue Law, both Fundar and the CIEP examined the ways that the congress had raised projected revenues relative to the draft budget presented by the government.

\section{Legal basis for establishment}

The Centro de Estudios de las Finanzas Públicas was established by a congressional agreement published in the Official Gazette in 1998. One year later, in September 1999, the Organic Law of Congress formally recognised the CEFP as one of the five study centres ${ }^{6}$ serving the congress. A first set of internal rules for the functioning of the CEFP and its various departments was published in the Official Gazette in 2002. ${ }^{7}$ The CEFP's role was subsequently recognised in the 2006 Budget and Fiscal Responsibility Law.

\section{Mandate}

The CEFP has a broad mandate to provide objective, non-partisan and timely analysis to the congress on the public finances. As noted earlier, its mandate was expanded in the 2006 BFRL to include providing cost estimates of bills originating in the congress. The CEFP's activities are focussed on central government public finances; however, the CEFP does analyse intergovernmental transfers from the federal budget to states. ${ }^{8}$

\section{Functions}

The various functions of the CEFP are laid out in the 1998 resolution, the Organic Law of Congress, the CEFP's internal rules and the 2006 BFRL. Its main tasks are:

- Analysis of the government's quarterly reports on the state of the economy, public finances and debt; the proposed budget (revenue law and expenditure decree); the annual report on the National Development Plan Changes; and the report on foreign trade and tariffs.

- Briefing notes and/or longer studies on topics related to the public finances. It is quite common for parliamentary committees to ask the CEFP for information and the CEFP typically responds in writing. In 2011, the CEFP reports receiving 286 such requests, all of which were answered in writing. 
- Costing of legislation that originates in the legislature. In 2011, the CEFP reported 288 requests for budget and income cost impacts of new bills, again answered in writing. This task is the most time-consuming, with the CEFP estimating that around $65 \%$ of staff time is spent on it.

- Analyse the government's short-term and medium-term projections and produce their own (covering one and five years ahead). Currently, neither the government nor the CEFP produce projections that exceed five years.

In addition to the above, the CEFP seeks to enrich the public debate on the public finances through its Journal of Public Finance (published two to four times a year) and activities such as conferences or seminars and an annual prize for the best piece of new research on public finances.

As a non-partisan unit, the CEFP is precluded from making normative policy recommendations. It is not required by legislation to monitor adherence to the fiscal rules currently in place in Mexico $^{9}$ or to cost election platforms.

\section{Work programme}

The CEFP Director General is responsible for preparing the draft work programme and submitting it to the Chamber of Deputies' Committee on the CEFP for review. The Director General also appears before the committee to present and answer questions on the draft work programme. The work programme must be approved no later than February. ${ }^{10}$ The 1998 resolution and the CEFP's internal rules describe the types of analysis to be produced by the CEFP and its divisions. These includes requirements for certain pieces of CEFP analysis that must be incorporated into the work programme, specifically: analysis of the government's quarterly reports on the state of the economy, public finances and debt; analysis of the proposed budget (revenue law and expenditure decree); and the annual report on the National Development Plan within one month of their receipt by the congress. The CEFP may also propose undertaking research projects outside of what is outlined in its mandate, but this is subject to approval from the Committee on the CEFP.

The Finance Committee, the Budget and Public Accounts Committee, other committees, individual member of Congress and the Senate Finance Committee can all request reports and analysis from the CEFP. In executing the annual work programme, the CEFP accords priority to the Chamber of Deputies' Finance Committee and Budget and Public Accounts Committee, or to any committee with pending legislation that requires budget impact analysis. It normally answers their requests with a turnaround time of 30 to 45 days. Other committee or individual member requests may take longer to respond to, especially if the request is received during the September-November budget cycle when CEFP is on a tight deadline to provide analysis of the revenue and spending bills.

\section{Budget}

Since 2010, the CEFP's budget is not managed by CEFP directly but by the congress's overall administration, as is the case with the congress's other study centres. While data on the 2010 and 2011 budgets was not available for this study, the 2009 budget for the CEFP was MXN 50682024 (nearly USD 4 million), a decline of about 12\% from CEFP's 2008 budget of MXN 57809 634. This reflects in part the congress's efforts to cut public spending in response to the economic crisis. The 1998 resolution of the Chamber of Deputies does not explicitly describe funding for the CEFP. In practice, since it is part of the legislative support services, 
the CEFP is a component of the administrative budget of the Chamber of Deputies (funded entirely by annual appropriations). The steps involved in CEFP budget approval are: the CEFP Director General submits a draft budget to the committee responsible for congressional administration; this committee scrutinises the budget of the CEFP in light of the total budget of the congress and may make modifications before it is sent to the Budget Committee; the Budget Committee may also make modifications before it approves the entire budget of the congress in the context of adopting the annual expenditure decree.

\section{Staffing}

\subsection{Leadership}

The 1998 resolution of the Chamber of Deputies lays out the formal procedures for appointing the Director General of the CEFP (articles 8-11). It provides for the position to be filled through an open competition. To assist in the appointment process, the governing body of the Chamber of Deputies - the Junta de coordinación politica - appoints a jury comprised of academics and well-known professionals in the field of public finance, including two experts from the National College of Economists ${ }^{11}$ and the National College of Political Science and Public Administration. ${ }^{12}$ The jury helps to design the terms of reference, reviews the applicants and establishes a shortlist of three candidates. If it is unable to identify suitable candidates for the shortlist within a three-month period, the competition is re-opened. The Junta identifies and votes on its preferred candidate within the shortlist. The proposed candidate is then put forward for approval by the plenary. If the Chamber does not approve the candidate, the whole process is repeated.

According to the 1998 resolution (Article 11), there are certain restrictions which any candidate must meet. He or she must:

- be a Mexican citizen in full exercise of their rights;

- be at least 30 years of age when appointed;

- hold a bachelor's degree in economics, public administration, or a discipline related to public finance from a recognised academic institution;

- have at least five years of professional experience in the field of public finance; and

- be of good reputation with no criminal convictions.

The five explicit criteria above do not make reference to candidates' political affiliation. However, the CEFP is a non-partisan institution and, as such, candidates should not be chosen based on political affiliation or act in a partisan manner during their tenure, even if they may have held political positions in the past. CEFP Directors have come from a variety of academic and professional backgrounds in economics, audit, accounting, business and politics. ${ }^{13}$

The 1998 resolution provides for the Director General of CEFP to be appointed for a five-year term that is renewable once. However, none of the past five Directors to date have served a full five-year term or been renewed. According to article 10 of the 1998 resolution, the Director General can be removed from office for cause by a two-thirds weighted vote, after a hearing before the Junta.

\subsection{Staff}

The CEFP currently has around 59 full-time equivalent staff, around half of whom are spread among its core divisions for its substantive work: Macroeconomic and Sectoral 
Studies (eight staff), Revenue Studies (nine staff), Budget and Public Expenditure Studies (13 staff). The remaining staff include the CEFP leadership and those providing administrative and technical support. The number of staff has stayed more or less the same since the CEFP's inception despite the additional demands on the CEFP regarding costings since 2006, which may indicate the need for additional resources.

CEFP staff are hired through open competition. ${ }^{14}$ In practice, most applicants, especially researchers, are drawn directly from graduate school programmes in Mexico's leading universities ${ }^{15}$ after passing an examination ${ }^{16}$ and interview process. They are hired by the congress and not by the CEFP directly and are subject to the same rules and conditions (pay scale, code of conduct, etc.) as other congressional staff. ${ }^{17}$ The congress also sets the number of CEFP staff. As the pay scales of CEFP staff are slightly lower than that of the government's civil service for comparable duties, and as the CEFP is a researchoriented organisation, it is quite rare for a government civil servant with experience in, for example, the Ministry of Finance and Public Credit, to transfer to the CEFP. However, there are several senior staff at the CEFP with backgrounds working for non-governmental organisations or government. It is very rare for the CEFP to make use of outside consultants for its work.

\section{Access to information}

The 1998 resolution includes a provision for the CEFP to request from the Ministry of Finance information it deems necessary for its work. The CEFP's access to information was further strengthened in legislation by the 2006 BFRL (see Articles 42, 106 and 107). Nevertheless, the CEFP reports some difficulties in getting information in a timely manner. Delays are due in part to procedural issues - the ministry provides the requested information first to the relevant committee which is then responsible for transmitting it to the CEFP. Similarly, the CEFP reports some difficulties with the format in which information is given. For example, when the CEFP requested access to the database for the draft budget, the Ministry of Finance provided a PDF file. The CEFP then had to create its own database and manually re-enter the information in the PDF file at a time when the CEFP was on a tight deadline to make its report to the congress. On the positive side however, in recent years the Ministry of Finance has made a much wider variety of budget-related information publicly available.

\section{Transparency}

With the permission of the congress, much of the information produced by the CEFP is published on its website, including key documents such as its analysis of the draft annual revenue law, the draft annual expenditure decree and the Ministry of Finance's quarterly fiscal reports. The CEFP also publishes many studies on topics in public finance, monthly news bulletins (which follow various economic indicators) and its own CEFP Journal of Public Finance. At times, additional information and tools have also been made publicly available. For example, from 2007 to 2009 the CEFP published its forecasting work. The CEFP's congressional clients (committees and members) decide whether they would like to publish other research requests; typically these are not published. Costings of proposed legislation are treated as internal committee documents and are also not published.

Although the CEFP has a staff member assigned to respond to media questions, in practice the CEFP avoids the limelight and lets its work speak for itself. Apart from the public outreach activities described in Section VIII, the CEFP relies on publication of its work on its 
website as its main form of communication with the media and the public. As a general rule, the CEFP does not send out news releases or hold news conferences (although the Director General may occasionally agree to be interviewed by the media). This is seen as the prerogative of members of the congress. Nevertheless, the work of the CEFP receives regular media coverage.

\section{Governance, advisory support, monitoring and evaluation}

The Chamber of Deputies' Committee on the CEFP provides broad oversight of all aspects of the CEFP. The CEFP does not have an independent advisory board or a panel of outside experts to provide comments on CEFP's annual work programme or the quality of its outputs. In general, evaluations of the CEFP's work are informal, notably from comments and feedback by committees and members in the congress, peers, or the media.

\section{Concluding remarks}

The CEFP was established in 1998 to provide the congress with objective, non-partisan and timely analysis on public finances. The CEFP has significantly enhanced capacities within the legislature for independent budget analysis and is a model for many Latin American countries looking to do the same. Its work has been widely reported in the media and has contributed to the public debate on the budget and public finances.

Although modelled in part on the United States CBO, the CEFP does not have the same autonomy granted to the $\mathrm{CBO}$ and cannot claim to be fully independent. Given the difficulties that any non-partisan institution faces when working in a highly partisan environment, it might be useful to explore ways to enhance the CEFP's autonomy and to protect it from political interference or perceptions of political interference, for example, in the leadership appointment process. This could be done in part by examining the various models for independent fiscal institutions in other OECD countries, particularly those institutions under the legislature, and how they have dealt with similar challenges. In addition, given the broadening of the CEFP's mandate, particularly around costing, there is a case to be made for increasing the CEFP's resources.

\section{Notes}

1. With three main political parties: the PRI, the Partido Acción Nacional (PAN), and the Partido de la Revolución Democrática (PRD).

2. Subsequently, in the 2000 presidential elections, PRI lost to the PAN candidate, Vicente Fox, for the first time ever. This was a second major event for active political pluralism in Mexican politics.

3. The BFRL was followed by several additional pieces of legislation in 2007 and 2008 on integral fiscal reform, public sector pension reform, and accounting. See OECD (2009) for a more in depth description of this legislation.

4. By law, CONEVAL is in charge of measuring poverty and assessing the social policy.

5. INEGI is the independent institution in charge of producing Mexico's official statistics.

6. There are four other research organisations attached to the congress that specialise in constitutional, agriculture, social and gender issues.

7. There have been several subsequent updates to these rules.

8. Mexico is a federation of 31 states and a federal capital district.

9. The fiscal rule at federal level pertains to the financial balance, which includes interest payments but excludes the cost of the banking sector rescue package, public-private partnership schemes, 
PIDIREGAS and the long-term investment schemes of PEMEX, the national oil company. There are also two fiscal rules that apply at sub-national level. OECD (2009) discusses the three fiscal rules.

10. Article 3 of the 1998 Resolution.

11. Colegio Nacional de Economistas (CNE), a professional organisation of Mexican economists.

12. Colegio Nacional de Ciencias Políticas y Administración Pública.

13. For example: as political advisors, Member of Congress, etc.

14. Article 12 of the 1998 Resolution establishing the CEFP also provides for staff to be promoted based on merit.

15. Most have a Master's degree in economics or a related field.

16. The exams are announced in the major national newspapers.

17. Information on the salaries and benefits of congressional staff are available online as part of the Congress's efforts for increased transparency: www.diputados.gob.mx/transparencia.htm. A directory with the contact information of all CEFP staff is also available online at: www.cefp.gob.mx/ institucion/directori01.pdf.

\section{Bibliography}

CEFP (2011), "Analysis of the 2012 Spending Budget", Centro de Estudios de las Finanzas Públicas, Congress of Mexico, Mexico City, notacefp/061/2011.

Centre for Public Finance Studies (Centro de Estudios de las Finanzas Públicas) (2015), www.cefp.gob.mx.

Chamber of Deputies of Mexico (2015), www.diputados.gob.mx.

IMF (2002), "Report on the Observance of Standards and Codes - Fiscal Transparency Module", IMF Country Report 02/2002, International Monetary Fund, Washington, DC.

OECD (2009), “OECD Review of Budgeting in Mexico", OECD Journal on Budgeting, Vol. 2009, Supplement 1, OECD, Paris.

Santiso, C. (2004), "Legislatures and Budget Oversight in Latin America: Strengthening Public Finance Accountability in Emerging Economies", OECD Journal on Budgeting, Vo. 4, No. 2, OECD, Paris, pp. 47-76.

Senate of Mexico (2015), www.senado.gob.mx.

\section{Legislation}

Congressional Resolution Creating the Centre for Public Finance Studies (Acuerdo Parlamentario para la Creación de la Unidad de Estudios de Finanzas Públicas de la Camara de Diputados), 15 April 1998.

Organic Law of Congress (LEY Orgánica del Congreso General de los Estados Unidos Mexicanos), 3 September 1999. 



\section{Netherlands}

\section{CPB Netherlands Bureau for Economic Policy Analysis}

Established: 1945.

Enabling legislation: Law Concerning the Preparation of a Central Economic Plan adopted in 1947. Sustainable Public Finances Act (Wet Houdbare Overheidsfinanciën), 13 December 2013.

Mandate: Independent analysis relevant for economic policy making, particularly macroeconomic forecasting and the costing of policy proposals.

Budget: EUR 13 million (2011).

Staff: 117 full-time equivalents (2012). 


\section{Context}

The $\mathrm{CPB}^{1}$ was founded on the proposal of Social Affairs Minister Willem Drees on 3 September 1945 and commenced its work on 15 September. Highly regarded economist Jan Tinbergen was appointed as its first Director. ${ }^{2}$ At the time, the Netherlands was faced with an urgent need to rebuild the country following the Second World War and to restore economic and employment growth. Hein Vos, who served as Minister of Economic Affairs in the emergency Schermerhorn-Drees government, ${ }^{3}$ asked Tinbergen to prepare a proposal for a new economic planning bureau. In an unpublished blueprint in 1943, Tinbergen had argued for a small agency to quantify the size and composition of the national economy and to analyse the policy measures needed for long-term economic development. Vos's idea was for a new agency that would periodically draft a macroeconomic plan with guidelines for the government's economic policy. Ultimately, the CPB chose to emphasise macroeconomic assessment and forecasting ${ }^{4}$ and its annual Central Economic Plan has never contained any such guidelines.

The first legislative proposal for the CPB (1946) was rejected by the parliament. However in April 1947, following a change of government, a second legislative proposal was approved and the CPB's legal status was established in the Law Concerning the Preparation of a Central Economic Plan.

There was broad political support for the establishment of the CPB and for combining forward planning with well-founded economic analysis. Nevertheless, the extent to which the government should intervene in the economy was a source of debate since there were still memories of painful policy responses during the Great Depression. Also, Keynesian views on macro-fiscal management were new. Another central issue at the time was whether the $\mathrm{CPB}$ should explicitly issue policy advice or limit itself to analysing the effects of proposed policy measures. The latter option was chosen and is still in place.

The Netherlands is now a member of the EU and the euro zone. As such, it is subject to the requirements of the Stability and Growth Pact (SGP) and the European fiscal compact. For many decades, the Netherlands has had coalition governments. Since the 1960s, coalition agreements include medium-term fiscal objectives. ${ }^{5}$ Since 1994, the agreements between political parties in government have been supplemented with a fiscal rule on total government expenditure. This is combined with a rule not to introduce new policy measures that would change revenues coming from tax and social security contributions (other than those agreed in the coalition agreement). The government's fiscal rule supplements the EU fiscal rules on deficits and gross debt. Despite the various changes in the way fiscal policy and government decision-making have been managed in the past 60 years, the CPB has consistently provided independent analysis of the economic impact of fiscal and other policies. While the CPB has seen many changes of government, its independence has not been compromised and its existence has not been threatened. 


\section{Relationship with the executive and the legislature}

The CPB is an agency under the Ministry of Economic Affairs, Agriculture and Innovation. ${ }^{6}$ Although the $\mathrm{CPB}$ is part of the executive branch of government, it enjoys considerable independence, including by having its own advisory board with private sector representatives and by deciding on its own annual work programme. CPB's offices are also physically separate from those of the Ministry of Economic Affairs.

CPB's independence within the executive is de facto, not de jure: "independence" is not mentioned in the 1947 law. However, a new decree relating to all Dutch planning bureaus was issued in 21 February 2012. ${ }^{7}$ The decree clarifies some aspects of the CPB and other bureaus' independence, including the way the planning bureaus are to conduct research, the contents of their reports and the methodology to be employed.

The parliament can request research from the CPB. Until 2009, political parties and the parliament had to make a formal request for $\mathrm{CPB}$ analysis via the Minister of Economic Affairs. This procedure required the CPB to first report to the government after which the Ministry of Economic Affairs sent the CPB's report to the parliament. In 2009, a two-day delay in releasing a CPB report raised suspicions in the parliament that the government had tried to influence the report's conclusions. Subsequently, the procedure was changed. The CPB can now respond direct to parliamentary requests. This has enhanced the CPB's independence from the government. The February 2012 decree for the planning bureaus provides details on the new procedure; it also includes provisions for treating non-public requests for policy analysis received from politicians and other actors such as national trade unions and employer federations.

Although the CPB serves both chambers of the parliament, it is more frequently in contact with the House of Representatives. The head of the CPB regularly appears before the Finance Committee of the House of Representatives to explain new forecasts. The head may also appear before other committees to explain CPB analysis of specific issues. The same holds true for Deputy Directors and senior members of the CPB staff. The parliament has an opportunity to scrutinise the CPB's annual budget as it does for all government ministries. However, the parliament does not play any role in the key appointments at the $\mathrm{CPB}$ or other aspects of the CPB's functioning.

There is no other institution that prepares budget and economic analysis in as much depth as the CPB. Although the Central Bank of the Netherlands and some commercial banks also prepare macroeconomic and financial forecasts, the CPB is the only institution that prepares detailed projections in public finance and budget impact analysis of political parties' policies.

\section{Box 1. Role of the legislature in the budget process}

The Netherlands is a parliamentary democracy. The parliament is bicameral, with a 150-member House of Representatives (directly elected by proportional representation on a four-year cycle) and a 75-member Senate (indirectly elected, by 12 provincial councils). The House of Representatives has greater budgetary powers, as the Senate does not have the right to amend a bill; it can only adopt or reject it.

The constitution requires the budget to be presented to the parliament on the third Tuesday of September. This happens when the Minister of Finance presents to the House of 


\section{Box 1. Role of the legislature in the budget process (cont.)}

Representatives a budget overview and 23 budget bills on behalf of cabinet ministers responsible for specific policy areas. The parliament has three months for budget scrutiny (for the steps of budget approval, see Table 4 of Bos, 2008) and all 23 appropriation acts are usually adopted before the end of December. The House of Representatives can amend the draft budget, in principle without limit. However, coalition agreements, especially spending ceilings, restrict the house from making significant modifications to the government's draft budget. Although reallocations between the 23 spending bills by the House of Representatives are possible, in practice this rarely happens because proposals to increase one budget line item without decreasing another line item would not be adopted by a majority of members on account of the ceilings in the coalition agreement. In the parliament, budget policies are first discussed generally in plenary session. Later, each spending bill is examined in detail by committees and each responsible minister must respond in writing to questions from a specific parliamentary committee before which he/ she appears.

The Finance Committee of the House of Representatives is responsible for scrutinising overall budget aggregates. The Public Expenditure Committee is primarily concerned with budget procedures and rules, not with the 23 spending bills. Sectoral committees of the House of Representatives and of the Senate examine the spending bills, which are subsequently adopted in a plenary session. These sessions are open to the public. Technical support to the legislature during the budget process can be provided by the CPB or by the parliament's Bureau for Research and Public Expenditure (BOR), a small unit that provides analytical notes to MPs on budgetary and other issues. Box 2 below describes the BOR's tasks and activities.

The parliament experimented with establishing its own independent Council of Economic Advisors (Raad van Economisch Adviseurs, REA) from 2005-07. There was broad cross-party support at the time of its establishment (the vote was 100 for, 50 against). The goal was to provide the House of Representatives with independent policy advice on financial and economic affairs. The council's six members (university professors in economics and public finance) were appointed by the house's Committee on Finance. To ensure the independence of the REA, the council members could be in no way connected to the government or other related entities. The independence of the council was also reflected in its agenda and the timing of advice: both were determined by the council itself. During its three years of existence, the council published ten reports on macro-fiscal and specific issues (e.g. the tax base, ageing, housing, government regulation). However, after a critical interim assessment by the parliament, council members announced that they would not seek re-appointment, despite the fact that some parties expressed disappointment in this decision. In a self-assessment (REA, 2007), the council recognised that it had relatively little interaction with the parliament. In addition, some political parties criticised the style and content of the REA reports, which were perceived to be critical of some government policies. The council's website still exists and all council reports can still be downloaded.

Since 2013, legislation integrating new EU requirements into Dutch law gives the role of monitoring compliance with the fiscal rules to the Council of State. In the case of noncompliance the Council of State must assess the government's correction plans. While the CPB does not formally monitor compliance with the fiscal rules, it does so indirectly through calculations with respect to public finances and expenditure ceilings. 


\section{Box 2. The Parliamentary Bureau for Research and Public Expenditure (Bureau Onderzoek en Rijksuitgaven, BOR)}

The BOR was established in December 2007 by merging the Research and Verification Bureau of the House of Representatives and experts of the Public Expenditure Committee. Its creation was an internal decision of the House of Representatives and it is not established in law or in the House's internal Rules and Regulations.

The BOR, which is politically neutral in its work, has three main tasks:

- Supporting parliamentary investigations, enquiries and research. This is done both in-house within the BOR and by providing BOR resources for one-off studies commissioned by standing committees of the House of Representatives.

- Providing analytical notes to parliamentary standing committees, especially on budgetrelated matters. All standing committees are served equally.

- Advising MPs and sharing knowledge, including drafting amendments to the budget bills and providing briefings to MPs on budget, financial and other matters.

Each year, the BOR prepares about 150 written notes to MPs, including on the draft budget bills, the annual public accounts and other government documents with budget implications, especially major projects. These notes suggest questions that standing committees may ask government ministers when called upon to defend their budget proposals or outcomes. The BOR also supports the parliament's efforts to prepare "foresight studies" (a relatively new development recommended to improve parliamentary oversight), ex post evaluations, and ad hoc budget-related research of relevance to the parliament. The BOR does not prepare revenue and spending projections to "compete with" those of the CPB. Nor does it prepare assessments of the impact of new budget proposals or draft laws.

The BOR employs about 15 staff (12 FTE), formally appointed by the Secretary General of Parliament. Staff are recruited for their technical abilities, not by political affiliation. Most staff are generalists but they specialise their work according to the standing committee they serve. The head of the BOR and all staff are recruited and paid according to civil service rules and regulations. BOR staff salaries are comparable to those of staff in ministries.

The BOR's notes are not published externally. The rationale for this policy is that BOR notes to standing committees are comparable to the unpublished speaking notes prepared by government ministries for their ministers. BOR notes are, however, accessible internally to all MPs and parliamentary staff on the Intranet of the house. Exceptionally, a standing committee may authorise the publication of a BOR note if it is considered highly pertinent and if MPs want to use the note in a debate or receive a minister's formal reaction on it.

The BOR's budget in 2011 was EUR 0.9 million. It is part of the administrative budget for parliamentary support services and is integrated into the parliament's budget that is approved as one of the 23 annual appropriations acts. For 2012-15, the budget of all government ministries - and that of the parliament - is highly restrained. The BOR's annual budget has been relatively spared. For example, the number of full-time staff is expected to remain constant in coming years.

A first evaluation of the BOR was conducted in 2009 (see evaluation of BOR).

\section{Legal basis for establishment}

In 1947, the CPB obtained a legal basis with the adoption of the Law Concerning the Preparation of a Central Economic Plan. This law establishes the CPB as a part of the Ministry of Economic Affairs. It briefly specifies the CPB's mandate and creates the CPB's 
oversight body, the Central Planning Commission. The law is worded in a general way and is not a fundamental reference for the CPB. The law has never been amended, although new regulations on the planning agencies were adopted in 2012. The CPB's de facto role as the institution responsible for macroeconomic projections was formalised under the 2013 Sustainable Public Finances Act which embedded new European requirements in Dutch law.

\section{Mandate}

The CPB's mandate has consistently been to conduct independent analysis relevant for economic policy making. The CPB is also responsible for the official government forecasts of economic and fiscal developments. ${ }^{8}$ The only document that the CPB is mandated by law to produce is the annual Central Economic Plan, which provides an overview of the actual and projected economic situation. ${ }^{9}$

Over the years, the activities within the CPB's mandate have broadened substantially. Since the 1960s, the CPB has been publishing reports on the state of public finances and costings for policy proposals. Since the 1980s, it has been costing political parties' election manifestos ${ }^{10}$ and coalition agreements after elections. Since the 1990s, the CPB has been preparing long-term fiscal and debt analyses. The $\mathrm{CPB}$ continues to make spatial cost-benefit analyses and has a broad research agenda. Finally, the CPB reports on a wide variety of microeconomic and sector-specific topics such as health care, housing, the labour market and welfare policies.

The CPB does not have a mandate to influence fiscal policy directly. It does not provide normative assessments of coalition governments' commitments and fiscal objectives. It does not formally monitor compliance with EU fiscal rules, although, as noted earlier, it does this indirectly.

\section{Functions}

Forecasting, costing of policy proposals and research are CPB's major functions. Today, macroeconomic modelling and forecasting take up less time than in the early years of the $\mathrm{CPB}$, even though these activities are still crucial. About two-thirds of CPB staff time is devoted to research and one-third to policy analysis. ${ }^{11}$

\section{Forecasting}

The CPB is the only macroeconomic forecaster for the government and for the parliament. Modelling is used extensively by CPB in preparing the following forecasts:

- Short-term macroeconomic and fiscal forecasts: The CPB updates and publishes macro forecasts four times a year. The main forecasts are the Central Economic Plan, published every spring, and the Macro Economic Outlook, which is published jointly with the annual budget at the opening of the parliamentary year each September. Short updates of these forecasts are published in June and December. The time horizon of these projections is the upcoming budget year and one out-year. The impact of forecast budget changes in net real income of various groups of households is also analysed.

- Revenue forecasting: The CPB forecasts tax revenues. The Tax Office provides the CPB with monthly revenue realisations and the Ministry of Finance provides information on planned changes in tax laws in future years. The Ministry of Finance is responsible for the budget estimates of revenues. 
- Medium-term baseline budget projections: The CPB prepares, at least once every four years, a medium-term baseline forecast for the upcoming budget year and three outyears. The medium-term forecast is the basis for costing political parties' electoral platforms and for the medium-term expenditure framework consistent with the coalition agreement of each new government.

- Pre-election forecasts: These are published six months prior to parliamentary elections.

- Long-term forecasts: Every few years, the CPB publishes a long-term forecast (up to 50 years) that focuses on the sustainability of public finances. These projections and the medium-term budget projections are the basis for the advice for the next period of government by the National Advisory Group on Budgetary Principles. ${ }^{12}$

\section{Budget analysis}

The CPB analyses the budgetary impact of new policy measures. At times, the CPB's estimates of savings from new budget cuts are lower than the estimates of the Ministry of Finance. The CPB also analyses the budgetary proposals of new coalition agreements and updates the government's medium-term projections based on new coalition agreements. When a coalition agreement is modified in a substantial way, the CPB analyses the economic and budgetary impact.

\section{Costing and cost-benefit analysis}

All major infrastructure projects must be subjected to cost-benefit analysis, which is performed either by the CPB or another research institute. ${ }^{13}$ The CPB may provide a second opinion on the cost-benefit analysis of another research institute. Moreover, every ministry can request a cost estimate and/or economic impact forecast of any policy initiative. In practice, no major policy initiative is submitted to the Cabinet of Ministers without a forecast of its cost by the CPB. The parliament and political parties also have access to CPB's costing "service". For example, opposition political parties' "shadow budget"14 proposals are often first costed by the $\mathrm{CPB}$, at the request of the political party concerned, prior to their presentation to the parliament.

\section{Costing of election manifestos}

Political parties and civil society organisations can request costing and economic impact forecasts from the CPB. This tradition has grown since 1986 and, although voluntary, all major parties now ask for such costings. The scope of such evaluations has expanded substantially as more political parties request analyses. The CPB not only analyses the short-term effects on economic growth and public finance, but also examines the long-term effects and the impact of the proposals on the distribution of income and unemployment. Most major political parties also ask the CPB to cost major sectoral policy topics, like education, mobility, environment and the housing market. This process has had the advantage of making party manifestos much more specific.

\section{Research}

The CPB initiates its own research programme to analyse policy-relevant issues. This programme is independent of ministries' requests for costing and impact studies. The CPB has examined, for example, the economic effects of ageing, globalisation, health care, education, the financial crisis and the regulation of markets. In some instances, such work is co-financed externally. Although the conclusions of these studies can be politically 
sensitive, the CPB makes every effort to maintain its reputation of being strictly neutral. $\mathrm{CPB}$ researchers also conduct research for the European Commission, often as part of international consortia.

The CPB does not provide normative policy advice to the government. Nor does the CPB comment on the government's economic or budget policies apart from considerations of feasibility and impact. And the CPB does not formally monitor compliance with fiscal rules.

\section{Work programme}

The Director of the CPB decides on CPB's annual work programme. The CPB sets its own priorities in accordance with various needs, including: the preparation of certain annual outputs each year, notably those linked to the annual budget cycle; the CPB's perceived research needs for the central government on economic topics; and research topics suggested by government ministries with which the CPB consults. The CPB also follows the guidance on its work programme provided by its advisory board, the Central Planning Commission and by the Minister of Economic Affairs. The minister can make special requests for certain research, although this rarely happens.

Various institutions can request analysis from the CPB. Roughly $60 \%$ of requests come from government ministries (mainly the socio-economic departments); $30 \%$ from political parties, parliamentary committees and individual parliamentarians (mainly in the lower house), and the remaining $10 \%$ are from labour or trade unions, the employers' federation, the Social and Economic Council ${ }^{15}$ and others. There is no automatic system for prioritising requests. This is left to the discretion of the director of the CPB, who is guided by the provisions of the February 2012 decree on the planning bureaus. Currently, the number of requests received is manageable. In the future, with the prospect of further declines in CPB staffing, it may be challenging to meet all requests, especially if the House of Representatives seeks more analysis from the CPB.

\section{Budget}

The CPB budget is part of the budget of the Ministry of Economic Affairs, Agriculture and Innovation, which follows standard budget preparation procedures for government ministries. Based on its coalition agreement, a new government adopts a multi-annual budget that provides the starting point for subsequent annual draft budgets. Following a cabinet decision on the budget framework, usually in April, the Ministry of Finance sends "Letters of Totals" to each ministry, indicating maximum spending for the upcoming new fiscal year (which begins on 1 January).

The CPB's draft annual budget is first prepared internally and approved by the director. In May, it is discussed with the Ministry of Economic Affairs, Agriculture and Innovation. These discussions may lead to changes in the budgeted amounts, not because of any specific work that the CPB is proposing, but because the general cuts in government spending are also applied to the $\mathrm{CPB} .{ }^{16}$ Once these discussions take place, the CPB budget for year $t+1$ and four out-years is finalised by the end of June. In August, when the cabinet reviews the budget's revenue projections, the amount of proposed budget spending may be fine-tuned. The CPB's net spending is included in Appropriation Bill XIII (i.e. the one pertaining to the Ministry of Economic Affairs, Agriculture and Innovation).

The CPB is not entirely funded by the lump-sum allocation from the central government budget as it is authorised to receive revenue for analytical work contracted for third 
parties. ${ }^{17}$ CPB's "clients" are limited to central government ministries, local governments, European institutions and international governmental organisations. The CPB is not allowed to compete with commercial research bureaus. The revenue for work received from external sources cannot exceed $20 \%$ of the CPB's spending funded through the annual budget. Recently these revenues have amounted to $10-15 \%$ of spending.

Administrative spending in all government ministries has been falling in real terms since 2002 and the CPB's funding has not been spared. However, the declines in the CPB's budget have often been less than the average for all government ministries. Nonetheless, for 2002-06 and 2008-10, the CPB's budget fell by $11 \%$ and $10 \%$ respectively, to EUR 13 million. A further reduction of $10 \%$ has been decided for 2011-15. ${ }^{18}$

\section{Staffing}

\subsection{Leadership}

The Director of the CBP is appointed by the Cabinet of Ministers upon a proposal by the Minister of Economic Affairs. In selecting a new head of the CPB, the main criterion is the ability to perform the required duties in a professional and non-political manner. This is not a written rule but a long-standing practice that is accepted by all political parties. When directors change, which is relatively infrequently, the Minister of Economic Affairs and his/her advisors consult widely including with the Minister/Ministry of Finance and university professors involved in economic policy making. The background and qualifications for a new director are not formally laid out. Current informal understandings are that the director needs to be a top Dutch economist with considerable experience in policy issues.

Each appointment is for a seven-year period that is renewable once. The seven-year term is delinked from changes in government that occur at least every four years. This enhances CPB's independence from political influences. The formal appointment process and the director's salary follow the rules applicable for higher civil servants. Should removal be necessary, this would also follow civil service procedures. However, during its entire 65 years of operation, no CPB director has ever been removed.

\subsection{Staff}

The staff of the CPB are civil servants. As such, they are recruited, dismissed and remunerated according to the civil service regulations, and are subject to civil service rules on conflicts of interest. The terms of employment and range of salary scales are shown on the CPB website. ${ }^{19}$

The CPB hires staff both domestically and internationally (strong Dutch language skills are needed). CPB's professional employees are either policy analysts or researchers. Policy analysts address short-term and medium-term policy issues that are raised by the government, political parties, the parliament and other interest groups. Researchers investigate new themes or prepare the ground for future policy analysis. Researchers must have qualifications and experience in economics or econometrics. Although a $\mathrm{PhD}$ is not a prerequisite for a position at the $\mathrm{CPB}$, it is preferred and in recent years, the share of research staff with PhDs has risen. Policy analysts need at least a higher vocational education. ${ }^{20}$ Recruitment and selection policies for professional staff aim at attracting strong candidates with a broad interest in applied policy-relevant issues, rather than highly specialised personnel. The bureau's policy is to avoid its staff becoming locked into 
just a single topic. Nonetheless, the CPB recognises the need to recruit specialist staff, including mathematicians, IT specialists, technicians and administrators. All staff are hired by the director of the $\mathrm{CPB}$, who is supported by a human resources unit.

The across-the-government budget cuts have resulted in a considerable fall in the number of CPB staff, which peaked at $158 \mathrm{FTE}$ in 2002. In 2010, there were $148 \mathrm{FTE}$. In 2011, the number dropped to 135 and in 2012 to 117, of which 91 work in economics and public finance while the others are mainly administrative. The staff work either in one of the CPB's five sectors (public finance, macroeconomics, labour and education, competition and regulation, and climate and regional economics) or in one of the four support units (executive secretariat, human resources, internal affairs and IT). ${ }^{21}$

The CPB has an academic partners and visiting scholars programme for prominent university researchers who work together with $\mathrm{CPB}$ staff in writing academic papers and who advise the CPB in its research. Academic partners are appointed to work for a period of one year, with the option of extending the appointment. Because of this programme, the $\mathrm{CPB}$ does not use outside consultants for operational work. Finally, the CPB has ties with a number of foreign institutes for economic policy analysis (see www.cpb.nl/en/internationalpartners, which includes Sweden's Fiscal Council and the United Kingdom's Office for Budget Responsibility). Co-operation is on the basis of mutual independence: each partner remains fully responsible for the content and quality of its work. ${ }^{22}$

\section{Access to information}

Although ministries are not legally obliged to provide information to the CPB, they co-operate with the CPB for making the official economic forecast and providing other information needed by the CPB to respond to requests for analysis. Being a government "insider", the CPB has relatively easy access to non-published information held by the ministries and information is received in a timely manner. For costing, the Ministry of Finance provides much of the needed information. For specialised issues such as health and social security, the $\mathrm{CPB}$ receives the required information directly from the relevant ministry.

There are no standard procedures for communicating with ministries. At the working level, there is regular contact between ministry and CPB staff. At higher levels, the CPB director or senior CPB staff meet with high-level civil servants in different government committees, such as the Central Economic Committee. Within the Ministry of Economic Affairs, the CPB director holds regular meetings with the Secretary General.

\section{Transparency}

All CPB reports are publicly available in electronic form. These are published by the CPB under its own authority. The CPB's analytical methods are fully transparent: all assumptions, empirical data and economic models are fully specified and published. All major CPB publications are accompanied by a news release. For its spring forecast (the Central Economic Plan), a news conference is normally organised. If the CPB director judges that a major CPB study warrants a news conference, he/she may choose to hold such a conference. News conferences are attended by journalists from all major daily newspapers, and the remarks of the director are typically reported by the major radio and television stations.

Special costing requests done by the $\mathrm{CPB}$ and submitted to a client remain confidential until the client reviews them. If the request for a $\mathrm{CPB}$ analysis is formal (e.g. a contract), the CPB normally publishes the report. It is rare for a $\mathrm{CPB}$ client not to publish an analytical 
report prepared by the CPB under contract, although it has happened. If the request is informal, the client decides on its publication. However, should the client mention part of the report in public, the CPB will publish the full report.

Most requests to the $\mathrm{CPB}$ from the media are channelled through the $\mathrm{CPB}$ media officer. Nonetheless, CPB staff members may explain to the media their technical research results. Each $\mathrm{CPB}$ staff member is listed on the $\mathrm{CPB}$ website, facilitating direct media contact with an individual staff member. The CPB keeps internal records of media coverage of its work.

\section{Governance, advisory support, monitoring and evaluation}

The 1947 law established an advisory board for the CPB: the Central Planning Commission (CPC). The CPC advises the management of the CPB on its work programme. CPC members, who are well-respected experts in economic policy making and public finance, are formally appointed by the Minister of Economic Affairs for a three-year term, with the possibility of renewal for one consecutive term, after consultation with the Cabinet of Ministers. Currently there are eight members on the commission. The management of the CPB takes the CPC's advice very seriously and incorporates CPC suggestions as much as possible.

About every five years, the work of the CPB is evaluated through peer reviews by academics (on scientific value) and by clients (on policy relevance). Nearly all of the academics for the scientific review are non-Dutch, which enhances objectivity. ${ }^{23}$ Finally, the $\mathrm{CPB}$ encourages close contact with the academic community, and CPB staff are encouraged to publish in academic journals and to work with academics.

\section{Concluding remarks}

As a 65-year-old independent government institution, with a reputation for providing objective analysis, relatively accurate and unbiased forecasts ${ }^{24}$ and cost-benefit analyses, the CPB has considerable credibility in the eyes of the government, the parliament, the media and the public. It is the government's and the parliament's only forecaster of macroeconomic and budgetary developments. CPB's short-term, medium-term and longterm projections of economic and fiscal developments serve as the backbone of budgetary processes and policy discussions. The five-year projections on the basis of unchanged revenue and expenditure policies provide a firm basis for assessing the cost of new election platforms of political parties and also the coalition agreements of new governments. The CPB's costings of election platforms have had a positive impact in terms of making party manifestos more specific so that the costings are meaningful.

The CPB has considerable autonomy despite the formal appointment of the CPB director by a government minister, the lack of a status for CPB staff separate from the civil service and the financial dependence of the CPB on the national budget. Several elements contribute to the CPB's de facto independence, including: the seven-year renewable term of the $\mathrm{CPB}$ director (c.f. four-year election cycles), the extensive discretion given to the CPB director for establishing the annual work programme; an independent advisory board that oversees the CPB annual work programme; periodic independent evaluations of $\mathrm{CPB}$ outputs (by academics and by CPB clients); the authority granted to the CPB to respond directly to requests for policy analysis from the parliament; and the publication of $\mathrm{CPB}$ forecasts and analyses under its own authority. 
While the CPB's specific contribution to Dutch fiscal performance is difficult to measure, there are three channels of influence. First, before elections, the National Advisory Group on Budgetary Principles, which includes the CPB Director, suggests fiscal targets and a medium-term fiscal framework. Although a new government is not obliged to take on board the advice, the group's views have influenced government coalition agreements. Second, the CPB's analyses of election platforms have raised awareness of the need, at a political level, for prudent and sustainable budget policies. Third, the CPB's preelection analyses of political parties' proposed policies are subsequently used in negotiations for the four-year coalition agreement by the parties forming a new government. These features make the $\mathrm{CPB}$ an independent institution that plays a wider role than similar agencies in other countries. ${ }^{25}$

\section{Notes}

1. Literally translated from the Dutch, the agency is the "Central Planning Bureau". However, its English name, CPB Netherlands Bureau for Economic Policy Analysis, better describes its function. The CPB has never been engaged in economic planning. Rather it analyses the effects of current and future government policies.

2. In 1936, Tinbergen constructed the first econometric model for the Dutch economy, which is generally considered the first econometric model in the world (Don and Verbruggen, 2006). In 1969, he received the Nobel Prize for his pioneering work in econometric modeling.

3. In place from 4 June 1945 to 3 July 1946.

4. CPB's first macro model became operational in 1953. It served as a basis for forecasting and policy advice for most of the 1950s. At the time, the use of such a model to analyse the expected impact of particular policies was ground breaking. It reflected Tinbergen's view on planning, namely that policy makers should define the targets of government policy while the optimal mix of instruments for achieving targets should be chosen on the basis of an economic model (Bos and Teulings, 2013).

5. Box 1 of Blöndal and Kristensen (2001) lays out the main features of coalition agreements on budget policy.

6. Prior to 2011, the Ministry of Economic Affairs and the Ministry of Agriculture were separate ministries.

7. The CPB has two sister planning bureaus: the Netherlands Institute for Social Research (SCP) and the Netherlands Environmental Assessment Agency (PBL). The directors of the three bureaus meet periodically to discuss work plans and to ensure that efforts are complementary. As from 2015, the three bureaus will be housed in the same building.

8. CPB's fiscal projections are for general government. Local government fiscal data is submitted to the CPB with considerable lags, which adds to the uncertainty of CPB's fiscal projections for local governments. In its analysis of public policies, the CPB's focus is also on the impact on the central government's finances.

9. The CPB has never prepared detailed central planning documents comparable to those of the former centrally planned economies of Eastern Europe and the Soviet Union. "Central Economic Plan" is a misnomer.

10. Bos and Teulings (2011) discuss the 25-year experience of costing election platforms.

11. Figure 2.2 of CPB (2009) discusses the various activities of CPB in more detail.

12. The group is comprised of senior government officials responsible for financial and economic policy making, the director of CPB, and the Governor of the Central Bank. For more details, see Bos (2008).

13. Examples are: Netherlands Economic Institute and the Tinbergen Institute.

14. "Shadow budgets" are selected policy proposals made by political parties during the annual budget debate in the parliament. See Box 8 of Blöndal and Kristensen (2001)

15. This council is composed of representatives from trade unions, employers' organisations and independent experts. The council discusses draft agreements on major socio-economic issues like social security, wage rates and pensions. 
16. For example, in 2010, following agreement to increase civil service salaries, all ministries - and the CPB - had to agree on a staff retrenchment plan.

17. The basis for this authorisation was formalised in the February 2012 decree on the Dutch planning bureaus.

18. www.rijksbegroting.nl/2012/voorbereiding/begroting,kst160374_16.html. CPB budget projections made in 2011 for the 2012 budget show the CPB's total budget rounded to the nearest million euros. In previous years, before the merger of the Ministries of Economic Affairs and of Agriculture, the CPB's budget projections were shown in slightly more detail. See www.rijksbegroting.nl/2011/ voorbereiding/begroting?hoofdstuk=40.6.

19. See www.cpb.nl/en/working-cpb.

20. Chart 2.1 of CPB (2009) shows the composition of staff by educational qualifications.

21. For details of the responsibilities of each of the five sectors and four management support directorates, see www.cpb.nl/en/organisation. This organisational structure has been operational since September 2011; prior to this restructuring there were six sectors (see CPB, 2009).

22. Until recently, the CPB had a Young Professionals Programme (YPP) which aimed at attracting talented young academics, economists and non-economists without a PhD in economics. The YPP was a two-year programme in which a young professional participated in three projects and took courses in the extended Masters programme at the Tinbergen Institute. Due to budget cuts, the YPP has been suspended.

23. CPB (2009) is the most recent such evaluation; Annex A identifies the members of the review committee.

24. Bos (2008) discusses the accuracy of projections and refers to a more detailed CPB study in 2006 by Kranendonk and Verbruggen; Box 6 of Bos discusses the CPB's use of cautious economic assumptions from 1994 to 2007.

25. Bos and Teulings (2010) reflect more fully on the distinct roles of the CPB.

\section{Bibliography}

Blöndal, J.R. and J.K. Kristensen (2001), "Budgeting in the Netherlands", OECD Journal on Budgeting, Vol. 1, No. 3, OECD, Paris, pp. 43-80.

Bos, F. (2008), "The Dutch Fiscal Framework: History, Current Practice and the Role of the Central Planning Bureau", OECD Journal on Budgeting, Vol. 8, No. 1, OECD, Paris, pp. 7-48.

Bos, F. and C. Teulings (2010), "CPB and Dutch Fiscal Policy in view of the Financial Crisis and Ageing", CPB Document No. 218, Central Planning Bureau, The Hague, www.cpb.nl.

Bos, F. and C. Teulings (2011), "Evaluating Election Platforms: A Task for Fiscal Councils? Scope and Rules of the Game in view of 25 Years of Dutch Practice", Munich Personal RePEc Archive, http:// mpra.ub.uni-muenchen.de/31536.

Bos, F. and C. Teulings (2013), “The World's Oldest Fiscal Watchdog: CPB's Analyses Foster Consensus on Economic Policy", in G. Kopits (ed.), Restoring Public Debt Sustainability: The Role of Independent Fiscal Institutions, Oxford University Press, Oxford.

Council of Economic Advisors (Raad van Economisch Adviseurs) 2005-07, www.tweedekamer.nl/ kamerleden/commissies/raad_van_economisch_adviseurs/index.jsp.

Council of State (RvS) (2015), www.raadvanstate.nl.

CPB (2009), "Charting CPB's Course", www.cpb.nl/en/article/charting-cpb\%E2\%80\%99s-course-selfassessment-cpb.

CPB Netherlands Bureau for Economic Policy Analysis (2015), www.cpb.nl/en.

Don, F.J.H. and J. Verbruggen (2006), Models and Methods for Economic Policy; 60 Years of Evolution at CPB, CPB Discussion Paper 55, Central Planning Bureau, The Hague, www.cpb.nl.

Parliament of the Netherlands (2015), www.parlement.nl.

REA (2007), "Zelfevaluatie van de Raad van Economisch Adviseurs", Netherlands Fiscal Council, The Hague, www.parlis.nl/pdf/kamerstukken/KST110479.pdf. 


\section{Legislation}

Law Concerning the Preparation of a Central Economic Plan (Wet voorbereiding van de vaststelling van een Centraal Economisch Plan), 21 April 1947.

Guidelines for the Planning Offices (Aanwijzingen voor de Planbureaus), Government Gazette, No. 3200, 21 February, 2012.

Sustainable Public Finances Act (Wet Houdbare Overheidsfinanciën), 13 December 2013. 


\section{Portugal}

\section{Portuguese Public Finance Council (CFP)}

Established: 2011.

Enabling legislation: The 5th amendment to the Budget Framework Law 51/2001 (Law 22/2011, 20 May 2011) formally established the council. The CFP's statutes were adopted in Law 54/2011 of 19 October 2011 and amended by Law 82-B/2014 of 31 December 2014.

Mandate: To undertake an independent assessment of the government's fiscal strategy.

Budget: EUR 2.53 million in (2014).

Staff: Five council members; staff recruitment of 15 to 20 staff is ongoing. 


\section{Context}

The creation of the Conselho das Finanças Públicas or Portuguese Public Finance Council (acronym CFP in Portuguese) in 2011 was part of a broader package of reforms to improve budget management. In 2010, the government and the largest opposition party considered establishing such a council and a working group was set up to draft its statutes in January 2011. The statutes project was presented in April and in May 2011 CFP was created by law, in the context of an amendment to the Budget Framework Law. The plans to operationalise the CFP were subsequently included as part of the bailout agreement with the IMF/EU signed on 17 May 2011. Parliament approved the statutes under Law No. 54/2011 of 19 October 2011.

The CFP is not the only independent body providing budget analysis. In 2005, the Budget Committee of the parliament recognised that a non-partisan office would be useful to serve its need for technical budget analysis. Subsequently, in 2006, a Parliamentary Technical Support Unit (acronym UTAO in Portuguese) was established by law. In 2011, the parliament confirmed that it would like UTAO to continue its activities. UTAO's legal basis, functions, budget, staffing and reporting are described in the Annex.

Prior to 2005, there was little integration of medium-term fiscal developments and annual budget processes. Moreover, coverage of general government accounts was incomplete and budget processes were fragmented. To address these shortcomings, the Socialist governments of 2005-11 decided to revise the 2001 Budget Framework Law. In April 2010, the then Minister of Finance set up a task force to propose amendments to the law. ${ }^{1}$ Issues addressed included: establishing a multi-annual budget framework and a balanced budget rule; addressing budget fragmentation and control; introducing programme budgeting; and creating an independent fiscal council. In October 2010, a protocol was signed by the government and the largest opposition party to enable adoption of the budget for 2011. The protocol included a reference to the creation of an independent fiscal agency. The Governor of the Central Bank of Portugal also provided strong support for the establishment of the CFP. ${ }^{2}$

In December 2010, the incumbent Socialist government and the Social Democratic Party signed an agreement that included the appointment of a group of non-partisan experts to prepare draft statutes for an independent fiscal council. ${ }^{3}$ In April 2011, the working group delivered its proposals and made them available on its website. ${ }^{4}$

Regarding fiscal rules, in addition to the EU-wide deficit and debt rules applying to all member states, Portugal now has a structural deficit rule which was introduced in the amendments to the 2001 Budget Framework Law in May 2011. It requires a multi-annual framework for budgetary planning. The medium-term framework defines ceilings on expenditure by the central government. Transfers to social security and the autonomous regions and local governments are also subject to ceilings. Besides these national fiscal rules, sub-national governments have limits on net debt. A fiscal rule also applies to government entities with financial autonomy (these account for over one-fifth of general government spending) and are required to balance their budgets. 
The IMF/EU programme lent support to the various budget reforms and included specific deadlines for adopting the council's statutes and making the CFP operational. ${ }^{5}$ Following a parliamentary debate, the statutes were approved by the parliament in October 2011; they did not differ significantly from the draft of April 2011. In December 2011, the five members of the CFP's Senior Board were chosen. In February 2012, the council members' tenures officially began and the first council meeting was held in Lisbon. At this time, the CFP, being an entirely new agency, started working on the necessary preconditions to become fully operational, such as finding appropriate premises and finalizing its work plan, budget and staffing requirements.

\section{Relationship with the executive and the legislature}

The CFP is independent of both the executive and the parliament. Its statutes indicate that, in performing its functions, the council cannot request or receive instructions from the parliament, the executive, or any other public or private entity. The President of the Republic, the government and the parliament receive the council's reports. To support the council's independence, the Court of Auditors and the Central Bank of Portugal play a unique role in its budget and appointment of council members.

The focus of the council's work is on assessing fiscal projections and compliance with fiscal rules. This requires the CFP to interact with other independent institutions, notably the National Institute of Statistics, the Court of Auditors and the Central Bank of Portugal. It also requires the government to provide information to the CFP. The failure to provide information will be subject to dissuasive actions.

Parliament does not play a role in appointing council members. However, the parliament does scrutinise and approve the CFP's annual budget in the context of approving the annual budget for all state-financed entities. The Budget Committee plays a pivotal role in budget discussions in the parliament (Box 1). It is served by UTAO whose tasks overlap somewhat with those of the CFP: both the CFP and UTAO analyse the draft annual budget and updates of the medium-term projections of the stability programme.

\section{Box 1. Role of the legislature in the budget process}

The Portuguese system of government is semi-presidential. Presidential elections are held every five years. The Prime Minister is the leader of the majority party (or coalition of parties) in the 230-seat unicameral parliament, to which members are elected by proportional representation for four-year terms.

The Budget Framework Law requires the government's proposed budget to be presented to the parliament by 15 October and approved by the end of November. This leaves a relatively short period of 45 days for parliamentary budget review. The draft annual budget and the draft budget execution law (on the State General Account) are discussed in the Budget and Finance Committee, which holds hearings and allocates articles to be discussed and voted in the Budget Committee or in the plenary session. Discussions in the Budget and Finance Committee are open to the public. The Budget and Finance Committee votes on amendments proposed by members of the parliament. While the parliament has unlimited power to amend the draft budget, in practice few amendments are adopted, despite a large number of proposals from opposition parties. 


\section{Box 1. Role of the legislature in the budget process (cont.)}

The Parliamentary Technical Support Unit (UTAO; see Annex) provides analytical support to the Budget and Finance Committee. In 2011, the parliament confirmed that it would like UTAO to continue its activities (i.e. the CFP would not replace UTAO) and endorsed hiring additional staff (increased from two staff in 2009 to six staff as of 2012). Source: OECD (2008)

\section{Legal basis for establishment}

The Fifth Amendment to the Budget Framework Law 91/2001 (Law 22/2011) formally established the council in May 2011. The CFP's statutes are laid out in Law 54/2011, adopted on 19 October 2011, as amended by Law 82-B/2014 of 31 December 2014.

\section{Mandate}

The CFP's mandate is clearly laid out in the Budget Framework Law and in its statutes. The latter specify that the council "is to undertake an independent assessment of the consistency, compliance and sustainability of fiscal policy and to enhance, through increased transparency, the quality of democracy and economic policy-making and to reinforce the financial credibility of the State." Article 12-I(1) of the Budget Framework Law is more specific regarding the council's assessments of fiscal projections and monitoring of compliance with fiscal rules. The CFP is "responsible for undertaking an assessment of the objectives proposed for the macroeconomic and fiscal projections, the long-term sustainability of public accounts and compliance with the budget balance rules and the rules on expenditure by the central government (both laid down in law), and the indebtedness rules of autonomous regions and local governments enshrined in the respective financing laws". The CFP's statutes identify eight specific tasks and various reporting requirements.

The subsequent approval at the European level of the so-called "2-pack" and the incorporation into the budget framework law of the intergovernmental Treaty on Stability, Coordination and Governance in the Economic and Monetary Union (Fiscal Compact) gave CFP a formal role in the endorsement of the macroeconomic forecasts underlying the national medium-term fiscal plans and draft budgets, as well as in the national correction mechanism that shall be triggered automatically in the event of significant observed deviations from the medium-term objective or the adjustment path towards it. The endorsement process was first applied for the draft budget for 2015, in October 2014, the first budget proposal following the conclusion of the adjustment programme. A Memorandum of Understanding with the Ministry of Finance that defines how the analysis of the macroeconomic projections underlying the Stability Program and the State Budget Proposal is to be performed, and defines the information to be supplied by the Ministry of Finance for this purpose was signed in February 2015. ${ }^{7}$

\section{Functions}

The CFP's specific tasks are spelt out in its statutes. Notably the council is to:

- assess the macroeconomic scenarios adopted by the government and the consistency of forecasts of budget projections with these scenarios; 
- assess whether fiscal rules laid down in law are complied with;

- analyse the dynamics of public debt and its sustainability;

- analyse the dynamics of existing commitments, with special emphasis on pension and health systems and public-private partnerships (PPPs), including an assessment of their implications for fiscal sustainability;

- assess the financial position of the autonomous regions and local governments;

- assess the economic and financial situation of public enterprises and their potential impact on consolidated public accounts and their sustainability;

- analyse tax expenditure; and

- monitor the budget out-turn.

The CFP assesses projections and now has a formal role in endorsing the macroeconomic forecast in the context of the European Semester, but does not produce them. It does not have a costing role. Consistent with the above tasks, the CFP publishes various annual reports, notably its assessments of the government's multi-annual framework of budget planning, the government's stability programme updates (consistent with EU requirements) and the draft annual state budget. For the latter, the CFP report is released to assist the parliament's debate on the budget in late October or early November.

CFP assesses the macroeconomic scenario for the draft state budget and the stability programme and CFP's opinion is included in these documents. CFP also publishes quarterly reports on the budget out-turn, as well as two reports per year on the budget out-turn of social security. In March 2015, the council published its first report on the state of the Portuguese public finances, as well as the respective constraints, under a no-policy change assumption for the next four years. ${ }^{8}$ The goal of this publication was to highlight the intertemporal consequences of fiscal policy to policy makers and the public. This report will be updated twice a year: before the presentation of the stability programme and before the presentation of the draft annual budget. Apart from these, regular publications CFP has also published reports and opinions on subnational finances and on the reform of the budget framework law. To aid communication with the wider public CFP has published non-technical notebooks on complex issues such as government debt, social protection systems, differences between cash accounting and national accounting, as well as a glossary. ${ }^{9}$

Given the relatively short period for parliamentary debate on the annual budget (45 days), one potential challenge for the CFP is to conduct its analysis and present its report to the government and the parliament in a timely manner. Concerning the sustainability of the public finances, as well as other areas specified in the statutes, CFP decides on the frequency reports. The CFP can undertake work at its own initiative.

\section{Work programme}

The CFPs annual work programme is based on the eight specific tasks and the obligatory reports outlined in its statutes. As mentioned in the previous section the scope of CFP publications has been extended gradually over time to cover its mandate. Initially, priority was given to ensuring that the obligatory reports were prepared in a timely manner. In 2012, the CFP spent a certain amount of time on logistical issues associated with making it operational: e.g. recruitment of secretariat staff, preparation of the 2013 CFP budget, setting up its offices and ensuring adequate IT support and website development. 


\section{Budget}

The financial independence of the CFP and its capacity to fulfil its mission are guaranteed through state budget appropriations, which "can only be reduced in duly justified exceptional circumstances" (statutes, article 27[3]). The Senior Board of the CFP is responsible for preparing the council's draft budget, which is subject to a favourable opinion of the President of the Court of Auditors and the Governor of the Central Bank of Portugal. Once this opinion is obtained, the CFP's annual budget follows the budget review and approval procedures that apply to comparable independent or constitutional bodies (e.g. the budget of the Court of Auditors). The budget of the CFP has been a separate line item since the revised 2012 state budget and was set at EUR 2.53 million in for FY 2014. So far this has proved adequate for the CFP to fulfil its activities.

\section{Staffing}

\subsection{Leadership}

The statutes specify that there are three governing bodies of the council: the Senior Board, the Executive Committee and the auditor.

\section{The Senior Board}

The Senior Board is a collegial body of five members: a President, a Vice-President, one executive member and two non-executive members. The President convenes meetings of the Senior Board after hearing the Vice-President's opinion. She/he also presides over meetings of both the Senior Board and the Executive Committee, and takes part in the dayto-day running of the council.

Each member is appointed by the government (Council of Ministers) on a joint proposal of the President of the Court of Auditors and the Governor of the Central Bank. The term of all members is seven years, non-renewable except for the non-executive members who are eligible for re-appointment once. During an initial five-year transition period, members' terms are staggered: the President for seven years (non-renewable); the Vice-President and the executive member for five years (non-renewable); and the two nonexecutive members for three years (renewable once). The Senior Board's terms are delinked from election cycles; this enhances the independence of the CFP.

None of the five council members is eligible for appointment to the Senior Board if he/ she has held political positions during the previous two years. The statutes are specific on prohibiting the appointment of members of: parliament (neither European nor national), the government (national, regional or local), an executive body of a political party, or a public manager (these include managers of autonomous public entities, notably stateowned enterprises, municipal enterprises, public institutes and the central bank). The statutes also elaborate on qualifications for membership:

- personalities of acknowledged merit, with experience in the areas of economics and public finance and a high degree of independence;

- nationality (a maximum of two non-national members, preferably from EU member states; the President must be a Portuguese citizen);

- residency (the President and the executive member must reside in Portugal); and

- gender (all five members cannot be of the same gender). 
The statutes specify a limited number of reasons for dismissing a member. Apart from permanent incapacity or death, these are: conflicts of interest, legal restraint or incapacity decreed by the courts, being found guilty of a crime (once all appeals are exhausted), unjustified absences from two meetings and serious misconduct. Dismissal for serious misconduct would follow a procedure jointly agreed by the President of the Court of Auditors and the Governor of the Central Bank of Portugal. These provisions reduce the risk of dismissals for political reasons. A member may also voluntarily resign from the council.

The five Senior Board members were formally appointed on 19 January 2011 and took office in a ceremony before the President of the Assembly of the Republic on 16 February 2012. The Non-Executive Members' terms were renewed in 18 November 2014. All members have had extensive experience in public finance, with backgrounds working for the Central Bank of Portugal, in academia, other independent fiscal institutions and international organisations. Two members, including the Vice-President, are non-Portuguese citizens, which enhances the independence of the council's assessments of the consistency of fiscal policy. The two foreign CFP members work part-time, whereas the three Portuguese members are full-time. Senior Board members cannot hold any other public or private positions in Portugal (or abroad if these conflict with their tasks at the CFP). Unpaid higher education teaching or academic research is the only exception allowed.

The remuneration of the Senior Board members and CFP staff is determined by a special three-person Remunerations Committee appointed by the Minister of Finance upon a joint proposal of the President of the Court of Auditors and the Governor of the Central Bank. This committee, while safeguarding its independence, takes into account the budgetary situation of the state and any legal constraints on higher salaries (article 20 of the statutes). Remuneration is to include social security provisions.

\section{The Executive Committee}

The Executive Committee ensures the day-to-day running of the council. The committee is comprised of the President and the executive member of the Senior Board and the head of the staff. All three are full-time positions.

\subsection{Staff}

The CFP will be supported by a full-time secretariat of 15 to 20 staff. As of 2015, ten staff members with backgrounds in economics, and six supporting staff had been recruited. The head of the secretariat staff is to be appointed from among the staff, on commission, for a three-year renewable term, following the decision of the Senior Board. Staff are recruited according to terms defined by the Remunerations Committee, with priority being given to staff already employed in the public administration. The IT support function is outsourced. External consultants may also be used for specific tasks or projects.

In addition to the need for staff capable of macro-fiscal analysis, the secretariat requires specialists in specific areas of public finance analysis, notably pension and health systems, PPPs and the financial positions of autonomous regions, local governments and public enterprises. In most of these areas, the recruitment challenges are still significant, including understanding complex arrangements and obtaining viable data for analysis and fiscal risk statements.

The recruitment of staff is still ongoing, and is not easy. First, although staff salaries do not necessarily have to follow civil service scales - individual contracts including 
remuneration levels will be determined by the Remunerations Committee - the total remuneration of CFP staff is subject to the ceilings applied to civil service salaries (which have been reduced twice recently as part of the crisis-management government spending cuts). Second, although the CFP would prefer public finance specialists with considerable experience, the pool of such candidates is not large. An additional barrier to recruitment of academics was lifted in 2014. While staff are precluded from performing tasks in other public or private entities, Law No. 82-B/2014 now allows for staff to undertake "teaching duties in higher education institutions and research activity, as well as conference addresses, lectures, short-term training courses and other activities of an identical nature, when duly authorised by the Executive Committee."

\section{Access to information}

The CFP's statutes state that the CFP shall have access to all the economic and financial information necessary for the accomplishment of its mission and all public bodies are duty-bound to supply this information in a timely manner. In particular, the government is required to provide the council with the macroeconomic models it used and their underlying assumptions. If a public body does not fulfil the duty of providing the information in good time, this shall be stated on the council's webpage. If inability to access information becomes a serious issue, the President of the Republic, the parliament, the Court of Auditors and the Central Bank of Portugal shall be duly informed. To date, there has been no significant difficulty in accessing the necessary information, except the case of some relevant non-financial information.

For its part, the council indicated to various agencies the information it must have on a regular and automatic basis. According to its statutes, access may be limited in cases where there are legal restrictions in terms of state secrecy, judicial secrecy and banking secrecy.

\section{Transparency}

The CFP intends to be very transparent in its activities. Its statutes require all council reports to be sent to the President of the Republic, the government, the parliament, the Court of Auditors and the Central Bank, and all reports are made publicly available on the council's website in Portuguese and English. This commitment was demonstrated since the publication of the first reports in 2012.

Relations with the media and the parliament are evolving as the council's work progresses. Amongst the specific responsibilities of the CFP President and Vice-President is holding news conferences and taking part in parliamentary hearings, notably when CFP reports are released.

\section{Governance, advisory support, monitoring and evaluation}

According to its statutes, an internal auditor is an integral part of the council. The auditor will be responsible for the control of the CFP's financial and asset management. $\mathrm{He} / \mathrm{she}$ will make regular examinations of the financial and economic situation of the council and ensure that there is compliance with norms that govern its activities. The auditor will issue an opinion on the council's management report and accounts. The auditor will be a chartered accountant or from an audit firm, and will be appointed for a five-year non-renewable term by the Minister of Finance, on the joint proposal of the President of the Court of Auditors and the Governor of the Central Bank of Portugal. 
The CFP is also subject to legal and financial control by the Court of Auditors which could, in principle, evaluate the performance of the CFP. In practice, the CFP's credibility is likely to be established informally, especially by feedback from the media, the parliament and spokespersons for major political parties. The statutes do not include any provisions for a periodic peer review of the CFP's performance.

\section{Concluding remarks}

The Portuguese Public Finance Council has a well-conceived and clear legal framework, which provides firm underpinnings for its independence from both the government and the parliament. The role of other independent bodies - notably the Court of Auditors and Central Bank of Portugal - in assuring the council's independence is unusual. In particular, these two institutions play a role in issuing an opinion on the CFP's budget, the appointment of council members and its internal auditor; they would be notified should the government not provide necessary information to the CFP.

The CFP's mandate to assess the consistency and sustainability of public finance is a huge task, especially given that Portugal's new budget procedures - the medium-term budget framework and expenditure ceilings - are still evolving. The budget framework's emphasis on comprehensiveness requires the CFP to examine specific budget issues such as pensions and healthcare systems, and public finances in autonomous regions, local governments, public enterprises and PPPs.

While the council has been able to deal with most of the initial logistical issues around its establishment, challenges remain in terms of attracting the full quotient of qualified secretariat staff needed to carry out its mandate. Despite not being at full capacity, CFP reports have generated significant media attention and are visible in current debates on the public finances.

\section{Notes}

1. For the task force's report, see Sarmento (2010).

2. See Speech of Governor in November 2010 at the 6th annual conference of the Portuguese Economists Association.

3. The members of the working group, who had university or Bank of Portugal experience, were: António Pinto Barbosa (Co-ordinator), Teodora Cardoso (who was later appointed Chair of the CFP) and João Loureiro.

4. The statutes project is now available at www.cfp.pt/about-us/1-2history/?lang=en.

5. The May 2011 agreement with the IMF/EU required the publication of a medium-term fiscal strategy document (IMF Memorandum of Economic and Financial Policies (MEFP) May 2011). In the first review of the programme, the government committed to adopt the statutes of the fiscal council by the end of September 2011 and to make the council operational by the end December 2011 (see IMF MEFP September 2011) and paragraph 3.14 of IMF (2011).

6. In particular Regulation (EU) No 473/2013 of the European Parliament and of the Council of 21 May 2013 on common provisions for monitoring and assessing draft budgetary plans and ensuring the correction of excessive deficit of the Member States in the euro area.

7. See www.cfp.pt/news/memorandum-of-understanding-between-the-ministry-of-finance-and-the-portuguesepublic-finance-council/?lang=en.

8. See the report No. 3/2015 "Public Finance: Position and Constraints 2015-2019", available at www.cfp.pt/publications/public-finance-position-and-constraints-2015-2019/?lang=en\#.VsM-L032bcs.

9. See www.cfp.pt/?post_type=publications\&doc=1\&lang=en. 


\section{Bibliography}

Assembly of the Republic of Portugal (2015), www.parlamento.pt.

Fiscal Policy Council Working Group (2015), www.cfinpub.org/en-US/OsEstatutos/Pages/OsEstatutos.aspx (accessed in January 2012, no longer available online).

IMF (2011), “Portugal: Second Review Under the Extended Arrangement”, IMF Country Report No. 11/363, International Monetary Fund, Washington, DC.

OECD (2008), "Budgeting in Portugal”, OECD Journal on Budgeting, Vol. 8, No. 3, OECD, Paris, pp. 7-66.

Portuguese Public Finance Council (2015), www.cfp.pt.

Sarmento, Morais L. et al. (2010), Revisão da Lei de Enquadramento Orçamental - Relatório do Grupo de Trabalho nomeado pelo Despacho No. 8065/2010, 30 April, Ministry of Finance, Lisbon.

\section{Legislation}

Law 22/2011, which was the fifth amendment to the 2001 Budget Framework Law (Lei $n^{\circ} 22 / 2011$ de 20 de Maio, Quinta alteração à Lei n 91/2001 de enquadramento orçamental), 20 May 2011.

Law 54/2011, approves the Statutes of the Council of Public Finances (Estatutos do Conselho das Finanças Públicas), 19 October 2011. 


\section{Portuguese Parliamentary Technical Support Unit (UTAO)}

\footnotetext{
Parliamentary Technical Support Unit (UTAO)
Established: 2006 .
Enabling legislation: Established by Resolution 53/2006 of the parliament. This was confirmed by Law 13/2010 which amended the law governing the departments and services of the assembly.

Mandate: The mandate of UTAO is to support the Budget Committee with technical research and analysis.

Budget: Included in the parliament's administrative budget.

Staff: Currently six staff are seconded from other government-funded bodies.
} 


\section{Context}

The UTAO's creation in 2006 was linked to the need to provide non-partisan budget analysis to the parliament, particularly the Budget and Finance Committee (hereafter "Budget Committee"). The emphasis was on establishing a unit that could provide technical and non-partisan analysis of the draft annual budget and budget execution. Prior to 2005, poor recording of budget transactions had led to fiscal surprises, with Portugal being subject to the EU's Excessive Deficit Procedure in 2002 and 2005. In 2006, the Socialist Party had an absolute majority in the parliament, although the chair of the Budget Committee is by tradition from an opposition party (in 2006, a Social Democrat). This contributed to the broad political consensus for establishing a small UTAO in August 2006. It was envisaged that the UTAO would be staffed by three to five persons.

\section{Relationship with the executive and the legislature}

The UTAO is a specialised unit within the parliament's Directorate of Technical Support and Secretarial Services (DSATS). The UTAO functions under the Speaker of Parliament, who acts on proposals from the Budget Committee.

\section{Legal basis for establishment}

The UTAO was established by Resolution 53/2006 of the parliament. Its formal existence was confirmed by Law 13/2010, which amended the Law Governing the Organisation and Modus Operandi of the Departments and Services of the Assembly of the Republic.

\section{Mandate}

UTAO's mandate is to provide technical support to the Budget Committee.

\section{Functions}

The unit's functions are to prepare studies pertaining to: analysis of government bills on the state budget; assessments of the general state accounts; the monitoring of budget execution; analysis of revisions of the stability and growth programme; studies on the budgetary impact of legislative initiatives that are transmitted to the Budget Committee at the discretion of the President of the Assembly and other studies requested by the Budget Committee. The work of the UTAO is of a technical nature.

Due to a lack of staff, the UTAO has not been able to fully perform all of its functions. For example, it has not been able to develop in-house macro-fiscal models to develop baseline "no policy change" budget forecasts, on which alternative budget scenarios could be prepared. Also, the task of costing the budget impact of draft legislation has not been well developed, again because of lack of resources. Staff growth in 2011 (relative to earlier years) has enabled UTAO to increase the number of documents it produces. For example, it started producing a monthly analysis on budget execution and on public debt. 


\section{Work programme}

UTAO's annual work programme is prepared by the UTAO and approved by the Budget Committee. Much of the UTAO's work programme is framed around a set of regular reports. The release of its main reports on the annual budget and stability programme update are timed to coincide with parliamentary discussions. On-demand requests from the Budget Committee make up only a very small portion of the UTAO's work. Budget-related analysis requests from other parliamentary committees or from individual MPs are transmitted to the UTAO via the Budget Committee, which decides whether the UTAO will respond to these requests. There is one exception: the President of the Assembly may request the UTAO directly to analyse a specific issue. This is a rare occurrence.

\section{Budget}

The UTAO does not have a separate budget. Its operating costs are funded from the administrative budget of the parliament. Each year, at least 15 days before the draft state budget law is presented to the parliament, the draft budget for the parliament is drawn up by the competent departments and services, and co-ordinated by the Secretary General of Parliament, in accordance with guidelines and objectives set in advance by the Board of Administration. The draft budget is presented to and approved by this board before it is presented for the approval of the parliament in plenary session, after which the parliament passes the state budget. The UTAO Co-ordinator plays no role in executing the unit's "budget". So far there have been no attempts to block the material resources needed to conduct the UTAO's work. Decisions on individual spending items (such as for meeting travel costs) are made by the Director of the Directorate of Technical Support and Secretarial Services (DSATS) or by the Secretary General of Parliament (for major spending requests). The unit's main costs are for staff salaries (about EUR 350000 a year). Salaries were reduced by $10 \%$ on average in 2011 and by nearly 14\% in 2012, in line with the spending cuts applied to civil servants.

\section{Staffing}

\subsection{Leadership}

Since March 2011, a Co-ordinator is chosen from among the UTAO's staff.

\subsection{Staff}

The unit began with three staff in 2006, and operated with only two staff from 2007 to 2009. ${ }^{1}$ In October-November 2009, UTAO was closed down for two months. At the end of 2009, the UTAO's staff of two were asked to return until a new selection procedure was completed. In 2010, following an agreement between the two major political parties, the parliament passed Resolution 57/2010 that envisages an increase in staff to eight to 10 . However, in December 2011, because of the spending cuts being applied across the civil service, and potential overlap with the work of the newly created CFP, the Budget Committee decided not to increase the number of staff beyond the existing six. The lack of staff has limited the ability of the UTAO to fully perform its functions.

Staff, including the Co-ordinator, are typically seconded from other governmentfunded bodies. ${ }^{2}$ Secondments are annual and renewable for the duration of the legislature, when all secondments end. Recruitment of staff follows DSATS's procedures: the parliamentary service advertises UTAO positions, using qualification criteria formulated by the Budget Committee. The Secretary General of Parliament (who is appointed by the 
President of the Assembly) creates a selection committee to choose among the candidates for UTAO positions. The Budget Committee is not involved in the selection process, nor is the UTAO Co-ordinator consulted on appointments of UTAO staff. The short duration of secondments and the lack of a formal employment contract with the parliament creates considerable uncertainty for UTAO staff. Moreover, there are no written provisions for dismissals. Hence a UTAO member can be removed relatively easily, as happened in 2009. In contrast, the legislature taking office in June 2011 did not bring about any changes to UTAO's composition and the secondments of its members were renewed. The UTAO staff may resign after giving one month's notice.

\section{Access to information}

The UTAO experienced poor access to information from the government from 2006 to 2009. However, since the adoption of Law 13/2010, access has improved greatly and the Ministry of Finance now provides online access to its budget execution database.

\section{Transparency}

The UTAO prepares reports for the Budget Committee. Subject to the committee's approval, the reports are published on the website of the Budget Committee of Parliament. As stipulated in Law 13/2010, in exercising its duties the UTAO must act with strict impartiality and objectivity. Each year, about 30 analytical and technical notes are prepared; however, the key documents which receive the most attention are the analyses of: the government's annual update of the stability programme (i.e. proposed mediumterm budget strategy); the proposed annual budget; monthly budget execution (and debt) reports; and the government's report on the state general accounts. Published UTAO reports or notes often receive attention from the media and national fiscal policy experts. The UTAO itself does not deal directly with external bodies or the media; this is considered the role of members of the Budget Committee.

\section{Governance, advisory support, monitoring and evaluation}

The UTAO is overseen by the Budget Committee of the parliament. There is no other advisory board that oversees its work, although the quality of its work is under permanent scrutiny by national experts in fiscal policy, by MPs and by the media.

\section{Concluding remarks}

The UTAO provides important analytical capacity to the parliament but has suffered from a lack of resources. It has managed to survive considerable difficulties and continues to find its place along with other institutions providing independent budget and fiscal analysis such as the newer Portuguese Public Finance Council.

\section{Notes}

1. The OECD (2008) recommended that the parliament should consider increasing the number of staff of the UTAO.

2. In 2012, for example, the majority of staff were on secondment from the Ministry of Finance, one was from the Central Bank of Portugal and one was from a public university. 


\section{Bibliography}

OECD (2008), "Budgeting in Portugal", OECD Journal on Budgeting, Vol. 8, No. 3, OECD, Paris, pp. 7-66.

UTAO (2015), www.parlamento.pt/OrcamentoEstado/Paginas/UTAO_UnidadeTecnicadeApoioOrcamental.aspx. 



\section{Slovak Republic}

\section{Council for Budget Responsibility (Rada pre rozpočtovú zodpovednost')}

Established: 27 June 2012.

Enabling legislation: Constitutional Law on Budgetary Responsibility (Ústavný zákon o rozpočtovej zodpovednosti), 8 December 2011.

Mandate: Publish a report on fiscal sustainability; submit to the parliament an evaluation of fiscal policy in relation to fiscal rules and transparency rules; on its own initiative, publish costings of draft legislation; monitor and evaluate fiscal performance; and perform related activities prescribed by law.

Budget: EUR 1.3 million (2015).

Staff: Three council members, 11.5 analysts and two secretariat staff (2015). 


\section{Context}

The idea for an independent fiscal watchdog in the Slovak Republic originated with a working paper by the National Bank of Slovakia (Horváth and Ódor, 2009). This gave rise to discussions with the various political parties prior to the elections scheduled for June 2010, and the idea was included in the government programme of the centre-right coalition published in August 2010. During 2011, a cross-party parliamentary committee developed the draft legislation, which was presented in September 2011. The draft legislation was signed by a member of the parliament from each of the political parties represented in the National Council of the Slovak Republic. In December of the same year, by a majority of 146 out of 147 parliamentarians the National Council passed the Constitutional Law on Budget Responsibility, including provisions for the establishment of a Council for Budget Responsibility (CBR) (Ódor, 2012).

The negotiations leading up to the adoption of the legislation took place in the context of a fundamental economic crisis in Europe and sovereign debt crises in a number of countries. ${ }^{1}$ The Slovak Republic's fiscal position was affected by these developments, which led to rising debt levels, although still within the European Union's official limit of $60 \%$ of gross domestic product. Despite this international dimension, the process remained grounded in domestic politics. However, the resulting legislation is compatible with the new fiscal treaty adopted by some European governments, which promotes domestic fiscal rules and independent fiscal institutions.

The main comparative reference during the drafting of the provisions on the Council for Budget Responsibility in the Slovak Republic was the experience of Hungary's Fiscal Council (Porubský, 2011). The initial idea was to create a fiscal watchdog under the parliament, which was thought to protect its independence. However, when the Hungarian government replaced its original Fiscal Council, with had been under the authority of the Hungarian parliament, with a much weaker body in 2011, it was felt in the Slovak Republic that institutional independence along with financing from the central bank might offer greater protection from potential political interference. The latter arrangement resembles the institutional set-up of Austria's Government Debt Committee (and to some degree the newly established Portuguese Public Finance Council), although this example did not play a major role in the discussions leading up to the creation of the Council for Budget Responsibility.

The creation of the council is part of a broader set of measures. These include: a constitutional debt limit, expenditure ceilings, strengthened fiscal rules for municipalities and enhanced fiscal transparency. The council is seen as the watchdog that works to enforce this fiscal framework. The debt limit is set at $60 \%$ of gross domestic product and relates to the official Eurostat figure. From 2017, the debt limit will gradually decrease until it reaches $50 \%$ of gross domestic product from the 2028 fiscal year onwards. Several fully automatic sanction mechanisms are triggered at different levels below the limit. The debt limits are subject to four numerically defined escape clauses relating to: major recessions, banking system bailouts, natural disasters, and international guarantee schemes. 
The statutory debt limit is not the operational target; expenditure ceilings are expected to play this role and underpin the implementation of the debt limit. The Constitutional Law on Budgetary Responsibility also contains a no-bailout clause and automatic financial sanctions for municipalities breaching a debt threshold of $60 \%$ of their revenues. With regard to fiscal transparency, the law provides a statutory basis for two independent committees responsible for macroeconomic and tax forecasts for the budget. There is also a requirement to include several important pieces of information in the budget and the accounts. These relate to: consolidated budget figures, tax expenditures, implicit and contingent liabilities, net worth, one-off effects, financial results of state companies, and a debt management strategy.

\section{Relationship with the executive and the legislature}

The council is an independent institution. The National Bank of Slovakia provides funding for its operation. Initially, the idea was to place the council under the authority of the parliament; but institutional autonomy along with financing from the central bank was thought to be a better guarantee of its independence. It was thought that the governor of the central bank would arguably suffer higher reputational costs than the government from any attempt to eliminate an independent fiscal watchdog since fiscal stability directly supports monetary policy. The European Central Bank would also likely question such an attempt and thus exert peer pressure. The parliament has a role in appointing members of the council, and is also a statutory recipient of one of the council's required reports. The council may be asked to participate in hearings of the Budget and Finance Committee.

Since the council is tasked with assessing the government's compliance with the debt limit, it has a potential role in triggering the sanctions outlined in Articles 5 and 12 of the law. These depend on various thresholds in relation to the debt limit and increase in severity: first, an open letter by the Minister of Finance to the National Council; then reform proposals from the government; an expenditure freeze, including politician's salaries; a balanced budget requirement; and ultimately a vote of no-confidence in the government once the debt limit has been reached or exceeded.

Article 8 of the law provides a statutory basis for two complementary institutions, which are already operational: the Committee on Tax Revenue Forecasts and the Macroeconomic Forecasting Committee. These committees are advisory bodies to the Minister of Finance and produce their forecasts twice a year, which inform the budget preparation process. The existence of these institutions limits the need to give such forecasting responsibilities to the council, which is left with a more focussed mandate.

\section{Box 1. Role of the legislature in the budget process}

The Slovak Republic is a parliamentary republic. The government is led by the Prime Minister and exercises executive power. The President is the head of state and the formal head of the executive, though with very limited powers. The President is elected by direct, popular vote for a five-year term. The National Council of the Slovak Republic is a unicameral legislature with 150 seats. Members are elected for four-year terms on the basis of proportional representation.

The draft budget has to be presented to the National Council by 15 October, two and a half months prior to the start of the fiscal year. The constitution does not impose constraints 


\section{Box 1. Role of the legislature in the budget process (cont.)}

on the powers of the National Council to amend the budget proposal. The 13-member Committee on Finance and Budget plays the central role in examining the budget, with input from other parliamentary committees. In practice, parliamentary amendments to the budget are not uncommon, but their overall impact is typically limited. The National Council does not have a budget research unit to support its scrutiny of the budget.

\section{Legal basis for establishment}

The legal basis for the establishment of the council is the Constitutional Law on Budgetary Responsibility (Ústavný zákon o rozpočtovej zodpovednosti), which received parliamentary approval on 8 December 2011. Hereafter, it is referred to simply as "the law".

\section{Mandate}

Article 4(1) of the law spells out five specific duties of the council. It must:

a) Develop and publish a report on sustainability, including the baseline scenario and the determination of sustainability indicators, annually by 30 April and always within 30 days after consideration of a government programme and expressed confidence in government.

b) Prepare and submit to the National Council a report evaluating the implementation of the fiscal rules and fiscal transparency rules established in the law with reference to the previous fiscal year, each year by 31 August.

c) Prepare and publish at its own initiative opinions on draft legislation submitted to the National Council, particularly in terms of implications for the general government budget and long-term sustainability. Such advice may also develop at the instigation of a parliamentary group. This does not include normative advice.

d) Perform other activities related to monitoring and evaluating fiscal development in the Slovak Republic and the assessment of compliance with the rules of budgetary responsibility.

e) Perform other activities prescribed by law.

The mandate is clear and provides a relatively narrow primary focus on fiscal sustainability analysis and the assessment of compliance with fiscal and transparency rules. These two items are linked to specific reporting deadlines. Costing activities are also possible, but not required. The potential to carry out "other activities" related to the mandate provides flexibility and appears to allow the council to engage in a range of complementary activities - as long as they do not distract from its core mandate. Institutional coverage is comprehensive, including general government and other entities as well if their operations may affect public finances. The law does not specify any particular limitations.

\section{Functions}

The mandate of the council requires it to conduct analyses of long-term fiscal sustainability, which the law defines as a situation where general government revenues and expenditure under a baseline scenario for the next 50 years will not increase public debt above the upper limit of public debt enshrined in the legislation. Article 2 of the law provides precise definitions of a range of related concepts, including: the long-term baseline, the indicator of fiscal sustainability, the structural primary balance, net wealth of the Slovak 
Republic, public enterprises, commitments and tax expenditures. The second core function of the council is to assess compliance with the fiscal and transparency rules contained in the legislation. Finally, the council can choose to cost individual pieces of legislation. ${ }^{2}$

The nature of the council's work is positive, or descriptive, rather than normative. It has no mandate to formulate explicit policy recommendations. Its mandate calls for a high level of expertise in fiscal analysis. The council has no role in macroeconomic forecasting for the government, which is the task of a separate body. Moreover, it has no mandate to cost the election platforms of political parties. Its functions are both prospective, when analysing long-term fiscal sustainability or the draft budget, and retrospective, when assessing the government's compliance with fiscal and transparency rules. The legal mandate of the council prioritises these two functions, leaving the third function, costing of legislation, as optional.

\section{Work programme}

The work programme is guided by the mandate of the council. It establishes two specific annual reporting deadlines: 30 April for the report on fiscal sustainability, and 31 August for the report to the National Council on the government's compliance with fiscal and transparency rules. Parliamentary groups can request the council to cost particular pieces of legislation, but ultimately the council has discretion in whether to do so. As noted above, the mandate also provides a degree of flexibility in terms of the council's engagement in other activities that are related to its mandate. The legal framework allows it to determine its own work programme, within the requirements of its mandate.

\section{Budget}

Article 3(8) of the law stipulates that the expenditures for the office that supports the council are financed from the budget of the National Bank of Slovakia. The National Bank must be immediately reimbursed for these expenses from the state budget, if it makes such a request to the Ministry of Finance. The council has autonomy in determining the allocation of funds across various items of expenditure, within the overall spending limit established by the National Bank. According to the memorandum that accompanied the draft of the establishing legislation, the intention was to fund the council with approximately EUR 2 million in 2013, and to subsequently link its allocation to the nominal growth of the current budget of the National Bank. The budget was set at EUR 916000 in 2014.

The envisaged funding process is rather unique among the independent fiscal institutions reviewed in this publication. When the initial proposals were being discussed, the European Central Bank objected that direct central bank funding for the council constituted monetary financing. As a result, the provision was inserted to allow the National Bank to immediately reclaim the money from the state budget. Interestingly, the Government Debt Committee in Austria is also attached to that country's central bank and funded directly from its budget, but apparently this has not given rise to similar concerns.

\section{Staffing}

\subsection{Leadership}

Article 3 of the law regulates membership of the CBR. The council has three members: one chair and two other members. The chair is elected (and can be recalled) by the National Council of the Slovak Republic with the support of at least a three-fifths majority vote of 
members, based on a proposal by the government. One council member is elected (and can be recalled) by the National Council with an absolute majority of members present, based on a proposal of the President of the Slovak Republic. Another member is elected (and can be recalled) by the National Council with an absolute majority of members present, based on a proposal by the Governor of the National Bank of Slovakia. Council members have the status of public officials.

At least one council member is expected to be full-time. The two other members could potentially be part-time, but at least half of their time should be spent on their council work. There are no statutory rules for remuneration. An earlier draft of the law set an exact figure for remuneration of the chair and members, but this provision was removed in the final approved legislation. It is expected that the chair's remuneration will be similar to that of the vice-governor of the central bank.

Council members serve seven year non-renewable terms. If a member's term expires, a member resigns, or dies or is declared dead, the relevant nominating body is entitled to propose a replacement to the National Council within one month. If a member becomes ineligible to serve on the council due to a conviction for an intentional crime, the National Council itself nominates a replacement within one month. A council member may be removed from office only if convicted of an intentional criminal act, if a court decision deprives them of their legal capacity, or if they are unable for a period of six months to carry out their functions.

Council members must have appropriate expertise and experience, at minimum a completed master's degree and at least five years of experience in public finance and macroeconomics. A person who has been convicted of an intentional crime is not eligible to be a member, and full legal capacity is required. Membership of the council is also incompatible with holding a position with a political party or political movement, or with a company. Also excluded are the President of the Slovak Republic, members of the parliament, members of the European Parliament, members of the government, members of the European Commission, mayors, governors of a region, members of a municipal or regional council, or individuals on the board of the National Bank of Slovakia. A former council member may not become a member of the government until more than three years have expired since the end of their membership. These provisions allow for the appointment of foreign nationals if they have sufficient knowledge of the Slovak economy, and officials involved in the process expect this possibility to be utilised in practice.

The first appointments fall under special provisions contained in Article 10 of the law. The National Council has to elect the first members of the CBR with a three-fifths majority of deputies present. Moreover, the start of the first term of each member will be staggered to avoid all terms expiring at the same time and thereby disrupting the work of the council. The CBR has to submit its first required report (on fiscal sustainability) 6 months after the election of all members, and the second required report (on the implementation of the fiscal and transparency rules) 12 months after the election of all members.

The first three council members were elected on 27 June 2012 by constitutional majority. They included an economist and, former Governor of the National Bank of Slovakia with a background in commercial banking and economists with experience working in the central bank, as advisors to the Prime Minister and the Minister of Finance, and in academia. 


\subsection{Staff}

According to Article 3(7) of the law, the council has the support of a secretariat in an office located in the capital city. The staff is being recruited based on their ability to carry out the required analytical and administrative tasks to enable the council to fulfil its functions. The recruitment of about 15 to 20 analysts is planned in the medium-term. At the end of 2012, eight analysts were working for the council. These analysts are mainly economists with experience in the public sector (central bank, Ministry of Finance), although several junior analysts were recruited directly from university. Given the small pool of candidates in the Slovak Republic, there was some concern that the National Bank of Slovakia and the Ministry of Finance would lose staff to the council. While this did indeed happen, the council agreed not to hire more than one staff member from each institution for one year in order to allow them to prepare for possible staff changes in advance. The council is solely responsible for hiring the staff for its office and terms and conditions are along the lines of those of the central bank. While the council may hire outside consultants, there were no plans to do so at the time this note was written.

\section{Access to information}

According to Article 4(2) of the law, the council has the right to require government entities to provide data that are necessary to carry out its functions. Public entities must provide advice and the necessary assistance upon request. The law does not contain specific restrictions with regard to the council's access to relevant data held by government entities. The council has established a memorandum of understanding on informationsharing with the analytical unit of the Ministry of Finance, the National Audit Office and the National Bank of Slovakia. To date, access has generally been good. Should the council experience problems obtaining necessary information in the future, it would state this publically in its report.

\section{Transparency}

The mandate contained in Article 4(1) of the law prescribes the publication of the required reports. In addition, Article 7(1) requires the council to publish on its website its methodology and assumptions for analysing fiscal sustainability. In addition to its main reports, the council publishes on its website: data sets, procurement information and contracts, presentations, blogs, a citizens' budget or "budget for the people", and an annual report. The council also maintains an English version of its website.

\section{Governance, advisory support, monitoring and evaluation}

The law establishing the council does not make provision for an oversight board or advisory panels, other than the distinction that it makes between members of the council and the staff of its office. The law does not mention systematic peer review of the reports of the council, or any other monitoring and evaluation arrangements.

However, in line with the OECD's recommendations on external evaluation, the council members took the initiative to establish an Advisory Panel comprising five wellrespected foreign experts on fiscal councils and rules. The first Advisory Panel includes the former head of the Hungarian Fiscal Council and a current member of the Portuguese Public Finance Council, the first Canadian Parliamentary Budget Officer, an executive director in the Italian central bank and two academics. The panel's main task is to provide 
advice on methodological issues. Its members work on a pro bono basis and are expected to meet at least once a year and to be available for consultation electronically. ${ }^{3}$

\section{Concluding remarks}

The Slovak Republic's Council for Budget Responsibility was created on the basis of a consensus that brought together all political parties in support of its legal framework. This approach has led to a solid statutory basis for this new institution. The funding and staff level have allowed the council to meet the requirements of its mandate and to undertake important work at their own initiative. Since 2013, the council has also played a leadership role among European independent fiscal institutions, creating a new informal network of EU IFIs to help share information and co-ordinate communication with relevant EU institutions.

\section{Notes}

1. The crisis directly affected the political situation within the Slovak Republic as a first vote to approve the expansion of the European Financial Stability Fund in October 2011, which was linked to a confidence motion, toppled the centre-right coalition government in power since June 2010. This triggered new elections in March 2012 that were won by the socialist Smer party. Smer pledged to stick with the previous government's policy of reducing the deficit.

2. The CBR published four reports in 2012: a discussion paper on evaluating fiscal sustainability, an ex-ante evaluation of the draft budget for 2013-15, a costing of the latest pension reform and a report on fiscal sustainability.

3. The first meeting of the Advisory Panel to the CBR took place on 4 October 2013, in Bratislava. The advisors discussed with the members of the Council for Budget Responsibility issues ranging from the fiscal framework of the CBR to its economic models, methods of measuring the output gap and structural balance of public finances, OECD principles for independent fiscal institutions as well as long-term sustainability of public finance.

\section{Bibliography}

Council for Budget Responsibility (Rada pre rozpočtovú zodpovednost') (2015), www.rozpoctovarada.sk.

Horváth, M. and L. Ódor (2009), "Making Fiscal Commitments Credible: Institutions for a Responsible and Transparent Fiscal Policy in Slovakia", Working and Discussion Papers DP 2/2009, Research Department of the National Bank of Slovakia, Bratislava.

National Council of the Slovak Republic (2015), www.nrsr.sk.

Ódor, L. (2012), "Fiscal Framework in Slovakia: Searching for Synergies between Rules and Institutions", presentation at the 4th Annual Meeting of OECD Parliamentary Budget Officials and Independent Fiscal Institutions, Paris, 23-24 February.

Porubský, J. (2011), “Dlh pripravuje o suverenitu”, Forbes (Slovakia), November, Business Consulting and Media Ltd., Bratislava, pp. 18-19.

\section{Legislation}

Constitutional Law on Budgetary Responsibility (Ústavný zákon o rozpočtovej zodpovednosti), 8 December 2011.

Proposal of the Members of the National Council of the Slovak Republic for a Constitutional Law on Budgetary Responsibility (Návrh skupiny poslancov Národnej rady Slovenskej republiky na vydanie ústavného zákona o rozpočtovej zodpovednosti), 8 November 2011. 


\section{Spain}

\section{Independent Authority for Fiscal Responsibility (Autoridad Independiente de Responsabilidad Fiscal - AIReF)}

Established: 2013

Enabling legislation: Organic Law 6/2013 of 14 November on the establishment of an Independent Authority for Fiscal Responsibility.

Mandate: Ensuring the effective compliance by public administrations with the budgetary stability principle as set forth in Article 135 of the Spanish constitution through continuous monitoring of the budgetary cycle, public indebtedness and assessment of economic forecasts.

Budget: EUR 4.48 million (2015).

Staff: 35 (2015). 


\section{Context}

The establishment of the Autoridad Independiente de Responsabilidad Fiscal (AIReF) in November 2013 was the result of two closely related reform processes. The first was an internal reform process aimed at reinforcing the Spanish budgetary fiscal framework to ensure budgetary discipline at all levels of the public administration, restore sound public finances and set them on a sustainable path. The second reform process was externally driven by the new EU economic and fiscal policy governance framework in the aftermath of the economic and financial crisis.

The national reform process began with the modification of Article 135 of the Spanish constitution in September 2011, which obliges all levels of the public administration to respect the principle of budgetary stability. This constitutional reform had the support of the two major national political parties, the People's Party (PP) and the Spanish Socialist Workers' Party (PSOE). Spain's commitment to public budgetary stability is thus set at the highest normative level. According to Article 135, central and regional governments cannot exceed the thresholds for structural deficit set out by the European regulations. As the limit is established in structural terms, the countercyclical stance of fiscal policy is reinforced and the functioning of automatic stabilisers strengthened. In the case of local governments, their headline budgets should be balanced. As for the public debt of the general government, the article establishes that its ratio to GDP cannot exceed the threshold established in the Treaty on the Functioning of the European Union (EU). These limits on structural deficit and public debt can only be exceeded in exceptional circumstances, such as major natural disasters or severe economic recession, and cases of exceptional circumstances must be approved by the parliament. The new deficit and debt ceilings will be binding from 2020 onwards in order to allow a smooth transition. With this reform, Spain became the second country in Europe to introduce this type of rule in its constitution.

Article 135 is upheld by a new organic law, meaning that it applies to all layers of the Spanish public administration, something which is of particular relevance in a highly decentralised country such as Spain. The government that took office in December 2011 reformed the existing fiscal rules through the adoption in April 2012 of the Organic Law 2/2012 on Budgetary Stability and Financial Sustainability. This law amended the previous budgetary framework and introduced three types of numerical fiscal rules as well as the monitoring procedures and preventive and corrective measures to ensure compliance with the rules. The current numerical fiscal rules are:

- Budget balance rule - the public administration cannot run a structural deficit. Exceptionally, the central and regional governments may record a deficit in the event of natural disasters, severe economic recession, force majeure or other extraordinary situations beyond their control. Local governments must keep balanced budgets. The social security administration must record surpluses or be balanced. A structural deficit of up to $0.4 \%$ of GDP is allowed when structural reforms with short-term costs but positive medium-term impact on the budget are implemented. 
- Public debt rule - general government debt is limited to $60 \%$ of GDP. ${ }^{1}$ That figure is divided across the different levels of public administration as follows: $44 \%$ of GDP for central government, $13 \%$ of GDP for all the regions and 3\% of GDP for local governments. Net debt issuance is banned for any administration exceeding those ceilings.

- Expenditure rule - changes in government spending cannot exceed a reference rate, namely the Spanish economy medium-term nominal GDP growth rate. This rule must be followed by the central, regional and local governments.

AIReF was established as part of this reform package to help ensure implementation of this new fiscal framework. Indeed, the Organic Law 6/2013, approved on 14 November 2013, established the new independent fiscal authority as the institution responsible for ensuring the effective compliance by the various public administrations with the budgetary stability principle as set forth in Article 135 of the constitution through a continuous monitoring of the budgetary cycle, public indebtedness and the analysis of economic forecasts. AIReF monitors all the stages of the budgetary process and provides independent analysis and assessment, including an assessment the macroeconomic forecasts. The establishment of AIReF was approved with the support of the governing political party (57\% of the votes), with negative votes from all the remaining political parties who argued that the proposed institutional design could jeopardise independence. However, since the AIReF began working, it has seen an increase in cross-party support.

In parallel with the national reform process, the EU was conducting a reform of its economic and fiscal governance system by strengthening co-ordination, monitoring and surveillance mechanisms (implemented through the fiscal compact and the six-pack and twopack). First, Directive 2011/85/EU on requirements for budgetary frameworks of the member states established that country-specific numerical fiscal rules shall contain the effective and timely monitoring of compliance with the rules based on reliable and independent analysis carried out by independent bodies. Second, Regulation 473/2013 on common provisions for monitoring and assessing draft budgetary plans established that member states shall have in place independent bodies for monitoring compliance with numerical fiscal rules.

The European Council also recommended in 2012 and again in 2013 the creation of an independent fiscal institution for Spain to provide independent analysis and advice, and to monitor compliance of fiscal policy with national and EU fiscal rules in the context of the EU economic policy surveillance procedure for two years. With the approval of the Organic Law 6/2013, Spain met the European requirements and completed the deep reform of its budgetary framework begun in 2011.

\section{Box 1. Role of the legislature in the budget process}

Spain is a parliamentary monarchy with a bicameral parliament. The Congress of Deputies, or lower house, has 350 members, elected for four-year terms through a system of proportional representation. The Senate, or upper house, comprises 266 members with 208 elected by popular vote for four-year terms and 58 appointed by the regional legislatures.

The role of the parliament in the budget process is well-defined in the Spanish constitution. According to Article 134, the government is responsible for preparing the draft budget and the parliament is responsible for scrutinizing, amending and approving the draft budget. Parliamentary amendments are restricted in so far as they cannot change the total deficit or surplus proposed by the executive. While this power is used in practice, amendments tend to represent only a very small portion of proposed spending in the budget. 


\section{Box 1. Role of the legislature in the budget process (cont.)}

The constitution also specifies the timing of legislative debate. The government's draft budget must be submitted to the parliament three months before the expiration of the budget law for the previous year. The "General Budgetary Law" acts in concert with the constitution, setting 1 October of each year as the deadline for submission of the draft budget to the parliament.

The draft budget submitted by the government must take into account the three-year budgetary stability targets previously agreed upon by the parliament. This medium-term budgetary planning is regulated by the Organic Law on Budgetary Stability and Financial Sustainability (amended in April 2012).

The debate and approval process for the draft budget is outlined in the Standing Orders of the Congress (1982) and the Senate (1994). Normally, the budget is debated for two months in the lower house and one month in the Senate. Debate is led by Budget Committees in both chambers.

During the first round of debate in the Congress, the draft budget can be rejected and returned to the government for revisions, although this happens exceedingly rarely in practice. This is not considered a vote of confidence. Once the draft budget is approved by the Congress, it is submitted to the Senate which may introduce partial amendments. Senate amendments must be approved by a simple majority in the Congress. While the Senate has the power to veto the draft budget received from the Congress, the Congress can override this veto with an absolute majority. If Congress fails to override the veto in a first vote, a second vote must be held within two months and a simple majority in the Congress serves to lift the veto. If the second vote fails to garner a simple majority, the draft budget is sent back to the government for revisions; but this is a rare occurrence.

Once approved, the budget enters into force on 1 January. If the Budget Bill is not passed before the first day of the corresponding financial year, the budget of the previous financial year is automatically extended until the new one is approved.

Although the Standing Orders of the lower house do not contain specific provisions on the powers of the Budget Committee, at the start of a new legislative term the Budget Committees typically adopt a decision to hold quarterly public hearings with the Secretary of State for Budget and Public Expenditure in order to monitor budget implementation and budget trends.

As a general rule, the public is not allowed to attend committee meetings; however they can follow committee meetings through live broadcasts on the Congress' official website. Information on committee hearings can also be found in the Official Gazette published on the Internet.

The technical support available to the legislature on the budget comes in several forms:

1. Secretariats of the Budget Committees comprised of two Clerks and two-to-three staff assistants who mainly play a procedural role in forwarding information from the government on the budget to members of both houses.

2. The Public Finances and Economic Research Section (PFERS), one of four units reporting to the Directorate of Research, Analysis and Publications, provides analysis of budgetrelated issues to the lower chamber. Specifically, PFERS supports the Budget Committee during the annual budget process by: providing technical verification of amendments presented that would modify appropriations; costing amendments approved on income and appropriations as compared with the estimates made by the government; and answering queries from deputies and staff of party groups. In addition, information on 


\section{Box 1. Role of the legislature in the budget process (cont.)}

the implementation of the central government budget and the 17 regional government budgets (incomes, expenditures and balances) is subject to synthesis and analysis by PFERS on a monthly basis. This information is made available to members of the Congress through the internal network. Finally, since the early nineties, PFERS provides members with an overview of information related to the macroeconomic forecasts, covering information from government, private institutions in Spain and international bodies like the OECD, IMF, or European Commission.

3. The Cortes Generales Budget Office (see Box 2 below).

The autonomous regions have their own budgetary processes, but there are common features. They all have unicameral regional parliaments. The regional governments are responsible for the preparation of the draft budget and the regional parliaments can approve, reject or partially amend the drafts. If a regional budget is not approved by its regional parliament, the previous one is automatically extended until the new one is approved.

\section{Box 2. The Cortes Generales Budget Office}

The Spanish parliament has established a parliamentary budget office, although it has yet to become fully functional. The Cortes Generales Budget Office was created by law (Law $37 / 2010$, November 15 on the creation of the Budget Office of the Spanish Parliament) as a bicameral unit. Its main duties are outlined in Section 4 of the law as:

1. follow-up and oversight of the implementation of the general state budget and its settlement, as well as providing technical advice to the chamber's official bodies and deputies, senators or party groups in response to any query they may submit regarding the budget, its implementation or settlement status, or regarding public revenues and spending;

2. compiling and tabling financial and budgetary information provided by other public and private institutions;

3. follow-up of law-making activities that may affect public revenues or spending; and

4. any other task entrusted by the bureaus of the chambers, on their own initiative or on the request of the Budget Committees.

In July 2011, a joint resolution adopted by the bureaus of the two chambers defined the structure of the office as having two units: one economic and one budgetary. This has yet to be fully implemented.

The first Director of the Budget Office was appointed on 30 April 2013. According to Decision 19/07/2011, staff of the Budget Office will be drawn mainly from among civil servants in the Spanish parliament and the Director of the office shall be appointed by the bureaus of both chambers from among persons of recognised standing and professional experience in budgetary, economic and/or financial fields.

The first Director launched a project to facilitate access to the general state administration's accounting information and budgetary databases in order to be able to provide detailed and updated information on the execution of the state budget. The first Director resigned in September 2014 and a successor was appointed.

In December 2014, a convention between the parliament and the government was signed on the completion of section four (3) of the Law 37/2010 which states that "the necessary 


\section{Box 2. The Cortes Generales Budget Office (cont.)}

co-operation arrangements and procedures shall be put in place with the general state administration, in such a way that the office may avail of the information required to carry out its duties. The Cortes Generales Budget Office shall have access to the general state administration's accounting information and budgetary databases, including the state public sector and social security joint services and management agencies, directly or via queries to the bodies directly in charge of their administration. Ad hoc arrangements may be made for the establishment of specific and direct information flows between the Cortes Generales Budget Office and the Ministry of Economy and Finance budgetary information, co-ordination and programming services." As of February 2015, access to the general state administration's accounting information and budgetary databases had still not been implemented.

\section{Relationship with the executive and the legislature}

AIReF is a public law institution with its own legal personality and full public and private capacity to act. Although it is attached to the Ministry of Finance and Public Administrations, it has been conceived as an entity with functional autonomy and fully independent from the budgetary authorities. According to the organic law, the AIReF President and staff cannot seek or take any instructions whatsoever from any institution, whether public or private.

The appointment of the President of AIReF must be approved by the appropriate commissions committees of the Congress and the Senate, in practice the Committee for Public Finances and Public Administrations. The President's non-renewable mandate lasts six years which makes it independent from the political cycles of four-year general elections. The President of AIReF cannot be dismissed without a hearing of the relevant Commission of the Congress and the Senate.

In addition, the AIReF President is supposed to appear, at least once a year, before the appropriate committees of the Congress of Deputies and the Senate. Additional hearings can be asked for by the parliament or by AIReF's President. In AIReF's first year, however, the parliament did not take advantage of this provision.

The main source of funding for AIReF is a fee for the supervision, analysis, advice and monitoring of fiscal policy charged to all public administrations under its surveillance. In addition, AIReF can charge for specific studies and assignments carried out, as specified annually in the central government budget, and the products and income derived from the property and rights that constitute their assets.

The authority's influence is reinforced by the principle of "comply or explain" contained in the organic law. This principle applies to all the reports which are mandatory for AIReF by law (i.e., on macroeconomic forecasts, on the draft budget or on the stability programme). If the public administration or an institution receiving such a report decides to ignore AIReF recommendations, detailed reasons must be provided and the report must be included in the corresponding file. However, there is no time limit to respond to these recommendations beyond the need to include them in the proper file. So far, the practical implementation of this principle has had different results. Some administrations have answered that they will apply the recommendations while others have failed to answer altogether; but none have provided an explanation on why they are not planning to apply a recommendation. ${ }^{2}$ To reinforce the effectiveness of this principle, in March 2015 AIReF 
has issued a regulation ${ }^{3}$ clarifying the different nature of the recommendations (on limitations to scope, on the object of the report and best-practice guidelines), how to overcome them and specific deadlines.

The Spanish legislation does not foresee a formal relationship with other national public institutions involved in the surveillance of fiscal policy (mainly the State Audit Office). It is, however, explicitly recognized by the law that AIReF can, in co-ordination with the Ministry of Finance, collaborate with other institutions and organisms of the EU, in particular the European Commission, for the performance of the duties attached to monitoring public finances. AIReF can co-operate as well with other independent fiscal institutions from other member states. AIReF must report quarterly to the Ministry of Finance and Public Administrations on the communications and information exchanges carried out with EU institutions and organisations, particularly those with the European Commission.

There is no other national institution providing such a wide range of analysis on fiscal policy issues, although some institutions can conduct a partial analysis. For instance, some private or public institutions produce macroeconomic forecasts. In fact, AIReF uses as a benchmark the macroeconomic forecasts produced by a panel of forecasters (FUNCAS or Consensus), the Banco de España or the European Commission in its assessment of government forecasts. Private research departments and think tanks also analyse several aspects of budgetary policy such as the fiscal policy stance, the sustainability of the public finances and long-term projections of public expenditure. Nonetheless, none of these institutions have any active role in monitoring whether fiscal policy adheres to the Spanish budgetary framework, a task which is the sole responsibility of AIReF.

\section{Legal basis for establishment}

The legal basis for the establishment of AIReF is:

- Organic Law 6/2013 of 14 November on the establishment of an Independent Authority for Fiscal Responsibility. The whole of the organic law refers to the fiscal authority.

- Royal Decree 215/2014 of 28 March approving the organic statute of the Independent Fiscal Responsibility Authority. The statute was informed by the views of AIReF's President as well as those of the Banco de España, the European Commission, the IMF, the regional governments and the Spanish federation of municipalities.

Other relevant legislation includes:

- Reform of article 135 of the Spanish Constitution, 27 September 2011.

- Organic Law 2/2012 of 27 April on Budgetary Stability and Financial Sustainability.

- Law 23/2013 of 23 December regulating the Sustainability Factor and the Index for Revaluation of the Social Security Pension Scheme.

\section{Mandate}

According to the organic law and the royal decree, AIReF enjoys a rather broad mandate to ensure effective compliance by all public administrations with the budgetary stability principle as set forth in Article 135 of the Spanish constitution. This includes the continuous monitoring of the budgetary cycle and public indebtedness, as well as the analysis of economic forecasts. Therefore, AIReF provides independent assessment and monitoring for all the stages of the budgetary process. 
The mandate is also clear. AIReF is in charge of the budgetary stability principle and several mandatory competences are established. The mandate takes into account the provisions of the Treaty on Stability, the Co-ordination and Governance in the Economic and Monetary Union and the so called six-pack and two-pack rules reforming EU economic governance. The mandate is also flexible as it allows AIReF to issue other technical judgements on its own initiative.

One of the distinguishing features of AIReF is that it performs its duties for every level of the public sector, something which is of particular relevance in a highly decentralized country like Spain. The general government sector ${ }^{4}$ includes the following subsectors: central government, which encompasses the state and central administration bodies; autonomous regions; local governments; and the social security administration. ${ }^{5}$ Given the very relevant role of sub-national entities in Spanish expenditure and their political autonomy, this approach is an important feature to the mandate.

The law and royal decree establish an exhaustive list of topics that AIReF should examine through its reports. These include:

1. macroeconomic forecasts report;

2. draft stability programme;

3. draft budgets and main budgetary lines of general government;

4. budgets of public administrations;

5. budget implementation, public debt and the debt ceiling rule;

6. methodology to calculate trend patterns of revenues and expenditure and the growth reference rate;

7. determination of individual objectives (budget balance and public debt) for autonomous regions;

8. economic-financial and rebalancing plans for the central administration and the autonomous regions;

9. application of correction mechanisms; and

10. occurrence of exceptional circumstances affecting budgetary stability and financial sustainability.

These reports are mandatory and have to be issued within specific deadlines. For some reports the deadline is set in law, while others should be issued within ten days of the submission of the information and documentation needed for their preparation.

Issuing and publishing opinions is the main discretionary instrument that the legislation gives to AIReF. Opinions are technical value judgements or appraisals on any matter under its mandate made at AIReF's own initiative. Before issuing an opinion, a draft is sent to any of the relevant administrations or entities to verify that there are no factual mistakes, ambiguities or inaccuracies. Administrations have ten days to respond, although a response is not required.

AIReF must issue a compulsory opinion on the Sustainability Factor and the Index for Revaluation of the Social Security Pension Scheme as set forth in Law 23/2013 reforming the pensions system.

AIReF must perform studies at the request of the government or the co-ordination bodies in the government, sub-national entities and the social security system. ${ }^{6}$ AIReF may also perform studies at the request of autonomous regions and local governments provided 
they refer to matters under each administration's competence and that they do not affect any other administration. Before the preparation of such a study, a budget and progress schedule must be established and submitted to the interested party for approval. According to Article 23.1 of the statute, these requested studies are compulsory. Although AIReF has some freedom to set its fees and the ability to hire external consultants, this creates a potential risk in terms of workload.

\section{Functions}

AIReF evaluates compliance with the principles of budgetary stability and financial sustainability through continuous assessment of the budgetary cycle and public indebtedness and through analysis of economic forecasts. The analysis is broad and multidimensional, covering the subsectors of the general government individually and as a whole.

On the macroeconomic front, the focus is on ex ante analysis: AIReF endorses and assesses the macroeconomic forecasts considered for draft budgets, evaluates the mid-term to long-term sustainability of public finances and assesses the methodology to calculate the growth reference rate and the income and expenditure trend forecasts. Additionally, there is also ex-post evaluation of past government macroeconomic forecasts.

On the budgetary front, it analyses, ex ante the budgets of the different subsectors of the general government and the consolidated budget and, ex post, their budget implementation and execution. It also assesses ex ante the revaluation index of the social security pension scheme, the individual objectives of the autonomous regions and the economic-financial and rebalancing plans for the central administration and the autonomous regions. ${ }^{7}$

All of them are aimed at ensuring an early detection of any risk of deviations from the objectives being pursued.

AIReF is still exploring the best way to communicate its appraisals. The intended approach is based to a maximum extent on robust quantitative analysis that helps to determine the underlying uncertainty about fiscal and macroeconomic variables (in contraposition with point estimates). This approach is sometimes complemented by "balance of risks" and/or scenario analysis. Given the nature of AIReF's mandate, it is unavoidable that the appraisals also reflect judgements, although AIReF tries as much as possible to use positive analysis.

AIReF monitors ex ante and ex post compliance with fiscal rules. To implement the constitutional budgetary stability principle, the Organic Law on Budgetary Stability and Financial Sustainability introduced three types of fiscal rules to be fulfilled by all public administrations: a budget balance rule, a public debt rule and an expenditure rule. AIReF provides independent assessments on compliance with fiscal targets and assesses the risk of deviation. As such AIReF plays a role in the preventive, corrective and coercive procedures to achieve compliance with the targets. ${ }^{8}$ AIReF may report on the appropriateness of implementing any of the preventive, corrective and coercive measures as well as on the monitoring of those already adopted. It may report in its quarterly publication of nonfinancial operations of the public administrations in national accounts terms, or at the time it issues monitoring reports on economic and financial plans. Reports are submitted to the administration or authority in charge of activating the relevant mechanisms and measures as well as to the Ministry of Finance and Public Administrations. In addition, under the 
corrective procedure and prior to their approval, all economic-financial and rebalancing plans for the central government and the autonomous regions are reported by AIReF before submitting the plan to the parliament or for the approval of the Fiscal and Financial Policy Council ${ }^{9}$ respectively.

Despite its broad mandate, AIReF is not tasked with costing analysis or estimating effects of legislation. As a general rule, AIReF does not provide normative recommendations on policy measures since the nature of its mandate and analysis is positive. Nonetheless, based on this positive analysis, AIReF is allowed by law to include certain recommendations in its mandatory reports that are subject to the "comply or explain" principle which in turn has been recently clarified by AIReF. Examples of the current AIReF approach and the analysis conducted can be found below.

\section{Box 3. Recent AIReF publications}

Although AIReF has only been operating for several months, it has already published an impressive number of reports, opinions and working papers, whose contents are summarised below.

Report on Macroeconomic Forecasts. The report states whether the macroeconomic forecasts underpinning draft budget plans are endorsed by AIReF or not. This report is supplemented by a report on Macroeconomic Forecasts for Autonomous Regions' Draft Budgets in which AIReF endorses (or not) the macroeconomic forecasts of the autonomous regions that did not use central government macroeconomic forecasts.

* Report on draft budgets and main budgetary lines of General Government. This report contains a global assessment of the general government consolidated perspective, and a detailed analysis on stability and debt objectives, and on the expenditure rule, for each subsector. The report includes an analysis of the revenue and expenditure forecasts for the current and the forthcoming year for each subsector and identifies items for which risks of non-compliance exist. This report is supplemented by subsequent reports in which individual autonomous regions are studied in more depth once they present their draft budgets.

* Report on the Economic and Financial Plans of the Autonomous Regions. In these reports AIReF evaluated compliance of the autonomous regions with the objectives set in the economic and financial plans and the magnitude of possible deviations.

* Report on the methodology to calculate revenue and expenditure trends and the reference growth rate. The report assesses the revision of the cyclical sensitivity of the budget of the general government sector as a whole and all of its subsectors as a consequence of the revisions made at EU level.

* Mandatory opinion on the determination of the Revaluation Pension Index. In November, AIReF verified that results of the formula applied to calculate the pension revaluation for 2015 implied an increase below the legal minimum of $0.25 \%$.

- Opinion on Compliance with Deficit and Debt Targets. This opinion states the risks of non-compliance with the public debt threshold established for 2020 of $60 \%$ of GDP.

- Opinion on changes in budget cycle procedures. This opinion calls for multi-year budget scenarios, harmonization of budget structures of all public administrations and enhancement of transparency.

In addition to the above AIReF published two working papers: one on the long-term sustainability of Government finances and the other on the understanding financial sustainability. 


\section{Work programme}

During the first quarter of each year, AIReF prepares and publishes an Action Plan including all mandatory reports and opinions and requested studies. This Action Plan is approved by the President, following deliberation by the Management Committee. In addition, AIReF publishes a calendar on its website indicating the deadline for submission by public administrations of all the information available and necessary to issue the authority's reports. AIReF develops the methodology, objective criteria and specific aspects to be considered in the different reports and studies, and they must be duly accounted for.

The organic law and the royal decree specify the mandatory reports to be completed and their deadlines. These are summarized in the table below. ${ }^{10}$

\section{Figure 1. Timing of mandatory reports}

\begin{tabular}{|c|c|c|c|c|c|c|c|c|c|c|c|c|}
\hline Regular Report /Opinion & Jan & Feb & Mar & Apr & May & Jun & Jul & Aug & Sep & Oct & $\mathrm{Nov}$ & Dec \\
\hline Action Plan & & & & & & & & & & & & \\
\hline Endorsement of macroeconomic forecas & & & & & & & & & & & & \\
\hline Draft Stability Programme & & & & & & & & & & & & \\
\hline $\begin{array}{l}\text { Individual Objectives for Autonomous } \\
\text { Regions }\end{array}$ & & & & & & & & & & & & \\
\hline $\begin{array}{l}\text { Reports on the Analysis of Budget } \\
\text { Implementation, Public Debt and Debt- } \\
\text { Ceiling Rule }\end{array}$ & & & & & & & & & & & & \\
\hline $\begin{array}{l}\text { Draft budgets and main budgetary lines } \\
\text { General Government }\end{array}$ & & & & & & & & & & & & \\
\hline $\begin{array}{l}\text { Opinion on the Sustainability Factor and } \\
\text { the Index for Revaluation of the Social } \\
\text { Security Pension Scheme }\end{array}$ & & & & & & & & & & & & \\
\hline Budgets of Public Administrations & & & & & & & & & & & & \\
\hline Budgetary mile stones & Jan & Feb & Mar & Ap & May & Jun & Jul & Aug & Sep & Oct & $\mathrm{Nov}$ & Dec \\
\hline Government macroeconomic forecasts & & & & SP & & & & & BP & & & \\
\hline Draft Budgetary Plan (BP) & & & & & & & & & & & & \\
\hline Budgetary Plan & & & & & & & & & & & & \\
\hline Draft Stability Programme (SP) & & & & & & & & & & & & \\
\hline Deasllnes & & & & & & & & & & & & \\
\hline
\end{tabular}

AIReF also publishes working papers on its website to disseminate knowledge on fiscal sustainability issues and is developing agreements with universities and think tanks to foster research and staff exchange opportunities. Finally, AIReF publishes an annual report on its activities that is widely disseminated.

Given its commitment to transparency and accountability, AIReF disseminates information on the methodologies, assumptions and data that underpin any of its analyses, as well as research underpinning most of its technical work ${ }^{11}$ which are published on the web page for public information. This ensures that results can be replicated and the analysis is subject to external review.

\section{Budget}

The AIReF budget is included into the central government budget following negotiations with the Ministry of Finance and Public Administrations. It is approved by the parliament. Article 11 of Law 6/2013 states that AIReF will be provided with sufficient financial resources to fulfil its mandate. AIReF's total budget for 2015 is EUR 4.48 million and staff costs accounted for the $71 \%$ of the budget.

Main AIReF revenues are the supervision fees established in Law 6/2013, subject to regulations on fees and public prices. These fees are collected from the different public administrations and the rate can only be amended in the Central Government Budget Law. For 
2015, the supervision fees represent around $80 \%$ of the AIReF budget. Furthermore, AIReF can obtain revenues from additional studies requested by public administrations. ${ }^{12}$ Finally, funds from the general state budget ${ }^{13}$ could be allocated to AIReF if the revenues obtained through fees and from studies are below the amount in total budget approved by the parliament. AIReF has also its own assets, independent from the general state administration.

The government maintains general control over staff costs, mainly the number of positions and overall salary costs, as it does with most independent bodies in the public sector following a standard procedure.

\section{Staffing}

\subsection{Leadership}

The head of AIReF is the President. The President is responsible for AIReF management and represents AIReF publicly. The President is assisted by a Management Committee composed of the three division Directors and, at the request of the President, the Chief of Staff. The President may delegate some management functions to the division Directors.

The AIReF President is appointed by the Council of Ministers on the proposal of the Minister of Finance and Public Administrations for a non-renewable six-year term which is delinked from the four-year electoral cycle. Prior to the appointment, the nominated candidate must appear before the Congress of Deputies Finance and Public Administrations Committee which assesses the candidate's experience, training and skills.

Candidates must be professionals of recognised standing and with a minimum experience of ten years in the fields of budgetary, economic and financial analysis of the public sector. ${ }^{14}$ The position of President is full-time, remunerated and subject to the same incompatibility scheme as other senior members of the administration.

The President can only be removed for the reasons provided in the organic law: incompatibility, incapacity to perform his/her functions, conviction for an intentional offence or a gross breach of his/her obligations. The removal must be authorised by the government (Council of Ministers) after investigation by the Minister of Finance and Public Administrations. During such an investigation, the President and other members of the AIReF Management Committee should be heard. The relevant committees of the Congress and the Senate should be also consulted.

\subsection{Staff}

AIReF's staff is generally made up of civil servants; but professionals coming from relevant national or international institutions who meet the requirements for specific positions can also be hired on a temporary basis. Furthermore, staff members from other institutions, such as the central bank, can be assigned on temporary secondments. AIReF's regulations also allow for an internship programme for students who wish to complete their training at the AIReF.

The President is responsible for hiring all staff according to legally established procedures for public sector recruitment and in full compliance with the principles of equality, merit and skills. Transparency is ensured by law and, in the case of the AIReF, is enhanced by publishing all staff backgrounds online. Because AIReF must follow regulations covering public sector employees, including on grades and wages, the Ministry of Finance and Public Administrations maintains some control over staff matters, such as number and type of positions and overall staff costs, as in other public institutions. The 
hiring process is slightly different for senior management: division Directors are appointed and removed by the Council of Ministers on the proposal of the AIReF's President. A minimum of ten years of experience is required to become a division Director.

Since mid-September 2014, AIReF has filled the majority of staff positions. Some recruitment procedures are still pending, but the 35 positions initially foreseen ${ }^{15}$ were filled by the end of 2014. Additionally, five officials from the Banco de España have been seconded to AIReF for one year and staff numbers may increase in 2015. The typical professional background for AIReF staff is a civil servant with a significant experience in fields related to AIReF's mandate, such as fiscal policy, economic analysis, economic modelling, budget management, public accounting or public auditing.

The staff is currently organised in 3 divisions: macroeconomic analysis (6 senior analysts), budgetary analysis (13 senior analysts) and institutional and legal affairs (4 officials). Furthermore, the President is assisted by a technical office (2 senior advisors) and a communications officer. AIReF is supported by 6 administrative assistants.

Figure 2. AIReF organisational chart

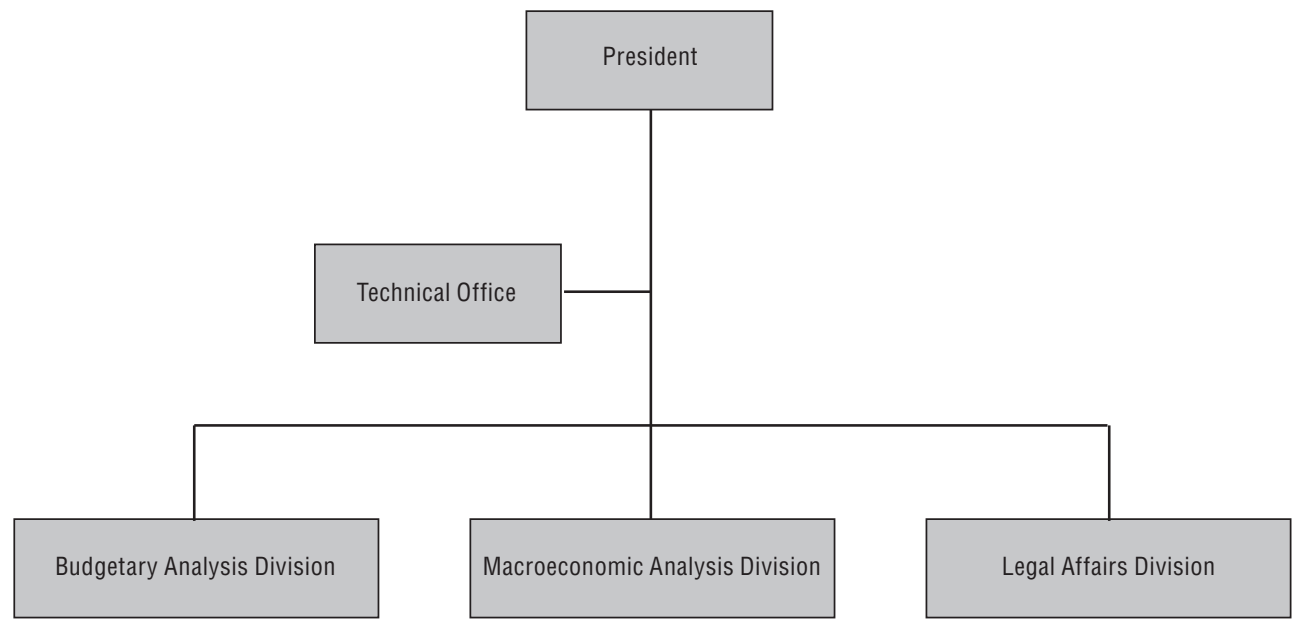

AIReF is also interested in collaborating with other institutions such as universities, think tanks and other public agencies in order to improve and enhance its analytical capacity. AIReF can use outside consultants for specific tasks such as developing a communications strategy or initiating an external evaluation.

\section{Access to information}

Access to information for AIReF is enshrined in article 4 of the Organic Law 6/2013 on the creation of AIReF and further developed by its organic statute. In order to ensure a timely and relevant information flow, it is intended to further develop information-sharing procedures and other details by an order of the Minister of Finance and Public Administrations. AIReF issued a report on the draft order in October 2014. So far, the approval of this order is still pending, although this has not prevented access to information as foreseen under the Organic Law 6/2013.

AIReF has three main channels to request information:

- Information is received on an on-going basis according to an order of the Minister of Finance (e.g. government macroeconomic forecasts). The draft order makes the General 
Government Economic-Financial Information Agency ${ }^{16}$ the main channel for AIReF's information and most information needs must be requested through this Agency.

- Specific information for each report is to be determined by a resolution of the AIReF President, notwithstanding any other complementary information that might be later requested.

- Additional information is to be requested by the AIReF President through the Ministry of Finance or directly to any public administration, which according to Article 6.5 of AIReF's statute must be provided between 5 to 15 days.

The only limitation on these obligations is ancillary information such as drafts, internal memorandums or communications. Information should be provided electronically, unless otherwise authorised by AIReF in extraordinary and justified cases.

One of the main challenges is to implement simplified procedures that allow for the availability of the information in a flexible, fast and comprehensive manner, reducing as much as possible the administrative burden for the AIReF itself and for the public administrations.

In cases of non-compliance, AIReF may release a public warning on its website. In the event of serious or repeated non-compliance, the President of AIReF informs the government as well as the Spanish parliament in order to apply the sanctioning mechanism provided in law.

AIReF has already issued some recommendations in its reports requesting, in general terms, for improvements in the information available not only to AIReF but also to the general public. ${ }^{17}$ For instance, it has recommended that methods, assumptions and data used in the preparation of the forecasts be made public. It has also recommended that the list of entities included in the general government sector and within each one of the subsectors, in accordance with the current System of National and Regional Accounts (ESA, 2012), be made public.

\section{Transparency}

Transparency is among core AIReF values. AIReF understands transparency as a commitment to provide the public with all relevant information on its reports, opinions and studies, as well as on the fundamentals thereof in an open, clear and timely manner. All these documents are published online in Spanish and English. Only the additional studies made at the request of another public administration need its authorisation to be published.

AIReF disseminates the methodology, assumptions and data that underpin any analyses and research underpinning its reports, opinions and studies in collaboration with the various public administrations and international organisations. In the case of the use of quantitative methodologies, the relevant files are also published in order to ensure results can be replicated. All of the President's resolutions and the Management Committee's minutes are also available on AIReF website.

Three publications are also critical to this transparency goal: the 2015-2020 Strategic Guidelines which set the mid-term strategy; the Action Plan detailing the specific goals, tools and reports to be developed in the current year; and the Annual Report summarising previous year activities. 
In March 2015, AIReF set up a transparency portal to broaden and reinforce transparency in public affairs as a mechanism to facilitate control of public conduct and enhance institutional governance.

AIReF is working to implement a comprehensive and modern communications strategy through the web, social networks and more traditional media. Although AIReF has only just begun its activities, it is already well known in the media. Its reports have received substantial media coverage and it has become a reference for economic journalists dealing with fiscal sustainability issues. AIReF monitors media coverage of its work. AIReF is not yet well known in the general public, but is working to remedy this in the longer term. AIReF's website had 7504 single users from July 2014 to December 2014. During this same period, AIReF was cited in print newspapers 1355 times and in online newspapers 2624 times.

\section{Governance, advisory support, monitoring and evaluation}

As noted earlier, the President is assisted by the Management Committee composed of the three division Directors and, currently and at his request, by the Chief of Staff. Moreover, should the President wish, the Management Committee may be attended by experts of recognised standing nationally or internationally based on the subjects to be covered. The attendance of experts at meetings of the Management Committee does not entail the right to receive any remuneration. So far, no outside experts have attended the Management Committee meetings.

In March 2015, AIReF established a nine-member ${ }^{18}$ Advisory Board of professionals drawn from the world of academia and the public administration. Members of the Advisory Board must be acknowledged experts in their fields in Spain or internationally with at least ten years of experience in budgetary, economic and financial analysis. The Advisory Board is divided into two panels focusing on the two key areas covered by AIReF's remit: economic analysis and budgetary and institutional analysis. Each panel will meet twice a year, although additional meetings can be called. Advisory Board members serve a three-year term.

AIReF's President has committed to conduct a mid-term independent assessment of AIReF activity.

\section{Concluding remarks}

Although AIReF is a young institution, it has already produced a significant body of work in comparison to many of its equally young peers, and has garnered significant media attention. Its website is a model of transparency.

Its major short-term challenge is to establish its independence and credibility. Only then can AIReF hope to successfully promote fiscal sustainability through its various roles designed to influence and persuade policy makers, including public assessments ex ante and ex post of budgetary plans, evaluation of macroeconomic forecasts and provision of mid-term to long-term budgetary projections. Other shorter-term challenges include: developing and publishing its own analytical toolkit, developing a medium-term independent assessment, and integrating the national and European dimension in its monitoring of fiscal rules.

To build its reputation for independent and high-quality advice and analysis, AIReF seeks to act as transparently as possible. Advice and analysis are made publicly available. By promoting transparency, AIReF contributes to raising the reputational and electoral costs of undesirable policies, and to increasing public awareness on fiscal stability. Transparency is also critical when dealing with local and regional administrations. 
Building creditability takes time and skill. AIReF will also need to continue to develop internal know-how by hiring and retaining highly qualified staff.

Royal Decree 215/2014 of 28 March approving the Organic Statue of the Independent Fiscal Responsibility Authority.

\section{Notes}

1. Article 135 of the Spanish constitution establishes that public debt cannot exceed the European reference value. However, its distribution across levels of government will need to be updated by amending the current Organic Law on Budgetary Stability and Financial Sustainability.

2. The 2014 AIReF Annual Report contains all recommendations issued to different public administrations.

3. www.airef.es/es/contenidos/resoluciones/116-calendario-de-solicitud-y-recepcion-de-informacion-para-laemision-de-informes-y-el-seguimiento-de-las-recomendaciones-para-2015. This is to be translated into English.

4. This sector is defined in the European System of National and Regional Accounts.

5. In principle, all other public entities not included above will likewise be deemed to belong to the public sector and will be subject to AIReF monitoring and assessment.

6. These are: the Fiscal and Financial Policy Council, the National Local Administration Commission and the Financial Commission of Social Security.

7. Within AIReF, these duties are assigned to the economic and budget analysis divisions. The division of economic analysis deals with the macroeconomic forecasts and with the sustainability of public finances. The division of budget analysis is divided into two main different areas: state and social security, and autonomous regions and local governments.

8. The preventive, corrective and coercive procedures are set by the Organic Law on Budgetary Stability and Financial Sustainability. Briefly, the preventive procedure starts with the identification of the risk of non-compliance with stability, debt and spending rule targets. In the case of autonomous regions or local governments, the central government presents a public and reasoned non-compliance risk warning to the administration responsible, which has a month to take the necessary risk prevention measures. For a corrective procedure, if any administration is not compliant, the automatic correction measures are activated implying an ex ante authorisation of debt operations. Then, the administration concerned draws up an economic and financial plan to achieve compliance with the targets or the spending rule over the course of the current year and the subsequent year. Lastly, the coercive procedure is activated if the economic and financial plan is not presented, not approved or not fulfilled. It consists of freezing credits and carrying out the corresponding withholding of credits to guarantee compliance with the target set, and lodging an interest-bearing deposit in the central bank equivalent to $0.2 \%$ of its nominal GDP when requested by the Ministry of Finance and Public Administrations. If any of these actions are not taken, the central government may decide to send a commission of experts whose proposals could be binding. If this order is not heeded, the central government, subject in some cases to the approval of an absolute majority of the Senate, takes the measures necessary to compel implementation by the autonomous community or local government.

9. The Fiscal and Financial Policy Council's goal is to ensure adequate fiscal and financial policy coordination between the autonomous regions and the government. It consists of the Ministry of Finance and Public Administrations and the Finance Council Members of each autonomous region.

10. Note that the opinion on the Sustainability Factor and the Index for Revaluation of the Social Security Pension Scheme is also compulsory.

11. Only the studies made at the request of another public administration need authorisation to be published.

12. As of 31 March 2015, no public administration has requested a study.

13. The amount is decided in a yearly basis (article 44 of AIReF's statute).

14. AIReF's first President brought more than 30 years of professional experience in the field of budget, economic and financial analysis in the public and private sector in Spain (such as the Banco de España and Spain's Banco Bilbao Vizcaya Argentaria) and abroad (European Central Bank). 
15. Including the President and the division Directors.

16. www.minhap.gob.es/es-ES/CDI/Paginas/centraldeinformacion.aspx.

17. For further information on the recommendations issued, see the 2014 AIReF Annual Report.

18. The Advisory Board has a minimum of 8 and a maximum of 12 members. The first Advisory Board is comprised of Spanish nationals, although non-nationals may also be appointed.

\section{Bibliography}

Autoridad Independiente de Responsibilidad Fiscal (AIReF) (2015), www.airef.es.

Congress of Deputies of Spain (2015), www.congreso.es.

Escrivá, José Luis (2014), “AIReF (Spanish Independent Fiscal Institution) Scope and Challenges”, Sixth Annual Meeting of OECD Parliamentary Budget Officials and Independent Fiscal Institutions, OECD, Jerusalem, 31 March-1 April.

Senate of Spain (2015), www.senado.es.

\section{Legislation}

Organic Law 6/2013 of 14 November on the establishment of an Independent Authority for Fiscal Responsibility. 



\section{Sweden}

\section{Swedish Fiscal Policy Council (Finanspolitiska rådet)}

Established: 2007.

Enabling legislation: Ordinance with Instructions for the Fiscal Policy Council (Förordning med instruktion för Finanspolitiska rådet, SFS 2011:446), 28 April 2011, and Ordinance with Instructions for the Fiscal Policy Council (Förordning med instruktion för Finanspolitiska rådet, SFS 2007:760), 1 November 2007.

Mandate: The council is to review and assess the extent to which fiscal and economic policy objectives are being achieved; and assess whether fiscal policy is consistent with long-term sustainable public finances and the budgetary targets. It shall also: assess the fiscal policy stance in relation to cyclical developments; assess whether fiscal policy is in line with healthy long-term sustainable growth and leads to long-term sustainable high employment; examine the clarity of the budget bills; and analyse the effects of fiscal policy on the distribution of welfare in the short and the long term. It may also review and assess the quality of forecasts. It should further promote public debate on economic policy.

Budget: SEK 8931000 (2012).

Staff: Six council members (as from 1 July 2011; previously eight), four secretariat staff, one secretariat administrator. 


\section{Context}

A government-appointed commission recommended the creation of an independent fiscal policy council in 2002 (Commission on Stabilisation Policy in the EMU, 2002). The recommendation was inspired by earlier proposals in the policy debate (Calmfors, 1999, 2001, 2002) and by a background report prepared for the commission (Wyplosz, 2002). Unlike in some other countries, the proposal was not made in the context of an acute fiscal crisis. Sweden had recently rebalanced the budget and recorded positive general government balances. Instead, the commission worried that fiscal policy would be too loose in good economic times in order to retain sufficient fiscal space for counter-cyclical measures during downturns (Calmfors, 2011a).

The creation of a fiscal policy council was not part of a broader set of budget reforms, but it was meant to complement and reinforce new institutional arrangements introduced in the 1990s following a deep economic and fiscal crisis (Molander, 1999). These reforms had strengthened top-down budgeting in the executive as well as the legislature and introduced a new fiscal framework (Blöndal, 2001; Wehner, 2007). The latter includes a surplus target for government net lending of 1\% of GDP over the business cycle, a three-year expenditure ceiling for central government and a balanced budget requirement for local authorities (Ljungman, 2006; Ministry of Finance, 2011).

The Commission on Stabilisation Policy in the EMU had been tasked by the government to analyse the steps necessary in the event of the country's adoption of the euro. The recommendation to create an independent fiscal policy council was not endorsed by the then Social Democratic government. However, the recommendation received support from the liberal-conservative opposition, including the chief economist of the Moderate Party, Anders Borg. The 2006 elections led to the formation of a liberal-conservative government. Following his appointment as Minister for Finance in the new government, Borg initiated the creation of the Swedish Fiscal Policy Council (FPC) in 2007.

All three opposition parties - the Social Democrats, the Left Party and the Greens voted in the parliament against the creation of such a body. For example, the former communist Left Party criticised that the council would provide "false scientific clothing for the government's right-wing policy" (cited in Calmfors, 2011a). An agreement between the government and opposition parties subsequently established a broader consensus on the remit of the Council. Prior to the creation of the FPC, several models were considered in the general debate (Calmfors, 2003, 2005). One question was whether certain fiscal policy decisions should be delegated to an independent body or whether its role should be advisory only. However, the idea of delegating actual fiscal policy decisions remained largely academic and lacked support from political decision makers. Reference was made to advisory bodies in Belgium, Denmark and Germany, for instance. 


\section{Relationship with the executive and the legislature}

The FPC is a government agency that is accountable to the Ministry of Finance. The FPC has no formal relationship with the Riksdag (the Swedish parliament) or any other institution involved in the surveillance of public policy, such as the National Audit Office or the central bank. Moreover, there is no specific legislative requirement for the government to respond to the recommendations of the FPC. The government has, however, chosen to include a chapter commenting on the council's report in the annual budget bill. In practice, the FPC interacts with the Finance Committee of the Riksdag in a public hearing following the publication of its report, which is also attended by the Minister for Finance. The Finance Committee also draws on the FPC report during its deliberations on the Spring Fiscal Policy Bill and its report on the bill includes comments on the analysis by the council.

\section{Box 1. Role of the legislature in the budget process}

Sweden has a parliamentary system with a unicameral parliament, the Riksdag. The Riksdag considers and approves broad guidelines for fiscal policy in a Spring Fiscal Policy Bill, which is presented in April. The publication of the FPC's report follows the presentation of this bill and supports its evaluation. The annual budget is presented in September, more than three months prior to the start of the fiscal year. Formally, the Riksdag has unfettered powers to amend the budget.

Procedural reforms in the mid-1990s introduced a strict top-down budgeting procedure which requires individual amendments to be within previously approved aggregates for overall spending as well as 27 expenditure areas. Prior to these reforms, the Riksdag frequently made amendments to the government's budget proposal, but this has been rare in recent years.

The Finance Committee plays a central role in discussing the overall expenditure total as well as its distribution across the 27 expenditure areas, while different sectoral committees discuss allocations within these areas. Parliamentary committees can hold public or closed meetings. Open meetings are for public hearings only, not for deliberation or decisionmaking. Committee reports are published and made available to the public. The Finance Committee is assisted by a small secretariat of about 10 people, including economists and lawyers. Political parties, committees and individual MPs may also request analytic support from a budget office comprised of six to seven economists and statisticians that is part of the Riksdag research service.

The status of the FPC as an ordinary government agency accountable to the Ministry of Finance might be criticised as limiting its independence, and the possibility of placing it instead under the authority of the parliament has been raised (Calmfors, 2011a). This would give it a similar status to the National Audit Office, Sweden's supreme audit institution, which is an independent organisation under the Riksdag. On the other hand, government agencies in Sweden generally have a high degree of independence. Formally, a minister cannot directly instruct an agency what to do in a specific situation, although pressure might be exerted in other ways. One specific mechanism that helps to protect the independence of the FPC is that its members are appointed on the basis of recommendations from the council itself.

So far, the FPC has not yet experienced a change in government. However, the current government itself has, at times, been highly critical of the role and work of the FPC. The council's new ordinance in 2011 was based on a cross-party agreement between the 
government and the three opposition parties in the then red-green alliance (the Social Democrats, the Greens and the Left), which meant that these parties gave up their earlier resistance to the FPC and endorsed it. This has created a stronger political basis for the council. The agreement also means that changes to the legal status of the FPC are unlikely in the near future.

The role and mandate of the FPC must be understood within a broader institutional context. There are several other bodies with substantially larger resources that carry out complementary roles, in particular macroeconomic and fiscal forecasting (Calmfors, 2011b). For example, the National Institute for Economic Research produces regular macroeconomic forecasts and can model the effects of policy proposals. Both the Office for Budget Management and the National Debt Office produce central government budget forecasts. The existence of these other government agencies helps to explain why the FPC does not have an independent forecasting function and why it can operate with comparatively small resources. In addition, the National Audit Office audits and evaluates the government, including its adherence to the fiscal framework. Sweden also has a tradition of academic involvement in economic policy debates and some think tanks produce work on fiscal policy and the budget.

\section{Legal basis for establishment}

The first Ordinance with Instructions for the Fiscal Policy Council (SFS 2007:760) was issued on 1 November 2007. It was replaced by a new ordinance (SFS 2011:446) on 28 April 2011. The revision created a separate Head of the agency, apparently to relieve the chair of the council from burdensome administrative duties. The membership of the FPC was also reduced from eight to six. These changes might make it easier for the government to appoint members to the council. The 2011 revision also introduced a more focussed mandate so that some council tasks receive greater emphasis, while others have lower priority or are optional.

\section{Mandate}

The mandate of the FPC is clearly defined in Paragraphs 5 to 9 of the 2011 ordinance. The council is to review and assess the extent to which the fiscal and economic policy objectives proposed by the government and decided by the parliament are being achieved and thus contribute to more transparency and clarity about the aims and effectiveness of economic policy. In particular, on the basis of the Spring Fiscal Policy Bill and the budget bill, the council has to assess whether fiscal policy is consistent with the long-term sustainability of public finances and the budgetary targets, particularly the surplus target and the expenditure ceiling. It also has to: assess the fiscal policy stance in relation to cyclical developments in the economy; assess whether fiscal policy is in line with healthy long-term sustainable growth and leads to long-term sustainable high employment; examine the clarity of the budget bills, particularly with respect to the stated basis of economic policy and the reasons for proposed measures; and analyse the effects of fiscal policy on the distribution of welfare in the short and the long term. In addition, the council may review and assess the quality of the forecasts presented and the models on which the forecasts are based. Furthermore, it should promote public debate on economic policy.

In the first four years of its existence, the FPC understood its legal framework as giving it a broad mandate to comment on government policy, including normative policy recommendations (Calmfors, 2011a). Its specific functions include: the evaluation of fiscal 
transparency; the ex post and ex ante evaluation of fiscal policy; an assessment of the government's adherence to its fiscal rules; and the evaluation of fiscal sustainability. The requirement to evaluate the distributional effects of fiscal policy was added in 2011, based on an initiative by the opposition parties. The 2011 revision of the ordinance also reordered the different components of the mandate to emphasise as priorities the assessments of fiscal sustainability and the government's adherence to its fiscal rules. Unlike in some other countries, the FPC has no formal forecasting functions, although it has the option to evaluate the quality of forecasts and the underlying models. The institutional coverage of its remit does not explicitly exclude it from considering developments beyond the central government level. Moreover, the ordinance does not specify any particular limitations on the work of the FPC.

According to paragraph 12 of the 2011 ordinance, the FPC has to submit a report to the government no later than 15 May of each year. The deadline is 10 May for years with elections to the European Parliament. The report contains the analyses and assessments carried out by the council, and it must include any dissenting opinions from any of its members. The FPC has also chosen to commission and publish background papers on various aspects of economic policy.

\section{Functions}

The FPC's mandate allows it to produce a wide range of analyses. These include: analyses of the executive budget proposals, budget policy options (for example, changes in spending and taxation), the economic impact of government regulation, macroeconomic developments, taxation, and medium-term and long-term estimates. In 2009, the FPC provided written comments on the government's budget bill, citing its mandate to stimulate debate on economic policy. The document is much shorter than the council's regular report, and mostly of a qualitative nature. Overall, the resources of the FPC are entirely focussed on the production of its annual report.

A separate agency under the Ministry of Finance - the National Institute of Economic Research - performs analyses and forecasts of the Swedish and international economy and conducts related research. The FPC is not required to provide macro-fiscal forecasts; but it may choose to evaluate the quality of forecasts and their underlying models. For instance, the council evaluated the quality of government forecasts in chapter five of its 2010 report. Also, the FPC has no role in costing individual policy proposals and legislation, nor does it assess the fiscal consequences of the electoral programmes of political parties.

On the other hand, the FPC has a clear mandate to evaluate the long-term sustainability of public finances and the government's compliance with its fiscal rules. For instance, in its 2009 report, the Council criticised the government for weakening the credibility of the expenditure ceiling by manipulating the timing of local government grants. The government chose to disburse some of these grants in December 2009, when there was sufficient space under the expenditure ceiling, while the Spring Fiscal Policy Bill had announced the payments for 2010. The FPC has also reviewed the government's fiscal sustainability measures and related methodological issues, for instance in chapter five of its 2011 report.

Sweden's FPC has not shied away from making normative policy recommendations within the remit of its mandate. The basis for any such comments and recommendations has been the government's own objectives. In other words, the council does not challenge 
the objectives of the government, but uses them as a standard against which to assess individual policy measures (Calmfors, 2011a). The statutory provisions do not prescribe whether the council's assessments should be of an ex ante or ex post nature. In practice, the work of the FPC combines comments on new policy proposals and existing policies.

\section{Work programme}

The council's single obligatory task is to write an annual report. Within the limits of its mandate, it has full autonomy to determine the specific content and focus of a report. The annual report is due in mid-May, about one month after the presentation of the government's Spring Fiscal Policy Bill which contains guidelines for economic policy and the budget. The Riksdag adopts a decision on the Spring Fiscal Policy Bill in June. The council's report is timed to support this debate as well as the following preparation of the annual budget, which is presented in September.

The council's instructions describe its duties in general terms and are issued by the government, not by the Minister of Finance. In theory, the government could ask the council to carry out a particular analysis, but this has not happened in practice. There is no formal requirement for the FPC to respond to requests for analysis from other actors, such as the Riksdag or political parties. In practice, the council's mandate provides substantial autonomy to undertake analyses on its own initiative. For instance, each year it publishes several background papers on diverse topics. Examples include papers on: the effects of health insurance reforms, fiscal consolidation, risk premia on sovereign debt, the effects of education reforms and labour market policies, and net wealth analysis. All of these are available in electronic form from the council's website.

\section{Budget}

The FPC received an appropriation of SEK 8931000 in 2012 and SEK 7357000 in 2011. The 2010 appropriation was SEK 7297 000; but the available funds totalled SEK 7867000 due to savings from past years. The actual outcome in 2010 was SEK 7550 000. Similarly, available funds in 2009 amounted to SEK 7877000 which exceeded the appropriation of SEK 7070000. The actual outcome for that year was SEK 6471 000. In 2008, the appropriation was SEK 5975000 but the Ministry of Finance made available SEK 7095000 to help set up the council. Actual spending in the FPC's first year amounted to SEK 6473000.

The FPC has the status of an agency under the Ministry of Finance, which means that its budget is set as part of the regular annual budget process. Each autumn, the government proposes an annual allocation which is discussed and approved by the Riksdag. The level of funding has been subject to controversy. Ordinary members of the council receive only a small stipend that does not appear to be commensurate with the time and effort they invest (Calmfors, 2010). Instead, members rely on funding from their regular employers, such as research institutes and universities. Given the council's broad and challenging remit, it can be argued that the overall funding level of about one million euros in 2011 is not commensurate with the agency's mandate.

On 18 November 2010, the FPC wrote an open letter to the government to highlight the perceived lack of funding. The Minister for Finance was reported to have reacted negatively to the letter and instead suggested cutting the council's allocation. Outright cuts to the FPC's budget did not occur. While the 2012 allocation is an improvement compared to previous years, critics argue that this may not be enough to resolve the tension between 
the council's mandate, and its funding and members' pay. On the other hand, the Ministry of Finance points out that members have the support of the secretariat and are not supposed to write the annual reports by themselves.

\section{Staffing}

\subsection{Leadership}

The composition and appointment procedure is regulated in the 2011 ordinance that governs the council (Paragraphs 4 and 11). The FPC has consisted of six members since 1 July 2011. This is the maximum permitted by the ordinance. Previously, the council had eight members. The FPC has a chair and a deputy chair. The government appoints all of the members, following proposals from the council itself. The government is not required to appoint the proposed individuals. However, given that the proposals are public, there would presumably be a "reputational cost" attached to ignoring the council's suggestions (Calmfors, 2011a).

Appointments are valid for a fixed period: no more than six consecutive years for the chair and no more than three consecutive years for other members. In contrast, the electoral term is four years, which means that it is possible that members appointed by a previous government would continue to serve on the council after a new government has taken office. The ordinance does not prescribe a particular process for the removal of the chair or any of the members prior to the expiration of their term, but formally the government could remove members.

The FPC has to submit its proposals for members to the government no later than three months before appointments expire. Appointments are on a part-time basis. There are no explicit restrictions on who may be appointed to the FPC, but the ordinance requires the council to present proposals that balance scholarly expertise in economics with practical experience in economic policy making, and it should strive for a gender balance. The council may include non-nationals. Of the members serving in early 2012, two are women and four are men. In terms of professional background, five are economists with full-time positions at universities and one is the chair of another agency with previous work experience as Budget Director in the Ministry of Finance and as one of three heads of the Swedish National Audit Office. In terms of nationality, one member is Norwegian; previous appointments have included nationals of Denmark and Finland.

As compensation for their service, the chair receives about EUR 1600 , the vice-chair EUR 1100 and ordinary members EUR 1000 a month. These amounts have been criticised as insufficient. The response of the Ministry of Finance to this criticism is that pay levels are not unfavourable compared to other agencies. For example, board members of the Swedish Social Insurance Agency with around 13000 employees receive the same remuneration.

\subsection{Staff}

The secretariat of the FPC consists of four analysts plus an administrator who support the work of the council. The secretariat is located on the premises of the National Institute of Economic Research, but operates independently from it. Since the legal changes in 2011, the chair of the FPC is no longer the administrative head of the council. Instead, the Head of the agency is appointed by the government and runs the secretariat, including the appointment and dismissal of staff. This is the structure that generally applies to government agencies in Sweden. 
The government announced the first appointment to this position on 13 October 2011. Under the new legal framework, the Head of the agency is also solely in charge of the budget. The chair and members have no formal control over the budget. On the other hand, the council is responsible for the annual report and for its work. In practice, as in other agencies, this arrangement relies on the co-operation of the individuals involved. It may work less well when there are disagreements.

Of the five current staff members, three are senior economists with a PhD in economics and previous work experience in government (including the Ministry of Finance), one is a junior economist hired straight from university and the administrator has a business degree and previous administrative experience in government. The staff of the FPC are employed under the standard conditions that apply to Swedish government agencies. There are no specific formal conflict-of-interest regulations that apply to council members or staff. The FPC can use outside consultants, for instance to prepare background analyses for its annual reports.

\section{Access to information}

The FPC has access to non-public background information and material used by the Ministry of Finance for the preparation of the Budget Bill. However, the Council must request access to this material. It is impossible to judge with certainty the degree to which non-public information is disclosed in practice. According to FPC staff, the Ministry of Finance has not threatened to limit its access to information.

\section{Transparency}

Swedish and English versions of all FPC reports are publically available on the institution's website and in printed form. The council issues a news release and holds a news conference each May in conjunction with the publication of its annual report. The reports and their discussion in the parliament receive extensive coverage in the electronic and print media, including the main television and radio stations and national newspapers. The FPC is also referenced in the Swedish media throughout the year in connection with public finance and economic policy items that receive current attention. The chair and other members receive frequent media requests for comments on policy developments throughout the year.

The Council has also acquired an international reputation. For instance, in the run-up to elections in 2010, it was cited by Britain's future Chancellor of the Exchequer, George Osborne, as an inspiration for his party's pledge to create the Office for Budget Responsibility. In a 2010 report, the International Monetary Fund repeatedly refers to the "central" role of the FPC in assessing Sweden's fiscal policy. The council has generally been open about its interactions with other institutions, and publishes presentations and conference material on its website. It used an open letter to the government to complain about a perceived shortfall in funding for the institution.

\section{Governance, advisory support, monitoring and evaluation}

The FPC does not have an oversight board or panel of advisors to guide its work, nor is its work systematically subjected to peer review. However, it receives attention as part of international assessments of Sweden's overall fiscal governance arrangements (International Monetary Fund, 2010). Like any government agency, the FPC has to submit its 
accounts to the National Audit Office. Moreover, most of the members of the FPC are active academics who would risk their reputation if the council published work of poor quality or with a political bias (Calmfors, 2010).

Internally, the performance of any agency is reviewed annually during negotiations between the administrative head of the agency and the responsible state secretary in the relevant ministry. The FPC is accountable to the Ministry of Finance. Until the 2011 ordinance took effect, the chair of the FPC had to discuss the council's performance and negotiate its funding directly with the Ministry of Finance, which was a source of tensions. Under the 2011 statutory framework, the chair of the FPC is no longer the administrative Head of the agency, which is now a separate position. It remains to be seen whether this new arrangement will reduce these tensions in the longer term.

\section{Concluding remarks}

In a short time, the FPC has established itself as a vocal fiscal policy watchdog. Its commentary is sought domestically and it has also acquired an international reputation. On the other hand, it is still too early to judge whether the FPC has succeeded in enhancing fiscal discipline in the budget process, or whether its role has helped to lock in the impressive consolidation gains made with previous reforms. Prior to 2011, the council's role following a possible change of government was uncertain. This risk was much reduced when the government reached a political agreement with opposition parties in the spring of 2011. As a result, the existence of a council now has support from a substantial majority in the parliament.

\section{Bibliography}

Blöndal, J.R. (2001), "Budgeting in Sweden”, OECD Journal on Budgeting, Vol. 1, No. 1, OECD, Paris, pp. 27-57.

Calmfors, L. (1999), “Den politiska processen kan fungera batter”, Dagens Nyheter, 27 November, Bonnier, Stockholm.

Calmfors, L. (2001), "Sverige är redo för EMU-medlemskap”, Dagens Nyheter, 22 November, Bonnier, Stockholm.

Calmfors, L. (2002), "EMU kräver mer politisk disciplin”, Dagens Nyheter, 3 January, Bonnier, Stockholm.

Calmfors, L. (2003), "Fiscal Policy to Stabilise the Domestic Economy in the EMU: What Can We Learn from Monetary Policy?”, CESifo Economic Studies, Vol. 49, No. 3, CESifo Group, Munich, pp. 319-353.

Calmfors, L. (2005), "What Remains of the Stability Pact and What Next?", Swedish Institute for European Policy Studies, Stockholm, www.sieps.se/sites/default/files/49-20058.pdf.

Calmfors, L. (2010), "The Swedish Fiscal Policy Council: Experiences and Lessons”, paper prepared for the Conference on Independent Fiscal Policy Institutions, 18-19 March, Budapest.

Calmfors, L. (2011a), “The Swedish Fiscal Policy Council”, Wirtschaftspolitische Blätter, Vol. 58, No. 1, Austrian Chamber of Commerce, Vienna , pp. 49-62.

Calmfors, L. (2011a), “Sweden: Watchdog with a Broad Remit”, unpublished manuscript.

Commission on Stabilisation Policy in the EMU (2002), Stabiliseringspolitik i valutaunionen, SOU 2002:16, Ministry of Finance, Stockholm, www.regeringen.se/sb/d/108/a/1677.

International Monetary Fund (2010), “Sweden: Staff Report for the 2010 Article IV Consultation”, IMF Country Report No. 10/220, International Monetary Fund, Washington, DC.

Ljungman, G. (2006), "The Medium-Term Fiscal Framework in Sweden”, OECD Journal on Budgeting, Vol. 6, No. 3, OECD, Paris, pp. 93-109.

Ministry of Finance (2011), "The Swedish Fiscal Policy Framework", Ministry of Finance, Stockholm, www.regeringen.se/sb/d/14625/a/164299 (accessed in January 2012, no longer available online). 
Molander, P. (1999), "Reforming Budgetary Institutions: Swedish Experiences" in R.R. Strauch and J. von Hagen (eds.), Institutions, Politics and Fiscal Policy, Kluwer Academic Publishers, Boston, pp. 191-214.

Riksdag (2015), www.riksdagen.se/en.

Swedish Fiscal Policy Council (Finanspolitiska rådet) (2015), www.finanspolitiskaradet.se.

Swedish Fiscal Policy Council (various years), "Swedish Fiscal Policy: Report of the Swedish Fiscal Policy Council", Swedish Fiscal Policy Council, Stockholm, www.finanspolitiskaradet.se.

Swedish Fiscal Policy Council (2009), "Comments on the 2010 Budget Bill”, 19 October, Swedish Fiscal Policy Council, Stockholm, www.finanspolitiskaradet.se.

Wehner, J. (2007), "Budget Reform and Legislative Control in Sweden", Journal of European Public Policy, Vol. 14, No. 2, Taylor and Francis, Oxford, pp. 313-332.

Wyplosz, C. (2002), "Fiscal Policy: Institutions vs Rules", Appendix 5 in Commission on Stabilisation Policy in EMU, Stabiliseringspolitik i valutaunionen, SOU 2002:16, Ministry of Finance, Stockholm, www.regeringen.se/sb/d/108/a/1677.

\section{Legislation}

Ordinance with Instructions for the Fiscal Policy Council (Förordning med instruktion för Finanspolitiska rådet, SFS 2011:446), 28 April 2011.

Ordinance with Instructions for the Fiscal Policy Council (Förordning med instruktion för Finanspolitiska rådet, SFS 2007:760), 1 November 2007. 


\section{United Kingdom}

\section{Office for Budget Responsibility (OBR)}

Established: 2010.

Enabling legislation: Budget Responsibility and National Audit Act 2011 and the Charter for Budget Responsibility.

Mandate: To examine and report on the sustainability of the public finances.

Budget: GBP 2.075 million (2014).

Staff: 22 (three Budget Responsibility Committee, two non-executive members, 17 secretariat staff). 


\section{Context}

Under the 1998 Code for Fiscal Stability, two fiscal rules were in place in the UK in the decade prior to the financial crisis: a "golden rule" that allowed the government to borrow only to cover net investment (and not current spending) over the economic cycle and a sustainable investment rule that required that public sector net debt as a proportion of GDP be held over the economic cycle at a stable and prudent level, in practice no higher than $40 \%$ (OECD, 2009).

While the economic forecasting record under this framework was good, fiscal forecasts from 2000 onwards were consistently optimistic. As the government itself decided the dates on which the economic cycle started and finished, it could also gain fiscal leeway by making ex post changes to its dating of the cycle, thus undermining credibility of the rule as a constraint on behaviour. The framework was also largely retrospective and governments risked having to make politically unfeasible cuts in spending at the end of a cycle in order to make up for previous overspending.

In the event, government spending increased significantly from 2002, but tax revenues disappointed. As a consequence, the budget deficit did not narrow as the government had hoped in the years prior to the recession. When the recession struck, the deficit then widened dramatically between 2007-07 and 2009-10 as a fall in nominal (as well as real) GDP weakened receipts (especially in cash terms) and pushed up public spending (especially as a share of GDP). ${ }^{1}$ In response, the fiscal rules were suspended in late 2008 and replaced by a temporary operating rule to "improve the cyclically adjusted budget each year, once the economy emerges from the downturn, so it reaches balance and debt is falling as a proportion of GDP once the global shocks have worked their way through the economy in full" (OECD, 2011a). Subsequently, the 2010 Fiscal Responsibility Act also "set targets to reduce the deficit as a share of GDP in each year to 2015/16, to halve the deficit by 2013/14, and to set debt as a share of GDP on a downwards path by 2015/16" (OECD, 2011a).

The idea for an Office for Budget Responsibility $(\mathrm{OBR})^{2}$ was first formally proposed in September 2008 by the then opposition Conservative Party as part of their economic policy document, Reconstruction: - Plan for a strong economy. Following the May 2010 elections, the newly installed Conservative-Liberal Democrat coalition government launched the OBR in interim form as one of its first acts. ${ }^{3}$ The new government also replaced the rules set out in the Fiscal Responsibility Act with a "fiscal mandate" to balance the cyclically adjusted current balance by the end of a five-year rolling horizon, and a supplementary target that public sector net debt be falling at a fixed date of 2015/16 (OECD, 2011a).

In its interim form the OBR comprised a three-person Budget Responsibility Committee (BRC), chaired by Sir Alan Budd (former Treasury Chief Economic Adviser) and aided by a small secretariat of Treasury employees. They produced two forecasts in the first six weeks of the coalition government's tenure: one before the June "emergency budget" and another taking into account the measures announced on budget day. ${ }^{4}$ The interim OBR was also tasked with providing advice on the arrangements for the permanent OBR, which it duly 
did. The interim OBR experienced a brief period of controversy when its first Chair left earlier than external commentators had expected ${ }^{5}$ and the OBR's independence was called into question by some in parliament and the media.

On 15 July 2010, the House of Commons Treasury Select Committee (TSC) announced a swift inquiry into the permanent arrangements for the Office for Budget Responsibility to "assess the arrangements proposed by the interim OBR" and "consider alternative arrangements and international comparisons". ${ }^{6}$ It specifically called for evidence on: "the remit of the permanent OBR, appropriate means of ensuring both independence and accountability, and appropriate resources for the OBR. ${ }^{7}$ The TSC's report was published in September 2010. Key recommendations were for:

- the establishment of the OBR as an institution with its own legal personality, responsible for appointing its own staff;

- a requirement on the OBR to act transparently, objectively and independently;

- a clear remit and set of core tasks;

- a requirement that the responsible select committee should have a veto over appointment or dismissal of the Chair of the permanent body and the members of the Budget Responsibility Committee;

- a small group of non-executive directors to support the Budget Responsibility Committee;

- a requirement that government officials support the OBR when it is preparing forecasts; and

- a requirement that the OBR have a right of access to the information it needs. ${ }^{8}$

The TSC further expressed the view that the legislation establishing the OBR should not require future governments to use OBR forecasts and that the "arrangements adopted for the permanent OBR should be subject to comprehensive review no later than five years after it is established by statute" 9 The TSC's key recommendations were all taken on board in the legislation and related documents. ${ }^{10}$ In its deliberations, the TSC touched briefly on other models in the United States, Canada and Europe, including evidence from the Chair of the then recently established Hungarian Fiscal Council; however, it did "not conduct an exhaustive examination of the various ways in which a fiscal council could be structured but focus[ed] on the government's proposals and how they can be made to work".

In October 2010, Robert Chote, a former Director of the Institute for Fiscal Studies (IFS), was appointed as the second OBR Chair with the assent of the TSC. In December 2010, the OBR moved out of the Treasury building. These measures were seen as enhancing OBR independence. In March 2011, the Budget Responsibility and National Audit Act ${ }^{11}$ passed the parliament and, on 4 April, the OBR became an "executive non-departmental public body". ${ }^{12}$ The establishment of the OBR was endorsed across party lines, with the opposition expressing some concern about the adequacy of safeguards for its independence.

\section{Relationship with the executive and the legislature}

The OBR is under the executive rather than the parliament, but is a legally separate, arms-length entity with its own oversight board. It does buy some administrative support services from the Treasury (e.g. human resources and finance services, set out in a service level agreement) and from the Attorney General's Office, with which it now shares accommodation (e.g. IT support, also set out in an agreement).

The OBR's core functions are established by legislation, including the responsibility to provide the official economic and fiscal forecasts to the Chancellor of the Exchequer. 
However, neither the government or the parliament have a right of direction over OBR analysis and the OBR takes full responsibility for the content of its publications and other pronouncements. OBR work requires close communication with government departments, particularly to get the information and data needed for its forecasts. HM Treasury, the Department for Work and Pensions, and HM Revenue and Customs all provide external expertise used in the core OBR reports (see the Memorandum of Understanding below) and this interdependence gives the OBR access to capacity far beyond its actual staff size. The first external review of the OBR estimated that the OBR can draw upon the power of approximately 125 full-time-equivalent staff from other government agencies. To safeguard its independence, the OBR makes information on such contacts publicly available. The OBR has no formal relationship with the Bank of England, although their respective staffs meet regularly to discuss forecasting issues of mutual interest.

There are a range of mechanisms built in to ensure appropriate oversight of the OBR by the parliament and to help safeguard the OBR's independence. The parliament scrutinises the OBR budget and the Treasury Select Committee has a veto on leadership appointments and dismissals. Although pre-appointment hearings by parliamentary committees are common, veto power over appointments or dismissals is extremely unusual in the UK context. All OBR reports must be published and sent to the parliament and the OBR answers parliamentary questions and appears before parliamentary committees.

While there are both think tanks (such as the Institute for Fiscal Studies, IFS or the National Institute of Economic and Social Research (NIESR)) and private sector institutions that provide independent forecasts and complementary analysis, they do not have the access to confidential government information and data that the OBR has.

\section{Box 1. Role of the legislature in the budget process}

The United Kingdom is a parliamentary system with a bicameral legislature: the House of Commons (or lower house) with 650 members elected under the first-past-the-post system, and the House of Lords (or upper house) whose members are appointed. ${ }^{1}$ The House of Commons plays the dominant role in the budget process.

In March/April, just prior to the start of the fiscal year, the Chancellor of the Exchequer makes the budget speech in the House of Commons. ${ }^{2}$ The speech includes: a review of how the United Kingdom economy is performing, forecasts of how the economy will perform in the future and details of any changes to taxation. The Chancellor's statement is followed by several days of debate. Budget resolutions (tax measures announced in the budget) are agreed and the Finance Bill starts its passage through the parliament in the same manner as any other public bill. Between 1997 and 2010, the Chancellor of the Exchequer also presented an annual pre-budget report (in effect a second budget) to the House of Commons in November/December which included a report of progress since the previous budget, an update on the state of the economy and details of any proposed changes to taxation. From 2010, the new government replaced the Pre-Budget Report with an Autumn Statement (again, much like a second budget), at which the Chancellor presents the OBR's updated economic and fiscal forecast to the parliament and may also set out new policy measures.

Under resolutions dating back to the 17th century, the House of Commons asserts its sole right to initiate and amend money bills; the House of Lords may not reject and can only delay such bills for a month. Its Economic Affairs Committee appoints a subcommittee to consider certain policy aspects of the Finance Bill and to make recommendations. The 


\section{Box 1. Role of the legislature in the budget process (cont.)}

House of Commons has the power to amend the budget, but it may only decrease existing expenditures or revenues. In practice, the House of Commons almost never makes amendments to the government's budget proposal against the government's wishes. Party discipline is particularly strong during budget debates and by convention a vote on the budget is considered a vote of confidence in the government.

Unlike the majority of OECD national parliaments, the House of Commons does not have a dedicated budget or finance committee to oversee or co-ordinate the budget approval process. Sectoral committees formally consider appropriations for each respective sector and the Treasury Committee examines the expenditure, administration and policy of HM Treasury, HM Revenue and Customs, and associated public bodies, including the Bank of England and the Financial Services Authority (OECD, 2011b). Committee meetings are open to the public and committee reports are published. While the United Kingdom Parliament has had a tradition of relatively weak ex ante scrutiny of the budget, it has a strong tradition of ex post oversight of the public accounts through the Commons Public Accounts Committee (PAC).

The United Kingdom Parliament significantly increased its research capacity with the 2002 establishment of the Scrutiny Unit to provide specialist expertise to select committees with a focus on financial matters and draft bills. This new unit was the result of modernizing efforts within the House of Common, more specifically recommendations from the Procedure Committee (1998/99), the Liaison Committee (2000) and the Modernisation Committee. Today, the Scrutiny Unit has a staff of around 14 including lawyers, accountants, an economist and a statistician, as well as House of Commons Clerks and a small team of administrative staff. Staff are often seconded from government departments. Within its remit to provide financial expertise to House of Commons departmental select committees, the Scrutiny Unit undertakes systematic reviews of the estimates, departmental reports, resource accounts and spending review settlements. These reviews are then discussed with the relevant select committees and may lead to written questions for departments or briefings for oral evidence sessions. The Scrutiny Unit also assists select committees to improve the quality of the financial information provided by government departments. For example, it is currently supporting the House of Commons' engagement with the Treasury's "Alignment Project", which aims to simplify the presentation of financial information on public expenditure. It also prepares guidance notes, shares examples of best practice, and gives presentations and training to Members and their staff.

Note:

1. The number of members of the House of Lords is not fixed. See www.parliament.uk for more details.

2. In election years, after a change of government, a budget will usually be introduced by the incoming Chancellor of the Exchequer, whether or not the outgoing Chancellor has already delivered one.

\section{Legal basis for establishment}

The enabling legislation ${ }^{13}$ for the OBR is the Budget Responsibility and National Audit Act 2011 which provides for the establishment of the office and sets out its functions and broad governance structure. The Act also requires the government to lay before the parliament a Charter for Budget Responsibility (April 2011) which sets out the OBR's remit, how it is to perform its duties, the required content of its key publications and the arrangements for determining the timing of its forecasts and other key publications. Several additional documents also serve to determine the OBR's functioning in greater detail: 
- A Framework Document (April 2011, updated in April 2014 to include details of a new multi-year budget agreement) drawn up by the Treasury and agreed with the OBR covers OBR governance and management arrangements, including the purposes of the OBR, how it is accountable to the parliament and the Chancellor, its governance and structure, the responsibilities of the accounting officer, the content of the annual report, the audit arrangements and its managements and budgeting processes.

- A Memorandum of Understanding (April 2011) sets out the agreed working relationship between the OBR, HM Revenue and Customs, the Department for Work and Pensions, and HM Treasury, including effective work arrangements, each institution's key responsibilities, co-ordination of the forecast process and the process for information sharing.

\section{Mandate}

The Budget Responsibility and National Audit Act mandates the OBR "to examine and report on the sustainability of the public finances". ${ }^{14}$ It also specifies four main tasks:

1. Producing the official five-year economic and fiscal forecasts twice a year. The Chancellor sets the dates at which the OBR should produce these forecasts, one of which will be alongside the spring budget in March or April. To date, the other has been in the autumn.

2. Assessing the government's progress in achieving its fiscal targets alongside its forecasts.

3. Assessing the accuracy of its previous forecasts.

4. Analysing the long-term sustainability of the public finances (based on 50-year projections). This analysis is published in the OBR Fiscal Sustainability Report in summer.

The Act also specifies that in producing its forecasts the OBR should consider the effect of government policy, and to this end the OBR scrutinises and - if it is content to do so certifies as "reasonable and central" the government's costings of new policy measures.

The OBR can also undertake analysis relevant to its mandate on a discretionary basis. While the mandate at first appears fairly broad, the above tasks take up most of OBR capacity during the year. In addition, the OBR operates under several restrictions. Like the majority of the office's counterparts in other countries, it is precluded from making normative policy recommendations (Article 4.12 of the charter). More unusual, however, is the restriction that the OBR confine its analysis to existing government policies and not look at the impact of alternative policy options.

There have been several proposals to expand the OBR mandate to include the costing of pre-election policy proposals. This possibility was first raised by the Treasury Committee in 2010 and, with the 2015 general election looming, saw renewed interest and discussion culminating in a one-off evidence session on the topic in March $2014 .{ }^{15}$ While not ruling out the possibility of taking on this new role - and noting the potential for improving the quality of policy development for individual parties and the quality of public debate in the run-up to an election - the OBR Chairman pointed to capacity constraints and the need for a clear consensus on the "rules of the game" (e.g. which parties should be involved, the scope of policies to be assessed, the timetable, the involvement of civil servants, etc.). The proposal to expand the OBR mandate was not supported by the Chancellor of the Exchequer who raised concerns about putting the OBR in highly politically contested territory during the first general election after it was created. It remains to be seen whether this issue will be raised again for subsequent elections. 
The first external review of the OBR also took a cautious stance saying:

Given that the organisational underpinnings of the OBR are in their institutional infancy and are interdependent with a host of government departments and agencies, it is recommended that caution be exercised in considering the expansion of the OBR mandate (e.g. costing certification of opposition manifestos). The OBR may not have the organisational capacity to expand its remit without further drawing on the resources of other government departments. In addition, the particularly narrow legal framework of the OBR and its interdependencies with the executive branch may risk creating perceptions of conflicts-of-interest. (Recommendation 4)

Subsequently, an HM Treasury Review of the OBR led by Sir Dave Ramsden and published in September 2015 (the Ramsden Review) considered whether the OBR's remit should be expanded, to include the costing of opposition policies or other areas that have been proposed. The Ramsden Review recommended that no changes should be made to the OBR's remit and underpinning legislation.

\section{Functions}

The OBR has been tasked with producing the official forecasts for the economy and public finances. These five-year forecasts are published twice a year in its Economic and Fiscal Outlook (EFO) publication. Its spring EFO is published at the same time as the budget and incorporates the impact of any tax and spending policy measures announced in the budget. The OBR also produces an annual Forecast Evaluation Report that examines what lessons can be learned from its recent forecasting performance in order to improve the techniques used. The Ramsden Review of the OBR also recommended that the OBR should work systematically with forecasting departments on model development, building on existing practice to ensure key models are fit for practice.

The OBR assesses the long-term sustainability of the public finances through its annual Fiscal Sustainability Report which includes long-term (50-year) projections for different categories of spending and revenue on a bi-annual basis; analyses the public sector's balance sheet; and reports different indicators of long-term sustainability. The Ramsden Review of the OBR also recommended that the OBR produce a new report on fiscal risks.

While the OBR is not tasked with producing the costings of new policies, it is required to scrutinise the costings of budget measures produced by government departments. In particular, during the run-up to budgets and other policy statements, the OBR subjects the government's draft costings of tax and spending measures to detailed challenge and scrutiny. It then states in the EFO and the Treasury's costing documents whether it endorses the costings that the government finally publishes as reasonable central estimates, or whether it did not have sufficient information to do so. In the event that the OBR disagrees with a government costing, it would incorporate its own preferred costing in its published forecasts. Since December 2014 the OBR has also published an assessment of the uncertainty surrounding each costing.

The OBR is also tasked with assessing progress towards the government's fiscal targets. Currently, the government has set itself two medium-term fiscal targets: to balance the cyclically adjusted current budget five years ahead and to have public sector net debt falling in 2016/17. The OBR includes an assessment of whether the government has a greater than $50 \%$ probability of hitting these targets under current policy when it prepares the EFO. 
The OBR assesses the government's performance against the welfare cap and, in order to facilitate open and constructive debate about welfare spending, publishes information on the trends in and drivers of welfare spending in its annual Welfare Trends Report.

In addition, the OBR has decided to publish on a monthly basis brief analyses of the latest public finances data released by the Treasury and Office for National Statistics, explaining how it should be interpreted in light of the most recent OBR public finances forecast for the current year. It publishes Briefing Papers (describing its work and explaining the material it presents), Discussion Papers (seeking views on aspects of its work), Working Papers, Occasional Papers (for example, an Assessment of the Effect of Oil Price Fluctuations on the Public Finances) and answers to parliamentary questions. It has made an effort to enrich public debate on public finances through presentations and talks in various fora.

The OBR does not assess alternative policy paths and measures and, as is the case with the majority of independent fiscal institutions today, it does not provide normative commentary on the merits of policy. These constraints were seen by its designers as critical to avoid the perception that the OBR is advocating or arbitrating between alternative policy approaches in a way that could undermine its independence or the credibility of its forecasts. The OBR does not have a role in costing election platforms.

The first external review of the OBR found that:

“The OBR's products satisfy its legislative mandate and are methodologically sound. The quality of analysis and commitment to transparency often surpass those of its international peer group and the work done previously by HM Treasury, and improve with each successive publication."

\section{Work programme}

The OBR decides its own work programme within the bounds of its legislated mandate which includes timings for reports. It is required to: present medium-term forecasts of the United Kingdom economy twice a year; scrutinise the government's draft costings of tax and spending measures during the run-up to budgets and other policy statements; produce a report on the long-term sustainability of the public finances and assess the government's progress towards achieving its fiscal targets. The OBR can and does undertake analyses on its own initiative and both the government and the parliament can request additional analysis, although it is up to the OBR to decide whether to carry out such requests.

\section{Budget}

The Treasury provided the OBR with an initial annual budget of GBP 1.75 million for the four-year spending review period. The OBR budget is part of the Treasury Group budget (which in addition to HM Treasury includes other arms-length bodies, for example the United Kingdom's Debt Management Office) and has a separate line in the Treasury's estimate approved by the parliament. It is subject to the same reporting requirements as the Treasury and other Government departments. ${ }^{16}$ In order to "protect the independence of the OBR and ensure transparency in the resources that are provided to the OBR", the OBR can also submit a memorandum alongside the Treasury estimate and submits its own Annual Report to the parliament each year detailing its budget and expenditure. As such, the main protection for the OBR budget is that it is made public. The Chair of the OBR is the OBR accounting officer and is responsible to notify the Principal Accounting Officer in the Treasury if the OBR is unable to operate within its agreed budget. The OBR budget can be 
reviewed at the request of the OBR accounting officer with accompanying business case or at the point at which the Treasury's departmental expenditure limits are reviewed (see Articles 8.7-8.9 of the Framework Document).

In May 2014 the OBR agreed a new delegated budget with the Treasury, which sets out a further multi-annual funding commitment to 2017-18. Whilst departmental spending limits had not been set for other departments for 2016-17 and 2017-18 at that time, the OBR's delegated budget included an indicative amount for these years. The latest budget delegation increased to GBP 2.146 million in 2015-16, which reflects extra resources required to cover additional responsibilities, such as forecasting devolved taxes and policing the government's welfare cap.

\section{Staffing}

\subsection{Leadership}

The OBR is led by the Budget Responsibility Committee (BRC) which comprises a Chair and two other members. The Chair holds a full-time position while the other two members hold part-time positions (equivalent of three days a week) and remuneration is set along the lines of a similar position in the civil service. ${ }^{17}$ The appointment process is set in legislation and in the Framework Document. Appointments to the BRC are made by the Chancellor of the Exchequer following an open competitive process. Appointments are subject to the consent of the House of Commons Treasury Select Committee (following pre-appointment hearings). The Chair is consulted on the appointments of the other two BRC members. Appointments are for a five-year term renewable once. ${ }^{18}$

The Chancellor also appoints two part-time, unpaid non-executive members for a three-year term renewable once. Although the initial recruitment process was led by the Treasury, subsequent candidates must go through an OBR-led recruitment process before being nominated by the OBR to the Chancellor. While the recruitment process is OBR-led, a Treasury official will sit on the interview panel.

The Chancellor may, with the consent of the Treasury Committee, terminate appointments by written notice with immediate effect in the following circumstances:

- the member has been absent from meetings of the office without the office's permission for a period of more than three months;

- the member has become bankrupt or has made an arrangement with creditors;

- the member's estate has been sequestrated in Scotland or the member has entered into a debt arrangement programme under Part 1 of the Debt Arrangement and Attachment (Scotland) Act 2002, (asp 17) as the debtor or has, under Scots law, made a composition or arrangement with, or granted a trust deed for, the member's creditors;

- the member is unfit to continue the appointment because of misconduct;

- the member has failed to comply with the terms of the appointment; or

- the member is otherwise unable, unfit or unwilling to carry out the member's functions.

The OBR leadership is subject to the office's own code of practice, the Civil Service Management Code and the "Nolan Principles" (principles for public life set by the United Kingdom's Committee on Standards in Public Life).

The first external review of the OBR found high confidence in its leadership across stakeholders. 


\subsection{Staff}

The OBR has around 19 full-time-equivalent staff. ${ }^{19}$ The first wave of OBR staff (a mix of macroeconomic and fiscal or public finance forecasters, and one long-term-sustainability expert, office manager and media officer) were transferred from the Treasury, mostly remaining in the equivalent of the same post. This was essentially a machinery of government change - in which Treasury staff were given the right of first refusal and guaranteed the same terms and conditions. For the most part, the staff involved accepted this new opportunity with enthusiasm. Working at the OBR was seen as attractive as it was an opportunity to take on greater responsibilities, work is high profile and published, and the organisation is less hierarchical. Staff at junior levels can be more directly exposed to external scrutiny of their work than might be the case in a larger government department.

Under the Framework Document, the OBR has "responsibility for the recruitment, retention and motivation of its staff". After the first wave, staff have been recruited directly through an open competitive process with posts advertised in the civil service and externally. The OBR has recruited largely from the civil service (for example, from HM Revenue and Customs and the Office for National Statistics) but have also recruited economists from the Bank of England and the New Zealand Treasury. Recruitment mainly from the civil service may be explained by the fact that pay scales are lower than that of the private sector and the Bank of England. ${ }^{20}$ OBR staff are part of the civil service with terms and conditions along the lines of staff in the Treasury, although given the office's small size there is some additional flexibility in terms of grades. They are subject to a code of conduct, the Civil Service Code. The OBR may choose to use outside consultants for its work in the future, particularly for work on longer-term economic projections.

\section{Access to information}

The office's right to access all government information ${ }^{21}$ necessary to perform its duties is covered by legislation in article 9 of the Budget Responsibility and National Audit Act and Articles 4.13-4.14 of the Charter for Budget Responsibility. This right is further underpinned by the section on "Regular information exchange" (Paragraphs 19-28) in the "Memorandum of Understanding between the OBR, HM Treasury, Department for Work and Pensions and HM Revenue and Customs" which includes guidance on the timing of sharing of information necessary for key OBR reports.

The OBR has been given full access to the government forecasting and analytical models, and jointly maintains and develops the main macroeconomic model with the Treasury. It also has the freedom to develop its own models and has developed a small model of the UK economy, a long-term public finances model and a separate house price forecasting model. The OBR is restricted from accessing confidential taxpayer information and benefit claimant information (as is the Treasury) and information shared between the signatories of the Memorandum of Understanding is to be treated "in accordance with the requirements of the Freedom of Information Act 2000" (Paragraph 28). To date, the OBR has not experienced problems accessing relevant government information. This was underlined in its first external evaluation.

\section{Transparency}

The OBR seeks to operate in as transparent a manner as possible. The OBR website is its main form of communication with the media and the public. All of its work is published 
on the website along with the underlying assumptions and methodologies (the OBR's forecasting model is also public ${ }^{22}$ ). For example, the OBR has published a briefing paper to describe the fiscal forecasting process and provide detail on the specific processes underlying key receipts, lines of expenditure and financial transactions.

As the government uses OBR forecasts to set policies, the government receives the forecasts before they are given to the public ${ }^{23}$ and typically the OBR waits for the government to make a first statement and then immediately publishes and holds a news conference. To further enhance transparency the OBR publishes: responses to parliamentary questions, oral and written evidence to the parliament, information on its own governance arrangements, ${ }^{24}$ correspondence to and from the OBR, details of expenses incurred and hospitality received by BRC members on a quarterly basis and any expenditure in excess of GBP 500 twice a year.

The first external evaluation of the OBR found that it has served to foster transparency by encouraging other government departments and public bodies to behave in a more transparent fashion. For example, the OBR has been able to:

"...[F]orce a consistent timetable on the publication of forecasts requiring departments to adhere to a specific schedule. The structure and discipline imposed by the schedule and process has reduced the scope for discretionary budget measures, particularly those introduced late in the process and with, potentially, less scrutiny and transparency."

It further found that the "OBR's products demonstrate high levels of transparency regarding disclosure, risks and sensitivities" and that "they lend themselves to additional analysis by third parties." At the same time however, the external review noted that some documents could be seen as inaccessible to non-technical readers.

The OBR and its work have received substantial media coverage. One of the OBR analysts serves as a liaison between the media and OBR staff and organises news releases and news conferences. In practice, the Chair speaks on behalf of the OBR during news conferences (typically two or three times a year) and in interviews. The OBR monitors media coverage only informally.

\section{Governance, advisory support, monitoring and evaluation}

The OBR Oversight Board consists of the three members of the BRC, plus two nonexecutive members "with responsibility for ensuring that effective arrangements are in place to provide assurance on risk management, governance and internal control". Both the Oversight Board and its Audit Subcommittee are chaired by a non-executive member. The OBR publishes a full and transparent Annual Report each summer with a summary of OBR work over the previous year, plans for the next year, details of the budget and an assessment of the office's performance by the non-executive members (see the OBR website for the complete Terms of Reference for the Oversight Board and Audit Subcommittee).

The OBR is subject to internal audit in accordance with the Government Internal Audit Standards (GIAS). As the office's sponsoring department, the Treasury and the Treasury's internal audit service have certain rights of access to OBR information as laid out in section seven of the Framework Document, including: all documents prepared by the OBR internal auditor (or a contractor if this service has been contracted out); OBR records and personnel; and all records relevant to the Treasury's sponsoring function and operational investigations (excluding records pertaining to the main duty of the OBR). The OBR annual accounts are also subject to external audit by the Comptroller and Auditor General (C\&AG) 
and the C\&AG shares with the Treasury "information identified during the audit process and the audit report (together with any other outputs) at the end of the audit".

The OBR has established a nine-person panel of leading economic and fiscal experts to help develop and scrutinise the OBR work programme and methods. Panel members tend to have strong academic credentials and bring a range of professional experience in the central bank, the private sector, think tanks and international organisations. Membership is on a pro bono basis for a three-year term extendable by mutual consent. Members are not involved in the production of official OBR economic and fiscal forecasts and do not have access to the official forecasts ahead of publication. ${ }^{25}$

An independent review of the OBR was planned to take place at the end of five years. According to the TSC report, the review "should include an assessment of the OBR's performance, remit and institutional accountability arrangements", as well as whether there is a "case for the OBR becoming a parliamentary body with its resources determined by a House of Commons body, such as the Public Accounts Commission." It was expected that the review will look at, for example, the office's costing role and the restriction on looking at alternative policies. The latter has proved somewhat problematic in terms of OBR longer-term analyses given that governments do not set policies 50 years in advance.

A first external review - as required by the enabling legislation - was carried out by a team from the University of Ottawa, which included the former Canadian Parliamentary Budget Officer, and published in September 2014. The terms of reference for this review required that they evaluate the quality of OBR publications, the effectiveness of its methodology and governance and the capability of its staff to fulfil its mandate, pursuant to its legislation. For this first evaluation, the OBR was "assessed using a framework generally recognised among governments, via a methodology being developed by the University of Ottawa's Jean-Luc Pepin Research Chair, with the supporting sponsorship of the Organisation for Economic Co-operation and Development (OECD)". ${ }^{26}$

The review was largely positive, finding that the OBR had: "laudably achieved the core duties of its mandate", had "succeeded in reducing perceptions of bias in fiscal and economic forecasting and increased the transparency of its products" and enjoyed the confidence of stakeholder groups. The review's recommendations are in Box 2.

\section{Box 2. Recommendations from the External Review of the Office for Budget Responsibility}

The external review recommended that:

1. the survey of parliamentarians be reissued before the end of this session of the parliament;

2. long-term succession planning be undertaken to mitigate risks related to the eventual transition of the OBR senior leadership;

3. a formal fiscal community-wide staff development and rotation programme be established to maximise the talent pool upon which the OBR can draw;

4. caution be exercised in considering the expansion of the OBR mandate (e.g. costing certification of opposition manifestos);

5. additional backgrounders be included with the publication of major reports to aid the accessibility of the documents for non-technical readers. 
In June 2015, the Chancellor to the Exchequer asked Sir Dave Ramsden, Chief Economic Adviser to HM Treasury, to complete a government review of the OBR. The intention was for this to build on the work of the external review, focusing on the existing regime and framework of the OBR and its role in enhancing UK fiscal credibility. The Ramsden Review was published in September 2015 and recommended certain changes to the OBR's core duties and governance framework, including that the OBR produce a new report on fiscal risks and that the Treasury and the OBR should work together to put in place a succession plan for the turnover of BRC members and long-standing staff members.

\section{Concluding remarks}

The OBR has quickly established a reputation domestically and internationally as a vocal fiscal policy watchdog. Its work receives significant media coverage.

The OBR has been tasked with producing independent forecasts for the economy and public finances. The intention is that OBR forecasts be used as the government's official forecast on which policy is set and the fiscal mandate assessed, and there is no expectation of a parallel Treasury forecast. In practice, this means the Treasury has essentially relinquished the task of producing published forecasts while retaining important monitoring and analytical functions. However, while such an action may be politically costly, the Treasury is not prohibited from producing a parallel forecast.

The November 2011 OBR forecast was the first in which it gave the government the bad news that it no longer believed it was on course to hit its targets on unchanged policy. Early signs were positive - the government responded by adjusting policy to put itself back on course, rather than by criticising the forecast. However, the OBR role in publishing forecasts inevitably leaves it vulnerable to public criticism for errors against out-turn or even just for changing its forecasts for the future, as shown by early criticism of the OBR in the parliament for revising down a previous forecast of the economy's likely size in 2015. This despite the TSC 2010 Report's own caution that the "quality and authority of OBR forecasts can be measured over time, relative to other forecasts. Absolute accuracy is not a useful criterion."

The first external review of the OBR noted two coming challenges, or "inflection points": the first potential change in government (the OBR has so far only existed under the government that created it although it enjoys cross-party support) and change in leadership within the office. A change in government was seen as a potential risk by the reviewers as a change in funding levels since the OBR budget is linked of a government department. Another issue might be whether a different government would wish to take forward the proposals for expanding the OBR mandate. Concerns about a change in leadership demonstrate just how successful the first Chair and Budget Responsibility Committee members have been - indeed the external review concluded that the initial successes of the OBR are inextricably linked to its leadership. As noted earlier, the external review recommended that the OBR engage in long-term succession planning to mitigate any risks linked to a change in leadership.

The subsequent HM Treasury Review of the OBR considered whether the OBR's remit should be expanded, to include the costing of opposition policies or other areas that have been proposed. It recommended that no changes to the OBR's remit and underpinning legislation. 


\section{Notes}

1. The OBR's Working Paper No. 7: Crisis and consolidation in the public finances analyses the evolution of the public finances through the financial crisis and the expected period of consolidation.

2. The idea for an independent body of this type had been proposed previously in academic circles (Wren-Lewis, 2011).

3. The May 2010 elections resulted in a hung parliament where no party was able to command a majority in the House of Commons. The Conservative and Liberal Democrat parties formed a coalition government. The Labour Party, which had been in power since 1997, became the main opposition party.

4. The OBR's offices at that time were also located within the Treasury.

5. Although Sir Alan Budd's contract was initially for a three-month period.

6. See announcement: www.parliament.uk/business/committees/committees-a-z/commons-select/treasurycommittee/news/obr-inquiry-announced/.

7. Ibid. Oral and written evidence was received from the interim Budget Responsibility Committee, the Chancellor of the Exchequer, the Director of the Institute for Fiscal Studies and several academics. Several economists in the private sector and a range of United Kingdom and international organisations also submitted written evidence, such as: the Institute for Government, the Hansard Society, the UK Statistics Authority, the National Institute of Economic and Social Research, the Social Market Foundation, the Institute of Chartered Accountants in England and Wales, the Directorate General for Economic and Financial Affairs of the European Commission, the International Monetary Fund and the Hungarian Fiscal Council. Written evidence is available at: www.parliament.uk/business/committees/committees-a-z/commons-select/treasury-committee/inquiries1/ parliament-2010/obr-inquiry/.

8. See the Report Summary and related sections of the full report for further details.

9. Ibid.

10. See also the government's official response (November 2010) to the committee's report: www.official-documents.gov.uk/document/cm79/7962/7962.pdf.

11. The Act also: requires the Treasury to set out its approach to fiscal policy in a Charter for Budget Responsibility, sets out a new structure for the National Audit Office, and repeals the Fiscal Responsibility Act 2010.

12. This description comes from the explanatory note for the Budget Responsibility and National Audit Act.

13. Before the OBR's enabling legislation came into force, the OBR operated under terms of reference published on both the Treasury and OBR websites.

14. The OBR covers the public sector as a whole. In practice, it factors in total spending and borrowing by local government and state-owned enterprises in its analysis.

15. The televised recording of this session is available at: www.parliament.uk/business/committees/ committees-a-z/commons-select/treasury-committee/news/evidence-office-for-budget-responsiblity-/.

16. This includes: financial and non-financial performance information and monthly reporting on OBR cash management, its draw-down of grant-in-aid, forecast out-turn by resource heading, and other data required for the OSCAR (Online System for Central Accounting and Reporting) system.

17. Of the first two BRC members appointed, one held an academic position and the other was a former civil servant.

18. Initial appointments of BRC members were for three, four and five years so that BRC appointments will remain staggered.

19. However, the OBR can draw on staff resources in other government departments to complete its core work.

20. In addition, the civil service has been subject to a pay freeze.

21. "Government information" is defined as information held by any minister of the crown or government department.

22. http://budgetresponsibility.org.uk/macroeconomic-model/. 
23. Drafts are sent to the Treasury 4-6 weeks in advance. These drafts go through four rounds before being finalised around a week before publication day. The final rounds include data on government's planned policy announcements.

24. For example, the Oversight Board Terms of Reference, minutes of meetings, the three-year corporate and business plan.

25. In part due to confidentiality issues regarding government information.

26. The full terms of reference are published in the review.

\section{Bibliography}

Chote, R. (2011a), “The OBR: Almost One Year Old”, presentation at the OECD Parliamentary Budget Officials (PBO) Annual Meeting, OECD, Stockholm, 29 April.

Chote, R. (2011b), “The Office for Budget Responsibility: Can We Make a Difference?”, Ken Dixon Lecture given at the University of York, United Kingdom, 13 June.

Chote, R. (2013), “Britain's Fiscal Watchdog: A View from the Kennel”, Office for Budget Responsibilty, London, http://budgetresponsibility.org.uk/wordpress/docs/Lecture_May-2013.pdf.

Conservative Party (2010), "Reconstruction: Plan for a Strong Economy", Conservative Party, London, www.conservatives.com/ /media/Files/Downloadable\%20Files/Reconstruction_-_Plan_for_a_strong_ economy.ash $x$ ? dl=true.

Helgadottir, T. (2011), "Putting the OBR into Practice", presentation for an OECD seminar on "The UK Office of Budget Responsibility: Set Up of a New Fiscal Institution", Paris, 4 May.

HM Treasury (2010), "Government Response to the House of Commons Treasury Committee, Fourth Report of Session 2010-11: Office for Budget Responsibility", The Stationery Office, London, www.official-documents.gov.uk/document/cm79/7962/7962.pdf.

HM Treasury (2015a), www.hm-treasury.gov.uk.

HM Treasury (2015b), "HM Treasury review of the Office for Budget Responsibility Led by Sir Dave Ramsden, Chief Economic Adviser to HM Treasury", London, www.gou.uk/government/publications/ hm-treasury-review-of-the-office-for-budget-responsibility.

House of Commons Treasury Committee (2010), "Office for Budget Responsibility", Fourth Report of Session 2010-11, Volume I, Report, together with formal minutes, oral and written evidence, London, www.publications.parliament.uk/pa/cm201011/cmselect/cmtreasy/385/385.pdf.

Memorandum of Understanding between the Office for Budget Responsibility, HM Treasury, Department for Work and Pensions and HM Revenue and Customs (2011), London, http:// 86.54.44.148/wordpress/docs/obr_memorandum040411.pdf.

Office for Budget Responsibility and HM Treasury (2011), "Framework Document", London, http:// 86.54.44.148/wordpress/docs/obr_framework040411.pdf.

Office for Budget Responsibility of the United Kingdom (2015), http://budgetresponsibility.independent. gou.uk/.

OECD (2009), OECD Economic Surveys: United Kingdom 2009, OECD, Paris, http://dx.doi.org/10.1787/ eco_surveys-gbr-2009-en.

OECD (2011a), OECD Economic Surveys: United Kingdom 2011, OECD, Paris, http://dx.doi.org/10.1787/ eco_surveys-gbr-2011-en.

OECD (2011b), "Committee Structures for Budget Oversight", survey background note for the Parliamentary Budget Officials Network Annual Meeting, OECD, presented in Stockholm, 28-29 April, GOV/PGC/SBO(2011)6.

Page, K. (2014), External review of the Office for Budget Responsibility, Office of Budget Responsibility, London, http://budgetresponsibility.org.uk/wordpress/docs/External_review_2014.pdf.

Roberts, C. (2011), "Designing the UK Office for Budget Responsibility", presentation for an OECD seminar on "The UK Office of Budget Responsibility: Set Up of a New Fiscal Institution", OECD, Paris, 4 May.

Scrutiny Unit of the United Kingdom Parliament (2015), www.parliament.uk/mps-lords-and-offices/offices/ commons/scrutinyunit/. 
United Kingdom Parliament (2015), www.parliament.uk.

Wren-Lewis, S. (2011), "Fiscal Councils: The UK Office for Budget Responsibility", CESifo DICE Report 9(3), Ifo Institute, Munich, pp. 50-54.

\section{Legislation}

Budget Responsibility and National Audit Act, 22 March 2011.

Charter for Budget Responsibility, April 2011. 


\section{United States}

\section{Congressional Budget Office (CBO)}

Established: 1974.

Enabling legislation: Congressional Budget and Impoundment Act, 1974.

Mandate: To provide Congress with nonpartisan and objective budget analysis.

Budget: USD 46.8 million (2011).

Staff: 246 full-time equivalents (2011). 


\section{Context ${ }^{1}$}

The establishment of the Congressional Budget Office (CBO) in 1974 was part of a package of measures adopted by the congress to reassert its budgetary powers. ${ }^{2}$ This followed stand-offs between the legislature and the executive, particularly over the fact that the President was impounding spending that the congress had approved in annual appropriations acts. The CBO's creation also ended the executive's monopoly as the sole provider to the congress of budget information, forecasts and analysis. Partly as a result of the budget reforms in 1974, the congress's budgetary powers are the broadest of any legislature in the world (Wehner, 2010).

Prior to 1974, successive Presidents had restricted outlays to below the appropriations approved by the congress - a procedure known as "impoundment". Tensions between the legislature and the executive came to a head in 1973 when President Nixon refused to disburse nearly USD 12 billion of congressionally appropriated funds and challenged the congress to enact spending ceilings. The President wanted substantial authority to cut spending - a de facto line-item veto of appropriation acts. The congress opposed the President's proposal and instead sought to reform its budgetary role. Part of the congress's opposition was political: President Nixon (elected in 1972) was a Republican, whereas in the 93rd congress (1973-74), the Democratic Party held the majority in both houses.

A Joint Study Committee on Budget Control was created in the congress, composed of 32 members of the House of Representatives and the Senate. The committee's key mandate was to "propose procedures for improving congressional control over budgetary outlays and receipt totals". Fragmentation in the congressional budget was also a problem that needed to be addressed. The committee prepared two reports in 1973 whose recommendations included:

- Establishing a budget committee in each house, with responsibility for considering a congressional budget resolution that provides ceilings on total discretionary spending (previously no single congressional committee was responsible for total federal spending ${ }^{3}$ ).

- A joint staff for the new budget committees, which would be headed by a legislative budget director whose "staff would be highly trained, professional and non-partisan". California's Legislative Analyst's Office (established in 1941) was taken as a model for this recommendation.

Various congressional committees studied the proposals. The narrow scope of the legislature's budget staff - serving only the proposed new budget committees - was incorporated in the House of Representatives version of the budget reform bill. In contrast, the Senate version recommended the creation of an independent Congressional Office of the Budget "with a highly competent staff to guide it in fiscal policy and budgetary considerations, similar in expertise to the President's Office of Management and Budget (OMB)". The Senate believed that a separate new agency was needed to serve the entire congress and not only the newly created budget committees. The Senate version of the bill 
predominated when the compromise new legislation was signed into law by President Nixon in 12 July 1974 after receiving strong cross-party support. ${ }^{4}$ At the later stages of the congressional debate, it was not so much a question of whether a CBO should be created, but what should be its size and scope.

Once established, the CBO faced the immediate challenge of establishing itself as a credible and non-partisan organisation serving a highly partisan congress. In 1975, the Republican Party was suspicious of the CBO since it was perceived to have been created by a congress controlled by the Democratic Party. The move in late 1975 to a separate building about one kilometre from the congressional buildings was one early step in reinforcing the CBO's independent status. ${ }^{5}$

Early decisions by the CBO's first Director, Alice Rivlin, helped establish the CBO's non-partisan character (as opposed to being bipartisan ${ }^{6}$ ). Also, the fact that she was the Director for two consecutive four-year terms ${ }^{7}$ provided early stability in CBO leadership during the critical set-up period. In an environment in which the two main political parties were accustomed to using congressional support services (notably committee staff) for partisan ends, it was particularly important for the first CBO Director to clarify that the CBO would not be taking sides. The CBO's founding legislation provided considerable discretion for the CBO to establish its own agenda on matters not spelled out in the law. The following aspects (based on Joyce, 2011a) illustrate some important early choices:

- Not giving policy recommendations: The 1974 law did not prevent this. The choice not to give policy recommendations was made by Alice Rivlin, who drew a distinction between policy recommendations, which the CBO would "assiduously refrain from", and technical recommendations, which would be acceptable if asked for (e.g. for proposals regarding budget procedure or budget presentation).

- Initiating studies under its own authority: The CBO law requires only one mandatory report. Early on, it was decided that the $\mathrm{CBO}$ would initiate studies and projects that it considered highly relevant for the congress, rather than passively waiting for requests for budget-related studies from congressional committees. It is not surprising the CBO was attacked by congressional committee leaders for taking this position. Alice Rivlin's response was: "The report is our report, as stated in our statute."

- Remaining neutral when there were attacks from both sides: the first CBO director was rather pleased by the fact that the $C B O$ was attacked from both the right and the left (some observers perceived that the first CBO director held a "left of centre" position). Criticism from both sides of the political spectrum is an indicator that the CBO was indeed establishing itself as a non-partisan organisation.

- Serving the entire Congress (subject to the system of prioritisation of work for committees): The first CBO director was adamant that the office would not be a body serving just one house of the congress or being limited to act as a secretariat for the newly created Budget Committees, taking directions from the chairs of these committees (there was pressure for this).

- Not being an arbitrator: It would not intercede when there were disputes between the newly established Budget Committees and the traditionally powerful Appropriations Committees (and its subcommittees).

- Establishing relations with politicians from both sides of the political spectrum: This may have been a factor for a Republican senator - and Chair of the Senate Budget Committee - to support CBO's position not to be an arbitrator. 
- Recruiting politically neutral staff: In 1975, the initial influx of staff was recruited on the basis of their qualifications to perform non-partisan analysis and not because influential members of the congress suggested the names of politically astute candidates (there was pressure from congressional members to put forward their preferred choices).

\section{Relationship with the executive and the legislature}

The CBO is completely independent from the executive branch. Nevertheless, the CBO has impacted the relationship between the executive and the congress, and more specifically the work of the OMB. Joyce (2011a) argues that one effect of the CBO was to "keep OMB honest". For example, with the CBO essentially providing a check, there is little incentive for the $\mathrm{OMB}$ to prepare overly optimistic economic and fiscal projections. Today, the $\mathrm{CBO}$ and the $\mathrm{OMB}$ technical staff regularly exchange information, including the assumptions underlying their perspectives on the economic and budgetary outlooks.

The 1974 Act states that the CBO may use executive services: "The CBO Director is authorised, upon agreement with the head of any such department, agency, establishment, or regulatory agency or commission, to utilise its services, facilities, and personnel with or without reimbursement. The head of each such department is authorised to provide CBO such services, facilities, and personnel." In practice, CBO maintains close contacts with non-political staff of all federal government agencies to ensure that $\mathrm{CBO}$ fully understands the technical aspects of revenue and spending policies being implemented by agencies under the executive.

The CBO's tasks of analysing the President's budget proposal and conducting analyses of policy alternatives are risky activities, since the media or politicians can construe $C B O$ analysis as favouring one or some partisan policy alternatives over others. A turning point for the CBO's credibility and independence was reached early on in 1977 when it published a controversial study on President Carter's (Democrat) energy-savings policies (CBO estimates of energy savings were less optimistic than those of the administration). The study was released first at a news conference, with the congress being informed of it through the media. At the time, the Republican Party was delighted with the CBO study and, as noted earlier, their initially suspicious attitudes towards the $\mathrm{CBO}$ changed. In the early 1980s, the tables were turned when a CBO analysis was critical of the costs of policies of the Reagan (Republican) administration. In 1993, the CBO's report on the costing of the Clinton (Democrat) administration's healthcare reform proposals created a political storm, in part because the $\mathrm{CBO}$ analysis indicated that the proposals would add to the federal deficit over 1995-2000, whereas the administration estimated that the deficit would decline. ${ }^{8}$

The United States legislature plays a powerful role in federal budget processes (see Box 1). The 1974 Act requires the $\mathrm{CBO}$ to co-ordinate its operations with the other independent agencies under the congress. Accordingly, an interagency co-ordinating council has been set up. At quarterly meetings with the Government Accountability Office (GAO) (the investigative branch of the congress) and the Congressional Research Service (CRS), the three agencies seek to avoid duplication of effort. The $\mathrm{CBO}$ has a particularly close relationship with the GAO. The two agencies are in regular contact to ensure complementarity of support to the congress, especially regarding the work of costing new policies. 


\section{Box 1. Role of the legislature in the budget process}

The United States has a presidential system of government with strong separation of powers. The legislature is bicameral comprising the 435-seat House of Representatives and the 100-seat Senate (both directly elected, for two-year and six-year terms respectively). Each chamber has equal powers to change the shape and size of annual appropriation acts and other budget-related legislation.

The President is required by law to submit to the congress a draft budget (for the fiscal year beginning on 1 October) no later than the first Monday in February. Congress then has nearly eight months for budget scrutiny, by far the longest review period for any legislature worldwide (for the various steps involved in the budget approval timetable, see Box 5 of Blöndal et al., 2003). Congress can introduce amendments to annual appropriations bills, without limitations. In practice, substantial amendments are made.

On the revenue side, the key committees are the Ways and Means Committee (House) and Finance Committee (Senate). The Joint Committee on Taxation (JCT) is responsible for costing any tax proposals that modify the Inland Revenue Code (CBO must rely on the JCT for estimates of the impact of changes in taxes). On the spending side, the two Budget Committees establish non-binding spending ceilings and allocate them (in principle, jointly, in an annual "budget resolution"). The two Appropriations Committees (and their various subcommittees) make detailed spending proposals for annual appropriations. Reports of all congressional committees are published and committee meetings where the budget is discussed are open to the public.

Only one-third of total federal spending is approved in the 12 Appropriations Acts for annual "discretionary" spending. "Mandatory" spending (the remaining two-thirds of total spending) is approved by separate authorising legislation. It is not unusual for Appropriations Bills not to be approved by the beginning of the fiscal year. In this case, the congress votes on "continuing resolutions" (the duration of which is decided case by case) to keep government functioning, generally at the level of the previous years of funding.

Compared to other legislatures, the United States Congress has significant staff resources at its disposal. The Budget Committees have around 90 staff, all political appointees. The Appropriations Committees and their subcommittees also have a substantial number of staff, again all political appointees. Committees and members of the congress are also assisted by the Congressional Research Service (CRS) a non-partisan service within the Library of Congress. The CRS has 650 staff (450 of which are policy analysts, attorneys and information professionals in a variety of disciplines) divided into five divisions, among them the Government and Finance Division which covers budget-related topics. CRS experts assist at every stage of the legislative process - from the early considerations that precede bill drafting, through committee hearings and floor debate, to the oversight of enacted laws and various agency activities. CRS services include: reports on major policy issues; tailored confidential memoranda, briefings and consultations; seminars and workshops; expert congressional testimony; and responses to individual inquiries.

\section{Legal basis for establishment}

The CBO was established in the Congressional Budget and Impoundment Act 1974 (US Code, Title 2, Chapter 17). The key features of the Act are: the introduction of an annual budget resolution in the congress that fixes ceilings on the spending that is subject to Appropriation Acts; new impoundment control procedures; the creation of a budget committee for each house; and the creation of the CBO. This Act has been amended several times and additional legislation has since added to the CBO's mandate. 


\section{Mandate}

CBO's fundamental mandate was established in the 1974 legislation, namely to provide the congress with objective, non-partisan, and timely analyses and information to aid in economic and budgetary decisions on the wide array of programmes covered by the federal budget. As discussed above, the law left considerable discretion to the CBO Director to decide how to fulfil this mandate.

Later laws expanded the CBO's mandate. These include the Unfunded Mandates Reform Act 1995 (that amended the 1974 law), which requires the CBO to assess the costs (over ten fiscal years) of federal mandates and to prepare "mandate statements" for any draft legislation prepared by congressional committees. During the recent financial crisis, the $\mathrm{CBO}$ acquired additional specific mandates, notably new reporting requirements related to the Troubled Assets Relief Program and assessments of the employment impact of the American Recovery and Reinvestment Act 2009. The 1974 law obliges the CBO to prepare only one annual report. Specifically, the CBO Director must submit (before 1 April of each year) to the two congressional budget committees, for the fiscal year commencing on 1 October, a report that includes a discussion of national budget priorities and alternative ways of allocating budget spending among major programmes or functional categories. The law requires the report to include: alternative levels of total revenues, total new budget authority, and total outlays; and the levels of tax expenditures under existing law, taking into account projected economic factors and any changes proposed in the President's draft budget. Using its own discretion, the CBO prepares many other reports.

Since the United States is a federal country, the scope of the CBO's activities is limited to that of the federal government. Each of the 50 states has its own legislature, some of which have their own independent offices for budget analysis at state level. The CBO also does not analyse or project fiscal aggregates consolidated across all three levels of government (federal, state and local).

\section{Functions}

The CBO conducts both macro-budget analysis and costing of policy proposals. While budgetary analysis and projections are still fundamental CBO activities, with the new mandates that the $\mathrm{CBO}$ has acquired over the past two decades it now spends relatively more time on costing policy proposals compared to 20 or 30 years ago. More specific CBO functions are:

\section{Projections and budget policy analysis}

- Economic forecasts and baseline budget projections (report on the economic and budget outlook) cover the ten-year period used in the congressional budget process, thereby providing a basis to compare CBO projections with those shown in the OMB's "Analytical Perspectives" (the volume that accompanies the President's annual budget proposal). CBO describes the differences between the current projections and previous ones; compares their economic forecast with those of other forecasters; and shows the budgetary impact of some alternative policy assumptions. Forecast and budget projections are produced annually in January and updated in August. Baseline projections are updated in March.

- Long-term budget projections typically covering 25 years but which may extend as far as 75 years into the future. They incorporate long-term demographic trends and the longterm impact of rising healthcare costs. CBO also projects the economic impact of 
alternative long-term budget policies. Long-term projections are produced annually, usually in June.

- Analysis of the President's budget proposals (submitted to the congress in early February), with a preliminary analysis in March and a full analysis in April. CBO looks at likely direct effects that the President's budgetary proposals will have on outlays and revenues, their economic implications, and any effects that those economic changes will have on the budget.

- Assisting the Budget Committees in developing the congressional budget resolution by providing alternative spending and revenue paths, and estimating the effects of various policy options.

- Helping Congress to make budgetary choices by periodically providing budget options for reducing budget deficits, but not policy recommendations, in the short and longer term. The CBO also produces reports focusing specifically on policy options for social security.

- Each January preparing a report listing all programmes and activities funded for the current fiscal year for which authorisations of appropriations have expired or will expire during the current fiscal year.

- Monthly budget reviews analyse federal spending and revenue totals for the previous month, the current month, and the fiscal year to date.

\section{Cost estimates}

- Providing estimates of the cost of all appropriation bills at each stage of the legislative process, including estimates for numerous amendments considered during that process.

- Providing formal written estimates (typically between 500 and 700 annually) of the cost of virtually every bill reported by congressional committees CBO also provides preliminary informal estimates at earlier stages in the legislative process.

- Analysis of federal mandates - projected costs of proposed legislation for state and local governments or for the private sector (around 500 annually). CBO produces mandate statements with its cost estimates for each committee-approved bill and produces a report each spring listing all of its work analysing mandates in the previous year.

- Constructing statistical, behavioural, and computational models to project short-term and long-term costs and revenues of government programmes.

\section{Testifying before congressional committees and providing information to committee staff}

- Testifying to congressional committees on budget and economic issues, as well as on specific issues such as health care, climate change, national security, and financing infrastructure.

- Presenting CBO's budget proposals for the upcoming fiscal year.

- Providing detailed explanations of components of cost estimates and the estimating methodology.

\section{Other research and reports}

Although most of CBO's reports are written at the request of congressional authorities, it may also undertake research on its own initiative, even if potentially controversial. CBO's research has covered topics such as health care, income security, education, tax policy, 
energy, the environment, national security, financial issues, infrastructure, and others. In addition, CBO's working papers provide technical descriptions of $\mathrm{CBO}$ analyses or present original, independent work by $\mathrm{CBO}$ analysts.

Since 2008, CBO is required to report on the Troubled Asset Relief Program (TARP) twice a year within 45 days of the OMB's TARP report. The American Recovery and Reinvestment Act of 2009 requires CBO to provide a quarterly report assessing the programme's performance.

\section{Scorekeeping}

This function predates CBO's existence. ${ }^{9}$ Scorekeeping is tracking the cost of legislation against a budget constraint that is founded in law or in budget resolutions adopted by the budget committees. The CBO's task is to inform the budget committees of how the cumulative cost of legislation - both appropriation acts and other laws - compares with the budget constraint. Although the budget committees usually report budget resolutions, in 2011 and 2012, the congress did not adopt a final budget resolution. The budget constraint for scorekeeping can also be based on the ceilings for discretionary spending that may be adopted in law, such as the Budget Enforcement Act that was in effect from 1990 to 2002. Since the adoption of the Statutory Pay As You Go (PAYGO) Act 2010 and the Budget Control Act (BCA) 2011, scorekeeping is primarily against the constraints of these laws. The OMB also plays a scorekeeping role, as it must implement spending cuts ("sequestering") when the $\mathrm{BCA}$ rules are not respected. Finally, $\mathrm{CBO}$ is one of the three participants (along with the $\mathrm{OMB}$ and the Budget Committees) that update periodically the extensive rules for scorekeeping. ${ }^{10}$

\section{Monitoring fiscal rules}

The $\mathrm{CBO}$ was not given the task of monitoring fiscal rules. No such rules existed the time that the CBO was created. However, since 1974, Congress has adopted fiscal rules for specific time periods. The role of the $\mathrm{CBO}$ - and more generally, that of the legislative branch - was clarified in a Supreme Court case in 1987, following the adoption of the Balanced Budget and Emergency Deficit Control Act in 1985. This law included quantitative deficit targets for each year until 1990. To enforce the spending reductions to achieve the targets, the 1985 law assigned to the head of GAO - a legislative branch official - the task of ordering the "sequestering" of spending. The Supreme Court declared that this violated the constitutional separation of executive and legislative powers (Joyce, 2011). Since the court decision, the director of the OMB alone has the power to order sequestering. The OMB therefore is the key agency that monitors fiscal rules, including those adopted in 2010-11. The PAYGO Act 2010 requires all new legislation changing taxes, fees, or mandatory expenditures, taken together, to not increase projected deficits. The OMB is responsible for maintaining the scorecards needed to show that the law is being complied with. Nonetheless, the CBO provides PAYGO cost estimates to the Chairs of the Budget Committees and these are included in the congressional records. Also, the $\mathrm{CBO}$ analyses fiscal rules if they are part of new legislation. For example, the CBO analysis of the Budget Control Act 2011 indicates that USD 917 billion would be saved over 10 years (relative to the CBO's March 2011 adjusted baseline projection). Such analysis is reviewed by the Joint Select Committee on Deficit Reduction set up under this Act. CBO also has discretion to warn the congress to make spending cuts to achieve the quantitative targets for discretionary spending. ${ }^{11}$ 


\section{Work programme}

The CBO's annual work programme is determined by its statutory mandates and by congressional requests. The balance of work between these two main aspects is split roughly evenly, although it varies considerably from year to year. The Budget Analysis and Macroeconomic Analysis Divisions of the CBO perform the statutory duties of forecasting budget aggregates and costing and analysing budget proposals. The four "programme" divisions ${ }^{12}$ of $\mathrm{CBO}$, along with the Tax Analysis Division, respond primarily to congressional requests. The annual work programme is approved in the context of the annual $\mathrm{CBO}$ budget.

Any congressional committee or individual member can request the $\mathrm{CBO}$ to conduct studies of policies and institutions that have an impact on the budget. However, the CBO encourages members of the congress to respect the system of prioritisation laid down in the 1974 law, notably:

- First priority: assistance to the Budget Committees and Appropriations Committees of each house - the Ways and Means Committee (House) and Finance Committee (Senate). ${ }^{13}$ The CBO is required to provide budget-related information to these six committees, including that relating to: the budget, appropriation bills, other bills authorising new budget authority or tax expenditures; actual or forecast revenues; and other related information that the committee may request.

- Second priority: assistance to other committees and to individual members. The CBO is required to provide budget-related information and, to the extent practicable, such additional information as may be requested. The phrase "to the extent practicable" indicates that the six committees mentioned in the previous bullet take precedence over requests from all other congressional committees or from individual members of either house of the congress. $\mathrm{CBO}$ therefore encourages Members' requests to be channelled through one of the six budget-related committees. If members persist in requesting $\mathrm{CBO}$ analysis of specific proposals, $\mathrm{CBO}$ would again encourage the member to contact the Chair or Ranking Members of the relevant committee to discuss the request, i.e. the request would be refused. However, such cases are rare.

\section{Budget}

The 1974 Act states that $\mathrm{CBO}$ is to be funded by an annual appropriation as may be necessary to enable it to carry out its duties and functions. In practice, the CBO's funding is part of the budget of the legislative branch, which is approved by the congress as one of the 12 annual Appropriations Bills.

The steps involved in $\mathrm{CBO}$ budget approval are: the $\mathrm{CBO}$ Director submits a draft $\mathrm{CBO}$ budget to the Appropriations Committees of each house and testifies before the subcommittees concerned with the appropriations bill of the legislative branch; ${ }^{14}$ the subcommittees scrutinise the entire budget of the legislative branch and may modify allocations to its various components - the two houses of the congress and the various agencies supporting the congress (CBO, CRS, GAO, etc.); and the Appropriations Committees and the congress approve the Appropriations Bill. At the end of this process, the CBO's final budget is often slightly lower than its initial request, but not by a large amount.

The CBO's budget peaked at USD 46.8 million in FY2011 (CBO, 2012). Prior to 2011, the budget had been steadily increasing, largely because the congress had approved increases in staff, which account for $90 \%$ of the CBO's outlays. ${ }^{15}$ With the adoption of the Budget 
Control Act (BCA) in August 2011, multi-year ceilings have been placed on all discretionary spending and declines in inflation-adjusted spending are expected in all federal agencies in coming years. The legislature is expected to "lead by example" to restrain federal spending. For FY 2012, the CBO's approved budget declined by 6\% to USD 43.8 million. With a falling budget, $\mathrm{CBO}$ has been obliged to freeze hiring and not replace departing staff. Beyond FY 2012, under the spending ceilings in the BCA, the CBO's budget (in real terms) may decline further.

\section{Staffing}

\subsection{Leadership}

The 1974 Act lays out clear provisions concerning the CBO Director and his/her deputy, together with their salaries: "The Director shall be appointed by the Speaker of the House of Representatives and the President protempore of the Senate after considering recommendations received from the Committees on the Budget of the House and the Senate, without regard to political affiliation and solely on the basis of his fitness to perform his duties. The Deputy Director shall be appointed by the Director." At times, especially when one political party controls both houses of the congress (and hence the Speaker and President pro tempore positions), the Director may have been chosen in part because of his/her political affiliation.

Based especially on the precedents created by the first $\mathrm{CBO}$ director, successive $\mathrm{CBO}$ directors have transcended pressures emanating from their political affiliation. Chapters 2 and 8 of Joyce (2011a) document the political affiliation of every CBO Director from 1974 to 2011. Despite the apparent favouring of "politically affiliated" over "non-politically affiliated" directors on some occasions, all Directors have provided CBO analysis to the Budget Committees that has been critical of certain policies promoted by the party with which the Director was associated when appointed. In short, $\mathrm{CBO}$ has consistently provided independent and non-partisan budget analysis.

The term of office of the Director is four years, which can be renewed without limit. If an acting Director steps in to fill a vacancy prior to the expiration of a Director's term, it is only for the unexpired portion of that term. The 1974 law provides that the Director may be removed by either house of the congress by resolution, although in practice this has never happened. In addition, the CBO has post-employment restrictions on very senior staff, notably that former senior $\mathrm{CBO}$ employees are prevented from lobbying $\mathrm{CBO}$ employees for one year after their departure.

The 1974 law, as amended, specifies that the "CBO Director shall receive compensation at a per annum gross rate equal to the lower of: the highest annual rate of compensation of any officer of the Senate; or the highest annual rate of compensation of any officer of the House of Representatives. The Deputy Director shall receive compensation at an annual rate of pay that is USD 1000 less than the annual rate of pay received by the Director." Thus, the Director's salary is aligned to salaries elsewhere in the legislative branch. This salary is broadly on a par with comparable directors in executive branch agencies.

\subsection{Staff}

The 1974 Act specifies that "all CBO personnel shall be appointed without regard to political affiliation and solely on the basis of their fitness to perform their duties". It also specifies that $\mathrm{CBO}$ staff are appointed by the CBO Director, who "fixes the compensation of 
such personnel as may be necessary to carry out the duties and functions of CBO. For the purposes of pay and employment benefits, rights, and privileges, all personnel of $\mathrm{CBO}$ shall be treated as if they were employees of the House of Representatives." CBO staff are therefore not career civil servants. Nonetheless, СBO employees have access to federal pension schemes, health benefits and life insurance.

In early 1975, there was no shortage of applicants for positions at the newly created СBO. ${ }^{16}$ The prospect of working for the $\mathrm{CBO}$ was perceived to be attractive by many people. By the time Alice Rivlin first testified before Congress in 1975, the CBO had already hired or made commitments to 193 people. The senior staff that had been recruited - division heads or above - had considerable experience in either the administration (notably the OMB) or independent policy-oriented think tanks (e.g. Urban Institute, Brookings, RAND Corporation). CBO estimated that it needed 259 positions to fulfil its mandate. The House Appropriations Committee did not support the request for funding 259 staff. After intense congressional debate, this committee's views prevailed and in FY 1976, funding was provided for 193 positions. Since then, the congress approved steady increases in staff positions, with the number of staff (FTE) rising from 208 in 1997 to an average of 230 during 2001-08. As from 2009, there was a need to analyse the budgetary impact of new healthcare reform proposals and the takeover by the federal government of government-sponsored enterprises providing housing finance. For these needs, the $C B O$ requested new staff positions, with the objective of reaching 259 FTE in FY 2010. Although the request was not fully met by the congress (the number of staff averaged 250 in 2010), the CBO received additional financing in supplementary budget appropriations. This enabled staff size to peak at 254 in 2011. For the future, given the budget restraints in place, the number of CBO staff is likely to decline.

In February 1975, decisions had to be made concerning how the CBO would be organised internally to perform its two main functions: macro-budget analysis and costing of specific policies. At the time, there were two competing models. One option was to organise the $\mathrm{CBO}$ along functional lines: create divisions mainly by functional categories (defence, social security, health, etc.). The second was to organise CBO by its main outputs: macro-budget analysis and policy/programme analysis. The second model was chosen. CBO's staff and organisation still reflects this choice.

Over its history, CBO staff have been recruited from a wide variety of sources, including: direct hires from graduate school programmes; former employees of the OMB and other federal government agencies; academia; think tanks; other congressional agencies (GAO and CRS); and congressional committee staff. CBO values employees who have had experience in the areas they analyse. It generally avoids hiring individuals who have recently held a partisan position in the congress or the executive branch. CBO has not had difficulties recruiting competent and well-qualified professional staff, even though statutory salary limitations make it impossible for it to match salaries offered by some private sector entities that compete for $\mathrm{PhD}$ economists in specialised areas of finance, health and macroeconomic analysis.

CBO analysts typically have graduate degrees in economics or public policy, and a significant number have PhDs. The average tenure of a CBO analyst is 8.5 years. This average does not include a significant number of employees - including the present $\mathrm{CBO}$ Director - who have left and later returned. Within the $\mathrm{CBO}$, analysts do not often move between divisions. 
Once recruited, CBO employees are subject to the ethics rules of the House of Representatives. In addition, the $\mathrm{CBO}$ imposes rules regarding employee conduct, to ensure that personal perspectives do not bias CBO's work or undermine CBO's reputation for impartiality. The principal areas of concern are: financial and non-financial interests, political activity, public speech, negotiating future employment and post-employment activities. CBO employees are prohibited from participating in partisan political activity if such participation would tend to identify or appear to identify CBO with a political campaign, candidate or cause. CBO employees are required to obtain approval before engaging in public speeches on issues being considered by the congress. Like other congressional employees, СBO employees must disclose if they are negotiating future employment. $\mathrm{CBO}$ employees must do so early in the process and often have to be recused from specific matters.

$\mathrm{CBO}$ employees have the freedom to terminate their employment at any time for any reason or for no reason. Reciprocally, the CBO may terminate an employee's employment at any time, with or without cause or notice, for any or no reason other than reasons prohibited by law, i.e. CBO staff do not have any special employment protections.

Although CBO could use consultants, this rarely happens. It does have, however, a visiting scholars programme to strengthen links between $\mathrm{CBO}$ and public policy analysts. CBO's focus is on collaborating with scholars who specialise in macroeconomics, health economics, financial economics and public economics. CBO also has a summer intern programme which enables students to contribute to the CBO's work in programme areas such as budget and tax policy, and health care.

\section{Access to information}

The 1974 Act lays out clear provisions for CBO's access to information from the executive. The CBO director is authorised to secure information, data, estimates and statistics directly from the various departments, agencies and establishments of the executive branch, regulatory agencies and commissions of the government. All such departments must furnish the director with available material that he/she determines to be necessary (other than material for which the disclosure would be a violation of laws, such as those pertaining to national security). In practice, it is rare for the executive branch not to provide any material that is requested.

\section{Transparency}

The $\mathrm{CBO}$ is a highly transparent organisation. From the outset of $\mathrm{CBO}$ operations, it was decided to publish the Budget and Economic Outlook twice a year. Today, CBO prepares several reports on a regular cycle, including the annual analysis of the President's budget, CBO's long-term budget projections, and options for reducing the deficit. All of its regular analytic reports, its forecasting methodologies, and its costings are published in printed and electronic form and available without charge. In fiscal year 2010, CBO issued 33 studies and reports, 12 briefs, 12 Monthly Budget Reviews, 35 letters, 14 presentations, two background papers and numerous supplemental data. In addition, in calendar year 2010, it completed approximately 650 federal cost estimates, and about 475 estimates of the impact of new legislation on state and local governments and the private sector, including the identification of unfunded mandates. Any member of the congress or the public can subscribe to receive emails notifying them when $\mathrm{CBO}$ issues a cost estimate or a new publication. 
The 1974 Act requires the CBO to make available to the public all information, data, estimates and statistics obtained from the executive. Exceptions are specified in the law (e.g. information that is secret or confidential for specific reasons, such as national defence, the conduct of foreign relations, or unwarranted invasion of personal privacy). CBO does not publish "rough and ready" cost estimates provided to congressional committees before the committee has agreed on a new policy proposal or on a draft law. However, once a proposal is agreed to by a committee, $\mathrm{CBO}$ always provides and publishes a formal costing of the budget impact of the draft legislation.

The main means of communicating with the media is through release of reports, and CBO reports receive wide coverage. Compared to its early history, web-based outreach has made a dramatic difference to the accessibility and availability of CBO documents to the media and the public. In recent years, the CBO director initiated a blog which enhances further the visibility of CBO analysis. Over the years, the CBO has worked hard to develop good relationships with editors of well-respected newspapers, which has improved the media's understanding of the content of $\mathrm{CBO}$ reports and minimised the scope for deliberate distortions of the conclusions of CBO reports or attacks on its CBO's credibility. CBO employs a professionally-trained Communications Officer to deal with all media-related questions that journalists or the public may have on $\mathrm{CBO}$ reports. CBO monitors the coverage that it receives in the media, but does not keep formal records of all citings. The CBO Director could, if he or she chooses, make appearances in the media or organise news conferences. Although some CBO Directors have made more media appearances than others, in general CBO prefers to avoid the limelight and to "let the numbers speak for themselves".

Finally, the CBO Director or senior CBO staff appear before congressional committees about 20 times a year. ${ }^{17}$ Selected appearances are recorded live and made publicly available on the CBO's website.

\section{Governance, advisory support, monitoring and evaluation}

Under the 1974 Budget Act, the House and Senate Budget Committees are responsible for overseeing CBO's operations. However, oversight hearings by the committees have been discontinued since the 1990s. Nowadays, the Director frequently meets with the Chairs and Ranking Members of the Budget Committees to discuss oversight issues. Because CBO operations are funded in the annual Legislative Branch appropriations bill, the House and Senate Appropriations Subcommittees on the Legislative Branch annually review CBO's budget request and operations. The CBO Director presents the CBO budget request in formal testimony and he/she is asked to respond to various questions for the hearing record.

An innovation in CBO's early history was the creation of a Panel of Economic Advisors. The panel is composed of several of CBO's past directors and a number of eminent economists chosen by the CBO director after consultation with the Chairman, Ranking Members and senior staff of the Budget Committees and, at times, other relevant congressional committees. The advisors serve for a two-year term that can be renewed without limit. CBO hosts periodic meetings of the advisors and solicits their views between meetings via e-mail exchanges and telephone calls. The panel provides advice to further the reliability, professional quality and transparency of CBO's work. One specific task of the panel is to review CBO's preliminary forecasts of the economy. More recently, given the growing importance of the budgetary impact of healthcare reforms, CBO has established a Panel of Health Advisers, with about 20 widely acknowledged health policy experts, mainly 
drawn from academia and major think tanks. This panel meets periodically to advise CBO on its analyses of health care issues.

$\mathrm{CBO}$ conducts self-evaluations of its economic forecasting record. These generally show that $\mathrm{CBO}$ 's projections are on par with those of the administration or blue chip forecasters (which is an average of approximately 50 private-sector forecasts that is published periodically).

The CBO and all legislative branch support agencies are expected to comply with the spirit of the Government Performance and Results Act Modernization Act 2010, ${ }^{18}$ even though the law does not formally apply to the legislative branch. Thus, CBO includes performance data in its annual budget request. Finally, the Government Accountability Office could audit $\mathrm{CBO}$ operations, although in practice this does not happen.

\section{Concluding remarks}

СBO has established itself as a credible independent organisation with a reputation for providing the congress, and particularly its committees, with objective macro-budget analysis and costing of policies proposed in new legislation. At the same time, $\mathrm{CBO}$ is highly respected by the OMB and has been influential in improving the credibility of OMB's own work. CBO's credibility and non-partisan nature were established especially in its first eight years of operation (1975-82). Since then, the CBO has faithfully analysed and clarified budget policy options in a non-partisan manner.

The $\mathrm{CBO}$ chose not to make specific fiscal policy recommendations. Despite this selfimposed limitation, CBO's work is widely picked up by the media and there is strong evidence that $\mathrm{CBO}$ analysis influences congressional decision-making and the public debate on budget policy issues. In addition, as its analysis of medium-term and longerterm trends in federal revenues, expenditures, deficit and debt include not only baseline projections but also deficit-reducing policy options, the $\mathrm{CBO}$ provides to the congress adequate documentation for the adoption of fiscal policies that would improve the medium-term and long-term sustainability of federal finances. Finally, the CBO is highly transparent, with all of its work easily available to the congress, the media and the public.

Since the CBO is one of the oldest institutions of this type in the world (at the national level), some aspects of its experience gained over 35 years may be useful for the newer independent fiscal agencies in other countries. First, it is most important to remain nonpartisan and stand firm on this principle, even when there are attacks from both sides of the political spectrum. Second, staying away from making specific policy recommendations was a sound decision for the CBO. Third, the decisions made in the initial set-up period of an independent agency are crucial. Early on, for example, the CBO rigorously defended that "our reports are our reports", thereby enhancing CBO's objectivity. Fourth, the stable leadership of the $\mathrm{CBO}$ for its first eight years set the tone for subsequent directors. Fifth, $\mathrm{CBO}$ has considerable discretion to analyse emerging policy-related issues, even though there has been pressure to be subservient to the congress's political authorities. Sixth, establishing and maintaining transparency is essential. Finally, it is important to have safeguards to ensure that the director and all staff are selected on the basis of their technical merits and not on their political affiliation.

In considering the success of the $\mathrm{CBO}$, Joyce (2011b) concludes that "it is not mainly a 'budgeting' story, but instead a story of strong CBO leaders articulating a clear vision, dedicated public servants adhering to that vision and tolerant (but not always thrilled) 
elected officials recognising the benefits of having the institutional capacity to produce hard-headed, objective analysis. These are management lessons." While independent fiscal institutions in other countries may have additional factors at play (executive dominance, responsibility for monitoring compliance with fiscal rules, co-ordination of central (federal) and sub-national public finances, etc.) both the "management lesson" and the seven "CBO lessons" above are nevertheless useful for all.

\section{Notes}

1. Much of the material for this section was sourced from a recent book on the CBO (Joyce, 2011a).

2. Schick (2000) characterises the years 1921 to 1974 as the period of "presidential dominance" in federal budgeting.

3. The "total spending" ceiling was limited to outlays subject to annual appropriations.

4. Draft legislation was introduced in the House of Representatives by Al Ullman (Democrat) on 18 April 1973. At the voting stages, it was passed by the House Rules Committee on 5 December 1973 (386-23) and by the Senate on 22 March 1974 (80-0), after which it was reported by the Joint Conference Committee on 11 June 1974, and agreed to by the House on 18 June 1974 (401-6) and by the Senate on 21 June 1974 (75-0).

5. The CBO was initially temporarily located in an old hotel that had been converted into a Senate office building (Joyce, 2011a).

6. As explained in Anderson (2009), non-partisan connotes lack of political affiliation; bipartisan connotes serving the two main political parties equally.

7. To date, she is the only director of CBO to have served two full terms.

8. Chapter 6 of Joyce (2011a) discusses varying views as to whether the CBO report killed the healthcare reform proposals.

9. Scorekeeping was a function of the Joint Committee on the Reduction of the Deficit, which existed before 1974

10. Scorekeeping rules are complex. They have been summarised in Box 4.2 of Joyce (2011a).

11. As an example of such a warning, in 1989, the CBO director warned Congress that cuts of USD 70 billion would be needed to achieve the deficit targets of USD 64 billion for fiscal year 1991 (Joyce, 2011, p. 61).

12. The four programme divisions are: Financial Analysis, Health and Human Resources, Microeconomic Studies, and National Security.

13. By 1976 СВO had drawn up a policy on how it would prioritise its servicing of the six budget-related committees, as required by the 1974 Act.

14. See, for example, the CBO (2012).

15. Direct compensation accounts for nearly 70 per cent and benefits for about 20 per cent; the remaining ten per cent of the CBO's budget is for services, equipment, training and supplies.

16. In early 1975, the only employees of CBO were the former staffers of the Committee on the Reduction of Federal Expenditures, who were transferred to CBO as part of the 1974 legislation.

17. Whereas it is usually the CBO Director who presents CBO testimony before congressional committees, the deputy director or senior CBO staff testify on narrower topics or present a specific report.

18. This law updated the 1993 Act that introduced performance-based budgets in federal government agencies.

\section{Bibliography}

Anderson, B. (2009), "The Changing Role of Parliament in the Budget Process", OECD Journal on Budgeting, Vol. 9, No. 1, OECD, Paris, pp. 37-74.

CBO (2012), Testimony on CBO's Appropriation Request for Fiscal Year 2013, February 12, www.cbo.gov/sites/ default/files/cbofiles/attachments/BudgetRequestTestimony-House_0.pdf. 
Joyce, Philip G. (2011a), The Congressional Budget Office: Honest Numbers, Power and Policymaking, Georgetown University Press, Washington, DC.

Joyce, Philip G, (2011b), "Lessons of Management and Leadership from the Congressional Budget Office", Governing the States and Localities, www.governing.com/columns/mgmt-insights/lessonsmanagement-leadership-congressional-budget-office.html.

Blöndal, J.R., D.J. Kraan and M. Ruffner (2003), "Budgeting in the United States", OECD Journal on Budgeting, Vol. 3, No. 2, pp. 7-53.

Schick, A. (2000), The Federal Budget: Politics, Policy and Process, second edition, Brookings, Washington, DC.

United States Congressional Budget Office (2015), www.cbo.gov.

United States Congressional Research Service (2015), www.loc.gou/crsinfo.

United States Government Accountability Office (2015), www.gao.gov.

United States House of Representatives Committee on the Budget (2015), http://budget.house.gou.

Office of Management and Budget (2015), www.whitehouse.gov/omb.

United States Senate Budget Committee (2015), http://budget.senate.gov.

Wehner, J. (2010), Legislatures and the Budget Process: The Myth of Fiscal Control, Palgrave Macmillan. United Kingdom

\section{Legislation}

Congressional Budget and Impoundment Control Act of 1974 (Public Law 93-344; US Code Title 2, Chapter 17, Sections 201-612), 12 July 1974. 


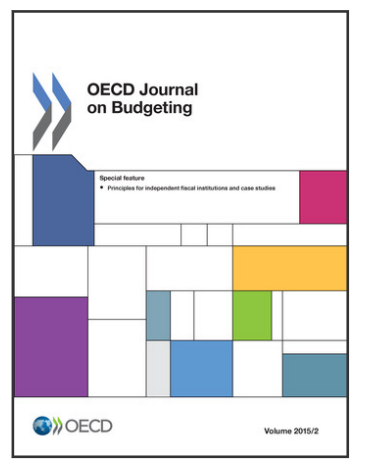

\section{From: \\ OECD Journal on Budgeting}

Access the journal at:

http://dx.doi.org/10.1787/16812336

\section{Please cite this article as:}

von Trapp, Lisa, lan Lienert and Joachim Wehner (2016), "Principles for independent fiscal institutions and case studies", OECD Journal on Budgeting, Vol. 15/2.

DOI: http://dx.doi.org/10.1787/budget-15-5jm2795tv625

This work is published under the responsibility of the Secretary-General of the OECD. The opinions expressed and arguments employed herein do not necessarily reflect the official views of OECD member countries.

This document and any map included herein are without prejudice to the status of or sovereignty over any territory, to the delimitation of international frontiers and boundaries and to the name of any territory, city or area.

You can copy, download or print OECD content for your own use, and you can include excerpts from OECD publications, databases and multimedia products in your own documents, presentations, blogs, websites and teaching materials, provided that suitable acknowledgment of OECD as source and copyright owner is given. All requests for public or commercial use and translation rights should be submitted to rights@oecd.org. Requests for permission to photocopy portions of this material for public or commercial use shall be addressed directly to the Copyright Clearance Center (CCC) at info@copyright.com or the Centre français d'exploitation du droit de copie (CFC) at contact@cfcopies.com. 